\title{
Neuroligin: \\ Charakterisierung eines neuronalen Transmembranproteins
}

\author{
Dissertation \\ zur Erlangung des Doktorgrades \\ der Mathematisch-Naturwissenschaftlichen Fakultäten \\ der Georg-August-Universität Göttingen
}

vorgelegt von

Antje Neeb

aus Bad Arolsen

Göttingen 2003 
Die vorliegende Arbeit wurde unter Anleitung von Prof. Dr. N. Brose, Abteilung Molekulare Neurobiologie des Max-Planck-Institutes für experimentelle Medizin in Göttingen, angefertigt.

Referent: Prof. Dr. R. Hardeland, Zoologisches Institut der Universität Göttingen.

Korreferent: Prof. Dr. D. Doenecke,

Zentrum Biochemie und Molekulare Zellbiologie der Universität Göttingen.

Tag der mündlichen Prüfung: $\quad$ 6. November 2003 
1.1 Das Nervensystem 1

1.2 Die Entwicklung des Nervensystems 1

1.3 Zelladhäsionsproteine vermitteln und stabilisieren den synaptischen Kontakt 2

1.3.1 Die Cadherine 3

1.3.2 Die Cadherin-ähnliche neuronale Rezeptoren 4

1.3.3 SynCAM 5

1.3.4 Das Neuroligin/Neurexin-System $\quad 6$

1.3.4.1 Neuroligin und Neurexin binden MAGuK-Proteine 7

1.3.4.2 Neuroligin induziert synaptische Differenzierung 8

1.4 Zielsetzung der Arbeit 9

2. MATERIAL UND METHODEN 10

$\begin{array}{ll}2.1 \text { Material } & 10\end{array}$

2.1.1 Geräte 10

2.1.2 Chemikalien 11

$\begin{array}{ll}2.1 .3 \text { Kits } & 13\end{array}$

2.1.4 Verbrauchsmaterialien 14

2.1.5 Materialien für die Zellkultur 14

2.1.6 Medien und Lösungen 16

2.1.6.1 Allgemeine Puffer und Stammlösungen 16

$\begin{array}{ll}\text { 2.1.6.2 Nährmedien } & 16\end{array}$

2.1.7 Vektoren und Gen-Bibliotheken $\quad 17$

$\begin{array}{ll}2.1 .8 \text { Oligonukleotide } & 17\end{array}$

2.1.9 Bakterienstämme 21

2.1.10 Eukaryontische Zellinien 21

$\begin{array}{ll}2.1 .11 \text { Tiere } & 21\end{array}$

2.1.12 Antikörper 22 
2.2.1 DNA-Arbeiten 23

2.2.1.1 Polymerase-Kettenreaktion (PCR) (Saiki et al., 1988) 23

2.2.1.2 Verwendung der PCR zur Einführung von Mutationen in eine DNA-Sequenz

(Higushi, 1990) 24

2.2.1.3 Reinigung von PCR-Fragmenten 24

2.2.1.4 Restriktionsverdau 25

2.2.1.5 Dephosphorylierung der 5'-Enden durch alkalische Phosphatase 25

2.2.1.6 Ligation 25

2.2.1.7 Präparation elektrokompetenter E. coli Zellen 25

2.2.1.8 Elektroporation 26

2.2.1.9 DNA-Präparation 26

2.2.1.10 Reinigung von Plasmid-DNA 26

2.2.1.10.1 Phenol-Chloroform-Extraktion 26

$\begin{array}{ll}\text { 2.2.1.10.2 DNA-Präzipitation } & 27\end{array}$

$\begin{array}{ll}\text { 2.2.1.11 Konzentrationsbestimmung von DNA } & 27\end{array}$

2.2.1.12 DNA-Sequenzierung (modifiziert nach Sanger et al., 1977) 27

2.2.1.13 Agarosegelelektrophorese von Nukleinsäuren 28

2.2.1.14 Isolation von DNA aus Agarosegelen 28

2.2.1.15 Transfer von DNA auf Nylonmembran (Southern, 1975) 28

2.2.1.16 Radioaktive Markierung von DNA 29

2.2.1.17 Hybridisierung von radioaktiven Sonden (Reeds und Mann, 1985) 29

2.2.1.18 Northernblot 30

2.2.1.19 In-situ-Hybridisierung $\quad 30$

2.2.1.19.1 Bereitstellung von Gehirnschnitten $\quad 30$

2.2.1.19.2 Auswahl spezifischer antisense-Oligonukleotide 30

2.2.1.19.3 Terminale Markierung von Oligonukleotide 31

2.2.1.19.4 Hybridisierung 31

2.2.1.20 Isolierung genomischer Sequenz aus einer Lambda-Phagen-Bibliothek 32

2.2.1.20.1 Durchsuchung der Phagen-Bibliothek 32

2.2.1.20.2 Phagenamplifikation 33

2.2.1.20.3 Präparation von Lambda-Phagen-DNA 33 
2.2.2 Protein-Protein-Interaktionen im Hefe-Doppelhybrid-System

(Fields und Song, 1989) 34

2.2.2.1 Transformation mit einer pVP16-cDNA-Bibliothek 35

2.2.2.2 Transformation in kleinem Maßstab 36

$\begin{array}{ll}\text { 2.2.2.3 } \beta \text {-Galaktosidasetests } & 37\end{array}$

$\begin{array}{ll}\text { 2.2.2.3.1 Filtertest } & 37\end{array}$

2.2.2.3.2 Flüssigtest $\quad 38$

2.2.2.4 Isolierung von pVP16-DNA aus doppelt-transfizierter Hefe 39

2.2.2.5 Sequenzanalyse und Datenbankrecherche 39

2.2.3 Arbeiten mit Proteinen $\quad 40$

2.2.3.1 Expression von GST-Fusionsproteinen (Guan und Dixon, 1991) 40

2.2.3.2 Kosedimentation von Proteinen an immobilisiertem GST-Fusionsprotein 40

2.2.3.3 Konzentrationsbestimmung von Proteinen 41

2.2.3.4 Herstellung polyklonaler Antikörper 41

2.2.3.5 Koimmunpräzipitation $\quad 42$

2.2.3.6 Subzelluläre Fraktionierung (Huttner et al., 1983) 42

2.2.3.7 SDS-PAGE zur Auftrennung von Proteinen (Laemmli, 1970) 43

2.2.3.8 Coomassie-Färbung (modifiziert nach Weber und Osborn, 1969) 44

2.2.3.9 Transfer von Proteinen auf Nitrozellulose

(Westernblot; Towbin et al., 1979) 44

2.2.3.10 Immundetektion von Proteinen durch

„enhanced chemiluminescence (ECL)“ (Westernblot) 45

2.2.3.11 Entfernen des Antikörpers von einer Nitrozellulose-Membran 45

2.2.4 Immunfärbungen $\quad 46$

2.2.4.1 Immunhistologie $\quad 46$

2.2.4.2 Immuncytochemie auf kultivierten Zellen 46

2.2.4.3 Immuno-Elektronenmikroskopie 47

$\begin{array}{ll}\text { 2.2.5 Zellkulturexperimente } & 48\end{array}$

2.2.5.1 Kultivierung von HEK293-Zellen 48

2.2.5.2 Transfektion von HEK293-Zellen mittels DNA-Kalziumphosphat-

Kopräzipitat (modifiziert nach Chen und Okayama, 1987) 
2.2.5.3 Primärkultur hippocampaler Neuronen

2.2.5.4 Transfektion von Neuronen mittels DNA-Kalziumphosphat-Kopräzipitat 50

2.2.5.5 Herstellung homolog rekombinanter embryonaler Stammzellen zur

Erzeugung von deletionsmutanten knockout-Mäusen

(Willnow und Herz, 1994) 51

2.2.5.5.1 Zellkultur $\quad 51$

2.2.5.5.2 Transfektion der ES-Zellen mit dem Deletionsvektor $\quad 51$

2.2.5.5.3 Selektion rekombinanter ES-Zellen $\quad 52$

2.2.5.5.4 Isolierung und Expansion selektionierter ES-Zellen 52

2.2.5.5.5 Einfrieren von ES-Zellen in 96-Lochplatten 53

2.2.5.5.6 DNA-Iolierung und Analyse der rekombinanten ES-Zellen 45

2.2.5.5.7 Blastozysteninjektion und Züchtung der Mäuse 54

3. ERGEBNISSE

3.1 Identifikation von mit Neuroliginen interagierenden Proteinen mit

Hilfe des Doppelhybridsystems in Hefe (yeast-two-hybrid-screen) 55

3.1.1 Analyse der im Hefesystem gefundenen Interaktionen 56

$\begin{array}{ll}3.2 \text { Nedd4.1 } & 58\end{array}$

3.2.1 Interaktion von Neuroligin und Nedd4.1 im Hefe-Doppelhybridsystem und

$\begin{array}{lr}\text { Kartierung der interagierenden Bereiche } & 58\end{array}$

3.2.2 Die Nedd4.1-Antikörper 60

$\begin{array}{ll}3.2 .3 \text { In-vitro-Bindungsstudie } & 61\end{array}$

3.2.4 Gewebeverteilung von Nedd4.1 63

3.2.5 Gewebeverteilung von Nedd4.1 innerhalb des Gehirns 64

3.2.5.1 In-situ-Hybridisierung $\quad 65$

3.2.5.2 Immunoblotanalyse der Gewebeverteilung 66

3.2.6 Nedd4 und Neuroligin 1 kollokalisieren in Neuronen 67

3.2.7 Subzelluläre Verteilung von Nedd4.1 69

$\begin{array}{ll}3.2 .8 \text { Elektronenmikroskopie } & 70\end{array}$

3.2.9 Entwicklungsabhängige Expression von Nedd4.1 im Gehirn 71

3.2.10 Funktionelle Analyse der Interaktion zwischen Nedd4.1 und Neuroligin $\quad 72$

3.2.10.1 Die Mutante Nedd4.1 ${ }^{\text {C843S }} 72$ 
3.2.10.2 Der Einfluß von Nedd4.1 auf die Konzentration von Neuroligin in der Zelle $\quad 75$

3.2.10.3 DHFR-Fusionsproteine als interne Kontrolle 76

3.2.11 Die Nedd4.1-Deletionslinie in Mäusen 77

3.2.11.1 Strategie der Nedd4.1-Deletion und Generation des Zielvektors 78

3.2.11.2 Herstellung rekombinanter ES-Zellen und Aufbau der Mauslinie 79

3.2.11.3 Analyse der ES-Zellen und Generation von Chimären 80

$\begin{array}{ll}\text { 3.2.11.4 Genotypisierung der Mäuse } & 81\end{array}$

3.2.11.5 Biochemische Analyse der heterozygoten Tiere 83

3.2.11.6 Die homozygoten Nedd4.1-Deletionsmutanten 84

$\begin{array}{ll}\text { 3.2.11.6.1 Phänotyp } & 84\end{array}$

3.2.11.6.2 Die Neuroligin -Konzentration in homozygoten

Nedd4.1-Deletionsmutanten $\quad 85$

3.3 Protein 4.1N und Protein 4.1B $\quad 86$

3.3.1 Die Interaktion von Neuroligin mit Protein 4.1N und Protein 4.1B im Hefe-Doppelhybridsystem 86

3.3.2 Die Protein 4.1-Antikörper $\quad 88$

3.3.3 Lokalisation der 4.1-Bindestelle auf der intrazellularen

Domäne von Neuroligin $1 \quad 89$

3.3.4 Koimmunpräzipitation von Protein 4.1B mit Neuroligin-Antikörper 90

3.3.5 Gewebeverteilung von Protein 4.1B und Protein 4.1N 91

3.3.6 Regionale Verteilung von Protein 4.1N und Protein 4.1B im Gehirn 93

3.3.6.1 In-situ-Hybridisierung 93

3.3.6.2 Immundetektion von Protein 4.1N und Protein 4.1B in den Gehirnregionen $\quad 95$

3.3.7 Neuroligin 1 und Protein 4.1B kollokalisieren in Neuronen 96

3.3.8 Subzelluläre Lokalisation der Proteine 4.1N und 4.1B 96

3.3.9 Entwicklungsabhängige Expression der Proteine 4.1N und 4.1B 98

3.3.10 Interaktion von Protein 4.1N und Protein 4.1B mit MAGuK-Proteinen 99

3.3.11 Integration des cytoplasmatischen Teils von Neuroligin 1

$\begin{array}{ll}\text { in Aktin-Mikrofilamenten } & 100\end{array}$

3.3.12 Zielsteuerung von Neuroligin 1-EGFP-Konstrukten in HEK293-Zellen $\quad 101$

3.3.13 Zielsteuerung der Neuroligin 1-EGFP-Fusionsproteine in Neuronen 103 


\subsection{Analyse der Proteinexpression von Neuroligin 1/2/3-Deletionsmutanten}

Mäusen

4.1 Nedd4.1

4.1.1 Ubiquitinierung reguliert die Stabilität und Zusammensetzung von Synapsen

4.1.2 Ubiquitinligasen katalysieren die Bindung von Ubiquitin an ihre Zielproteine

4.1.3 Nedd4.1 ist eine Ubiquitinligase

4.1.4 Nedd4.1 und Neuroligin interagieren über WW-Domänen

4.1.5 Nedd4.1 und Neuroligin kollokalisieren auf der postsynaptischen Seite exzitatorischer Synapsen

4.1.6 Die Expression von Nedd4.1 beginnt bereits während der Embryonalentwicklung

4.1.7 Die Bindung von Nedd4.1 an Neuroligin resultiert nicht in dessen Ubiquitinierung

4.1.8. Die Nedd4.1-Deletionsmutante in der Maus

4.1.8.1 Nedd4.1 ist für die Embryonalentwicklung essentiell

4.1.8.2 Die Expression von Neuroligin in Nedd4.1-knockout-Mäusen ist unverändert

\subsection{Protein 4.1N und Protein 4.1B}

4.2.1 Die Proteine 4.1N und 4.1B sind Bestandteile des Cytoskeletts 117

4.2.2 Cytoskelettproteine modulieren und stabilisieren Synapsen $\quad 118$

4.2.3 Die 4.1-Proteine sind Ankerproteine für eine Reihe unterschiedlicher Proteine 118

4.2.4 Die 4.1-Poteine und Synaptogenese 119

4.2.5 Neuroligin bindet an die C-terminale Domäne von

Protein 4.1B und Protein 4.1N

4.2.6 Neuroligin kollokalisiert mit Protein 4.1B und Protein 4.1N in Teilen des Gehirns

4.2.7 Die Expression von Neuroligin, Protein 4.1B und Protein 4.1N verläuft parallel zur Synaptogenese 
4.2.9 Die Verankerung von Neuroligin im Cytoskelett ist nicht abhängig von seiner Interaktion mit MAGuK-Proteinen

4.2.10 Der cytoplasmatische C-Terminus, nicht aber die PDZ-Interaktion ist essentiell für die Zielsteuerung und Neuroligin

4.2.11 Fazit 


\section{VERZEICHNUNG DER ABKÜRZUNGEN UND ANGLISMEN}

\section{HD}

AMBA

Amp

antisense

APS

AS

ATP

bp

BSA

bzw.

C2-Domäne

C-terminal

C-Terminus

cAMP

cDNA

cluster

CNR

CTD

D-PBS

dATP

$\mathrm{dCTP}$

DEPC

DHFR

DMEM

DMSO

DNA

DNAse

dNTP's

Drosophila

DTT

E. coli

ECL

EDTA

EGFP

EGTA
4.1-Homologiedomäne

Acrylamid/Bis-Lösung

Ampicillin

antiparallel zur kodierenden Sequenz orientiert Ammoniumpersulfat

Aminosäure

Adenosintriphosphat

Basenpaare

bovines Serumalbumin

beziehungsweise

Kalziumbindedomäne des Typs 2

am $\mathrm{COOH}-T e r m i n u s$ eines Proteins gelegen

$\mathrm{COOH}-\mathrm{Terminus}$ eines Proteins

zyklisches Adenosinmonophosphat

zu einem Transkriptionsprodukt

komplementäre DNA

Akkumulate

Cadherin-ähnlichen neuronalen Rezeptoren

C-terminale Domäne

Dulbecco's PBS

Desoxyadenosintriphosphat

Desoxycytosintriphosphat

Diethylpyrocarbonat

Dehydrofululatreduktase

Dulbecco's Modifiziertes Eagle Medium

Dimethylsulfoxid

Desoxyribonukleinsäure

Desoxyribonuklease

Desoxynukleosidtriphosphate

Drosophila melanogaster

Dithiothreitol

Escherichia coli

enhanced chemoluminescence

Ethylendiamintetraessigsäure

enhanced green fluorescent protein

Ethylendioxybis(ethylennitrilo)tetraessigsäure 
ES

et al.

$\mathrm{g}$

GDP

GFP

GST

GTP

$\mathrm{h}$

HECT

HEPES

$\mathrm{His}_{5}$

$\mathrm{His}_{6}$

insert

IPTG

$\mathrm{kb}$

$\mathrm{kDa}$

1

LIF

LTP

M

$\mathrm{M}_{\mathrm{r}} \times 10^{-3}$

$\mathrm{mA}$

MAGUK

$\mu \mathrm{Ci}$

$\mathrm{mg}$

Min.

$\mathrm{ml}$

$\mathrm{mM}$

mRNA

NL

$\mathrm{nm}$

$\mathrm{N}$-terminal

$\mathrm{N}$-Terminus

NMDAR

NSF

OD
Embryonale Stammzelle

et alteres

Gramm

Guanosindiphosphat

Grün fluoreszierendes Protein

Glutathion-S-Transferase

Guanosintriphosphat

Stunde

homolog zum E6AP-C $-\underline{-T e r m i n u s ~}$

$\mathrm{N}-2-H y d r o x y e t h y l p i p e r a z i n-\mathrm{N}-2-$

Ethylsulfonsäure

Peptidsequenz aus fünf Aminosäuren

Peptidsequenz aus sechs Aminosäuren

insertierte Sequenz

Isopropyl-b-thiogalactopyranosid

Kilobasenpaare

Kilodalton

Liter

leucemia inhibitory factor

long term potentiation (Langzeit-

Potenzierung)

Mol

relatives Molekulargewicht in $\mathrm{kDa}$

Milliampere

membrane associated guanylate kinase

membranassoziierte Guanylatkinase

Mikrocurie

Milligramm

Minute

Milliliter

Minimol

messenger RNA

Neuroligin

Nanometer

am $\mathrm{NH}_{2}$-Terminus eines Proteins gelegen

$\mathrm{NH}_{2}$-Terminus eines Proteins

N-Methyl-D-Aspartat-Rezeptor

$\mathrm{N}$-ethylmaleimide-sensitive fusion protein

optische Dichte 
ONPG

PAGE

PBS

PCR

PDZ

$\mathrm{pH}$

PMSF

primer

RNA

RNAse

rpm

RT

SABD

screen

SDS

sec.

sense

spine

spot

TEMED

Tris

UV

X-Gal

yeast-two-hybrid-system

YTH
o-Nitrophenyl b-D-Galactopyranosid

Polyacrylamidgelelektrophorese

phosphatgepufferte Salzlösung

Polymerase-Kettenreaktion

PSD95/dlg1/ZO-1

negativer dekadischer Logarithmus der

Protonenkonzentration

Phenyl-Methylsulfonyl-Fluorid

Startsequenz für die Polymerasereaktion

Ribonukleinsäure

Ribonuklease

rounds per minute

(Umdrehungen pro Minute)

Raumtemperatur

Spektrin/Aktin-Bindedomäne

Durchsuchung

Natriumdodecylsulfat

Sekunde

parallel zur kodierenden Sequenz orientiert

Ausformung des Dendriten, Vorläufer der

Postsynapse

Punkt

$\mathrm{N}, \mathrm{N}, \mathrm{N}, \mathrm{N}-\mathrm{Tetramethylethylendiamin}$

Tris-hydroxymethyl-aminomethan

Ultraviolett

5-Brom-4-Chlor-3-Indolyl-b-Galactosid

Hefe-Doppelhybridsystem

yeast-two-hybrid 


\section{EINLEITUNG}

\subsection{Das Nervensystem}

Das Zentralnervensystem ist ein komplexes Netzwerk von Zellen, welches ständig Informationen empfängt, analysiert, erkennt und Entscheidungen trifft. Durch das Zusammenspiel der einzelnen Neuronen im Gehirn wird es ermöglicht, alle wichtigen Aktionen des Organismus, bis hin zu komplexen Vorgängen, wie dem Lernen und dem emotionalen Verhalten, zu steuern.

Um Informationen aufzunehmen, zu verarbeiten und weiterzuleiten, besitzt das Nervensystem eine immense Anzahl von Zellfortsätzen (Axone und Dendriten), die von den Neuronen gebildet werden. An den Kontaktstellen zwischen Axon und Dendrit, den Synapsen, findet die Informationsweiterleitung statt.

\subsection{Die Entwicklung des Nervensystems}

Die Entwicklung und Differenzierung des Nervensystems der Vertebraten gliedert sich in drei Phasen.

In der ersten Phase wird die Bildung und Vermehrung von neuralen Stammzellen aus dem Ektoderm durch das darunter liegende Mesoderm induziert. Die ersten Nervenzellen entstehen aus verlängerten neuroektodermalen Zellen, die die Neuralplatte bilden. Die Ränder dieser Schicht verdicken sich und wandern apikal. Die so entstandenen Neuralwülste fusionieren schließlich, um das hohle Neuralrohr zu bilden. Einige Zellen an den Lippen der Neuralwülste werden weder in das Neuralrohr noch in das darüber liegende Ektoderm integriert, sie bleiben dazwischen liegen. Diese Zellen bilden die Neuralleiste, die Ausgangspunkt für die Entwicklung des periphereren Nervensystems ist. Im Laufe der Entwicklung durchläuft der anteriore Teil des Embryos eine Reihe von Anschwellungen, Einschnürungen und Krümmungen, durch die sich die verschiedenen Gehirnregionen bilden. Der caudale Teil des Neuralrohrs behält seine relativ einfache, rohrförmige Struktur und bildet das Rückenmark.

Im Neuralrohr vermehrt sich nur eine einzige, sich schnell teilenden Schicht von Zellen, die den Ventrikel umschließt. Die Tochterzellen dieser Schicht sind neuronale Vorläuferzellen, die sich sowohl zu Neuronen, als auch zu Gliazellen ausdifferenzieren können. Die noch undifferenzierten Nervenzellen wandern entlang radialer Gliazellen von ihrem Geburtsort im 
Innern des Neuralrohrs zur Außenseite. Nachdem sie ihre Zielregion erreicht haben, siedeln sie dort und differenzieren zu Neuronen.

Zu Beginn der zweiten Phase der Entwicklung des Nervensystems sind die Neuronen nicht mehr teilungsfähig. Die ebenfalls aus den Vorläuferzellen entstehenden Gliazellen behalten in der Regel ihre Teilungsfähigkeit. Die Nervenzelle bildet nun lange Fortsätze, die Axone und Dendriten. Das bis zu einem Meter lange Axon formt mit den Dendriten anderer Neuronen zahlreiche Synapsen, Schaltstellen, die den innerhalb der Zelle weitergeleiteten elektrischen Impuls in ein chemisches Signal umwandeln und auf diese Weise an andere Zellen weitergeben. Die Kommunikation zwischen den Zellen beginnt. Die zu kontaktierenden Zielzellen befinden sich teilweise in sehr weit entfernten Regionen des Körpers. Auf seinem Weg in das Zielgebiet werden Richtung und Geschwindigkeit des wachsenden Axons durch eine verbreiterte Struktur an seiner Spitze, dem Wachstumskegel, gesteuert. Auf der Oberfläche des Wachstumskegels befinden sich Rezeptoren und Zelladhäsionsmoleküle, durch die attraktive oder repulsive Signale von umgebenden Zellen aufgenommen werden können (Chiba und Keshiba, 1996; Goodman 1996). Auf diese Weise navigiert das Axon durch das Gewebe, bis es im Zielgebiet angekommen ist. Dort wird die Zielzelle ebenfalls durch Zell-Zielgebiet-Kommunikation mit Hilfe von Rezeptoren und Adhäsionsmolekülen ausgewählt und die Synapsenbildung eingeleitet.

In der dritten und letzten Phase der Entwicklung des Nervensystems werden die synaptischen Verbindungen verfeinert und moduliert. Die Häufigkeit mit der eine Synapse gebraucht wird, ist entscheidend für die Verstärkung oder Repression der Verbindung. Auf diese Weise werden in der frühen postnatalen Phase eine große Zahl der neu gebildeten Zell-Zell-Kontakte wieder eliminiert. Dieser Mechanismus der Feinregulierung neuronaler Verknüpfungen besteht bis in das Erwachsenenalter weiter.

\subsection{Zelladhäsionsproteine vermitteln und stabilisieren den synaptischen Kontakt}

Im Gegensatz zur Steuerung und Zielfindung des Axons ist über den molekularen Steuerungsmechanismus der späten Schritte der Synaptogenese wenig bekannt. Es ist nach wie vor unklar, wie das ankommende Axon seine Zielzelle erkennt und auswählt, auf welche Weise die prä- und postsynaptischen Proteinkomponenten zur richtigen Seite der Synapse transportiert werden oder wie der synaptische Kontakt erhalten und moduliert werden kann. 
Wie schon bei der Axonleitung ist es sehr wahrscheinlich, daß auch hier Zelladhäsionsmoleküle von Bedeutung sind. In den letzten zehn Jahren sind einige Zelladhäsionssysteme gefunden worden, die möglicherweise bei der Regulation der Synaptogenese im zentralen Nervensystem beteiligt sind:

1. Das Cadherin/Catenin System (Fannon und Colman 1996, Uchida et al., 1997)

2. Die Cadherin-ähnlichen neuronalen Rezeptoren (CNR; Kohmura et al., 1998)

3. Das synaptische Zelladhäsionsprotein SynCAM (Biederer et al., 2002)

4. Das Neuroligin/ $\beta$-Neurexin System (Song et al., 1999)

Diese sollen im Nachfolgenden kurz erläutert werden.

\subsubsection{Die Cadherine}

Cadherine bilden kalziumabhängig homotypische Zelladhäsionssysteme (Takeichi et al., 1988, 1994). Die Superfamilie der Cadherin-ähnlichen Proteine umfaßt die Gruppe der klassischen Cadherine, der desmosomalen Cadherine, der Protocadherine und der Cadherinähnlichen neuronalen Rezeptoren (CNR) (Bruses et al., 2000; Yagi und Takeichi, 2000; Ranscht et al., 2000). Sie sind in nahezu allen Zellverbindungen zu finden und sowohl bei der Entstehung von Kontakten während der Entwicklung, als auch für deren Stabilisierung im maturen Gewebe von Bedeutung.

Im Zusammenhang mit Synaptogenese-Prozessen sind zunächst die klassischen Cadherine, insbesondere das neuronale Cadherin (N-Cadherin) von Interesse. Klassische Cadherine bestehen aus einer großen extrazellulären, N-terminalen Domäne mit fünf sich wiederholenden Subdomänen (E1-E5), einer Typ I-integralen Transmembrandomäne und einer hoch konservierten, C-terminalen cytoplasmatischen Region. Sie bilden mehr als fünfzehn verschiedene Isoformen und eine große Zahl von Spleißvarianten. Extrazellulär binden die klassischen Cadherine mit wenigen Ausnahmen bevorzugt an Proteine des gleichen Subtyps. Die Spezifität dieser homotypischen Verbindung wird stets von mehreren Teilen der N-terminalen Domäne vermittelt. Die intrazellulären Bindungspartner der klassischen Cadherine, $\alpha-\mathrm{N}-\mathrm{Catenin}$ und $\beta$-Catenin, verankern das Protein mit dem AktinCytoskelett. Cadherine sind in einer Vielzahl unterschiedlicher Synapsenarten gefunden 
worden (Bruses et al., 2000), in denen sie die für die Transmitterfreisetzung verantwortliche aktive Zone und die für die Signalaufnahme verantwortliche postsynaptische Verdichtung flankieren (Fannon und Colman, 1996; Uchida et al., 1997; Inoue und Sanes, 1997). Während der Embryogenese wird N-Cadherin in neu entstehenden Kontakten sowohl spontan (Benson et al., 1998), als auch durch Aktivität (Bozdagi et al., 2000) bereits sehr früh exprimiert. Die Bindungseigenschaften, die Lokalisation, das Entwicklungsmuster und die große Diversität der klassischen Cadherine legen den Schluß nahe, daß diese Proteine eine wesentliche Rolle in der frühen Phase des Synaptogeneseprozesses spielen.

\subsubsection{Die Cadherin-ähnlichen neuronalen Rezeptoren}

Interessanterweise befinden sich nicht in allen Synapsen Cadherin/Catenin-Verknüpfungen (Uchida et al., 1997). Eliminiert man N-Cadherin aus kultivierten, hippocampalen Neuronen, führt das nicht zum Verlust der synaptischen Bindung und auch nicht zum Verlust der angegliederten Signaltransduktionskaskade (Huntley und Benson., 1999; Zhang und Benson 2001). Diese Befunde legen die Vermutung nahe, daß auch andere Cadherine an der Regulation von Zellerkennung in der frühen Phase der Synaptogenese beteiligt sind. Tatsächlich sind andere Mitglieder der Cadherin-Superfamilie in den Synapsen des zentralen Nervensystems gefunden worden (Kohmura et al., 1998), die zur Familie der Protocadherine gehören. Die genomische Struktur der Protocadherine erinnert an den Aufbau der T-ZellRezeptoren und Immunglobuline im Immunsystem. Die Gene der $\alpha$-, $\beta$ - und $\gamma$-Protocadherine sind in drei Gen-clustern organisiert, die für 52 Protocadherin-Gene kodieren. Das vollständige Transkript entsteht aus einem großen „variablen“ Exon, das für die extrazellulären Domänen mit sechs beziehungsweise sieben Ektodomänen kodiert, und drei „konstanten“ Exonen, die für die konservierte, familienspezifische cytoplasmatische Domäne kodieren (Yagi et al., 2000; Obata et al., 1998; Wu und Maniatis., 1999, 2000 und 2001; Sugino et al., 2000). Die Kombination von variablen und konstanten Exonen ermöglicht eine hohe Zahl von Spleißvarianten, die sowohl durch DNA-Umordnung wie auch durch somatische Mutationen entstehen (Hirayama et al., 2001). Dieser Mechanismus erlaubt den Cadherinen die Ausbildung einer enormen funktionellen Diversität. Die intrazelluläre Domäne der Cadherin-ähnlichen neuronalen Rezeptoren ist hoch konserviert und unterscheidet sich deutlich von denen der klassischen Cadherine. Ihr Bindungspartner ist Fyn, eine Rezeptortyrosinkinase (Kohmura et al., 1998). Fyn-deletionsmutante Mäuse haben Defekte in der LTP-Induktion und bei der räumlichen Orientierung (Grand et al., 1992). Die 
Bindung der Cadherin-ähnlichen neuronalen Rezeptoren an Fyn und ihre Lokalisation impliziert eine Rolle dieser Rezeptoren bei der Stabilisierung von synaptischen Kontakten, ähnlich der von klassischen Cadherinen.

\subsubsection{SynCAM}

In jüngster Zeit ist ein weiteres Protein entdeckt worden, das homotypische Zelladhäsion in Synapsen vermittelt. SynCAM gehört zur Familie der Immunglobulin-Domänen-Proteine (Biederer et al., 2002). Es besitzt drei extrazelluläre Immunglobulin-Domänen am NTerminus, gefolgt von einer Transmembrandomäne und einem kurzen cytoplasmatischen CTerminus, an dessen äußersten Ende sich die Erkennungssequenz für PDZ-Domänen des Typs 2 der MAGuK-Familie befindet (siehe 1.3.4.1). An ihn binden CASK und Syntenin (Biederer et al., 2002). SynCAM wird gehirnspezifisch expremiert und ist in der Synapse an den Zonen der Transmitterübertragung konzentriert. Die Expression von SynCAM beginnt in den ersten Tagen nach der Geburt und steigert sich im Verlauf der ersten drei Wochen, einer Phase, in der die meisten Synapsen entstehen. Die Immunglobulin-Domänen bilden kalziumunabhängig homotypische Bindungen, die bei Expression in Drosophila S2-Zellen Zelladhäsion vermitteln. Überexpression von SynCAM in kultivierten hippocampalen Neuronen erhöhte die Synapsenzahl und verdreifachte so die Frequenz der spontanen synaptischen Ministröme. Expression des cytoplasmatischen Teils hingegen inhibierte die Formation von Synapsen. Interessanterweise sind die äußersten drei Aminosäuren am C-Terminus, die die PDZDomänen-Interaktion vermitteln, für diesen Effekt essentiell. In nichtneuronalen HEK293Zellen überexpremiert, induzierte SynCAM die Bildung von Kontakten auf diesen Zellen durch kokultivierte Neuronen. Bei gleichzeitiger Expression von Glutamatrezeptoren waren in einigen dieser Zellen synaptische Ströme messbar, die möglicherweise durch synaptische Aktivität verursacht wurden (Biederer et al., 2002). 


\subsubsection{Das Neuroligin/Neurexin-System}

Die Cadherine und SynCAM spielen als homotypische Adhäsionproteine höchst wahrscheinlich eine bedeutende Rolle bei der Entstehung und Stabilisierung von Synapsen. Dennoch verlangt der asymmetrische Aufbau der Synapsen mit ihren definierten prä- und postsynaptischen Seiten ein asymmetrisches Adhäsionssystem. Die von den Zelladhäsionsmolekülen Neuroligin und $\beta$-Neurexin gebildeten Zell-Zell-Verbindungen stellen möglicherweise ein solches System dar.

Neuroligine und Neurexine sind gehirnspezifisch exprimierte, integrale Membranproteine des Typs I (Ichtchenko et al., 1995 und 1996, Ullrich et al., 1995). Neurexin I $\alpha$ ist ursprünglich als $\alpha$-Latrotoxin-Rezeptor entdeckt und gereinigt worden (Ushkaryov et al., 1992). Weitere Mitglieder der Proteinfamilie wurden durch Homologievergleiche identifiziert (Petrenko et al., 1993). Das mammale Genom kodiert drei Neurexingene (Neurexin I, -II, und -III). Jedes Gen steht unter der Kontrolle von zwei Promotoren, die die Primärtranskripte Neurexin- $\alpha$ und - $\beta$ generieren (Ushkaryov et al., 1994). Fünf verschiedene Spleißstellen, in die bis zu zwölf alternative inserts integriert werden können, führen zu einer umfassenden Polymorphie der Neurexin-Genprodukte, ähnlich der der Cadherine (Missler et al., 1998; Missler und Südhof, 1998; Ullrich et al., 1995).

Der extrazelluläre Teil eines bestimmten Spleißvariantentyps der $\beta$-Neurexine bindet an Neuroligin (Ichtchenko et al., 1995 und 1996; Nguyen und Südhof, 1997). Im humanen Genom sind bislang vier Neuroligin-Gene (Neuroligin 1, -2, -3 und -4; Ichtchenko et al., 1995; Bollinger et al., 2001) identifiziert worden. Aus dem Rattengenom sind bislang nur drei Neuroligin-Gene bekannt. Die Neuroligine 1, -2 und -3 sind gut charakterisiert. Die kodierenden Bereiche der zwischen 110 und $120 \mathrm{kDa}$ großen Genprodukte zeichnen sich durch zwei alternative Spleißstellen im extrazellulären Bereich aus. Die Insertionen unterscheiden sich jedoch abhängig vom Gen (Ichtchenko et al., 1995 und 1996).

Die Neuroligine 1, -2 und -3 werden ausschließlich in neuronalem Gewebe exprimiert (Ichtchenko et al., 1995). Elektronenmikroskopische Untersuchungen zeigen, daß Neuroligin 1 spezifisch auf der postsynaptischen Membran exzitatorischer Synapsen lokalisiert ist (Song et al., 1998). Die Expression der Neuroligine beginnt in der späten Phase der Embryonalentwicklung und verläuft in seiner Intensität parallel zur Synaptogeneserate. Der 
Expressionshöhepunkt liegt in der frühen postnatalen Phase (Irie et al., 1997, Song et al., 1998). Neuroligine bestehen aus einem großen extrazellulären, N-terminalen Bereich, der $\beta$ Neurexin bindet und in den synaptischen Spalt ragt, einer Transmembrandomäne und einem relativ kurzen cytoplasmatischen C-Terminus. Die N-terminale Domäne ist homolog zu Serinesterasen wie der Acetylcholinesterase ist aber aufgrund einer Substitution eines katalytischen Serinrestes durch ein Glycin enzymatisch nicht aktiv (Ichtchenko et al., 1995). Ähnliche katalytisch inaktive Serin-Esterasedomänen sind in anderen Zelloberflächenproteinen gefunden worden, wie etwa in den Drosophila-Proteinen Neurotactin und Gliotactin, welche Zell-Zell-Kontakte während der Embryogenese vermitteln (Hortsch et al., 1990; Auld et al., 1995).

\subsubsection{Neuroligin und Neurexin binden MAGuK-Proteine}

Die drei äußersten C-terminalen Aminosäuren am Ende von Neuroligin bilden die Erkennungssequenz für PDZ-Domänen-Proteine (Songyang et al., 1997), insbesondere für Proteine der 1. Klasse der Membran-asssoziierten Guanylatkinasen (MAGuKs), wie PSD95 (SAP90), PSD93 (Chapsyn110), SAP97 (hDlg) und SAP102 (Irie et al., 1997). MAGuKProteine organisieren die Akkumulation von Ionenkanälen und Rezeptoren und sorgen für deren Verknüpfung mit dem Cytoskelett und Proteinen des Cytosols (Anderson et al., 1996; Sheng und Kim, 1996; Kornau et al., 1997; Ziff, 1997; Craven und Bredt, 1998). Sie bilden das Grundgerüst der postsynaptischen Verdichtung und der aktiven Zone, ihre Bindungen unterliegen einem hohen Grad von Variabilität und Dynamik. Die charakteristische Domänenstruktur mit drei N-terminalen PDZ-Domänen, einer SH3-Domäne und einer inaktivierten Guanylatkinasedomäne ist innerhalb der MAGuK-Familie hoch konserviert. Alle drei Domänen stellen Protein-Protein-Interaktionsmodule dar, die sowohl miteinander, als auch mit unterschiedlichen anderen Proteinen Verbindungen knüpfen. Der am besten charakterisierte MAGuK-Interaktionspartner von Neuroligin ist PSD95.

Die Bindung von Neuroligin an PSD95 stellt den Kontakt von NL zu einer Vielzahl von Proteinen her. $\mathrm{Zu}$ den Bindungspartnern von PSD95 gehören Rezeptormoleküle, wie etwa die NMDA-Rezeptor-Untereinheit NR2A-C, bestimmte Kaliumkanal-Subtypen und Proteine der Signaltransduktion, wie die GTPase-aktivierungsproteine SynGAP (RasGAP), die RapGAP SPAR, die neuronale NO-Synthetase nNOS und Fyn (Kim et al., 1998; Pak et al., 2001; Brennman et al., 1996; Tezuka et al., 1999). PSD95 bindet außerdem Strukturproteine, wie 
GKAP und BEGAIN, die Verbindungen zum tiefer gelegenen Gerüst der postsynaptischen Verdichtung herstellen (Kim et al., 1997; Deguchi et al., 1998), und Komponenten des Cytoskeletts, wie das Microtubulin-assoziierte Protein CRIPT (Niethammer et al., 1998).

Durch die Vielzahl der Interaktionspartner, mit denen sie über die PDZ-Interaktionen in Verbindung stehen, können die Neuroligine auf die Rekrutierung und Verankerung von Proteinen in der postsynaptischen Verdichtung Einfluß nehmen. Auf der präsynaptischen Seite bildet $\beta$-Neurexin ebenfalls einen multimeren Proteinkomplex. An den äußersten CTerminus von $\beta$-Neurexin bindet CASK, das ebenfalls ein Mitglied der MAGuK-Familie ist (Hata et al., 1996). CASK komplexiert mit Mint1 und Veli und verbindet so das NL/ $\beta$ Neurexin-System mit Munc18, einer essentiellen Proteinkomponente des synaptischen Vesikelzyklus (Butz et al., 1998). Interessanterweise wird auf diese Weise auf beiden Seiten der direkte Kontakt zwischen Zelladhäsion und synaptischer Funktionalität hergestellt.

\subsubsection{Neuroligin induziert synaptische Differenzierung}

Die bisherigen Erkenntnisse weisen darauf hin, daß die Bindung von $\beta$-Neurexin an Neuroligin möglicherweise beiderseits der Synapse eine Signaltransduktionskette aktiviert, welche die Synthese und Rekrutierung der Komponenten der präsynaptischen aktiven Zone, beziehungsweise die der postsynaptischen Verdichtung aktiviert.

Tatsächlich konnte gezeigt werden, daß die Interaktion von rekombinantem Neuroligin 1 mit $\beta$-Neurexin in vivo Zelladhäsion vermittelt. Überexpression von Neuroligin 1 und $\beta$-Neurexin in Drosophila S2-Zellen führt zur Adhäsion dieser Zellen (Nguyen und Südhof, 1997).

Der Nachweis einer funktionellen Konsequenz dieser adhäsiven Fähigkeiten wurde mit Hilfe von rekombinant exprimierten Neuroligin 1 in HEK293-Zellen geführt. Expression von Neuroligin 1 und -2, nicht aber von anderen Zelladhäsionsproteinen wie N-Cadherin, auf der Oberfläche von HEK-Zellen induzierte die Ausbildung präsynaptischer Spezialisierung auf kontaktierenden, kokultivierten Neuronen (Scheiffele et al., 2000). Es kam zur Konzentration präsynaptischer Markerproteine sowie zur depolarisationsabhängigen Fusion synaptischer Vesikel an den Kontaktstellen. Die Ausbildung dieser „Semisynapsen“ konnte durch Applikation von rekombinanten $\beta$-Neurexin-IgG-Fusionsproteinen unterbunden werden. Diese Daten implizieren, daß die Bindung von Neuroligin an $\beta$-Neurexin für die Einleitung der präsynaptischen Differenzierung notwendig ist. 


\subsection{Zielsetzung der Arbeit}

Während die extrazellulären Interaktione zwischen Neuroliginen und $\beta$-Neurexinen recht gut untersucht und charakterisiert worden sind, ist nicht bekannt, wie die Neuroligine das von den $\beta$-Neurexinen erhaltene Signal an den intrazellulären Signaltransduktionsapparat weiterleiten. Es ist anzunehmen, daß neben der MAGuK-Interaktion, die sich an den drei äußersten Cterminalen Aminosäuren abspielt, noch weitere Proteine an den cytoplasmatischen Teil der Neuroligine binden. Aufbauend auf den Ergebnissen einer Diplomarbeit, in der mit Hilfe des Hefe-Doppelhybridsystems neue intrazelluläre Bindungspartner der Neuroligine identifiziert wurden, sollen drei Proteine und ihre Interaktion mit Neuroligin eingehender untersucht und charakterisiert werden: die Ubiquitinligase Nedd4.1 sowie die Strukturproteine $4.1 \mathrm{~N}$ und 4.1B. 


\section{MATERIAL UND METHODEN}

\subsection{Material}

\subsubsection{Geräte}

DNA-Sequenzer

Elektroporationsgerät

Entwicklungsmaschine

Gefrierschränke

Elektrophoresesytem für Agarose-Gele

Elektrophoresesytem für SDS-PAGE

FPLC-Säulenapparatur

Gelphotographiergerät

Geltrockner

Heizblöcke

Inkubatoren

Kühlschränke

PCR-Maschine

pH-Meter

Pipetten, Pipettierhilfen

Schüttler für 1,5 ml Reaktionsgefäße

Schüttelinkubator

Sonicator

Spannungsquelle

Spektralphotometer

Sterilbänke

UV-Crosslinker

Vortex Genie 2
Applied Biosystems, Weiterstadt

Bio-Rad Laboratories GmbH, München

Agfa-Gevaert GmbH, Martsel, Belgien

Liebherr, Ochsenhausen

Life-Technologies Gibco-BRL GmbH, Eggenstein-Leopoldshagen

Bio-Rad Laboratories GmbH, München

Pharmacia Biotech GmbH, Freiburg

Intas $\mathrm{GmbH}$, Göttingen

Biometra GmbH, Göttingen

Eppendorf GmbH,Hamburg,

Techne GmbH, Abingdon, England

Adolf Kühne AH, Heraeus GmbH, Hanau,

New Brunswig Scientific GmbH, Nurtingen

Liebherr, Ochsenhausen

Biometra GmbH, Göttingen

Knick, Schütt GmbH, Göttingen

Gilson, Villiers-le-Bel, Frankreich,

Brandt GmbH, Wertheim

Eppendorf GmbH, Hamburg

New Brunswig Scientific GmbH, Nurtingen

B. Braun Biotech International GmbH,

Melsungen

Pharmacia Biotech GmbH, Freiburg

Beckmann Instruments GmbH, München

Heraeus GmbH, Hanau

Biometra GmbH, Göttimgen

Bender \& Hobein GmbH, Zürich, Schweiz 
Wasserbäder

Zentrifugen
B. Braun, Melsungen

Beckmann Instruments $\mathrm{GmbH}$, München, Eppendorf GmbH, Hamburg,

Heraeus GmbH, Hanau

\subsubsection{Chemikalien}

Alle hier nicht aufgeführten Chemikalien wurden von der Firma Merck, Darmstadt in p. a. Qualität bezogen.

Agarose

Alkalische Phosphatase

Acrylamid-Bisacrylamid-Gemisch

Aminosäuren

Ammoniumpersulfat

Aprotinin

Bacto-Hefeextrakt

Bacto-Trypton

Bacto-Pepton

Bacto-Agar

Bacto-Yeast Nitrogen Base w/o Amino Acids

Bisindolylmaleimid (BIS)

Bradford Reagenz

Coomassie Blue R250

$\left[\alpha^{35} \mathrm{~S}\right] \mathrm{dATP}$

$\left[\alpha-{ }^{32} \mathrm{P}\right] \mathrm{dCTP}$

DEPC

Dextransulfat

DMSO Hybri-Max

DNA-Längenstandards

DNAse I
Life-Technologies Gibco-BRL GmbH, Eggenstein-Leopoldshagen

Roche Diagnostics GmbH, Basel, Schweiz

Bio-Rad Laboratories GmbH, München

Sigma-Aldrich GmbH, Deisenhofen

Sigma-Aldrich GmbH, Deisenhofen

Roche Diagnostics GmbH, Basel, Schweiz

DIFCO Laboratories GmbH, Augsburg

DIFCO Laboratories GmbH, Augsburg

DIFCO Laboratories GmbH, Augsburg

DIFCO Laboratories GmbH, Augsburg

DIFCO Laboratories GmbH, Augsburg

Sigma-Aldrich GmbH, Deisenhofen

Bio-Rad Laboratories GmbH, München

BioMol Feinchemikalien GmbH, Hamburg Amersham-Buchler GmbH, Braunschweig Amersham-Buchler GmbH, Braunschweig

Sigma-Aldrich GmbH, Deisenhofen

Sigma-Aldrich GmbH, Deisenhofen

Sigma-Aldrich GmbH, Deisenhofen

Life-Technologies Gibco-BRL GmbH,

Eggenstein-Leopoldshagen

Roche Diagnostics GmbH, Basel, Schweiz 
dNTP-Lösungen

ECL-Reagenzien

Entwickler

Ethidiumbromid

Ficoll 400

Fixierer

Fluoromount-G

Formamid

Freud'sches Adjuvans

Gelatine

Glutathion

Glutathion-Agarose

Glycin

Igepal

IPTG

Ionomycin

Lachsspermien-DNA

N-Laurylsarkosin

Leupeptin

Lysozym

$\beta$-Mercaptoethanol

Molekulargewichtsstandards für Proteine

Natriumcholat

Natrium-Desoxycholat

ONPG

Paraformaldehyd

PEG 8000

Pepstatin A

Pfu-Polymerase

PMSF (Pentylmethylensulfonylfluorid)

Polyvinylpyrolidon

Ponceau S
Pharmacia Biotech GmbH, Freiburg

Amersham-Buchler GmbH, Braunschweig

Kodak, Integra Bioscience GmbH, Fernwald

Sigma-Aldrich GmbH, Deisenhofen

Pharmacia Biotech GmbH, Freiburg

Kodak, Integra Bioscience GmbH, Fernwald

Southern Biotechnology Associates,

Birmingham, AL, USA

Fluca Chemie AG, Neu-Ulm

Sigma-Aldrich GmbH, Deisenhofen

DIFCO Laboratories GmbH, Augsburg

Sigma-Aldrich GmbH, Deisenhofen

Sigma-Aldrich GmbH, Deisenhofen

Bio-Rad Laboratories GmbH, München

Sigma-Aldrich GmbH, Deisenhofen

BioMol Feinchemikalien GmbH, Hamburg

Sigma-Aldrich GmbH, Deisenhofen

Sigma-Aldrich GmbH, Deisenhofen

Sigma-Aldrich GmbH, Deisenhofen

Roche Diagnostics GmbH, Basel, Schweiz

Sigma-Aldrich GmbH, Deisenhofen

Sigma-Aldrich GmbH, Deisenhofen

Bio-Rad Laboratories GmbH, München

Wako Chemicals GmbH, Neuss

Wako Chemicals GmbH, Neuss

Sigma-Aldrich GmbH, Deisenhofen

Boehringer Ingelheim Bioproducts

Partnership, Heidelberg

Sigma-Aldrich GmbH, Deisenhofen

Roche Diagnostics GmbH, Basel, Schweiz

Stratagene $\mathrm{GmbH}$, Heidelberg

Roche Diagnostics GmbH, Basel, Schweiz

Sigma-Aldrich GmbH, Deisenhofen

Sigma-Aldrich GmbH, Deisenhofen 
Protein-G-Sepharose

Restriktionsendonukleasen

RNAse A

SDS

Sekundäre Antikörper

T4 DNA-Ligase

Silver Grain Emulsion

TEMED

Terminale Transferase

Tris Base

Triton X-100

Trockenmilch (Glücksklee

Magermilchpulver)

Tween 20

(Polyoxyethylensorbitanmonolaurat)

$\mathrm{X}-\mathrm{Gal}$

Ziegenserum

\subsubsection{Kits}

Plasmid Mini-, Midi- und Maxi-Kits

Prime-It II Random Primer Labelling Kit

Qiaex II

QiaQuick PCR Purification Kit
Pharmacia Biotech GmbH, Freiburg

Roche Diagnostics GmbH, Basel, Schweiz,

New England Biolabs

Sigma-Aldrich GmbH, Deisenhofen

Roche Diagnostics GmbH, Basel, Schweiz

Bio-Rad Laboratories GmbH, München

Roche Diagnostics GmbH, Basel, Schweiz

Kodak, Integra Bioscience GmbH, Fernwald

Bio-Rad Laboratories GmbH, München

Roche Diagnostics GmbH, Basel, Schweiz

Sigma-Aldrich GmbH, Deisenhofen

Roche Diagnostics GmbH, Basel, Schweiz

Nestle Deutschland AG, Frankfurt/Main

Sigma-Aldrich GmbH, Deisenhofen

BioMol Feinchemikalien GmbH, Hamburg

Life-Technologies Gibco-BRL GmbH,

Eggenstein-Leopoldshagen

Qiagen GmbH, Hilden

Stratagene GmbH, Heidelberg

Qiagen $\mathrm{GmbH}$, Hilden

Qiagen $\mathrm{GmbH}$, Hilden

\subsubsection{Verbrauchsmaterialien}

Bio-Spin Chromatographiesäulen

Centricon-Säulen

Dialyseschläuche

ECL-Röntgenfilme
Bio-Rad Laboratories GmbH, München

Amicon GmbH, Witten

Spectrum Medical, Los Angeles, USA

Amersham-Buchler GmbH, Braunschweig 
Einmalchromatographieröhrchen $(15 \mathrm{ml})$

Elektroporationsküvetten

Glasperlen $(0,3 \mathrm{~mm})$

Hybond-N ${ }^{+}$Nylon Membran

Nitrozellulose-Filter $(13,7 \mathrm{~cm})$

Plastikwaren

Reaktionsgefäße

Röntgenfilme

Szintillationszählröhrchen

Szintillationslösung (OptiPhase „Supermix“)

Whatman-Cellulose Filter Nr. 1

Whatman-3 MM

\subsubsection{Materialien für die Zellkultur}

D-PBS

L-Glutamin (100 x)

Penicillin/Streptomycin

Zellkulturgefäße

Für die HEK293-Zellkultur:

DMEM (mit L-Glutamin, 4500 mg/l

D-Glucose, ohne Natriumpyruvat)

Fötales Rinderserum (hitzeinaktiviert, auf Viren und Mycoplasmen getestet) Trypsin-EDTA (1 x)
Bio-Rad Laboratories GmbH, München

Bio-Rad Laboratories GmbH, München

B. Braun Apperatebau, Melsungen

Amersham-Buchler GmbH, Braunschweig

Millipore GmbH, Eschborn

Greiner, Falcon, Brandt

Eppendorf GmbH, Hamburg

Kodak, Integra Bioscience GmbH, Fernwald

Canberra-Packard GmbH, Frankfurt

Fisons Chemicals, Loughborough Leic., England

Biometra GmbH. Göttingen

Whatman International Ltd., Maidstone,

England
Life-Technologies Gibco-BRL GmbH, Eggenstein-Leopoldshafen Life-Technologies Gibco-BRL GmbH, Eggenstein-Leopoldshafen 500 x, Boehringer Mannheim GmbH von den Firmen Greiner, Costar, Falcon und Nunc

Life-Technologies Gibco-BRL GmbH, Eggenstein-Leopoldshafen

Life-Technologies Gibco-BRL GmbH, Eggenstein-Leopoldshafen Life-Technologies Gibco-BRL GmbH, Eggenstein-Leopoldshafen 
$\underline{\text { Für die ES-Zellkultur: }}$

DMEM-Pulvermedium

fötales Rinderserum

Ganciclovir

ESGRO-LIF

100 x MEM nichtessentielle Aminosäuren

$\beta$-Mercaptoethanol (Zellkultur rein)

Mitomycin C

Mineralöl

Neomycin (G418-Sulfat)

N-Laurylsarcosin

Trypsin-EDTA (1 x) mit $4500 \mathrm{mg} / \mathrm{L}$ D-Glucose und L-Glutamin, Life-Technologies Gibco-BRL GmbH,

Eggenstein-Leopoldshafen

HyClone, Erembodegen-Aalst, Belgien

Roche Diagnostics GmbH, Basel, Schweiz

Life-Technologies Gibco-BRL GmbH,

Eggenstein-Leopoldshafen

Life-Technologies Gibco-BRL GmbH, Eggenstein-Leopoldshafen

Sigma-Aldrich GmbH, Deisenhofen Sigma-Aldrich GmbH, Deisenhofen Sigma-Aldrich GmbH, Deisenhofen Life-Technologies Gibco-BRL GmbH, Eggenstein-Leopoldshafen Sigma-Aldrich GmbH, Deisenhofen Life-Technologies Gibco-BRL GmbH, Eggenstein-Leopoldshafen

$\underline{\text { Für die Primärkultur hippocampaler Neuronen: }}$

DMEM (mit L-Glutamin, 4500 mg/l

D-Glucose, ohne Natriumpyruvat)

Neurobasalmedium

Fötales Rinderserum

(FKS, hitzeinaktiviert, auf Viren und

Mycoplasmen getestet)

B27-Supplement

steriles Zellkulturwasser

HBSS

Poly-D-Lysin (steril, Zellkultur-Qualität)
Life-Technologies Gibco-BRL GmbH, Eggenstein-Leopoldshafen

Life-Technologies Gibco-BRL GmbH, Eggenstein-Leopoldshafen

Life-Technologies Gibco-BRL GmbH, Eggenstein-Leopoldshafen

Life-Technologies Gibco-BRL GmbH, Eggenstein-Leopoldshafen

Life-Technologies Gibco-BRL GmbH, Eggenstein-Leopoldshafen Life-Technologies Gibco-BRL GmbH, Eggenstein-Leopoldshafen

Sigma-Aldrich GmbH, Deisenhofen 


\subsubsection{Medien und Lösungen}

\subsubsection{Allgemeine Puffer und Stammlösungen:}

Ethidiumbromid: $10 \mathrm{mg} / \mathrm{ml}$ Ethidiumbromid in dest. Wasser.

IPTG-Stammlösung: $30 \mathrm{mg} / \mathrm{ml}$ Isopropylthio- $\beta$-D-Galaktosid in dest. Wasser, sterilfiltriert.

PBS: $8 \mathrm{~g} \mathrm{NaCL}, 0,2 \mathrm{~g} \mathrm{KCl}, 1,44 \mathrm{~g} \mathrm{Na}_{2} \mathrm{HPO}_{4}$ 0,24 g KH${ }_{2} \mathrm{PO}_{4}$, pH 7,4, d- $\mathrm{H}_{2} \mathrm{O}$ ad 1 Liter.

PMSF-Stammlösung: 100 mM Phenylmethylsulfonylfluorid in Isopropanol.

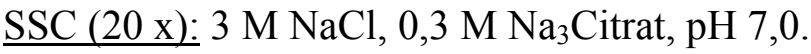

$\underline{\operatorname{SSPE}(20 \mathrm{x}):} 3 \mathrm{M} \mathrm{NaCl}, 0,2 \mathrm{M} \mathrm{NaH}_{2} \mathrm{PO}_{4}, 0,02 \mathrm{M} \mathrm{Na}_{2}$ EDTA, $\mathrm{pH}$ 7,4.

TE: $10 \mathrm{mM}$ Tris/HCl (pH 8,0), 1 mM EDTA (pH 8,0).

TAE: 4,84 g Tris Base, 1,142 ml Eisessig, 2 ml 0,5 M EDTA, pH 8,0.

TBE: 10,8 g Tris Base, 5,5 g Borsäure, 4 ml 0,5 M EDTA pH 8,0 mit HCL, d- $\mathrm{H}_{2} \mathrm{O}$ ad 1 Liter. TBS: 20 mM Tris/HCL pH 7,5-8,0, $140 \mathrm{mM} \mathrm{NaCl.}$

\subsubsection{Nährmedien:}

LB: 10 g Bacto-Trypton, 5 g Bacto-Hefeextrakt, 5 g NaCl, $100 \mu \mathrm{g} 10 \mathrm{~N} \mathrm{NaOH}, \mathrm{d}-\mathrm{H}_{2} \mathrm{O}$ ad 1 Liter.

LB-Agar: LB-Platten werden unter Zugabe von 15 g Agar je Liter Medium hergestellt. Für die Herstellung von Selektionsmedien werden die entsprechenden Agenzien nach dem Autoklavieren bei einer Temperatur von ca. $50^{\circ} \mathrm{C}$ zugegeben:

$200 \times$ Ampicillin-Stammlösung: $20 \mathrm{mg} / \mathrm{ml}$ in d- $\mathrm{H}_{2} \mathrm{O}$

$200 \times$ Kanamycin-Stammlösung: $20 \mathrm{mg} / \mathrm{ml}$ in d- $\mathrm{H}_{2} \mathrm{O}$

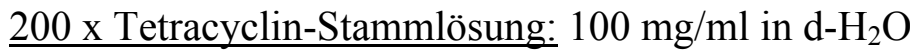




\subsubsection{Vektoren und Gen-Bibliotheken}

$\begin{array}{ll}\text { Lambda FIX II library } & \text { Stratagene GmbH, Heidelberg } \\ \text { pBluescript II SK +/- } & \text { Stratagene GmbH, Heidelberg } \\ \text { pcDNA-3 } & \text { Invitrogen, NV Leek, Niederlande } \\ \text { pCMV5 } & \text { David M. Russell } \\ \text { pCR2.1-TOPO } & \text { Invitrogen, NV Leek, Niederlande } \\ \text { pEGFP-N1 } & \text { BD Clontech Bioscience, Palo Alto, USA } \\ \text { pRc/CMV } & \text { Invitrogen, NV Leek, Niederlande } \\ \text { pRc/CMV-DHFR/HA/Ub } & \text { Martin Scheffner } \\ \text { pGex-KG } & \text { Guan \& Dixon, 1991 } \\ \text { pLexN } & \text { Vojtek et al., 1993 } \\ \text { pMT 107 } & \text { Treyer et al., 1994 } \\ \text { pTKneo3a } & \text { Rosahl, et al. 1993 } \\ \text { pVP16-3 } & \text { Vojtek et al., 1993 } \\ \text { R408 Helferphage } & \text { Stratagene GmbH, Heidelberg } \\ \text { QUICK-Clone Rattenhirn cDNA } & \text { BD Bioscience Clontech, Palo Alto, USA }\end{array}$

\subsubsection{Oligonukleotide}

Für die Amplifizierung der bei den Klonierungen verwendeten DNA-Fragmente wurden nachfolgend aufgeführte Oligonukleotide verwendet. Sie wurden von Ivonne Thannhäuser und Fritz Benseler mit dem abteilungseigenen Oligosynthesizer (ABI 394 DNA/RNA Synthesizer, Applied Biosystems, Weiterstadt) nach der automatisierten Festphasenmethode (Caruthers et al., 1992) synthetisiert. Die natürliche Sequenz der Genabschnitte flankieren Erkennungssequenzen für die Restriktionsenzyme. Diese zum Klonieren benutzten Palindrome sind in Klammern erwähnt und in der Sequenz unterstrichen. Die Basenpaar (bp) -Angaben beziehen sich auf die in der Genbank veröffentlichten Sequenzen (Zugangsnummern: RNU22952 für Neuroligin 1, RNU41662 für Neuroligin 2, AB033086 für Neuroligin 4, RNU50842 für Nedd4.1, AB019256 für Protein 4.1N, AB023204 für Protein 4.1B; http://www2.ncbi.nlm.nih.gov/genbank/). 


\section{Oligonukleotide für Neuroligin 1}

pLexN-Konstrukte:

600 GCG GAA TTC TAC TAC AAG AAA GAC AAG AGG AGA C (ERI, bp 2993-3017)

964 GCG GAA TTC TGC AGC CCT CAG CGC ACC ACG ACC (ERI, bp 3035-3053)

965 GCG GAA TTC ATT ATG TCT CTC CAA ATG AAG CAC (ERI, bp 3089-3103)

966 GCG GAA TTC ACT ATA CCA GGG ATT CAG CCC TTA C (ERI, bp 3260-3283)

807 GCG GGA TCC CTA TAC CCT GGT TGT TGA ATG (BHI, bp 3373-3353)

599 GCG GGA TCC TAA TGT GAA TGG GGG TGA G (BHI, bp 3354-3339)

967 GCG_GGA TCC CTA AGG GTG GGG GTG GGG CAG TG (BHI, bp 3340-3329)

968 GCG GGA TCC TCA AGC ATG GGT TAG GTC GTT GGT CGT G

(BHI, bp 3076-3052)

969 GCG GGA TCC TCA GGC GGT CCG AAG AAC CAC CTC (BHI, bp 3172-3152)

2572 GCC TGC CCC CCA GAT GCA ACT CTT GCT ATG

(MutationsoligosY782A, bp 3170-3199)

2571 CAT AGC AAG AGT TGC ATC TGG GGG GCA GGC

(Mutationsoligo Y782A, bp 3199-3170)

2614 GCC TGC CCC GCA GAT TAT ACT CTT GCT ATG

(Mutationoligo P780A, bp 3170-3199)

2615 CAT AGC AAG AGT ATA ATC TGC GGG GCA GGC

(Mutationsoligo P780A, bp 3199-3170)

3068 GCC TGC CCC GCA GAT GCA ACT CTT GCT ATG

(Mutationoligo P780A/Y782A, bp 3170-3199)

3067 CAT AGC AAG AGT TGC ATC TGC GGG GCA GGC

(Mutationsoligo P780A/Y782A, bp 3199-3170)

pGexKG Neuroligin1-ICD:

1677 GCG GGA TCC TAC TAC AAG AAA GAC AAG AGG (ERI bp 3347-3353)

1676 GCG GGA TCC TAC TAC AAG AAA GAC AAG AGG (BHI, bp 2993-3013)

2866 GCG GAA TTC GAA TGT GAA TGG GGG TGA G (ERI, bp 3354-3339)

pEGFP-Neuroligin1-Konstrukte:

1801 GAG CTG GTA CCT CAT CTG CAT AAT CTC AAT G (KpnI, bp 2727-2758)

1800 GCG GGA TCC TTG TCT TTC TTG TAG TAT AGG GC (BHI, bp 3017-2986)

2435 GCG GGA TCC ATA ATT TCC TCT TCT GGA G (BHI, bp 3093-3075) 
2434 GCG GGA TCC TGT GGA TGG ATG GAC TCA C (BHI, bp 3150-3132) 2436 GCG GGA TCC GGT GAC CTC CTC ATA GCA A (BHI, bp 3210-3192) 2433 GCG GGA TCC GGT ATA GTG TTG GGA ATC AT (BHI, bp 3267-3248) 2063 GCG GGA TCC AGT GTA TTA TTC TGT CCT CC (BHI, bp 3324-3305) 2060 GCG GGA TCC GTT GAA TGT GAA TGG GGG TG (BHI, bp 3360-3341) $1803 \mathrm{fl}$ (BHI, bp 3370)

Neuroligin1-DHFR-Fusionsprotein: 3092 ACT AAC TCT ACT GTA TCT GAC ACA TTG CAG CCA AC (bp 1893-1859) 3091 ATA CCG CGG CAT GGC ACT TCC CAG ATG CAT GTG GC (SacII, bp 841-866)

Oligonukleotide für Neuroligin 2 (YTH):

674 GCG GAA TTC CAG GAG CTG CGG TGC AGG CG (ERI, bp 2666-2685 sense) 808 GCG GGA TCC CTA TAC CCG AGT GGT GGA GTG (BHI, bp 3060-3041, antisense) 1133 GCG GGA TCC CTA GGT GGA GTG GGG ATG GGG

(BHI, bp 3049-3032 antisense)

Oligonukleotide für hNeuroligin 4 (Northernprobe): 2470 TTG AAC GAG ATA TTC C (bp 1928-1943) 2471 CAC TGA AGG TGT TAA A (bp 2624-2609)

Oligonukleotide für Nedd4.1

Nedd4.1-Klonierung:

1131 GCG GGT ACC GCC ATG GCA GCC GAC ACT GA (KpnI; bp 1-21 sense) 1132 GCG GAA TTC CTA ATC AAC CCC ATC AAA GCC CTG C (ERI, bp 2661-2639, antisense) 1249 CCA GGC GGT TGA AGG AGG TAT GTG CTC TG (Mutationsoligo, bp 2568-2548) 1250 CAG AGC ACA TAC CTC CTT CAA CCG CCT (Mutationsoligo, bp 2568-2548) 1251 TGA GTC TAG AAC AAC ACA ATG GAA AAG ACC AA (XbaI, bp 801-832) 1252 CGC AGA TCT CTA ATC AAC CCC ATC AAA GCC CTG C (XbaI, bp 2661-2631)

In-situ-Hybridisierungen: 2851 CCA GAC CTA TGC CAG CTA TAA CCT TCA CTC TCA CAA CTC GCG TGT (bp 218-262) 
2850 AAC CCA TCC AAC AGC TTG CCA TGA TAA ACC GCC ATC CCA GCC AC (bp 1881-1925)

$\underline{\text { KO-Primer }}$

kurzer Arm:

2815 ACT AGT CTT AAA GCC AAT ATG CAA ATA CCT (SpeI)

2814 GAT ATC CCC TCC TTG ATT ACC TTT TCT GCT (ERV)

Genotypisierung:

2817 TCC ACT GGA ATG GGA GTT AGA GCC ATA TTC (WT)

2816 TCT TGG TAT GCA CAT ATT GCA ATC GGT CCA

428 GAG CGC GCG CGC CGG AGT TGT TGA C (KO)

2081 GTG GTT TTG TCT TTT TAA AGC CAG GG

Oligonukleotide für Protein 4.1N

In-situ-Hybridisierungen:

2849 CAG CTC ATG TGG AAG GCT CCT CAT TTC ACC CTG ACT GGC TCG GC (bp 1692-1735)

2848 GCT TCC CGA GGG CTC CAG GCT CAA GCT CAG GAA CCA CGG AGT CTC (bp 424-468)

pGex-4.1HD:

1625 CGC GGA TCC AAT TCC AAT GAG AAG CAT CTG ACC (BHI, bp 287-310)

1623 GGC GAA TTC CCC GGA AGA ATG TAT GGT GCT CAA T (ERI, bp 1285-1262)

Oligonukleotide für Protein 4.1B

In-situ-Hybridisierungen:

2845 TTC CCA TTC CCA CTG TGA CGG TCT GCG GGT GCT GAT TCT GTG GC

(bp 2771-2814)

2844 TTC GGT TGT CAT GGT TGA TTG TTC TGG GGG AGA CGC GAA GGC CGG (bp 48-92) 
pGex-4.1HD:

1624 CGC GGA TCC GTG AAG AGG GAG GTC AGC GAC (BHI, bp 261-281)

1622 CCG GAA TTC TCT TTG GAG GTG CTT CTG GTA (ERI, bp 1281-1261)

\subsubsection{Bakterienstämme}

Escherichia coli B121/DE3

Escherichia coli HB101

Escherichia coli SURE

Escherichia coli XL1-Blue

Escherichia coli XL1-Blue MRA (P2)

\subsubsection{Eukaryotische Zellinien}

Saccharomyces cervisiae L40

Homo sapiens HEK293

Homo sapiens HEK293 B11

Mus musculus E14

Mus musculus MEF
Stratagene GmbH, Heidelberg

Invitrogen, NV Leek, Niederlande

Stratagene $\mathrm{GmbH}$, Heidelberg

Stratagene GmbH, Heidelberg

Stratagene $\mathrm{GmbH}$, Heidelberg
Vojtek et al., 1993

Humane embryonale Nierenfibroblasten, mit Adenovirus Typ 5 DNA transformiert; Eurobio Labratories GmbH, Raunheim

NL1-expremierende HEK293-Zellinie; Dr. Iris Augustin, MPI für exp. Medizin, Göttingen

Embryonale Stammzellen (ES-Zellen) der Maus (SV/29), Prof. K. Rajewski, Köln

Feeder-Zellinie für die ES-Zellkultur, Fibroblasten; Genome Systems, Inc, St. Louis, USA

\subsubsection{Tiere}

Die Tiere (C57Black/6-Mäuse, Wistar-Ratten, Chinchilla-Kaninchen) wurden aus institutseigenen Beständen bezogen. 


\subsubsection{Antikörper}

$\underline{\text { Primäre Antikörper: }}$

\begin{tabular}{|c|c|c|}
\hline Aktin: & A4700 & Sigma-Aldrich GmbH, Deisenhofen \\
\hline GDI: & D633 & Shisheva et al., 1994 \\
\hline HA-Epitop: & MMS-101R & $\mathrm{BABCO}$ \\
\hline$(\mathrm{His})_{5}$ : & 34660 & monoklonal, Qiagen GmbH, Hilden \\
\hline MAP2: & 1284959 & Boehringer Mannheim GmbH \\
\hline Nedd4.1: & Nedd4.1.5; Nedd4.1.6 & polyklonal, Antje Neeb \\
\hline NL1/2/3: & L067 & polyklonal, Ichtchenko et al., 1995 \\
\hline NL1/2/3: & $4 \mathrm{~F} 9$ & monoklonal, Song et al., 1999 \\
\hline NL1: & $4 \mathrm{C} 12$ & monoklonal, Song et al., 1999 \\
\hline NL1-ICD: & L066 & polyklonal, Ichtchenko et al., 1995 \\
\hline NL2: & 799 & polyklonal, Frederique Varoqueaux \\
\hline NL3: & 804 & polyklonal, Frederique Varoqueaux \\
\hline NMDAR: & 54.1 & monoklonal, Brose et al., 1994 \\
\hline Protein 4.1B: & 4.1B17; 4.1B18 & polyklonal, Antje Neeb \\
\hline Protein 4.1N: & $4.1 \mathrm{~N} 21 ; 4.1 \mathrm{~N} 22$ & polyklonal, Antje Neeb \\
\hline PSD93: & 919 & polyklonal, Synaptic Systems, Göttingen \\
\hline PSD95: & 918 & polyklonal, Synaptic Systems, Göttingen \\
\hline Rab3A: & 42.2 & monoklonal, Li et al., 1994 \\
\hline SAP97: & 2108339A & Affinity BioReagents, Golden, USA \\
\hline SAP102: & 921 & polyklonal, Egenhard Link \\
\hline Sec7.1: & $\operatorname{msec} 7$ & polyklonal, Henriette Koch \\
\hline Synaptobrevin: & 69.1 & monoklonal, Synaptic Systems, Göttingen \\
\hline Synaptophysin: & 7.2 & monoklonal, Jahn et al., 1985 \\
\hline Syntaxin1A/B: & I379 & polyklonal, Barnstable et al.,1985 \\
\hline Tubulin: & $\mathrm{T} 4026$ & Sigma-Aldrich GmbH, Deisenhofen \\
\hline
\end{tabular}

Sekundäre Antikörper:

Für die ECL-Reaktion (Meerrettich- Bio-Rad Laboratories GmbH, München peroxidase):

Fluoreszenzmarkierte Antikörper

Molecular Probes, Mobitec GmbH, Göttingen 


\subsection{Methoden}

Soweit nicht anders gekennzeichnet sind alle Methoden der Protokollsammlung Molecular Cloning (Sambrook et al., 1989) entnommen.

\subsubsection{DNA-Arbeiten}

2.2.1.1 Polymerase-Kettenreaktion (PCR) (Saiki et al., 1988)

Die Kettenreaktion der DNA-Polymerase eines thermophilen Bakteriums ermöglicht die Vervielfältigung und Modifikation eines definierten Abschnitts von einer Matrizen-DNA. Dieser Abschnitt wird durch ein zum 5'-Ende und ein zum 3'-Ende komplementäres Oligonukleotid, den sogenannten primer, terminiert. Für Klonierungen wird die PfuPolymerase verwendet, da diese wegen ihrer $3^{\prime}-5^{\prime}$-Exonukleaseaktivität eine sehr geringe Fehlerrate aufweist. Für die Genotypisierung von rekombinanten embryonalen Stammzellen wurde die Taq-Polymerase verwendet, da diese eine höhere Reaktionsgeschwindigkeit aufweist.

\begin{tabular}{|c|c|}
\hline PCR mit Pfu-Polymerase: & PCR zur Genotypisierung: \\
\hline $1 \mu l$ 1:100 verd. Matritzen-DNA & $1 \mu 1$ genomische DNA \\
\hline je $1 \mu 15^{\prime}$ - und 3'-Oligonukleotide $5 \mathrm{OD}_{260}$ & je $1 \mu 15^{\prime}$ - und 3 -Oligonukleotide $5 \mathrm{OD}_{260}$ \\
\hline $1 \mu \mathrm{l}$ dNTP-Mix $(2,5 \mathrm{mM})$ & $1 \mu \mathrm{l}$ dNTP-Mix $(2,5 \mathrm{mM})$ \\
\hline $5 \mu l 10 \times$ Polymerasepuffer & $2 \mu 110 x$ Polymerasepuffer \\
\hline $1 \mu 1$ Pfu-Polymerase & $1 \mu 1$ Taq-Polymerase \\
\hline $40 \mu \mathrm{ld}-\mathrm{H}_{2} \mathrm{O}$ & $13 \mu \mathrm{ld}-\mathrm{H}_{2} \mathrm{O}$ \\
\hline
\end{tabular}

Soll aus einer cDNA-Bibliothek (Rat Quick Clone cDNA von Clontech) ein DNA-Fragment durch obige PCR mit Pfu-Polymerase amplifiziert werden, so werden 0,1 $\mu 1$ der cDNABibliothek als Matrize eingesetzt.

Die Reaktion wird in einer PCR-Maschine durchgeführt. Zu Beginn wird die DNA bei $95^{\circ} \mathrm{C}$ für 3 Min. vollständig denaturiert. Die Hybridisierung der Oligonukleotide an die MatritzenDNA erfolgt für eine Minute bei der mit Hilfe des Programms „Oligo Order“ (Applied Biosystems, Weiterstadt) festgelegten Anlagerungstemperatur (zwischen $50^{\circ} \mathrm{C}$ und $65^{\circ} \mathrm{C}$ ), die Pfu-Polymerase synthetisiert pro Minute etwa 500 Basenpaare bei $72^{\circ} \mathrm{C}$, die Taq-Polymerase 
etwa 1000. Es werden in der Regel 33-35 Zyklen durchlaufen (bei Genotypisierungen 45). Ein Zyklus umfaßt Denaturierung, Hybridisierung und Synthese. Am Ende des PCRProgramms schließt sich ein fünfminütiger Syntheseschritt bei $72^{\circ} \mathrm{C}$ an, der sicherstellen soll, daß alle begonnenen Syntheseprodukte vervollständigt werden.

\subsubsection{Verwendung der PCR zur Einführung von Mutationen in eine DNA-Sequenz} (Higushi, 1990)

Mit Hilfe von mutierten Oligonukletiden erlaubt es die PCR, gezielte Mutationen einzelner Nukleotide in eine DNA-Sequenz einzuführen. Dies wird über zwei Schritte erreicht.

Zunächst wird die DNA-Sequenz, in der ein spezifischer Nukleotidaustausch stattfinden soll, in zwei Teilbereichen amplifiziert. Beide Bereiche tragen die Mutationen, das erste Amplifikat am 5', die zweite Amplifikat am 3'-Ende. In diesem Bereich überlappen sie über einige (10-20) Basenpaare. Als primer für die Teil-PCR werden Oligonukleotide generiert, die die entsprechenden Nukleotidsubstitutionen tragen. Sie werden gemeinsam mit flankierenden Oligonukleotiden verwendet, welche Anfang und Ende des zu amplifizierenden DNA-Stückes definieren. Die PCR-Reaktionen erfolgen unter den in Abschnitt 2.2.1.1 erläuterten Bedingungen. Die Teilstücke werden mittels Gelelektrophorese von überschüssigen Oligonukleotiden abgetrennt und anschließend gereinigt.

Im zweiten Schritt werden die Teilbereiche miteinander verbunden. Hierfür werden die Fragmente je 1:100 verdünnt und gemeinsam in einer PCR-Reaktion als Matritze eingesetzt, in der nur die äußeren Oligonukleotide zum Einsatz kommen. Für eine effiziente Amplifikation werden zunächst die beiden PCR-Produkte miteinander verküpft und aufgefüllt. Dies geschieht in einer PCR-Reaktion ohne primer-Zugabe für fünf bis zehn Zyklen. Da die beiden Stücke überlappen, dienen sie sich gegenseitig als primer und Matritze. Nach Zugabe der Oligonukleotide werden die verbundenen Stücke in ganzer Länge vermehrt.

\subsubsection{Reinigung von PCR-Fragmenten}

Für die weitere Verwendung von PCR-Fragmenten muß die DNA erst gereinigt werden, um das Enzym und den Salzen des Puffers zu enfernen. Für diesen Zweck wurde in der Qiaquick PCR Purification Kit der Firma Qiagen verwendet. 


\subsubsection{Restriktionsverdau}

Restriktionsendonukleasen des Typs 2 schneiden DNA an bestimmten, in der Regel durch palindromische Erkennungssequenzen definierten Stellen. Für einen Restriktionsansatz wird die DNA, eine der DNA-Menge entsprechende Menge Enzym (U) und der von der Firma mitgelieferte $10 \mathrm{x}$-Puffer mit Wasser auf das gewünschte Volumen aufgefüllt und der Ansatz 1-16 Stunden bei der für das Enzym optimalen Temperatur (in der Regel $37^{\circ} \mathrm{C}$ ) inkubiert.

\subsubsection{Dephosphorylierung der 5'-Enden durch alkalische Phosphatase}

Um die Religation von einem mit nur einem Restriktionsemzym geschnittenen Vektor zu verhindern, werden die 5'-terminalen Phosphatgruppen durch die alkalische Phosphatase abgespalten. Hierfür wird der geschnittene Vektor in dem vom Hersteller (Boehringer, Mannheim) mitgelieferten Puffer mit $1 \mu \mathrm{l}(20 \mathrm{U})$ alkalischer Phosphatase in einem Gesamtvolumen von $100 \mu \mathrm{l}$ über Nacht bei $37^{\circ} \mathrm{C}$ inkubiert.

\subsubsection{Ligation}

Die T4-DNA-Ligase katalysiert die Bildung einer Phosphordiesterbindung zwischen dem 3'OH Ende einer DNA-Kette und dem 5'-Phosphat Ende einer anderen Kette. Mit ihrer Hilfe können komplementäre Enden verknüpft werden, zum Beispiel um DNA-Fragmente in Vektoren einzugefügen. Für einen Ligationsansatz werden 20-100 ng geschnittener Vektor und etwa doppelt soviel zu klonierendes DNA -Fragment in einem $20 \mu$ l-Ligationsansatz gemeinsam mit $2 \mu 110$ x-Ligationspuffer des Herstellers (Boehringer, Mannheim) und $1 \mu 1$ T4-DNA-Ligase ( $5 \mathrm{U} / \mu \mathrm{l})$ für $4-16$ Stunden bei $16^{\circ} \mathrm{C}$ inkubiert.

\subsubsection{Präparation elektrokompetenter E. coli Zellen}

$100 \mathrm{ml}$ LB-Medium werden mit einem Klon eines Bakterienstammes angeimpft und über Nacht bei $37^{\circ} \mathrm{C}$ im Schüttelinkubator inkubiert. Nach einer 1:100-Verdünnung wird die Kultur bis $\mathrm{zu}$ einer $\mathrm{OD}_{600}$ von 0,5 bis 0,7 weitergeführt. Die Bakterien werden durch Zentrifugation (15 Min., 4000x g, $4^{\circ} \mathrm{C}$ ) geerntet und vorsichtig in eiskaltem, 10\%igem 
Glyzerin resuspendiert. Die Waschschritte erfolgen dreimal mit eiskalter 10\%iger Glyzerinlösung (1 1,500 $\mathrm{ml}$ und $250 \mathrm{ml}$ ), anschließend werden die Zellen in 3-4 $\mathrm{ml}$ der Glyzerinlösung (1-3 x $10^{10}$ Zellen/ml) resuspendiert, aliquotiert und in flüssigem Stickstoff eingefroren. Die Lagerung der Zellen erfolgt bei $-80^{\circ} \mathrm{C}$.

\subsubsection{Elektroporation}

Für die Transformation von Plasmid-DNA in kompetente E. coli-Zellen wird der E. coli Pulser der Firma Bio-Rad, München verwendet. Ein Microliter Plasmid-DNA (ca. 0,001 $\mu \mathrm{g} / \mu \mathrm{l}$ ) wird mit $40 \mu \mathrm{l}$ auf Eis aufgetauter Zellsuspension (elektrokompetente Zellen) für eine Minute auf Eis inkubiert. Dieses Gemisch wird in eine 0,1 cm breite Elektroporationsküvette überführt, die dann in die Kontaktschiene des Pulsers eingeführt wird. Es folgt ein Spannungspuls von 1,8 kV. Danach werden die Zellen mit $1 \mathrm{ml}$ Medium (LB) aus der Küvette gespült, in ein $1,5 \mathrm{ml}$ Reaktionsgefäß überführt und für $15-30$ Minuten bei $37^{\circ} \mathrm{C}$ inkubiert. Nach der Inkubation werden die Zellen abzentrifugiert und das Pellet in $100 \mu \mathrm{l}$ Medium resuspendiert und auf LB-Agar mit Ampicillin ausplattiert.

\subsubsection{DNA-Präparation}

Für die schnelle Präparation zur Analyse wird ein Standardprotokoll (Wilimzig et al., 1985) angewendet. Wird eine Plasmidpräparation hoher Reinheit benötigt, so wird das Plasmid Mini, Midi oder Maxi Kit von Qiagen verwendet. Zur Isolierung von DNA-Fragmenten aus Agarosegelen wird der Qiaex II-Kit der Firma Qiagen benutzt.

\subsubsection{Reinigung von Plasmid-DNA}

\subsection{Phenol-Chloroform-Extraktion}

Um Proteinverunreinigungen aus DNA-Lösungen abzutrennen, wird in Gemisch aus PhenolChloroform-Isoamylalkohol (25:24:1) verwendet. Hierfür wird ein Volumenanteil wässriger DNA-Lösung wird mit einem Volumenanteil des Extraktionsgemisches vermischt. Die Phasentrennung erfolgt durch 10minütige Zentrifugation bei $15000 \mathrm{x}$ g. Die obere wässrige Phase wird in ein neues Gefäß überführt und erneut extrahiert. Dieser Vorgang wird in der Regel zweimal wiederholt, bis in der Interphase keine Proteinverunreinigungen mehr 
erkennbar sind. Um Phenolreste zu entfernen, wird eine Extraktion mit Chloroform in gleicher Weise wiederholt. Anschließend wird die DNA gefällt (siehe 2.2.1.10.2).

\subsection{DNA-Präzipitation}

Um die DNA aufzukonzentrieren oder $\mathrm{zu}$ entsalzen, wird sie mit 1/10 Volumen $3 \mathrm{M}$ Natriumazetat und einem Volumen Isopropanol, bzw. 1/3 Volumen 7,5 $\mathrm{M} \mathrm{NH}_{4} \mathrm{OH}$ und 2,5 Volumen 100\%igem Ethanol gefällt (15 Min. bei 30000x g zentrifugieren). Das entstandene DNA-Pellet wird mit 70\%igem Ethanol gewaschen, erneut zentrifugiert, bei Raumtemperatur getrocknet und in einem adäquaten Volumen $\mathrm{d}-\mathrm{H}_{2} \mathrm{O}$ bzw. 1x $\mathrm{TE}$ aufgenommen.

\subsubsection{Konzentrationsbestimmung von DNA}

Neben der sehr ungenauen Mengenabschätzung auf einem Agarosegel durch einen mitgeführten Mengenstandard, läßt sich die DNA-Konzentration auch photometrisch bestimmen.

Hierfür wird die optische Dichte (OD) der DNA-Lösung bei $260 \mathrm{~nm}$ gemessen. Die Relation zwischen der gemessenen optischen Dichte und der DNA-Konzentration beträgt dann

für Einzelstrang-DNA: $\quad 1 \mathrm{OD}_{260}=30 \mu \mathrm{g} / \mathrm{ml}$ und

für Doppelstrang-DNA: $\quad 1 \mathrm{OD}_{260}=50 \mu \mathrm{g} / \mathrm{ml}$

Die Relation der optischen Dichten der Lösung bei 260 und $280 \mathrm{~nm}$ ist das Maß für ihre Verunreinigung mit Proteinen. Ihr Wert sollte zwischen 1,5 und 1,9 liegen.

\subsubsection{DNA-Sequenzierung (modifiziert nach Sanger et al., 1977)}

Die Sequenzierung von DNA erfolgt mittels cycle-sequencing mit fluoreszenzmarkierten Didesoxy-Terminatoren und einem Applied Biosystems 373 DNA sequencer (ABI, Weiterstadt). Diese Arbeiten wurden von Fritz Benseler und Ivonne Thannhäuser durchgeführt, die in der Abteilung unter anderem für die Sequenzierungen zuständig sind. 


\subsubsection{Agarosegelelektrophorese von Nukleinsäuren}

Durch Agarosegelelektrophorese werden DNA-Fragmente ihrer Länge nach aufgetrennt. Auf diese Weise lassen sich Restriktionsmuster nach einem analytischen Verdau vergleichen oder auch ausgeschnittene Fragmente von einem Vektor isolieren. Je nach Agarosekonzentration des verwendeten Gels werden die kleineren (1,3-2 \%) oder die größeren Fragmente (0,6-0,8 $\%)$ besser voneinander getrennt.

Die für die gewünschte Gelkonzentration benötigte Menge Agarose wird in TBE durch Aufkochen gelöst, nach Abkühlung auf $50^{\circ} \mathrm{C}$ Ethidiumbromid $(0,1 \mu \mathrm{g} / \mathrm{ml}$ Gellösung) zugegeben und in den vorbereiteten Gelträger gegossen. Ein eingelegter Kamm hält die Taschen zum Auftragen der Proben frei von Agarose. Das Gel wird in die Elektrophoresekammer eingebracht und der Laufpuffer (TBE) eingefüllt. Die DNA-Proben werden mit 10-20\% Probenpuffer (40\% Sucrose, 0,25\% Bromphenolblau) versetzt und in die Taschen des Gels pipettiert. Dann erfolgt die Auftrennung der Fragmente durch Anlegen einer Spannung von 80-120 V. Um die Größen der Fragmente bestimmen zu können, wird ein DNA-Längenstandard mitgeführt.

\subsubsection{Isolation von DNA aus Agarosegelen}

Nach dem Abtrennen eines für Subklonierungen aus einem Vektor herausgeschnittenen DNAFragments, muß dieses aus der Agarose isoliert werden. Hierfür wurde der Qiaex II Agarose Gel Extraction Kit der Firma Qiagen.

\subsubsection{Transfer von DNA auf Nylonmembran (Southern, 1975)}

Mit Hilfe von Kapillarkräften werden DNA-Fragmente aus Agarosegelen auf Hybond-N ${ }^{+}$ Nylonmembranen übertragen (Southern-Transfer). Nach der Agarosegelelektrophorese wird die DNA im Gel durch 20 minütige Inkubation in Denaturieringslösung $(1,5 \mathrm{M} \mathrm{NaCl} ; 0,5 \mathrm{M}$ $\mathrm{NaOH})$ in ihre Einzellstränge getrennt. Das Gel wird mit der Oberseite nach unten auf einen mit Denaturieringslösung getränkten Filterpapierstreifen aufgelegt, dessen Enden in ein Reservoir mit Denaturierungslösung eintauchen. Auf das Gel wird luftblasenfrei die ebenfalls mit Denaturieringslösung befeuchtete Nylonmembran, gefolgt von drei Lagen angefeuchtetem und einigen Lagen trockenem Filterpapier aufgelegt. Darauf wird ein Stapel 
aus Papiertüchern zentriert und mit einem Gewicht beschwert, damit ein konstanter Flüssigkeitsfluß gewährleistet ist. Der Transfer erfolgt über Nacht unter Ausnutzung der Kapillarkräfte im Gel. Die DNA-Fragmente diffundieren mit der Lösung in Richtung Membran und werden dort gebunden. Nach dem Transfer wird die Membran 5 Min. in Neutralisierungslösung (1 M Tris Base; $1,5 \mathrm{M} \mathrm{NaCl}$; pH 7,5) inkubiert, in 2x SSC (0,3 M $\mathrm{NaCl} ; 30 \mathrm{mM}$ Natriumcitrat) gewaschen und auf Filterpapier getrocknet. Die transferierte DNA wird durch UV-Bestrahlung $\left(1,0 \mathrm{~J} / \mathrm{cm}^{2}\right)$ kovalent an die Membran gebunden.

\subsubsection{Radioaktive Markierung von DNA}

Radioaktive Markierungen von DNA-Fragmenten werden mit dem Prime-It II - Random Primer Labelling Kit der Firma Stratagene mit $50 \mu \mathrm{Ci}[\alpha-32 \mathrm{P}]$ dCTP durchgeführt. Nicht eingebaute Nukleotide werden mit Bio-Spin Chromatographiesäulen der Firma Bio-Rad von der markierten Sonde getrennt.

\subsubsection{Hybridisierung von radioaktiven Sonden (Reeds und Mann, 1985)}

Eine Nylonmembran mit transferierter DNA (2.2.1.15) wird zunächst für mind. $2 \mathrm{~h}$ bei $42^{\circ} \mathrm{C}$ in einer Schale mit Hybridisierungslösung unter leichtem Schütteln inkubiert und anschließend mit dann die kurz zuvor denaturierte $\left(10\right.$ Min., $\left.95^{\circ} \mathrm{C}\right)$, radioaktiv markierte DNA-Sonde zugegeben. Die Membran wird bei gleicher Temperatur über Nacht geschüttelt. Am nächsten Morgen wird durch zweimalige Inkubation mit 2 x SSC; 0,1\% SDS und durch eine einmalige Inkubation mit 0,1x SSC; 0,1\% SDS (jeweils 20 Min., 55-60 ${ }^{\circ} \mathrm{C}$ im Schüttelwasserbad die nicht gebundene Radioaktivität abgewaschen. Die Membran wird getrocknet, auf einem Filterpapier mit Folie eingewickelt und in einer Autoradiographiekassette auf einem Röntgenfilm exponiert.

Hybridisierungslösung: $50 \mathrm{ml}$ Formamid; $5 \mathrm{ml} 100 \mathrm{x}$ Denhardt's Lösung; $15 \mathrm{ml} 10$ \% SDS; $25 \mathrm{ml} 20$ x SSC; $5 \mathrm{ml} \mathrm{d}-\mathrm{H}_{2} \mathrm{O} ; 1 \% 10 \mathrm{mg} / \mathrm{ml}$ denaturierte Lachsspermien-DNA. 


\subsubsection{Northernblot}

Die Northernblots mit Poly-(A) angereicherter RNA aus verschiedenen Geweben der Ratte wurden kommerziell bei der Firma Clontech erworben. Zur Markierung spezifischer Transkripte werden DNA-Sonden erzeugt. Die Markierung der Sonde, Hybridisierung und Auswertung erfolgt nach der in den Kapiteln 2.2.1.16 und 2.2.1.17 vorgestellten Arbeitsweise.

\subsubsection{In-situ-Hybridisierung}

Zur Lokalisationsanalyse von mRNA im zytologischen Schnitt werden markierte komplementäre Nukleinsäuren eingesetzt. Diese identifizieren durch In-situ-Hybridisierung die lokale Verteilung des jeweiligen Transkripts auf dem Gehirnschnitt.

\subsection{Bereitstellung von Gehirnschnitten}

Acht Wochen alte männliche Wistar-Ratten werden mit Diethylether anästhesiert und anschließend dekapitiert. Die Gehirne werden entnommen, sagittal halbiert und auf festem $\mathrm{CO}_{2}$ schockgefroren. Mit Hilfe eines Kryostaten werden $15 \mu \mathrm{m}$ dicke sagittale Schnitte angefertigt. Diese werden eine Stunde bei Raumtemperatur getrocknet und auf RNAse-armen, mit Silane beschichteten Objekträgern für 5 Min. in 4\% Paraformaldehyd und Phoshatgepufferter Saline (PBS) fixiert. Nach zweimaligem, fünfminütigem Waschen in PBS werden die Schnitte durch eine aufsteigende Alkoholreihe (50\%, 70\%, 95\%, 100\%) dehydriert und bis zur späteren Hybridisierung in 100\%igem Ethanol gelagert.

\subsection{Auswahl spezifischer antisense-Oligonukleotide}

Für jedes zu untersuchende Transkript wurden zwei unabhängige komplementäre Oligonukleotide synthetisiert. Hierzu wurde das Programm OLIGO 5.0 verwendet. Alle Oligonukleotide enthielten einen GC-Anteil von 55-60\%. Die Spezifität wurde durch vergleichende Datenbankrecherchen verifiziert. Außerdem wurde darauf geachtet, daß die Wahrscheinlichkeit der Bildung von Doppelsträngen innerhalb des Oligos bzw. mit einem weiteren gering war.

Die Sequenz der verwendeten Oligonukleotide ist unter 2.1.8 aufgeführt. 


\subsection{Terminale Markierung von Oligonukleotiden}

Die radioaktiven Markierungen der Oligonukleotide für die in-situ-Hybridisierungen wurden von der terminalen Transferase bei $37^{\circ} \mathrm{C}$ katalysiert.

Reaktionsansatz: $10,8 \mu \mathrm{l}$ DEPC- $\mathrm{H}_{2} \mathrm{O} ; 4,0 \mu \mathrm{l}$ 5x TdT Puffer; $1,2 \mu \mathrm{l} 25 \mathrm{nM} \mathrm{CoCl} ; 1,5 \mu 1$ Oligonukleotid; $1,0 \mu \mathrm{l}$ terminale Transferase; $1,5 \mu 1\left[\alpha-{ }^{35} \mathrm{~S}\right] \mathrm{dATP}$.

Nach 8 Min. wird die Addition von $\left[\alpha-{ }^{35}\right.$ S]dATP durch die Zugabe von $30 \mu$ TNES (14 ml 5 $\mathrm{M} \mathrm{NaCl} ; 10 \mathrm{ml} 1 \mathrm{M}$ TrisHCl, pH 7,5; $5 \mathrm{ml}$ 0,5 M EDTA, pH 8,0; $5 \mathrm{ml} \mathrm{10 \%} \mathrm{SDS;} 466 \mathrm{ml}$ DEPC- $\left.\mathrm{H}_{2} \mathrm{O}\right)$ gestoppt und nicht eingebaute Nukleotide über eine Bio-SpinChromatographiesäule der Firma Bio-Rad abgetrennt. Die Einbaurate wird mit einer $1 \mu 1$ Probe von markiertem Oligonukleotid und $2 \mathrm{ml}$ Szintillationslösung in einem Szintillationszählgerät ermittelt.

\subsection{Hybridisierung}

Pro Schnitt wird ein Äquivalent von 4 x $10^{5} \mathrm{cpm}$ radioaktiver Beladung in $110 \mu \mathrm{l}$ Hybridisierungspuffer eingesetzt. In den Kontrollexperimenten wird ein konkurrierender 1000facher Überschuß von nicht markiertem Oligonukleotid eingesetzt.

Die Schnitte werden über Nacht bei $42^{\circ} \mathrm{C}$ in einer Feuchtkammer inkubiert. Hierzu wird die Hybridisierungslösung auf den Schnitt aufgetragen und mit einem RNAse-armen, autoklavierten Deckgläschen eingedeckelt. Am nächsten Tag wird das Deckgläschen vorsichtig entfernt und der Schnitt nach folgendem Protokoll gewaschen:

Waschprotokoll:

20 Min. 1,0x SSC: $0,1 \% \beta$-Mercaptoethanol

$20 \mathrm{Min} \quad$. $\quad 1,0 \mathrm{x}$ SSC: $0,1 \% \beta$-Mercaptoethanol

$45 \mathrm{Min} \quad$. $\quad 1,0 \mathrm{x} \mathrm{SSC} ; 0,1 \% \beta$-Mercaptoethanol

5 Min. $\quad 1,0 x$ SSC

2 Min. $\quad 0,1 \times$ SSC

Nach dem Waschvorgang werden die Schnitte an der Luft getrocknet und durch eine aufsteigende Alkoholreihe dehydriert. Die Auswertung erfolgt durch Autoradiographie mittels des Röntgenfilms, Kodak BioMax MR, der für mindestens zwei Wochen auf den Schnitten exponiert wird. 
Hybridisierungspuffer: $5 \mathrm{ml}$ entionisiertes Formamid; $2 \mathrm{ml} 50 \%$ Dextransulfat; 0,6 $\mathrm{ml} 5 \mathrm{M}$ $\mathrm{NaCl} ; 0,3 \mathrm{ml} 1 \mathrm{M}$ Tris/HCl, pH 7,4; 0,08 ml 0,5M EDTA, pH 8,0; 0,2 ml 50x Denhardt's, RNAse-frei; 0,5 ml $10 \mathrm{mg} / \mathrm{ml}$ Polyadenylsäure; 0,83 ml $6 \mu \mathrm{g} / \mathrm{ml}$ Lachsspermien-DNA; 1,117 $\mathrm{ml}$ DEPC- $\mathrm{H}_{2} \mathrm{O}$, inklusive $5 \mu \mathrm{l} 1 \mathrm{M}$ DDT.

\subsubsection{Isolierung genomischer Sequenz aus einer Lambda-Phagen-Bibliothek}

\subsection{Durchsuchung der Phagen-Bibliothek}

Einzelne Klone einer Phagen-Bibliothek können durch Hybridisierung mit einer markierten Sonde isoliert werden. Überlappende Bereiche konstruieren vollständige Sequenzabfolgen, die genomische DNA repräsentieren.

Eine $50 \mathrm{ml}-\mathrm{Kultur}$ in LB-Medium mit $10 \mathrm{mM} \mathrm{MgSO}_{4}$ und $0,2 \%$ Maltose wird mit einer einzelnen Kolonie des Bakterienstammes E. coli MRA(P2) über Nacht bei $37^{\circ} \mathrm{C}$ inkubiert. Das Bakterienpellet wird durch einmaliges Waschen in SM-Puffer auf eine $\mathrm{OD}_{600}$ von 1 eingestellt. Zur Titerbestimmung wird eine Verdünnungsreihe der Bibliothek von $10^{-3}$ bis $10^{-6}$ hergestellt. Es werden jeweils 4001 Bakterien und 40 1 Phagen zusammen 20 Min. bei $37^{\circ} \mathrm{C}$ geschüttelt. Anschließend wird das Gemisch zusammen mit $8 \mathrm{ml}$ Top-Agar $\left(50^{\circ} \mathrm{C}\right)$ auf vorgewärmten LB-Platten $(\varnothing 15 \mathrm{~cm})$ ausplattiert und über Nacht bei $37^{\circ} \mathrm{C}$ inkubiert. Ein Titer von $5 \times 10^{5}$ Plaques pro Platte wird zum Ausplattieren der Bibliothek gewählt. Die Platten werden so lange bei $37^{\circ} \mathrm{C}$ inkubiert, bis die komplette Lyse eingetreten ist. Von den 20 erkalteten Platten werden doppelte Filter-Replikate angefertigt. Die anhaftende PhagenDNA wird durch Inkubation in Denaturierungslösung (5 Min.), Neutralisierungslösung (8 Min.), 2 x SSC (10 Min.) und anschließender Behandlung mit UV-Licht $\left(1,0 \mathrm{~J} / \mathrm{cm}^{2}\right)$ an die Membran kovalent gebunden. Die Filter werden eine Stunde bei $50^{\circ} \mathrm{C}$ in $2 \mathrm{x}$ SSC und $0,1 \%$ SDS gewaschen. Anschließend werden sie für zwei Stunden bei $42^{\circ} \mathrm{C}$ in einer Prähybridisierungslösung präinkubiert. Zur Hybridisierung wird eine $\left[\alpha-{ }^{32} \mathrm{P}\right]-\mathrm{dCTP}$ markierte DNA-Sonde (2.2.1.16) dazugegeben, und über Nacht bei $42^{\circ} \mathrm{C}$ im Schüttelbad inkubiert. Am nächsten Tag wird mehrmals mit 2x SSC; 0,1\% SDS gewaschen $\left(55-60^{\circ} \mathrm{C}\right)$, bis die Filter nur noch ein schwaches radioaktives Signal geben. Mit Hilfe der Autoradiographie können positive Signale einzelnen Plaqueregionen zugeordnet werden. Es werden nur Regionen weiterbearbeitet, die auf beiden Duplikaten ein positives Signal geben. Diese Regionen werden mit Pasteurpipetten ausgestochen und in $1 \mathrm{ml} \mathrm{SM-Puffer} \mathrm{mit} 201$ Chloroform über 
Nacht bei $4^{\circ} \mathrm{C}$ stehengelassen. Im zweiten Durchgang wird ein Phagentiter zwischen 5001000 Plaques pro Platte gewählt. Die Prozedur wird wie oben beschrieben wiederholt. Der isolierte positive Plaque wird mit dem spitzen Ende einer Pasteurpipette ausgestochen und in 2001 SM-Puffer mit 201 Chloroform über Nacht bei $4^{\circ} \mathrm{C}$ stehengelassen. Die Phagensuspension wird anschließend amplifiziert und zur Isolation der Phagen-DNA verwendet.

\subsection{Phagenamplifikation}

Zur Phagenamplifikation wird die Phagensuspension vom isolierten, positiven Klon wie oben beschrieben auf einen Titer von $5 \times 10^{5}$ Plaques pro Platte $(\varnothing 10 \mathrm{~cm})$ eingestellt. Das Gemisch aus Bakterien und Phagen wird mit $3 \mathrm{ml}$ Top-Agar ausplattiert und bei $37^{\circ} \mathrm{C}$ bis zur kompletten Lyse inkubiert. Die lysierte LB-Platte wird mit $4 \mathrm{ml}$ SM-Puffer etwa fünf Stunden bei Raumtemperatur inkubiert. Der Überstand wird abgenommen, $50 \mu$ Chloroform zugesetzt und über Nacht bei $4^{\circ} \mathrm{C}$ stehengelassen.

\subsection{Präparation von Lambda-Phagen-DNA}

Die inserts positiver Klone der genomischen DNA-Lambda FIX II-Phagen-Bibliothek von Stratagene werden durch Subklonierung in einen pBSK-Vektor untersucht. Hierzu werden $200 \mu$ Bakterien des Stammes E. coli XL1blueMRA (P2) ( $\mathrm{OD}_{600}=1$ in SM-Puffer) und verschiedene Volumina $(20 \mu \mathrm{l}-200 \mu \mathrm{l})$ eines amplifizierten Phagenlysats $15 \mathrm{Min}$. bei $37^{\circ} \mathrm{C}$ inkubiert. Zusammen mit $50 \mathrm{ml}$ Medium (LB mit $10 \mathrm{mM} \mathrm{MgSO}_{4}$ und 0,2\% Maltose) wird bis zur Zelldebris, gewöhnlich über Nacht, bei $37^{\circ} \mathrm{C}$ geschüttelt. Die Zelldebris tritt abhängig vom Verhältnis Bakterienkonzentration zu Phagenkonzentration ein. Anschließend werden $750 \mu \mathrm{l}$ Chloroform hinzugegeben und die Lösung $30 \mathrm{Min}$. bei $6000 \mathrm{x}$ g zentrifugiert. Die Aufarbeitung des zentrifugierten Überstandes geschieht nach folgendem Qiagen -Protokoll:

1) $100 \mu 1$ Puffer L1 (300 mM NaCl, $100 \mathrm{mM}$ TrisHCl; pH 7,5, $10 \mathrm{mM}$ EDTA, 0,2 mg/ml BSA, $20 \mathrm{mg} / \mathrm{ml}$ RNAse A, $6 \mathrm{mg} / \mathrm{ml}$ DNAse 1) hinzufügen und 30 Min. bei $37^{\circ} \mathrm{C}$ inkubieren.

2) $10 \mathrm{ml}$ Puffer L2 (30\% Polyethylenglykol (PEG 6000), $3 \mathrm{M} \mathrm{NaCl}$ ) hinzufügen und $60 \mathrm{Min}$. bei $0^{\circ} \mathrm{C}$ inkubieren.

3) 10 Min. bei $10000 \mathrm{x}$ g zentrifugieren.

4) Pellet in $3 \mathrm{ml}$ Puffer L3 (100 mM NaCl, $100 \mathrm{mM}$ Tris/HCl; pH 7,5, $25 \mathrm{mM}$ EDTA) aufnehmen 
5) $3 \mathrm{ml}$ Puffer L4 (4\% SDS) hinzufügen und $20 \mathrm{Min}$. bei $0^{\circ} \mathrm{C}$ inkubieren.

6) $3 \mathrm{ml}$ Puffer L5 (3 M Natriumazetat; pH 5,5) hinzufügen.

7) 30 Min. bei $15000 \mathrm{x}$ g zentrifugieren.

8) Überstand erneut 10 Min. bei 15000x g zentrifugieren.

Der Überstand wird über ein Qiagen Midi Kit gereinigt. Die gereinigte DNA wird über Nacht mit Not1 verdaut und das Restriktionsenzym anschliessend durch 20minütiges Erhitzen auf $70^{\circ} \mathrm{C}$ inaktiviert. Die Ligation erfolgt mit dephosporyliertem Not1-geschnittenem pBSKVektor. pBSK-Klone mit Inserts werden durch Restriktionsanalyse, Subklonierung und Sequenzierung untersucht. Die typische Insert-Größe variiert zwischen 12 und 20 kb.

\subsubsection{Protein-Protein-Interaktionen im Hefe-Doppelhybrid-System (Fields und Song,} 1989)

Kenntnisse über Protein-Protein-Interaktionen bilden häufig die Grundlage zum Verständnis der Proteinfunktion. Neben biochemischen Methoden Interaktionspartner zu identifizieren, hat sich das Doppelhybrid-System in der Hefe als ein überaus erfolgreicher genetischen Ansatz für die Entdeckung von Protein-Protein-Interaktionen herausgestellt. Grundlage des Hefe-Doppelhybrid-Systems bilden Transkriptionsaktivatoren. Transkriptionsaktivatoren bestehen aus zwei funktionellen Einheiten, der DNA-Bindungsdomäne und der Transkriptionsaktivatordomäne. Die Domänen müssen nicht notwendigerweise kovalent verknüpft sein, um einen funktionsfähigen Transkriptionsaktivator zu bilden. Diese Tatsache wird im Hefe-Doppelhybrid-System ausgenutzt, um aus einer cDNA-Bibliothek geeignete Interaktionskandidaten für ein spezifisches Protein zu isolieren.

Der pLexN-Vektor kodiert die DNA-Bindungsdomäne LexA zusammen mit einem Kernlokalisationssignal, der pVP16-Vektor kodiert für den Transkriptionsaktivator VP16. VP16 besitzt weder DNA-Bindungsdomäne noch Kernlokalisationssignal und kann daher nicht mit dem Transkriptionsapparat der Hefe interagieren.

Der verwendete Hefestamm Saccharomyces cerevisiae L40 ist auxotroph für Histidin, Tryptophan, Leuzin und Adenin. Eine Selektion auf Tryptophanmangelmedium liefert pLexN-transformierte Hefeklone. Gleichzeitiger Leuzinmangel erlaubt die Selektion auf pVP16 und pLexN doppelt-transformierte Hefeklone. Im Hefe-Doppelhybrid-System wird die cDNA des zu untersuchenden Proteins in den offenen Leserahmen des pLexN-Vektors kloniert. Eine Transformation des Konstrukts in Hefe führt zur Expression eines Fusionsproteins aus LexA-DNA-Bindungsdomäne, Kernlokalisationssignal und der 
Aminosäuresequenz des zu untersuchenden Proteins. Der kotransformierte Vektor pVP16 kodiert für ein Fusionsprotein aus Transkriptionsaktivatordomäne VP16 und zufälligen cDNA Sequenzen einer cDNA-Bibliothek. Interagieren die beiden Fusionsproteine LexA-X (bait) und VP16-Y (prey) miteinander, so wird der Komplex zusammen in den Kern der Hefezelle transloziert. Dort führt die räumliche Nähe von DNA-Bindungsdomäne (LexA) und Transkriptionsaktivatordomäne (VP16) zur Aktivierung nachgeschalteter Gene des lexAOperators.

In dem Hefestamm L40 steht sowohl das LacZ-Gen als auch das His3-Gen unter der Kontrolle des LexA-Operators. Das LacZ-Gen vermitteltet die $\beta$-Galaktosidase-Expression. Die Intensität der $\beta$-Galaktosidase-Expression spiegelt die Interaktionsstärke der Fusionsproteine LexA-X und VP16-Y wieder. Die durch das His3-Gen vermittelte HistidinAutotrophie führt auf Histidin-Mangelmedium zur Selektion von Hefeklonen, in denen baitund prey-Konstrukt miteinander interagieren. Während das Gen für Lysin-Autotrophie in der Nähe der lexA-Operatorsequenz des His3-Gens liegt, ist das Gen für Uracil-Autotrophie in der Nähe der lexA-Operatorsequenz vom LacZ-Gen. Eine zusätzliche Selektion auf Lysinmangel und Uracilmangel liefert die Sicherheit, daß die vierfachen lexAOperatorsequenzen vor dem His3-Gen und die achtfachen lexA-Operatorsequenzen vor dem LacZ-Gen nicht durch homologe Rekombination verloren gehen.

Die Suche nach Interaktionspartnern mit Hilfe des Hefe-Doppelhybrid-Systems ist an bestimmte Bindungen geknüpft. Da der Transkriptionsaktivatorkomplex im Kern aktiv ist, sollte das zu untersuchende Protein keine Transmembrandomänen enthalten. Ist dies der Fall, so muß ein bait-Konstrukt ohne Transmembrandomäne kloniert werden. Der zu untersuchende Bereich sollte auch nicht zu groß sein, da ansonsten die räumliche Nähe von DNA-Bindungsdomäne und Transkriptionsaktivatordomäne durch das voluminöse Fusionsprotein behindert werden kann. Kodierende Bereiche bis etwa 1500 Basenpaare liefern erfahrungsgemäß gute Resultate. Am aussichtsreichsten sind intrazelluläre Proteine und intrazelluläre Domänen von Transmembranproteinen. Außerdem sollte das Konstrukt vor dem Screen zusammen mit einem leeren pVP16-Vektor in einer Testtransformation (siehe 2.2.2.2) durch den $\beta$-Galaktosidase-Filtertest (siehe 2.2.2.3) auf Autoaktivität getestet werden.

\subsubsection{Transformation mit einer pVP16-cDNA-Bibliothek}

Das bait-Konstrukt in pLexN wird wie in der unter 2..2.2.2 beschriebenen Methode in L40Zellen transformiert und 3-5 Tage auf -UT-Agar angezogen. Eine Kolonie von dieser Platte wird in $2 \mathrm{ml}$-UT-Medium bei $30^{\circ} \mathrm{C}$ über Nacht inkubiert, am nächsten Tag in $100 \mathrm{ml}$ 
desselben Mediums verdünnt, und erneut über Nacht kultiviert. Mit der 100 ml Kultur wird am darauffolgenden Tag 1 Liter vorgewärmtes YPAD-Medium angeimpft $\left(\mathrm{OD}_{600}=0,3\right)$ und bis zum Erreichen der mittleren logarithmischen Phase $\left(\mathrm{OD}_{600}=0,8\right)$ bei $30^{\circ} \mathrm{C}$ im Schüttelinkubator inkubiert. Diese Zellen werden dann für 5 Minuten bei $1800 \mathrm{x} \mathrm{g}$ abzentrifugiert und in $500 \mathrm{ml}$ sterilem TE-Puffer resuspendiert. Nach einer erneuten Sedimentation wird das Pellet in $20 \mathrm{ml} 100 \mathrm{mM}$ LiAc/0,5x TE aufgenommen. Nach der Zugabe von $1 \mathrm{ml}$ denaturierter, gescherter Lachspermien-DNA-Lösung (10 mg/ml), $500 \mu \mathrm{g}$ der zu testenden pVP16-cDNA-Bibliothek und $140 \mathrm{ml} 100 \mathrm{mM} \mathrm{LiAc/40 \%} \mathrm{PEG/1} \mathrm{x} \mathrm{TE} \mathrm{wird}$ alles gut vermischt und $30 \mathrm{Min}$. bei $30^{\circ} \mathrm{C}$ inkubiert. Anschließend wird die Lösung in einen sterilen 2-Liter-Kolben überführt, 17,6 ml DMSO zugegeben und ein Hitzeschock (6 Min., $42^{\circ} \mathrm{C}$ ) durchgeführt. Die Suspension wird sofort mit $400 \mathrm{ml}$ YPA verdünnt und in einem Wasserbad auf Raumtemperatur abgekühlt. Die Zellen werden abzentrifugiert, mit $500 \mathrm{ml}$ YPA gewaschen und nach erneuter Zentrifugation in einem Liter vorgewärmtem $\left(30^{\circ} \mathrm{C}\right)$ YPAD-Medium aufgenommen. Es folgt eine Erholungszeit von $30 \mathrm{Min}$. bei $30^{\circ} \mathrm{C}$ in einem Liter vorgewärmten YPAD-Medium. Von diesem Schritt wird $1 \mathrm{ml}$ Kultur abzentrifugiert, in $1 \mathrm{ml}$-UTL aufgenommen. 10 bzw. $1 \mu \mathrm{l}$ der Suspension werden auf -UTL-Agar ausgestrichen, um die Transformationseffizienz zu ermitteln. Die restlichen Zellen werden mit $500 \mathrm{ml}$-UTL gewaschen und dann in einem Liter desselben Mediums für 4-16 Stunden bei $30^{\circ} \mathrm{C}$ geschüttelt.

Die Zellen werden erneut zentrifugiert, einmal mit $500 \mathrm{ml}$ und einmal mit $50 \mathrm{ml}$-THULLMedium gewaschen und schließlich in $10 \mathrm{ml}$-THULL-Medium resuspendiert. Aliquots der Suspension werden auf -THULL-Agar ausgestrichen. Abhängig von der Länge der Inkubationszeit werden 5-100 $\mu 1$ ausplattiert. Bei einer vierstündigen Inkubation sollten 50 Platten mit jeweils $100 \mu$ lausgestrichen werden, bei längeren Zeiträumen ist es sinnvoll, jeweils zehn Platten mit 5, 10, 25, 50 und $100 \mu$ Suspension auszustreichen. $1 \mu 1$ und 0,1 $\mu 1$ werden zur Ermittlung der Wachstumsrate auf -UTL gebracht. Die Platten werden für 3-6 Tage bei $30^{\circ} \mathrm{C}$ inkubiert.

\subsubsection{Transformation in kleinem Maßstab}

Kryokonservierte L40-Hefen werden auf einer YEPD-Platte ausgestrichen und für etwa zwei Tage inkubiert. Mit einem L40-Klon werden $10 \mathrm{ml}$ YPAD-Medium angeimpft und über Nacht bei $30^{\circ} \mathrm{C}$ inkubiert. Die Suspension wird am nächsten Tag 1:5 durch YPAD-Medium 
verdünnt und bis zu einer $\mathrm{OD}_{600}=0,4$ verdünnt. Nach 2-3 Stunden Wachstum im Schüttelinkubator bei $30^{\circ} \mathrm{C}$ werden die Zellen durch fünfminütige Zentrifugation $(1800 \mathrm{x} \mathrm{g}$ Raumtemperatur) pelletiert. Das Pellet wird in $40 \mathrm{ml}$ TE resuspendiert und anschließend erneut zentrifugiert. Der Überstand wird verworfen und die Zellen im Pellet in $2 \mathrm{ml} 100 \mathrm{mM}$ LiAc/0,5 x TE für 10 Min. bei Raumtemperatur inkubiert. Während dieser Zeit wird die DNA in sterile 1,5 ml Reaktionsgefäße überführt (je $1 \mu \mathrm{g}$ der zu transformierenden Plasmid-DNA und $100 \mu \mathrm{g}$ denaturierte, gescherte Heringsspermien-DNA als Träger-DNA). Zu diesem Gemisch werden $100 \mu \mathrm{l}$ der Hefesuspension gegeben. Nach Mischen erfolgt die Zugabe von $700 \mu 100 \mathrm{mM} \mathrm{LiAc} / 40 \% \mathrm{PEG} / 1 \mathrm{x}$ TE und eine 30minütige Inkubation bei $30^{\circ} \mathrm{C}$. Nach Ablauf der 30 Min. werden dem Ansatz $88 \mu$ DMSO zugegeben. Es folgt ein Hitzeschock für 7 Minuten bei $42^{\circ} \mathrm{C}$. Die Zellen werden sedimentiert, mit $1 \mathrm{ml}$ TE gewaschen, in 50-100 $\mu 1$ TE resuspendiert und schließlich auf entsprechendem Selektionsmedium (-UTL) ausplattiert.

\subsubsection{3 $\beta$-Galaktosidasetests}

Die Aktivität der $\beta$-Galaktosidase in den Hefeklonen korreliert positiv mit der Intensität der Interaktion der in der Hefe exprimierten Testklone. Die Messung der $\beta$-Galaktosidaseaktivität wird in den vorliegenden Versuchen auf zwei Arten analysiert. Eine Möglichkeit ist der rein qualitative Filtertest, der für die schnelle Analyse verwendet wird. Der andere Test mißt im optisch enzymatischen Test quantitativ die Stärke der Interaktion über die spezifische $\beta$-Galaktosidase-Aktivität in den Hefelysaten.

\subsection{Filtertest}

Die doppelt transformierten Hefen werden auf -UTL oder -THULL Agarplatten für 2-4 Tage bei $30^{\circ} \mathrm{C}$ kultiviert. Nachdem ausreichend große Kolonien auf den Platten gewachsen sind, werden runde Nitrozellulosefilter auf die Platten gelegt, wieder abgezogen und mit der Kolonienseite nach oben auf ein in flüssigem Stickstoff schwimmendes Aluminiumboot gelegt. Nach 30 Sekunden wird das „Boot“ kurz untergetaucht und anschließend langsam auf Raumtemperatur aufgewärmt.

In einer Petrischale mit $15 \mathrm{~cm}$ Durchmesser werden $5 \mathrm{ml}$ Z-Puffer $\left(60 \mathrm{mM} \mathrm{Na}_{2} \mathrm{HPO}_{4}, 40 \mathrm{mM}\right.$ $\mathrm{NaH}_{2} \mathrm{PO}_{4}, 10 \mathrm{mM} \mathrm{KCl}, 1 \mathrm{mM} \mathrm{MgSO}$, $\left.\mathrm{pH} 7,0\right)$ und $50 \mu \mathrm{l}$ X-Gal-Stammlösung (50 mg/ml 5- 
Bromo-4-Chloro-3-Indolyl- $\beta$-D-Galaktosid in Dimethylformamid) gemischt und ein passendes Filterpapier aufgelegt. Auf das Filterpapier wird die Nitrozellulose mit der Kolonienseite nach oben gelegt und die Platte bei $30^{\circ} \mathrm{C}$ inkubiert. Nach ca. 30 Minuten ist eine Interaktion an der blauen Färbung der Kolonien zu erkennen.

\subsection{Flüssigtest}

Die spezifische $\beta$-Galaktosidase-Aktivität ist proportional zur Intensität der Interaktion. Im Gegensatz zum $\beta$-Galaktosidase-Filtertest erlaubt der $\beta$-Galaktosidase-Flüssigtest eine Quantifizierung der Interaktionsstärke. In einer Farbreaktion wird das Substrat ONPG (oNitrophenyl- $\beta$-Galaktosid), katalysiert durch $\beta$-Galaktosidase, zum gelben Reaktionsprodukt o-Nitrophenol umgesetzt. Die Absorption von $1 \mathrm{nmol} / \mathrm{ml}$ o-Nitrophenol beträgt im Absorptionsmaximum $(420 \mathrm{~nm})$ 0,0045. Berücksichtigt man die $\mathrm{OD}_{420}$ der Probe, die Proteinkonzentration P (mg/ml), die Reaktionszeit T (Min.), und das Extraktvolumen V (ml) inklusive eines Korrekturfaktors von 1.7, so ergibt sich die spezifische Aktivität der untersuchten Probe nach folgender Formel:

$\frac{\mathrm{OD}_{420} \times 1,7}{0,0045 \times \text { Protein } \times \text { Extraktionsvolumen } \times \text { Zeit }}$

Es werden $5 \mathrm{ml}$-UT-Medium mit einem doppelt-transfizierten Hefeklon angeimpft und über Nacht bei $30^{\circ} \mathrm{C}$ angezogen. Die Zellen werden auf Eis gekühlt, zentrifugiert (5 Min., 1800x g, $4^{\circ} \mathrm{C}$ ) und das Pellet in $250 \mu \mathrm{l}$ Aufschlußpuffer (100 mM Tris/HCl pH 8,0; $1 \mathrm{mM}$ DTT; $20 \%$ Glycerol) resuspendiert. Unter Zugabe von 1,5 $\mu$ l PMSF (40 mM/Isopropanol) und säuregewaschenen Glasperlen werden die Hefezellen durch intensives Mischen (sechsmal etwa $15 \mathrm{~s}$ ) bei etwa $0^{\circ} \mathrm{C}$ aufgeschlossen. Nach der Zugabe von weiteren $250 \mu \mathrm{l}$ Aufschlußpuffer wird die Suspension abgenommen, und zur Abtrennung unlöslicher Bestandteile zentrifugiert. Mit einem $20 \mu \mathrm{l}$ Aliquot des Überstandes wird der Gesamtproteingehalt nach der Bradford-Methode (2.2.3.8) bestimmt. Es werden $100 \mu \mathrm{l}$ vom Überstand zu $900 \mu \mathrm{Z}$ Z-Puffer $\left(60 \mathrm{mM} \mathrm{Na} 2 \mathrm{HPO}_{4} ; 40 \mathrm{mM} \mathrm{NaH} \mathrm{PO}_{4} ; 10 \mathrm{mM} \mathrm{KCl} ; 1 \mathrm{mM}\right.$ $\mathrm{MgSO}_{4} ; 2,7 \% \beta$-Mercaptoethanol, $\left.\mathrm{pH} 7,0\right)$ gegeben und $5 \mathrm{Min}$. bei $28^{\circ} \mathrm{C}$ präinkubiert. Durch Zugabe von $0,2 \mathrm{ml}$ ONTG (4 $\mathrm{mg} / \mathrm{ml}$ in Z-Puffer) wird die Umsetzung zu o-Nitrophenol gestartet. Die Reaktion wird so lange bei $28^{\circ} \mathrm{C}$ inkubiert, bis eine deutliche Gelbfärbung sichtbar wird. Eine Zugabe von 0,5 $\mathrm{ml} 1 \mathrm{M} \mathrm{Na}_{2} \mathrm{CO}_{3}$ stoppt die Reaktion. Die Reaktionszeit wird protokolliert und die Absorption der Probe photometrisch ermittelt. 


\subsubsection{Isolierung von pVP16-DNA aus doppelttransformierter Hefe}

Die doppelttransformierten, selektionierten Hefeklone (2.2.2.1/2) werden im $\beta$-Galaktosidase-Filtertest (2.2.2.3) getestet. Positive Klone werden in $5 \mathrm{ml}$-L+UT-Medium über Nacht bei $30^{\circ} \mathrm{C}$ kultiviert. Am nächsten Tag wird das Hefepellet abzentrifugiert (5 Min., 1800 x g, Raumtemperatur) und in 0,3 ml Lysispuffer aufgenommen. Die Suspension wird mit $150 \mu \mathrm{l}$ säuregewaschener Glasperlen und $0,3 \mathrm{ml}$ DNA-Extraktionsgemisch versetzt. Durch intensives Mischen werden die Hefezellen aufgeschlossen. Anschließend wird die wässerige Phase durch Zentrifugation getrennt (1 Min., 15000 x g), abgenommen, und durch drei aufeinander folgende Isopropanol-Fällungen (2.2.1.10.2) wird die DNA von Salzrückständen befreit. Die DNA-Präparation besteht aus einem Gemisch von Hefe-DNA, pLexN-PlasmidDNA und pVP16-Plasmid-DNA. Die Elektroporation (2.2.1.8) in den Leuzin-auxotrophen E. coli-Stamm HB101 erzeugt Klone, die auf M9-Amp-Platten nach pVP16 Vektor mit Insert selektioniert werden können.

\subsubsection{Sequenzanalyse und Datenbankrecherche}

Die DNA-Sequenzanalyse erfolgt mit dem EDV-Programm Lasergene der Firma DNASTAR Inc. (Madision, WI, USA). Weitere Untersuchungen werden über den Internetzugang zum National Center for Biotechnology Information (http://www.ncbi.nlm.nih.gov/) vorgenommen. Hier wird hauptsächlich die Funktion des Blast Search zur Analyse nicht charakterisierter Sequenzen benutzt. Die Funktion PubMed wird zur aktuellen, übersichtlichen Literaturrecherche genutzt. Desweiteren wird der ISREC-Internetzugang (http://www.isrec.isb-sib.ch/software/PFSCAN_form.html) zur Bestimmung charakteristischer Proteindomänen genutzt. Über die Internetzugänge (http://www.expasy.ch/), (http://www.embl-heidelberg.de/) und (http://www.isrec.isbsib.ch/index.html) wurden weitere Untersuchungen zur computergestützten Sequenzanalyse durchgeführt. 


\subsubsection{Arbeiten mit Proteinen}

\subsubsection{Expression von GST-Fusionsproteinen (Guan und Dixon, 1991)}

Die Expression von Glutathion-S-Transferase-Fusionsprotein in Bakterien wird durch IPTG induziert (Guan und Dixon, 1991). Hierzu wird das gewünschte cDNA-Fragment in den offenen Leserahmen des Vektors pGexKG kloniert. Das Konstrukt wird in Bakterien des Stammes BL21/DE3 transformiert und eine Einzelkolonie über Nacht in $100 \mathrm{ml}$ LB-AmpMedium bei $37^{\circ} \mathrm{C}$ angezogen. Nach einer 1:10-Verdünnung am nächsten Morgen wird eine Stunde bei $37^{\circ} \mathrm{C}$ inkubiert und anschließend bei Raumtemperatur für 4-6 Stunden mit 0,8 mM IPTG induziert. Die Bakterien werden durch 20minütige Zentrifugation bei $4^{\circ} \mathrm{C}$ und $1500 \mathrm{x} \mathrm{g}$ geerntet, in $10 \mathrm{ml}$ Lysispuffer resuspendiert und 1 bis $3 \mathrm{Min}$. mit Ultraschall (mittlere Stärke) behandelt. Nach Zugabe von $1 \mathrm{ml} 10 \%$ igem Triton-X100 erfolgt bei $4^{\circ} \mathrm{C}$ eine 15 minütige Inkubation auf dem Schüttler. Unlösliche Bestandteile werden durch 20 Min. Zentrifugation bei 30000 x g abgetrennt. Das Protein im klaren Überstand wird nach Zugabe von $250 \mu \mathrm{l}$ Glutathionagarose über Nacht bei $4^{\circ} \mathrm{C}$ auf dem Drehrad gebunden. Anschließend wird die Matrix bei 1000 x g pelletiert, fünfmal mit kaltem PBS/0,1\% Triton-X100 gewaschen und in $50 \mathrm{mM}$ Tris/ $\mathrm{HCl}$; pH 8,0 aufgenommen. Das über Glutathion an die Agarose gebundene Fusionsprotein kann nun direkt für Kosedimentationsexperimente (2.2.3.2) verwendet oder mit einem Überschuß an Glutathion von der Agarose eluiert werden.

Für die Elution werden die an die Glutathion-Agarose gebundenen Fusionsproteine durch zweimaliges Waschen mit $100 \mathrm{mM}$ TrisHCl pH 8,0/ 0,1 \% Triton X-100/ 0,1 mM PMSF umgepuffert. Die Elution erfolgt in $10 \mathrm{ml}$ des oben genannten Puffers mit $30 \mathrm{mM}$ reduziertem Glutathion je dreimal für 30-60 Minuten bei Raumtemperatur. Die eluierten Proteine können nun durch Ultrafiltration im Centricon auf das gewünschte Volumen (0,5-1 ml) eingeengt werden.

\subsubsection{Kosedimentation von Proteinen des Rattengehirns an immobilisiertem GST- Fusionsprotein}

Protein $(20 \mathrm{mg})$ der P2-Fraktion einer subzellulären Fraktionierung (2.2.3.7) wird in insgesamt $10 \mathrm{ml}$ Interaktionspuffer (50 mM Tris/ $\mathrm{HCl}$ pH 7,5; $100 \mathrm{mM} \mathrm{NaCl} ; 1$ mM EGTA; 1 $\%$ NaCholat; 1\% Igepal; 0,1 mM PMSF; $1 \mu \mathrm{g} / \mathrm{ml}$ Aprotinin; 0,5 $\mu \mathrm{g} / \mathrm{ml}$ Leupeptin) gelöst, für 
30-60 Min. auf Eis gerührt und anschließend bei $45000 \mathrm{x}$ g für $90 \mathrm{Min}$. bei $4^{\circ} \mathrm{C}$ zentrifugiert. Der Überstand wird zu 100-200 $\mu \mathrm{g}$ immobilisiertem GST-Fusionsprotein (2.2.3.6) gegeben und für 2-3 Stunden oder über Nacht bei $4^{\circ} \mathrm{C}$ auf dem Drehrad inkubiert. Anschließend wird dreimal mit dem Interaktionspuffer gewaschen (Zentrifugation bei $1000 \mathrm{x} \mathrm{g}, 4^{\circ} \mathrm{C}$ ) und die Agarosekügelchen in SDS-Gel-Probenpuffer (2.2.3.1) aufgenommen. Die Proteine werden

durch SDS-PAGE (2.2.3.8) aufgetrennnt und anschließend mittels der Immundetektionsmethode (2.2.3.11) analysiert.

\subsubsection{Konzentrationsbestimmung von Proteinen}

Proteinkonzentrationen werden mit dem Protein Assay der Firma Bio-Rad, basierend auf der Bradford-Methode (Bradford, 1976), nach Herstellerangaben bestimmt. Als Kalibrierungsgerade dienten die Messwerte von BSA-Lösungen in bekannten Konzentrationen. Die optische Dichte wird bei $595 \mathrm{~nm}$ gemessen.

Reinheiten und Konzentrationen rekombinanter Fusionsproteine werden durch Vergleich mit standardisierten BSA-Mengen auf einem Coomassie-gefärbten SDS-Polyacrylamidgel abgeschätzt.

\subsubsection{Herstellung polyklonaler Antikörper}

Chinchilla bastard-Kanninchen werden mit gereinigten GST-Fusionsproteinen immunisiert (siehe 2.2.3.1). Vor der Immunisierung werden $5 \mathrm{ml}$ Vollblut entnommen, um das Präimmunserum zu gewinnen. Eine homogene Emulsion aus $500 \mu$ l Fusionsprotein $(0,6$ $\mu \mathrm{g} / \mathrm{ml}$ ) und $500 \mu \mathrm{l}$ komplettem Freud`schen Adjuvans wird subkutan injiziert. Jeweils im Abstand von 2 Wochen wird die Immunisierung zwei- bis dreimal wiederholt. Acht Tage nach der letzten Immunisierung werden $15 \mathrm{ml}$ Vollblut entnommen, das Serum abgetrennt und im Vergleich mit dem Präimmunserum mittels Immundetektionsanalyse auf Gewebehomogenat getestet (siehe 2.2.3.9/10). Es werden verschiedene Verdünnungsstufen probiert, um die optimale Antikörperkonzentration zu ermitteln. Das Serum wird aliquotiert und bei $-80^{\circ} \mathrm{C}$ aufbewahrt. 


\subsubsection{Koimmunpräzipitation}

Für die Koimmunpräziption von Proteinen mit Hilfe von Antikörpern werden die Proteine der synaptosomalen Fraktion (P2) wie unter 2.2.3.7 aufgeführt solubilisiert. Der gereinigte Überstand wird mit $5 \mu \mathrm{g}$ Antikörper versetzt und für $2-16 \mathrm{~h}$ bei $4^{\circ} \mathrm{C}$ auf dem Drehrad inkubiert. Der Antikörper und die von ihm gebundenen Proteine werden durch Zugabe von 15 $\mu 1$ Bettvolumen Protein-G-Sepharose immobilisiert. Die Präzipitation erfolgt durch weitere 2 h Inkubation. Die Sepharose-gekoppelten Immunkomplexe werden dreimal mit dem Extraktionspuffer mit reduziertem Detergenzgehalt gewaschen und dann in SDS-Probenpuffer resuspendiert. Die Analyse erfolgt durch Immundetekion (2.2.3.11).

2.2.3.6 Subzelluläre Fraktionierung (Huttner et al., 1983)

Mit Hilfe der subzellulären Fraktionierung lassen sich die Proteine eines Rattenhirnhomogenates in kompatimentäre Fraktionen aufteilen.

Alle Schritte werden bei $4^{\circ} \mathrm{C}$ ausgeführt. 20 Cortices aus Rattenhirn werden in $150 \mathrm{ml} 320$ $\mathrm{mM}$ Saccharose mit 0,1 mM PMSF und $2 \mu \mathrm{g} / \mathrm{ml}$ Pepstatin A mit einem Glas-TeflonHomogenisator homogenisiert, und bei 800 x g für 10 Min. zentrifugiert. Das Sediment (P1) wird aufbewahrt. Der Überstand wird bei 9200 x g für 15 Min. zentrifugiert. Das erhaltene Sediment wird durch Resuspension und erneute Zentrifugation in obigem Puffer gewaschen und aufbewahrt (P2). Der Überstand der ersten Zentrifugation wird bei $165000 \mathrm{x}$ g für eine Stunde zentrifugiert, das daraus resultierende Sediment (P3) und der Überstand (S3) werden aufbewahrt. Das ungereinigte synaptosomale Sediment (P2) wird in $15 \mathrm{ml} 320 \mathrm{mM}$ Saccharose resuspendiert und osmotischer Lyse durch Zugabe des neunfachem Volumens d$\mathrm{H}_{2} \mathrm{O}$ mit PMSF (0,1 mM Endkonzentration), Pepstatin A (2 $\mu \mathrm{g} / \mathrm{ml}$ Endkonzentration) und HEPES/KOH pH 7,4 (10 mM Endkonzentration) unterzogen. Diese Suspension wird 30 Min. gerührt und bei $25000 \mathrm{x}$ g für $20 \mathrm{Min}$. zentrifugiert. Der Überstand wird erneut zentrifugiert (165000 x g für 2 Stunden) und der daraus resultierende Überstand (LS2) und das Sediment (LP2) werden aufbewahrt. Das Sediment (LP1) wird nach Lyse und Zentrifugation in $10 \mathrm{ml}$ $320 \mathrm{mM}$ Saccharose; $1 \mathrm{mM}$ HEPES/KOH (pH 7,4) resuspendiert und auf einen kontinuierlichen Saccharose-Dichtegradienten (0,5 - 1,5 M; 0,1 mM PMSF, $2 \mu \mathrm{g} / \mathrm{ml}$ Pepstatin A und HEPES/KOH pH 7,4), geladen. Nach Zentrifugation (65000 x g, 150 Min.) wird die trübe Fraktion unterhalb der Myelinbande (entspricht etwa 0,8 - 1,3 M Saccharose) gesammelt, mit zwei Volumina d- $\mathrm{H}_{2} \mathrm{O}$ verdünnt und bei 37000 x g für 20 Min. zentrifugiert. Das resultierende Sediment (SPM) wird in 320 mM Saccharose; $1 \mathrm{mM} \mathrm{HEPES/KOH,} \mathrm{pH} \mathrm{7,4}$ resuspendiert. 
Die Fraktionen werden wie folgt bezeichnet: H, Homogenat; P1, nukleäres Sediment; P2, ungereinigtes synaptosomales Sediment; P3, leichtes Membransediment; S3, zytosolische Fraktion; LP1, lysierte synaptosomale Membranen; LP2, ungereinigte synaptische Vesikelfraktion; LS2, zytosolische synaptosomale Fraktion; SPM, synaptische Plasmamembranen.

\subsubsection{SDS-PAGE zur Auftrennung von Proteinen (Laemmli, 1970)}

Durch SDS-Polyacrylamidgelelektrophorese (SDS-PAGE) können Proteine aufgrund ihres Molekulargewichtes aufgetrennt werden. Das für die Denaturierung verwendete SDS ist in der Lage, Polypeptidketten aufzufalten. Eine konstante negative Beladung von etwa einem SDS-Molekül je drei Peptidreste führt im elektrischen Feld zur Auftrennung der Proteine nach Größe. Der Zusatz von Dithiothreitol führt zur Reduktion von Disulfidbrücken. Eine optimale Proteinauftrennung erreicht man durch eine diskontinuierliche SDS-PAGE, bei der das Gel in Sammel- (3,5\%) und Trenngel (7,5-15\%) unterteilt wird.

Sammelgelpuffer: $0,5 \mathrm{M}$ Tris/HCl pH 6,8; 0,4 \% SDS.

Trenngelpuffer: $\quad 1,5 \mathrm{M}$ Tris/ $\mathrm{HCl} \mathrm{pH} 8,8 ; 0,4 \%$ SDS.

AMBA: $\quad 30 \%$ Acrylamid/N,N'-Methylen-bis-Acrylamid Lösung 37,5:1.

10\% APS: $\quad 10 \%$ Ammoniumpersulfat in $\mathrm{d}-\mathrm{H}_{2} \mathrm{O}$.

Laufpuffer: $\quad 3 \mathrm{~g}$ Tris Base, $14,4 \mathrm{~g}$ Glycin, $2 \mathrm{~g} \mathrm{SDS}, \mathrm{d}-\mathrm{H}_{2} \mathrm{O}$ ad 1 Liter, $\mathrm{pH}$ 8,8.

Zusammensetzung der Gellösungen:

\begin{tabular}{|l|l|l|l|}
\hline & $12 \%$-Trenngel & $7 \%$-Trenngel & Sammelgel \\
\hline $\mathrm{d}-\mathrm{H}_{2} \mathrm{O}:$ & $1,75 \mathrm{ml}$ & $2,5 \mathrm{ml}$ & $1,25 \mathrm{ml}$ \\
\hline AMBA: & $2 \mathrm{ml}$ & $1,25 \mathrm{ml}$ & $250 \mu \mathrm{l}$ \\
\hline Puffer: & $1,25 \mathrm{ml}$ & $1,25 \mathrm{ml}$ & $500 \mu \mathrm{l}$ \\
\hline Temed: & $7 \mu \mathrm{l}$ & $7 \mu \mathrm{l}$ & $5 \mu 1$ Temed \\
\hline $10 \%$ APS: & $15 \mu \mathrm{l}$ & $15 \mu \mathrm{l}$ & $12 \mu \mathrm{l}$ \\
\hline
\end{tabular}


Die Komponenten des Trenngels (Tab. 1) werden gemischt und in die wie vom Hersteller beschrieben zusammengebaute Gießapparatur mit gründlich gereinigten Glasplatten gegossen. Um eine homogene Polymerisierung des Trenngels zu erzielen, ist es notwendig, das Gel vom Luftsauerstoff abzuschirmen. Deshalb wird nach dem Gießen mit wassergesättigtem Butanol überschichtet. Nachdem das Trenngel vollständig polymerisiert ist, wird das Butanol mit Wasser vom Gel gespült und die Kammer vorsichtig mit einem Filterpapier getrocknet. Dann werden die Komponenten des Sammelgels (Tab. 1) gemischt und auf das Trenngel gegossen. Um den Platz für das Laden der Proben freizuhalten, wird vorsichtig ein Kamm zwischen die Glasplatten geführt. Das fertige Gel wird in die Elektrophoresekammer eingesetzt und diese mit Laufpuffer gefüllt. Die Proben werden in $1 \mathrm{x}$ Probenpuffer und der Molekulargewichtsstandard auf das Gel geladen. Die Auftrennung der Proteine erfolgt bei konstanter Stromstärke (20 mA pro Gel). Um das Molekulargewicht zu ermitteln wird ein Molekulargewichtsstandard mitgeführt, Konzentrationsbestimmungen erfolgen durch den parallelen Auftrag standardisierter BSA-Mengen.

2.2.3.8 Coomassie-Färbung (modifiziert nach Weber und Osborn, 1969)

Das Gel wird 10-30 Min. bei Raumtemperatur in Färbelösung inkubiert und anschließend in der Entfärbelösung bis zur vollständigen Reduktion des Hintergrundes entfärbt. Alternativ dazu kann das Gel auch durch zweimaliges Kochen in Wasser für je 10 Min. entfärbt werden.

Färbelösung: $0,15 \%$ Coomassie Brillant Blue R250; $10 \%$ Eisessig; $25 \%$ Isopropanol in d$\mathrm{H}_{2} \mathrm{O}$ filtriert.

Entfärbelösung: $30 \%$ Methanol; $10 \%$ Eisessig in d- $\mathrm{H}_{2} \mathrm{O}$; filtriert.

2.2.3.9 Transfer von Proteinen auf Nitrozellulose (Westernblot; Towbin et al., 1979)

Die Proben werden zunächst einer SDS-PAGE unterzogen und dann auf eine Nitrozellulosemembran transferiert. Der Transfer der Proteine erfolgt bei $30 \mathrm{~mA}$ und $4^{\circ} \mathrm{C}$ über Nacht oder bei kleineren Proteinen bei $250 \mathrm{~mA}, 4^{\circ} \mathrm{C}$ für 2 Stunden in einer Blotkammer. Um die Vollständigkeit des Transfers zu überprüfen, wird die Membran durch kurzes 
Schwenken in Ponceau S Lösung $(0,1 \%(w / v) ; 5$ Eisessig; filtriert) angefärbt. Die Färbung läßt sich mit Hilfe von PBS vollständig entfernen.

Blotpuffer: 3 g Tris Base; 14,4 g Glycin; d- $\mathrm{H}_{2} \mathrm{O}$ ad 800 ml; $200 \mathrm{ml}$ Methanol.

\subsubsection{Immundetektion von Proteinen durch „Enhanced Chemiluminescence (ECL)“ (Westernblot)}

Mit Hilfe der Immundetektion können Proteine, die auf einer Nitrozellulosemembran (2.2.3.3) gebunden sind, durch Antikörper nachgewiesen werden.

Zunächst werden unspezifische Antikörperbindungsstellen auf der Membran durch 30minütige Inkubation in Blocklösung (1x TBS; 0,1 \% Twen 20; mit 5 \% Ziegenserum und 5 \% Trockenmilch) abgesättigt, dann der primäre Antikörper in Blocklösung verdünnt für eine Stunde bei Raumtemperatur unter leichter Agitation inkubiert. Anschließend wird fünfmal für jeweils fünf Minuten mit der Waschlösung (1x TBS; 0,1 \% Twen 20; 5 \% Trockenmilch) gewaschen. Der sekundäre Antikörper wird ebenfalls für eine Stunde in Blocklösung inkubiert. Dannach wird die Membran viermal mit Waschlösung und je einmal mit TBSTween (1x TBS; 0,1 \% Twen 20) und TBS für je fünf Minuten gewaschen. Die Detektion erfolgt mit ECL-Reagenz analog den Herstellerangaben, die Visualisierung erfolgt durch Exposition eines Röntgenfilms auf der Membran. Der Film wird durch Auflage einer Transparentfolie vor Feuchtigkeit geschützt, die Expositionszeiten variieren zwischen $1 \mathrm{sec}$ und 30 Min. je nach Antikörper- und Proteinkonzentration.

\subsubsection{Entfernen des Antikörpers von einer Nitrozellulose-Membran}

Die Membran wird in $2 \% \mathrm{SDS}, 62,5 \mathrm{mM}$ Tris/ $\mathrm{HCl} \mathrm{pH} 6,7$ auf $50^{\circ} \mathrm{C}$ vorgewärmt. Dann wird $\beta$-Mercaptoethanol bis zur Endkonzentration von $10 \mathrm{mM}$ zugegeben und für weitere 20-60 Min. bei $50^{\circ} \mathrm{C}$ inkubiert. Die Lösung wird abgegossen und die Membran zweimal für 10 Minuten bei Raumtemperatur mit TBS gewaschen und anschließend getrocknet. 


\subsubsection{Immunfärbungen}

\subsubsection{Immunhistologie}

Eine adulte Ratte wird mit Tribromoethanol anästhisiert. Nach kurzem Spülen mit physiologischer Kochsalzlösung $(50-100 \mathrm{ml})$ wird mit $300 \mathrm{ml}$ kalter 4\%iger Paraformaldehydlösung in PBS (pH 7.4 ) für 10 Min. perfundiert. Das Gehirn wird entnommen, in 20\%iger Sucroselösung/0,02 M PBS zur Kryoprotektion inkubiert und auf Trockeneis eingefrohren. Mit Hilfe des Kryostaten werden $10 \mu \mathrm{m}$ dicke Sagittalschnitte angefertigt und in Blocklösung (PBS mit 2\% Ziegenserum und 0,25\% Triton-X-100) präinkubiert. Der primäre Antikörper wird in Blocklösung verdünnt (4C12 anti Neuroligin, 1:2000; Nedd4.1.6 anti Nedd4.1, 1:1000; 4.1B17 1:2000) und mit den Schnitten für 16 Stunden bei $4^{\circ} \mathrm{C}$ unter leichter Agitation inkubiert. Nach drei Waschschritten mit PBS wird der sekundäre Antikörper (Alexa488- oder Alexa568-markierter Ziege-anti-Kanninchen- oder Ziege-anti-Maus-Antikörper, 1:400 in Blocklösung) für eine weitere Stunde bei Raumtemperatur inkubiert. Anschließend werden die Schnitte mit PBS gespült und mit 1.5\% N-Propylgallat auf Objektträgern fixiert. Die Visualisierung erfolgt mit Hilfe eines digitalen LSM510 laser scanning Mikroskops, die Analyse mit dem Programm LSM510 (Zeiss).

\subsubsection{Immuncytochemie}

Kultivierte Zellen (hippocampale Neuronen, siehe 2.2.5.3 oder HEK293-Zellen, siehe 2.2.5.1/2) werden bis zur gewünschten Dichte auf Deckgläsern kultiviert, mit D-PBS gewaschen und mit 4\%iger Paraformaldehydlösung (in D-PBS) für 10 Min. bei Raumtemperatur fixiert. Paraformaldehydreste werden durch dreimaliges Spülen mit D-PBS entfernt und die Deckgläser in $50 \mathrm{mM} \mathrm{NH}_{4} \mathrm{CL} / \mathrm{D}-\mathrm{PBS}$ für $10 \mathrm{Min}$. inkubiert.

Für die Färbung intrazellulärer Proteine werden die Zellen nach drei weiteren Waschungen mit D-PBS durch 0,2\%ige Triton-X-100-Lösung in D-PBS für 5 Min. aufgeschlossen, erneut gewaschen und dann in Blocklösung (4\% Ziegenserum in D-PBS) überführt. Die Zellen verbleiben für 5 Min. in der Blocklösung. In der Zwischenzeit wird eine lichtundurchlässige Kammer Parafilmstreifen auf einem nassen Filterpapier präpariert, auf den je $200 \mu \mathrm{l}$ des verdünnten primären Antikörpers oder Antikörpergemisches (4C12 anti Neuroligin, 1:2000; Nedd4.1.6 anti Nedd4.1, 1:1000; 4.1B17 1:2000) in Blocklösung aufgebracht werden. Das 
Deckgläschen wird mit den Zellen nach unten auf den Tropfen gelegt und die Kammer verschlossen. Es wird für $20 \mathrm{Min}$. bei Raumtemperatur inkubiert. Anschließend wird unter das Deckgläschen $1 \mathrm{ml}$ D-PBS pipettiert, um es hochzuspülen und wieder in das Gefäß zurückgelegt. Nach drei Waschungen mit D-PBS wird der sekundäre Antikörper (Alexa488oder Alexa568-markierter Ziege-anti-Kanninchen- oder Ziege-anti-Maus-Antikörper, 1:400 in Blocklösung) auf dieselbe Weise inkubiert und erneut gewaschen. Anschließend wird das Deckgläschen kurz in Wasser getaucht, vorsichtig von der Rückseite abgetupft und mit Fluoromount-G auf dem Objektträger fixiert. Die Visualisierung erfolgt mit Hilfe eines digitalen LSM510 laser scanning Mikroskops, die Analyse mit dem Programm LSM510 (Zeiss).

\subsubsection{Immuno-Elektronenmikroskopie}

Eine adulte, weibliche Ratte wird mit Tribromoethanol anästhisiert. Nach kurzem Spülen mit physiologischer Kochsalzlösung (50-100 ml) wird mit $300 \mathrm{ml}$ kalter 4\%iger Paraformaldehydlösung in PBS (pH 7.4) für 10 Min. perfundiert. Das Gehirn wird entnommen, $40 \mu \mathrm{m}$-dicke Vibrotomschnitte angefertigt und wie unter 2.2.4.1 beschrieben mit dem Antikörper inkubiert, mit der Ausnahme, daß der sekundäre Antikörper biotinyliert ist (VectorLabs, 1:300). Anschließen wird eine Avidin-Biotin-Peroxidase-Amplifizierung (Vectastain ABC, VectorLabs), eine DAB-Färbung und eine Silberintensivierung (nach Brandstatter et al., 1996) vorgenommen. Die Schnitte werden gründlich gewaschen, für eine Stunde mit $1 \%$ iger $\mathrm{OsO}_{4}$ in $\mathrm{PB}$ behandelt und in einer aufsteigenden Alkoholreihe $30 \%$, $50 \%, 70 \%, 85 \%, 95 \%, 100 \%$ Ethanol) und Propylenoxid dehydriert. Die Einbettung erfolgt in Durcupan (Durcupan ACM, Fluka), die Polymerisation dauert 48 Stunden bei $60^{\circ} \mathrm{C}$. Es werden Ultradünnschnitte am Ultraschneidegerät hergestellt und mit Uranylcitrat und Bleiacetat kontrastiert. Die Analyse erfolgt mit dem LEO 912AB TransmissionElektronenmikroskop (Zeiss). Die photographische Dokumentation wurde der Film Kodak TP6415 verwendet. Digitale Bilder wurden mit der ProScan CCD-Kamera erstellt und mit dem Programm Analysis 3.2 (Soft Imaging System) bearbeitet. 


\subsubsection{Zellkulturexperimente}

Alle Zellkulturarbeiten werden in einer Sterilbank durchgeführt. Die Kultivierung findet in Begasungsbrutschränken bei $37^{\circ} \mathrm{C}$ und $5 \% \mathrm{CO}_{2}$ in wasserdampfgesättigter Atmosphäre statt. Als Gebrauchsmaterial wird steril verpacktes oder autoklaviertes Zubehör verwendet. Die verwendeten Medien und Lösungen werden zur Sterilisation durch einen Sterilfilter $(0,2 \mathrm{~mm}$ Porengröße) filtriert oder autoklaviert und vor Gebrauch auf $37^{\circ} \mathrm{C}$ im Wasserbad/Brutschrank angewärmt.

\subsubsection{Kultivierung von HEK293-Zellen}

Tiefgefrorene HEK293-Zellen werden rasch in $37^{\circ} \mathrm{C}$-warmen Wasser aufgetaut und sofort in frischem angewärmten Kulturmedium (DMEM-Medium; $10 \%$ fötales Rinderserum; $2 \mathrm{mM}$ L-Glutamin; 1 x Penicillin/ Streptomycin-Lösung) aufgenommen. Die Zellsuspension wird in eine $10 \mathrm{~cm}$-Rundschale mit $10 \mathrm{ml}$ Medium überführt und bis zum Erreichen der Konfluenz unter den oben beschriebenen Bedingungen kultiviert. Für die Passage werden die Zellen mit D-PBS gewaschen und mit 0,25\% Trypsin behandelt. Sobald sich die Zellen vom Schalenboden lösen, werden sie mit reichlich Medium verdünnt, trituriert und in der gewünschten Verdünnung (zwischen 1:5 und 1:10) auf eine neue, mit Medium gefüllte Zellkulturschale ausgebracht.

Für die mikroskopische Analyse werden die Zellen auf Deckgläschen kultiviert. Um eine bessere Adhäsion der Zellen auf dem Untergrund zu erreichen, werden die Deckgläser mit Gelatine überzogen. Hierfür werden sie mit 0,5\%iger Gelatinelösung unter leichtem Schwenken für 1 Stunde bei Raumtemperatur inkubiert und dann zweimal mit D-PBS gewaschen. Die auf dem Glas haftende Gelatine wird durch 20minütige Inkubation mit 2\% Glutaraldehyd (in $\mathrm{d}-\mathrm{H}_{2} \mathrm{O}$ ) quervernetzt und dann, nach erneutem zweimaligen Waschen mit D-PBS, in 70\%iger Ethanollösung für $1 \mathrm{~h}$ sterilisiert. Die so vorbereiteten Deckgläschen werden unter sterilen Bedingungen zweimal mit sterilem D-PBS gespült und dann bis zur weiteren Verwendung in sterilem D-PBS im Kühlschrank aufbewart.

Für die Analyse wurden die Zellen auf den Deckgläschen zweimal mit D-PBS gewaschen, mit 3\%iger Paraformaldahydlösung (in D-PBS) für 10-20 Min. fixiert und anschließend erneut wie zuvor zweimal gewaschen. Die Deckgläser werden aus dem Kulturgefäß entnommen, kurz in d- $\mathrm{H}_{2} \mathrm{O}$ getaucht, vorsichtig auf der unbewachsenen Seite abgetupft und dann mit Fluoromount-G auf dem Objektträger fixiert. 


\subsubsection{Transfektion von HEK293-Zellen mittels DNA-Kalziumphosphat-Kopräzipitat}

(modifiziert nach Chen und Okayama, 1987)

Für die Transfektion von HEK293-Zellen werden $20 \mu$ g Plasmid-DNA in $50 \mu 1$ sterilem d$\mathrm{H}_{2} \mathrm{O}$ verdünnt. $\mathrm{Zu}$ der Lösung werden $500 \mathrm{ml}$ HBS-Puffer (10 mM Hepes/NaOH; pH 7,15; $137 \mathrm{mM} \mathrm{NaCl} ; 5 \mathrm{mM} \mathrm{KCl} ; 1 \mathrm{mM} \mathrm{MgCl} 2 ; 0,7 \mathrm{mM} \mathrm{Na}_{2} \mathrm{HPO}_{4}$; sterifiltriert) zugegeben und gemischt. Die Lösung wird mit $32 \mu 12 \mathrm{M} \mathrm{CaCl}_{2}$-Lösung versetzt, sofort gemischt und für 1020 Min. bei Raumtemperatur stehengelassen. Das DNA-Kalziumphospat-Kopräzipitat wird auf das Medium einer zu 70\% konfluenten $10 \mathrm{~cm}$ Zellkulturplatte getropft, vorsichtig vermischt und für 6-16 h im Brutschrank inkubiert. Dann werden die Zellen einmal mit DPBS gewaschen und mit frischem Medium versehen. Die Expression der transfizierten DNA ist nach etwa $16 \mathrm{~h}$ nachweisbar, die Analyse erfolgt nach ca. $48 \mathrm{~h}$.

\subsubsection{Primärkultur hippocampaler Neuronen}

Für die Mikroskopie bestimmte Neuronen werden auf Poly-D-Lysin-beschichteten Deckgläsern gezogen. Hierfür werden autoklavierte Deckgläser in 24-Loch-Platten ausgelegt, für $1 \mathrm{~h}$ oder über Nacht in steriler Poly-D-Lysin-Lösung $(0,05 \mathrm{mg} / \mathrm{ml}$, in HBSS) inkubiert und anschließend mit HBSS gewaschen. Die Neuronen werden Rattenembryonen (E19) entnommen. Die Hippocampi werden vorsichtig unter dem Binokular präpariert und in HBSS-Puffer gesammelt. Das Gewebe wird dreimal mit HBSS-Puffer gewaschen (die Sedimentation erfolgt ohne Zentrifugation), anschließend in $2 \mathrm{ml}$ Trypsinlösung $(0,5 \%$ in HBSS) aufgenommen und für $20 \mathrm{Min}$. bei $37^{\circ} \mathrm{C}$ im Wasserbad inkubiert. Nach fünf weiteren Waschschritten wird das Gewebe in DNase-Lösung (0,01\% DNase I in HBSS) aufgenommen. Die Vereinzelung der Neuronen erfolgt durch langsames, vorsichtiges Pipettieren der Lösung, je dreimal durch eine Kanüle. Die so präparierten Zellen werden in $20 \mathrm{ml}$ DMEM (mit 10\% FKS; 2 mM Glutamin und 1 x Penicillin/Streptomycin-Lösung) überführt, um das Trypsin zu inaktivieren, abzentrifugiert (800 x g, Raumtemperatur) und in $20 \mathrm{ml}$ Neurobasalmedium (Neurobasalmedium, $2 \mathrm{mM}$ L-Glutamin, 1 x B27) resuspendiert. Die Zellzahl wird mit Hilfe einer Neubauer-Zählkammer bestimmt. Es werden 60 000-80 000 Zellen in $500 \mu 1$ Neurobasalmedium pro Vertiefung ausplattiert. 


\subsubsection{Transfektion von Neuronen mittels DNA-Kalziumphosphat-Kopräzipitat}

Für die Transfektion eignen sich hippocampale Neuronen, die zwischen einem und sieben Tagen in Kultur gehalten wurden (2.2.4.3). Zunächst wird das Medium vorsichtig gegen $1 \mathrm{ml}$ im Brutschrank äquilibriertes Optimem ausgetauscht. Das abgenommenen Neurobasalmedium wird im Brutschrank aufbewart. Die Neuronen werden für eine Stunde in den Inkubator zurückgestellt. Anschließend werden zweimal $750 \mu l$ des Optimems abgenommen und durch dieselbe Menge frischen Mediums ersetzt. Abschließend werden 500 $\mu l$ abgenommen und die Zellen erneut für eine Stunde in den Inkubator zurückgestellt.

In der Zwischenzeit wird das DNA-Phosphat-Gemisch hergestellt, alle Arbeiten werden unter der Sterilbank ausgeführt. In ein steriles 1,5 ml-Eppendorf-Reaktionsgefäß werden $36.3 \mu 1$ Zellkulturwasser und 5,7 $\mu 12 \mathrm{M} \mathrm{CaCl}_{2}$ gegeben und vermischt. Es folgt die Zugabe von $3 \mu \mathrm{l}$ DNA $\left(1 \mu \mathrm{g} / \mu \mathrm{l}\right.$ in $\left.\mathrm{d}-\mathrm{H}_{2} \mathrm{O}\right)$ und erneutes, vorsichtiges Mischen im Schüttelheizblock bei Raumtemperatur bis alle Ansätze bereitstehen. Für die Initiierung der Komplexbildung wird das Reaktionsgefäß auf einem langsam rotieren Vortex-Mixer plaziert, $45 \mu 12$ x HBS zugegeben und einige Sekunden weitergemischt. Das Gemisch wird für 20 Min. im Dunkeln bei Raumtemperatur inkubiert. $30 \mu \mathrm{l}$ der Lösung werden auf die vorbereiteten Zellen pipettiert. Die Kulturgefäße werden für eine weitere Stunde im Brutschrank inkubiert. Das Optimem-Medium mit dem DNA-Kalziumphosphat-Kopräzipitat wird zunächst einmal gegen $1 \mathrm{ml}$ frisches Optimem ausgetauscht und dann dreimal mit $750 \mu \mathrm{l}$ als Teilausstausch gewaschen. Abschließend wird das Optimem durch das ursprüngliche Neurobasalmedium ersetzt. Die Neuronenkulturen verbleiben bis zur weiteren Bearbeitung im Brutschrank.

2x HBS: $274 \mathrm{mM} \mathrm{NaCl} ; 10 \mathrm{mM} \mathrm{KCl} ; 1,2 \mathrm{mM} \mathrm{Na}_{2} \mathrm{HPO}_{4} ; 15 \mathrm{mM}$ Glucose; $42 \mathrm{mM}$ Hepes. Es wird eine Reihe von 18 Puffern mit pH-Werten zwischen 6.93 und 7.10 hergestellt und in Testtransfektionen der bestgeeignete Puffer für die weiteren Experimente bestimmt. 


\subsubsection{Herstellung homolog rekombinanter embryonaler Stammzellen zur Erzeugung von deletionsmutanten knockout-Mäusen (Willnow und Herz, 1994)}

\subsection{Zellkultur}

Um die Omnipotenz der embryonalen Stammzellen (ES-Zellen) zu erhalten, werden diese auf einem Untergrund von Feeder-Zellen kultiviert. Hierfür werden embryonale Fibroblasten aus der Maus (MEF) verwendet. Das Auftauen und die Kultivierung der MEF erfolgt nach der unter 2.2.4.1 für die HEK293-Zellkultur beschriebenen Vorgehensweise in ES-Zellmedium. Konfluent gewachsene Feeder-Zellen werden 1:2,5 passagiert.

Für den Feeder-Rasen wird eine 0,1\%ige Gelatinelösung (in D-PBS) auf dem Boden des Zellkulturgefäßes für eine Stunde inkubiert und anschließend abgesaugt. Auf dieser Grundierug werden MEF angezogen. Beim Erreichen von 70\%iger Konfluenz werden weitere Zellteilungen durch Inkubation mit Mitomycin C (10 mg/ml in Feeder-Zellmedium) blockiert. Nach einer zweistündigen Inkubation werden die Zellen zur Entfernung des Mitosegiftes dreimal mit D-PBS gewaschen und anschliessend mit frischem Medium im Brutschrank weiterkultiviert.

Auf diesem Untergrund werden die ES-Zellen (E14) aufgebracht. Die Kulturbedingungen und das Medium sind dieselben wie für die Kultur der MEF. Die Passage erfolgt bei 50\%iger Konfluenz. Es muß sorgfälltig trituriert werden, um eine gute Vereinzelung der Zellen zu gewährleisten.

DMEM-Medium: DMEM-Pulver (siehe Materialteil) in einem Liter sterilen d- $\mathrm{H}_{2} \mathrm{O}$ lösen $\left(37^{\circ} \mathrm{C}\right), 2,2 \mathrm{~g}$ Natriumbicarbonat zugeben und steril-filtrieren.

ES-Zellmedium: $500 \mathrm{ml}$ DMEM-Medium; $95 \mathrm{ml}$ fötales Rinderserum; $6 \mathrm{ml} 100$ x MEM nicht essentielle Aminosäuren; $6 \mathrm{ml} \beta$-Mercaptoethanol-Lösung $(7 \mu \mathrm{l}$ in $10 \mathrm{ml} \mathrm{D}$ PBS); 1,2 ml 500x Penicillin/Streptomycin-Lösung; $63 \mu$ ESGRO-LIF.

\subsection{Transfektion der ES-Zellen mit dem Deletionsvektor}

$300 \mu \mathrm{g}$ Plasmid-DNA werden durch Restriktionsverdau mit der Endonuklease NotI linearisiert. Zur Reinigung wird die DNA zweimal mit 100\%igem Ethanol präzipitiert (2.2.1.10.2). Das Pellet wird mit 70\%igem Ethanol gewaschen, unter der Sterilbank für eine Stunde getrocknet und in 1,4 $\mathrm{ml}$ D-PBS aufgenommen. 
Für die Transfektion wird eine $25 \mathrm{~cm}^{2}$-Kulturflasche mit $80 \%$ konfluenten ES-Zellen vorbereitet. Die Zellen werden zweimal mit D-PBS gewaschen, trypsiniert, gut trituriert und nach der Zentrifugation noch zweimal mit D-PBS gewaschen. Das Zellpellet wird in 1,4 ml Plasmid-DNA/D-PBS-Lösung aufgenommen.

Für die Elektroporation wird der Ansatz auf zwei Elektroporationsküvetten $(0,4 \mathrm{~cm}$ Elektrodenabstand) verteilt. Die Küvetten werden 5 Min. auf Eis inkubiert. Die Elektroporation erfolgt bei $500 \mathrm{mF}$ und $23 \mathrm{~V}$ im Bio-Rad-Pulser. Die elektroporierten Zellen werden in Medium aufgenommen und auf zwei Rundschalen $(\varnothing 10 \mathrm{~cm})$ ausgesät.

\subsection{Selektion rekombinanter ES-Zellen}

Zwölf Stunden nach der Elektroporation wird das Medium erneuert und nach weiteren zwölf Stunden gegen Selektionsmedium ausgetauscht. Die Neomycin-Selektion (190 $\mu \mathrm{g} / \mathrm{ml})$, die nur das Wachstum von rekombinanten ES-Zellen erlaubt, erfolgt über 9 Tage. Vom dritten bis fünften Tag wird außerdem mit Ganziklovir ( $2 \mathrm{mM})$ selektioniert, um die ES-Zellklone abzutöten, die den Vektor zufällig integriert haben und noch intakte TK-Gene enthalten.

\subsection{Isolierung und Expansion selektionierter ES-Zellen}

Am zehnten Tag nach der Elektroporation erfolgt die Vereinzelung der Stammzellklone. Die ES-Zellen werden einmal mit D-PBS gewaschen und mit $10 \mathrm{ml}$ D-PBS bedeckt. Unter dem Binokular werden einzelne ES-Zellklone aufgenommen und in eine 96-Lochplatte mit jeweils $50 \mu 1$ Trypsin transferiert. Die Zellen werden 30 Min. bei Raumtemperatur und danach 5 Min. bei $37^{\circ} \mathrm{C}$ in der Trypsin-Lösung inkubiert. Nach Zugabe von $100 \mu 1$ ES-Zellmedium werden die Zellen gut trituriert und auf eine mit Feeder-Zellen bedeckte 96-Lochplatte transferiert. Nach etwa drei Tagen sind die ES-Zellen so weit gewachsen, daß sie passagiert werden können. Die Passage erfolgt 1:3. Zwei Platten werden mit Feeder-Rasen vorbereitet, sie werden später eingefroren. Eine der 96-Lochplatten ist nur mit Gelatine beschichtet und wird für die spätere DNA-Analyse verwendet. Nach der Identifizierung positiv rekombinierter ESZellklone wird eine eingefrorene Platte aufgetaut (2.2.23.7), und die betreffenden Klone werden in größeren Kulturschalen angereichert. 


\subsection{Einfrieren von ES-Zellen in 96-Lochplatten}

Die Zellklone werden in den 96-Lochplatten bis zur Konfluenz kultiviert. Vier Stunden vor dem Einfrieren wird das ES-Zellmedium gewechselt, danach werden die Zellen zweimal mit D-PBS gewaschen, $10 \mathrm{Min}$. bei $37^{\circ} \mathrm{C}$ mit jeweils $50 \mu 1$ Trypsin-Lösung inkubiert und nach der Zugabe von $50 \mu 1$ ES-Zellmedium trituriert. Anschließend werden die Zellen für 10 Min. auf $4^{\circ} \mathrm{C}$ abgekühlt. Zum Medium wird jeweils $100 \mu$ eiskaltes $2 \mathrm{x}$-Einfriermedium gegeben, gut durchmischt und mit $70 \mu 1$ Mineralöl pro Loch überschichtet. Die Zellkulturplatte wird in einer Styroporbox bei $-80^{\circ} \mathrm{C}$ für zwei Tage gelagert und anschließend in einen Tank mit flüssigem Stickstoff überführt.

2x-Einfriermedium: $20 \%$ DMSO / 20\% fötales Kälberserum / 60\% ES-Zellmedium

\subsection{DNA-Iolierung und Analyse der rekombinanten ES-Zellen}

Konflente ES-Zellklone werden zweimal mit D-PBS gewaschen und in jeweils $50 \mu \mathrm{l}$ Lysispuffer über Nacht bei $60^{\circ} \mathrm{C}$ in einer Feuchtkammer aufgeschlossen. Die genomische DNA wird durch Zugabe von $100 \mu \mathrm{l}$ kaltem Ethanol-Salzgemisch $(150 \mu 15 \mathrm{M} \mathrm{NaCl}$ in $10 \mathrm{ml}$ Ethanol; $-20^{\circ} \mathrm{C}$ ) für $30 \mathrm{Min}$. bei Raumtemperatur gefällt. Der Überstand wird dekantiert und die DNA dreimal mit 70\% Ethanol gewaschen. Die DNA-Pellets werden etwa 5-10 Min. bei Raumtemperatur getrocknet und anschließend in $50 \mu \mathrm{l}$ D-PBS aufgenommen. Die Analyse auf homologe Rekombination erfolgte durch Southernblot und spezifische PCR. Für die PCRAnalyse werden die Oligos 428 und 2801 verwendet, die den shortarm flankierend im neo ${ }^{R}$ Gen und außerhalb des shortarm hybridisieren.

Für die Southernblotanalyse wird das DNA-Sediment nicht in D-PBS aufgenommen, sondern in $40 \mu \mathrm{l}$ Reaktionsmix einem Restriktionsverdau unterzogen. Der Verdau erfolgt über Nacht bei $37^{\circ} \mathrm{C}$ in einer Feuchtkammer. Die verdaute genomische DNA wird auf einem $0,7 \% 1 \mathrm{x}$ TAE-Agarosegel bei konstant $20 \mathrm{~mA}$ elektrophoretisch getrennt und anschließend der Southernblotanalyse (2.2.1.15) unterzogen.

Lysispuffer: $10 \mathrm{mM}$ Tris/HCl, pH 7,5; 10 mM EDTA, pH 8,0; $10 \mathrm{mM} \mathrm{NaCl} ; 0,5 \% \mathrm{~N}-$ Laurylsarcosin; $1 \mathrm{mg} / \mathrm{ml}$ Proteinase K.

Reaktionsmix je Loch: $4 \mu 1$ 10x enzymspezifischer Restriktionspuffer; $0,4 \mu 110 \mathrm{mg} / \mathrm{ml} \mathrm{BSA}$; 15 U Restriktionsenzym; ad $40 \mu \mathrm{ld}-\mathrm{H}_{2} \mathrm{O}$. 


\subsection{Blastozysteninjektion und Züchtung der Mäuse}

Die Blastozysteninjektionen sowie die Zucht und Pflege rekombinanter Tiere werden von den Mitarbeitern des Tierhauses des MPI für experimentelle Medizin, Göttingen, unter tierärztlicher Leitung von Herrn Dr. Hermann Riedesel vorgenommen. Die Verpaarung chimärer Männchen sowie die gesamte weitere Zucht erfolgt mit C57Black/6-Mäusen. 


\section{ERGEBNISSE}

\subsection{Identifikation von mit Neuroliginen interagierenden Proteinen mit Hilfe des Doppelhybridsystems in Hefe (yeast-two-hybrid-screen)}

Einige der im folgenden beschriebenen Ergebnisse (Abb. 1, 2, 5A, 6A, 22; Tab. 1) wurden im Rahmen meiner Diplomarbeit erarbeitet. Soweit sie für das bessere Verständnis der Zusammenhänge dieser Arbeit von Bedeutung sind, werden sie hier noch einmal aufgeführt.

Mit dem Ziel, eine möglichst große Anzahl von Proteinen auf eine Interaktion mit Neuroligin zu überprüfen, wurden je ein yeast-two-hybrid-screen für Neuroligin 1 und Neuroligin 2 durchgeführt. Hierfür sind die cytoplasmatischen C-Termini (AS 754-843 von Neuroligin 1, AS 706-836 von Neuroligin 2, Abb. 1) durch PCR amplifiziert und in den Vektor pLexN kloniert worden. Mit diesen Konstrukten wurde eine Rattenhirn-cDNA-Bibliothek (postnataler Tag 8 in pVP16-3) analysiert.

\section{Neuroligin 1 (843 AS)}

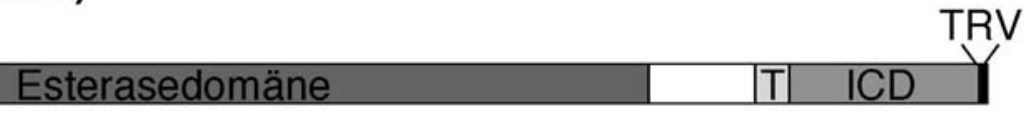

pLexN-NL1 (754-843)

Neuroligin 2 (836 AS)

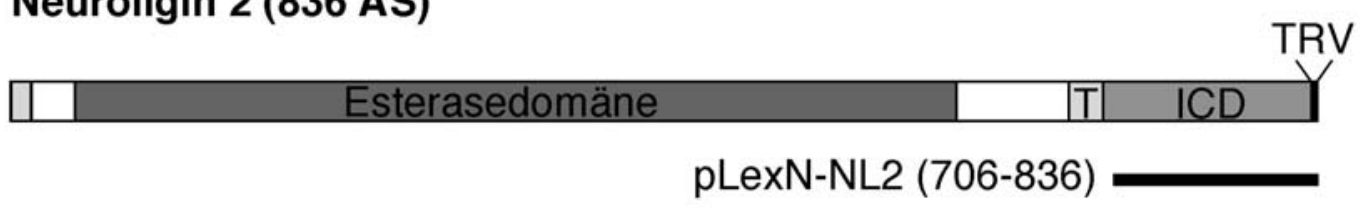

100 AS

Abb. 1: Im Hefe-Doppelhybrid-Experiment verwendete Konstrukte von Neuroligin 1 und Neuroligin 2.

Schematische Darstellung der verwendeten Sequenzbereiche und ihrer Lage in der Neuroligin-Sequenz. Die Domänen von Neuroligin 1 und Neuroligin 2 sind grau unterlegt. Hellgrau ist die N-terminale Signalsequenz gekennzeichnet. T, Transmembrandomäne; ICD, intrazellulare Domäne; TRV, Aminosäurenfolge der PDZ-Erkennungssequenz. In Klammern sind die im Konstrukt enthaltenden Aminosäurereste angegeben.

Die Transformationseffizienz im Neuroligin 1-Experiment betrug 6,2 x $10^{4}$ Zellen/ $\mu$ g DNA (31 Millionen Klone). Von den 2489 histidinautotrophen Klonen wurden 100 Klone genauer analysiert. Ein Klon war nach der Retransformation im $\beta$-Galaktosidasetest negativ, 11 Klone 
repräsentierten den leeren pVP16-3-Vektor. Sechzehn Klone wurden mit Hilfe der Southernblot-Methode in einem Dot-Blot-Verfahren als PSD95 identifiziert. Von den übrigen Klonen waren 26 keinem Datenbankeintrag zuzuordnen. Alle anderen Klone sind in Tabelle 1 aufgeführt.

Für das Neuroligin 2-Experiment betrug die Transformationseffizienz 8 x $10^{3}$ Zellen/ $\mu$ g DNA (4 Millionen Klone). Von 787 histidinautotrophen Kolonien wurden 200 Klone im $\beta$ Galaktosidase-Filtertest untersucht. Vier erwiesen sich nach Retransformation als negativ. Sechsundvierzig Klone waren ohne Insert, 31 wurden, wie bei Neuroligin 1 beschrieben, als PSD95 identifiziert. Es besaßen 60 Sequenzen entweder keinen offenen Leserahmen oder waren nicht lesbar oder waren in den Datenbanken nicht veröffentlicht.

Die restlichen Plasmide wurden sequenziert und die Sequenzen via BLASTn oder tBLASTn (siehe 2.2.2.5) mit nicht redundanten Datenbanken verglichen, um die Proteine $\mathrm{zu}$ identifizieren, für die sie kodieren. Die Ergebnisse der Sequenzvergleiche sind in Tabelle 1 aufgeführt.

\subsubsection{Analyse der im Hefesystem gefundenen Interaktionen}

Die Interaktionen von Neuroligin 1 mit den PDZ-Domänen-Proteinen der MAGuK-Proteine PSD95, SAP102, PSD93 und AIP1 waren bereits bekannt. Die übrigen im Experiment gefundenen Interaktionen wurden zunächst hinsichtlich der Spezifität ihrer Interaktion mit Neuroligin 1 und Neuroligin 2 überprüft. Zu diesem Zweck wurden die isolierten Klone im $\beta$ Galaktosidasetest (2.2.2.3) auf Interaktion mit dem LexA-Neuroligin-bait-Konstrukten und auf eine nicht spezifische Interaktion mit der DNA-Bindedomäne von LexA getestet. Alle Klone, die zwar mit dem LexA-Neuroligin-Fusionsprotein, nicht aber mit der LexA-DNABindedomäne alleine interagierten, wurden als potentiell spezifische Neuroligin-Interaktoren weiter untersucht. Die Konstrukte von Protein 4.1N, Protein 4.1B, Nedd4.1, Spa1/p1294, SHANK-1 und Carboxypeptidase E/H erwiesen sich als positiv. Von diesen erschienen die Protein 4.1N, Protein 4.1B, Nedd4.1, SHANK-1 und Spa1/p1294 aufgrund der über sie bekannten Daten als Interaktionspartner der Neuroligine interessant. Die Interaktionen der Neuroligine mit Nedd4.1 und den Mitgliedern der Protein 4.1-Familie, Protein 4.1N und Protein 4.1B wurden im Rahmen der vorliegenden Arbeit eingehender untersucht, da sie im Synaptogenesekontext diskutiert worden sind, aber noch nicht als Interaktionspartner von Neuroligin identifiziert wurden. 
Tab. 1: Ergebnisse der Datenbankanalyse von pVP16-3-Klonen aus den yeast-twohybrid-screens mit den C-terminalen Domänen von Neuroligin 1 und -2.

Die analysierten pVP16-3-Klone sind entsprechend der Häufigkeit ihres Auftretens sortiert. Quelle: Diplomarbeit Antje Neeb, 1998. NL: Neuroligin.

\begin{tabular}{|c|c|c|c|c|}
\hline \multirow[t]{2}{*}{ Protein } & \multirow[t]{2}{*}{ Funktion/Proteinfamilie } & \multicolumn{3}{|c|}{ Anzahl der Klone } \\
\hline & & NL1 & NL2 & Summe: \\
\hline PSD95 & MAGuK-Protein & $4(+16)$ & $3(+31)$ & 54 \\
\hline SAP102 & MAGuK-Protein & 17 & 6 & 23 \\
\hline AIP1 & MAGuK-Protein & 8 & 7 & 15 \\
\hline Ros1 & Rezeptortyrosinkinase (Onkogen) & 2 & 7 & 9 \\
\hline PSD93 & MAGuK-Protein & 3 & 5 & 8 \\
\hline Shank1 & Multidomänen Protein mit PDZ-Domänen & 6 & - & 6 \\
\hline Nedd4.1 & Ubiquitinligase mit $\mathrm{C} 2$ und WW-Domänen & 3 & 2 & 5 \\
\hline Protein $4.1 \mathrm{~N}$ & 4.1-Homolog & 4 & - & 4 \\
\hline Fibulin & Cadherin-Familie & 3 & - & 3 \\
\hline SodiumchannelI & Spannungsgesteuerter Natriumkanal & - & 3 & 3 \\
\hline Protein 4.1B & 4.1-Homolog & 2 & - & 2 \\
\hline Laminin & $\alpha$-Kette/Integrin-Rezeptor & 2 & - & 2 \\
\hline NGEF4 & Notch-Homolog & 2 & - & 2 \\
\hline $\mathrm{E} / \mathrm{H}$ & Carboxypeptidase & 2 & - & 2 \\
\hline NRF1 & Transkriptionsfaktor & 2 & - & 2 \\
\hline Spa1/p1294 & RAP-GAP mit PDZ-Domäne & 2 & - & 2 \\
\hline Pick1 & PKC-Bindeprotein mit PDZ-Domäne & - & 2 & 2 \\
\hline $\mathrm{O} / \mathrm{E}$ & Transkritionsfaktor & - & 2 & 2 \\
\hline Roaz1 & Zink-Finger-Protein & 1 & 1 & 2 \\
\hline Tag1 & Glycoprotein & 1 & - & 1 \\
\hline Tenascin & $\begin{array}{l}\text { Antiadhäsionsprotein der extrazellulären } \\
\text { Matrix }\end{array}$ & 1 & - & 1 \\
\hline FE65 & Transkriptionsfaktor mit WW-Domänen & 1 & - & 1 \\
\hline L Protein & Zelladhäsionsprotein & 1 & - & 1 \\
\hline KIAA0156 & RNA-Bindeprotein & 1 & - & 1 \\
\hline KIAA0609 & Methyltransferasedomäne & 1 & - & 1 \\
\hline Tsx 1 & Transkriptionsfaktor & 1 & - & 1 \\
\hline Nel1 & PKC-Bindeprotein & 1 & - & 1 \\
\hline GAS7 & $\begin{array}{l}\text { SH3-Domänen-Protein (wachstums- } \\
\text { stopspezifisch exprimiert) }\end{array}$ & - & 1 & 1 \\
\hline GST & Glutathion-S-Transferase & - & 1 & 1 \\
\hline Dystroglycan & Laminin-Rezeptor & - & 1 & 1 \\
\hline InsP-3'-5'- & Hydrolysiert Inositol-1,3,4-Triphosphat & - & 1 & 1 \\
\hline Phosphatase & Axonleitung & |- & 1 & 1 \\
\hline Hsp70 & Hitzeschockprotein & - & $\begin{array}{l}1 \\
1\end{array}$ & 1 \\
\hline Smad2 & Transkriptionsfaktor & - & 1 & 1 \\
\hline ТP2 & $\begin{array}{l}\text { Transporterprotein für die } \\
\text { Antigenpräsentation }\end{array}$ & - & 1 & 1 \\
\hline $\begin{array}{l}\beta \text {-Catenin (kurzer } \\
\text { Typ) }\end{array}$ & Transmembrales Zelladhäsionsprotein & - & 1 & 1 \\
\hline Cyclophilin & Peptidyl-cis/trans-Isomerase & - & 1 & 1 \\
\hline Adenylatzyklase & synthetisiert zyklisches AMP & - & 1 & 1 \\
\hline Luca15 & Tumorsupressorgenprodukt & - & 1 & 1 \\
\hline PEG3 & Transkriptionsfaktor & - & 1 & 1 \\
\hline 18S-Untereinheit & Teil des Ribosoms & - & 1 & 1 \\
\hline & & $\sum 87$ & $\sum 83$ & $\sum 170$ \\
\hline
\end{tabular}




\subsection{Nedd4.1}

\subsubsection{Interaktion von Neuroligin und Nedd4.1 im Hefe-Doppelhybridsystem und Kartierung der interagierenden Bereiche}

Unter den mit den intrazellulären Domänen von Neuroligin 1 und -2 interagierenden Klonen waren fünf, die homolog zu der Ubiquitinligase Nedd4.1 sind, zwei im Neuroligin 1-screen sowie drei im screen mit Neuroligin 2. Nedd4.1 ist eine Ubiquitinligase vom HECT-Typ, sie besteht aus 887 Aminosäuren und enthält eine C2-Domäne, drei WW-Domänen und eine Ubiquitinligasedomäne. Die Klone bildeten drei Gruppen, die sich im Bereich der zweiten und dritten WW-Domäne überschneiden (Abb. 2). WW-Domänen vermitteln Interaktionen zwischen Proteinen. Analog zu SH3-Domänen erkennen sie prolinreiche Regionen auf Zielproteinen, die den Konsensus PPXY ("PY-Motiv") tragen. Alle drei Neuroliginisoformen enthalten PY-Motive in ihrem cytoplasmatischen C-Terminus, welche auch in den humanen Neuroliginen konserviert sind (Abb. 3A).

Nedd4.1 (887AS)

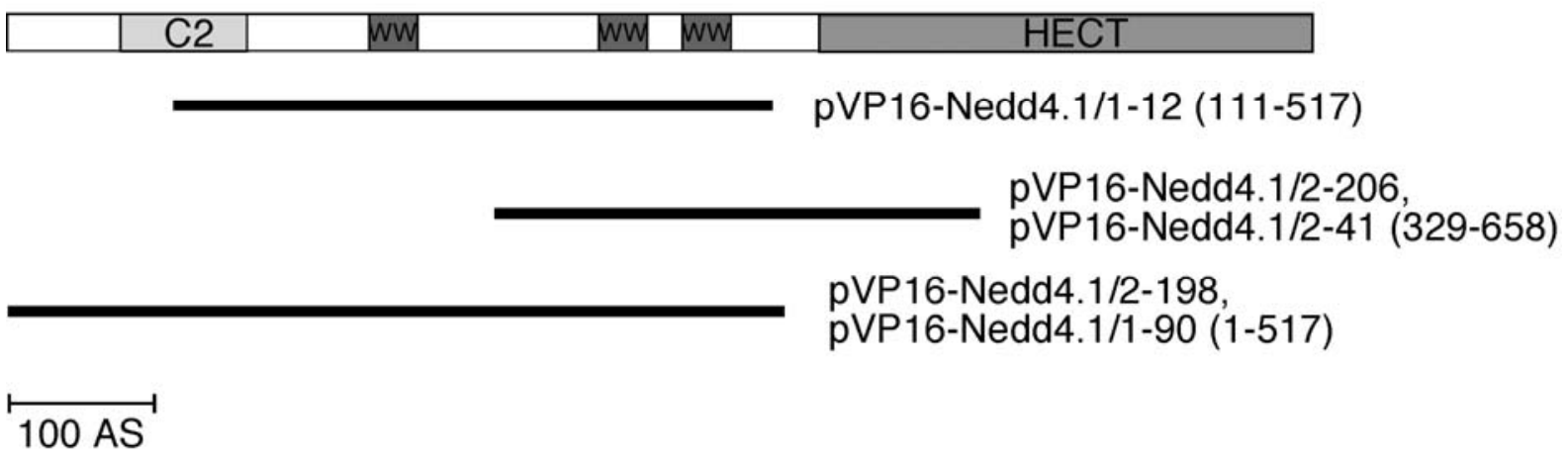

Abb. 2: Im Hefe-Doppelhybridsystem identifizierten Nedd4.1-Klone.

Schematische Darstellung des Nedd4.1-Proteins. Die Domänen sind grau unterlegt, die Lage der identifizierten pVP16-3-Klone ist durch Balken gekennzeichnet. C2, C2-Domäne; WW, WW-Domäne; HECT, Ubiquitinligasedomäne des HECT-Typs. Quelle: Dipomarbeit Antje Neeb, 1998.

Mit dem Ziel zu überprüfen, ob die Interaktion zwischen Neuroligin und Nedd4.1 tatsächlich von den WW-Domänen vermittelt wird, wurde durch gezielte Punktmutationen das PY-Motiv im bait-Vektor von Neuroligin 1 verändert. Es zeigte sich, daß die Substitution des Prolins 780 bzw. des Lysins 782 durch ein Arginin zu einer Reduktion der Bindungsintensität führte. Eine Doppelmutation beider Reste führte zum kompletten Verlust der Nedd4.1-Bindung (Abb. 3B und C). 
A

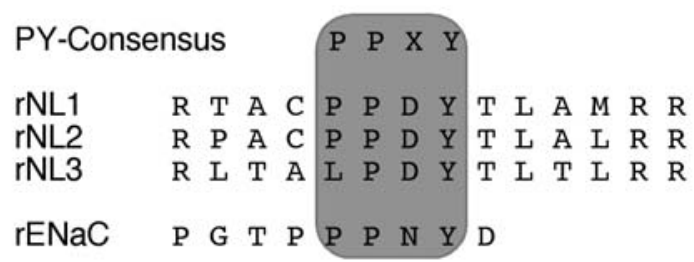

B

\begin{tabular}{|c|c|}
\hline bait-Vektor (in pLexN) & $\begin{array}{l}\text { Relative } \\
\beta \text {-Gal-Aktivität }\end{array}$ \\
\hline NL1 (754-843) & +++ \\
\hline NL1 (754-843) P780A & ++ \\
\hline NL1 (754-843) Y782A & ++ \\
\hline NL1 (754-843) P780A/Y782A & + \\
\hline
\end{tabular}

C

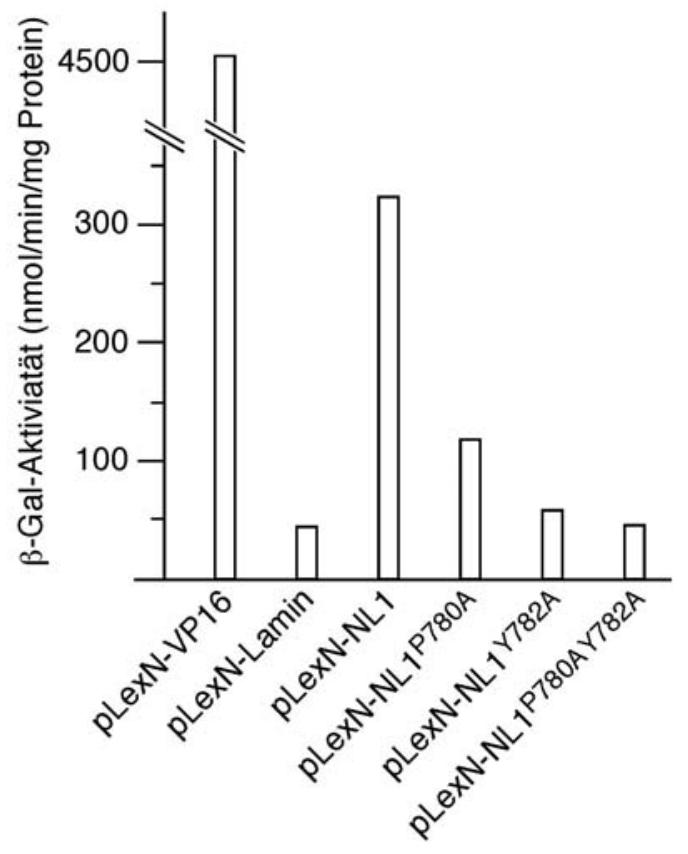

Abb. 3: Kartierung der Interaktionsdomäne für Nedd4.1.

A: Vergleich des PY-Motivs in Neuroligin 1, -2 und -3 mit dem des ENaC. Die Konsensussequenz ist grau unterlegt B: Die angegebenen Neuroligin-Konstrukte wurden mit pNedd4.1/1-12 in Hefen kotransformiert und die rekombinanten Hefen einem $\beta$ Galaktosidase-Filtertest unterzogen. -: negativ; +++: starke; ++: mittlere; +: leichte Reaktion. In Klammern sind die im Konstrukt enthaltenen Aminosäuren von Neuroligin 1 angegeben. Die hochgestellten Zahlen/Buchstabenkombinationen zeigen die eingeführten Mutationen. C: Quantitative Analyse der unter B beschriebenen Kotransformationsexperimente im $\beta$ Galaktosidase-Flüssigtest. Als Positivkontrolle diente pLexN-VP16, als Negativkontrolle pLexN-Lamin. 
Diese Daten zeigen, daß die Interaktion von Neddd4.1 mit den Neuroliginen durch Bindung der zweiten und dritten WW-Domäne an das PY-Motiv (Aminosäuren 778-782 in Neuroligin 1) erfolgt.

\subsubsection{Die Nedd4.1-Antikörper}

Mit Hilfe von gereinigten GST-Nedd4-Fusionsproteinen (GST-Nedd4.1/2-42, AS 329-658) wurden zwei Antiseren in Kaninchen erzeugt. Sie erhielten die Namen Nedd4.1.5 und Nedd4.1.6. Beide Antiseren erkennen im Westernblot eine Bande von 116 kDa sowohl im Synaptosomenextrakt aus Rattengehirn, als auch in einem Lysat von HEK293-Zellen, welche mit einem Nedd4.1-Expressionskonstrukt transfiziert worden sind. Die Größe der detektierten Bande stimmt mit der berechneten Größe gut überein. Sowohl in untransfizierten, wie auch in HEK293-Zellen, die mit einem nicht verwandten Protein transfiziert wurden, wurde von beiden Seren eine schmale Bande im selben Bereich detektiert, die auf endogenes Nedd4.1 in den Zellen hinweist (Abb.4). In den nachfolgenden Experimenten wurde, soweit nicht anders erwähnt, der Antikörper Nedd4.1.6 verwendet.

A
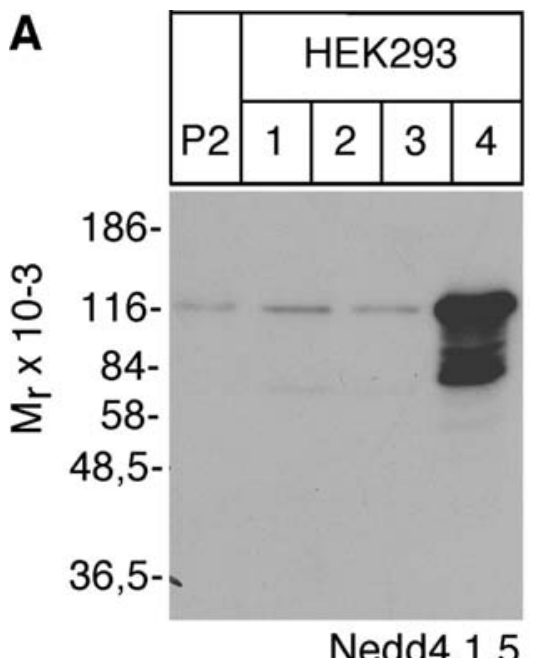

B

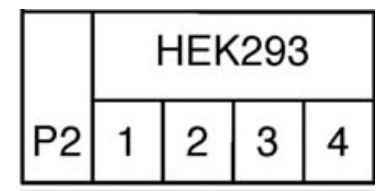

$186-$

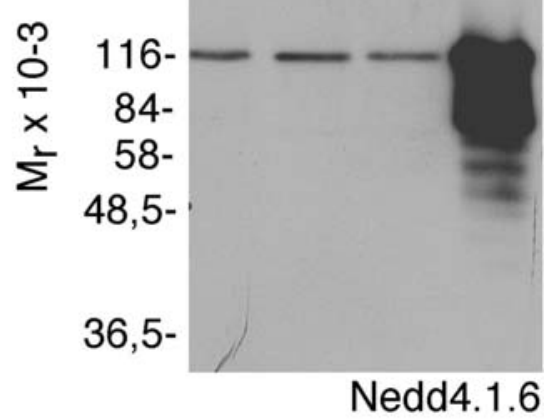

Abb. 4: Die Nedd4.1-Antikörper.

Die Antiseren Nedd4.1.5 und Nedd4.1.6 wurden im Westernblot getestet. Hierfür wurden die Proteine eines Synaptosomenextraktes aus Rattenhirn (P2) sowie aus solubilisierten HEK293Zellen, die (1) nicht, $(2,3)$ mit einem nicht verwandten Protein (Protein 4.1B; Protein 4.1N) oder (4) mit Nedd4.1 transformiert worden waren, per SDS-PAGE aufgetrennt und auf Nitrozellulose transferiert. Diese Membran wurde anschließend einer Immunoblotanalyse mit den angegeben Antiseren inkubiert. Immunreaktive Banden wurden mit ECL visualisiert. 


\subsubsection{In-vitro-Bindungsstudien}

Um die im Hefesytem gefundene Interaktion mit anderen Methoden zu verifizieren, wurden

zwei unterschiedliche biochemische Ansätze gewählt, die Kosedimentation an immobilisierten GST-Fusionsproteinen und die Koimmunpräzipitation.

Abbildung 5A zeigt das Ergebnis des Kosedimentationsexperimentes, das in der vorangegangenen Diplomarbeit erarbeitet wurde. GST-Fusionsproteine von Nedd4.1Teilbereichen (GST-Nedd4.1/1-12; AS 111-517) und GST-Nedd4.1/2-41; AS 329-658)) wurden in Bakterien exprimiert, gereinigt und an Glutathion-Agarose immobilisiert. Die Proteine wurden mit einem Synaptosomenextrakt inkubiert und anschließend gewaschen. Bindende Proteine wurden gemeinsam mit dem GST-Fusionsprotein eluiert, per SDS-PAGE aufgetrennt und mittels Westernblot analysiert. Als Negativkontrolle diente GST allein, als Positivkontrolle GST-p1294/Spa1 (AS 875-1547), dessen Interaktion mit Neuroligin bereits bekannt war. Beide GST-Nedd4.1-Fusionate banden Neuroligin 1 ebenso wie die Positivkontrolle. Im Experiment mit reinem GST ohne Fusionsanteil war Neuroligin 1 nicht detektierbar. Dies zeigt, daß Neuroligin 1 nicht an das Trägerprotein, sondern tatsächlich an die Nedd4.1-Fragmente band. Zusätzlich wurden dieselben Proben per Immundetektion mit einem Antikörper gegen das präsynaptische Protein Synaptophysin analysiert, um so die Spezifität der Interaktion $\mathrm{zu}$ kontrollieren. Synaptophysin ist ausschließlich in den Überständen nachweisbar, die in den Sedimenten nachgewiesene Bindung mit Neuroligin ist also nicht auf unspezifisch gebundenes Protein zurückzuführen.

Als weiterer biochemischer Nachweis einer Interaktion zwischen den Neuroliginen und Nedd4.1 diente die Koimmunpräzipitation. Der Antikörper 4F9, der alle drei Isoformen von Neuroligin erkennt, wurde wie oben beschrieben an Protein-G-Sepharose immobilisiert, mit einem Extrakt synaptosomaler Proteine inkubiert und anschließend gewaschen. Der an die Sepharosekügelchen gebundene Antikörper bindet das native Neuroligin im Extrakt und reinigt so auch eventuelle Interaktionspartner auf. Die Analyse erfolgte nach Elution der Immunkomplexe wiederum mit Hilfe von SDS-PAGE und der Immundetektionsmethode auf einem Westernblot (Abb. 5B). Im oberen Teil von Abbildung 5B ist die Analyse der Immunpräzipitation mit dem Neuroligin-Antikörper dargestellt, im unteren Teil die des Kontrollexperimentes (Präzipitation mit einem Antikörper, der Neuroligin nicht bindet). Auf den Sepharosekugeln ist neben Neuroligin 1, -2 und -3 auch Nedd4.1 nachweisbar, nicht aber Sytaxin, das als Kontrollprotein diente. 

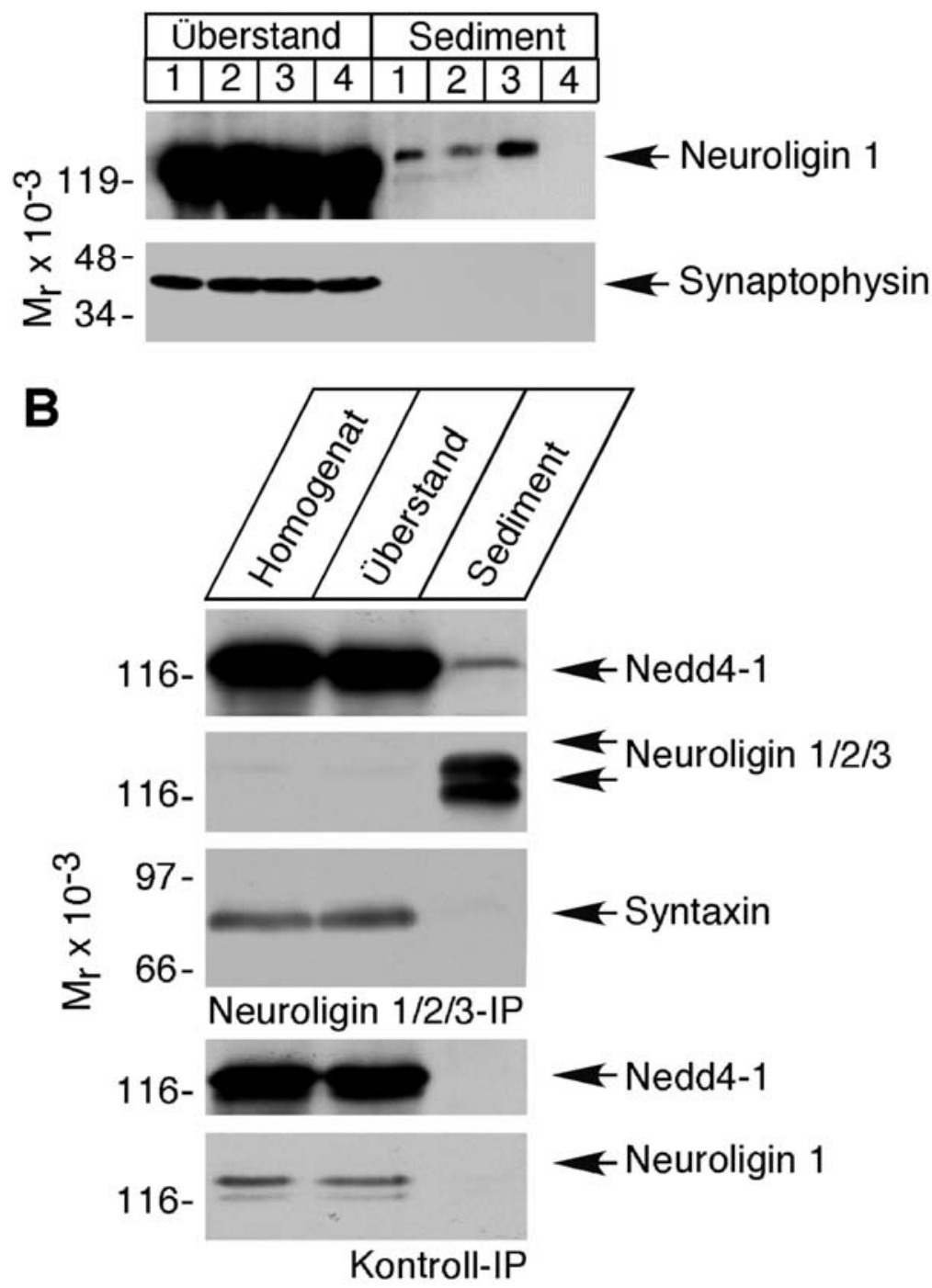
Abb. 5: Nedd4.1 und Neuroligin interagieren in Kosedimentations- und
Immunpräzipitationsexperimenten.

A: Kosedimentation. GST-Fusionsproteine von Nedd4.1 (GST-Nedd4.1/1-12; AS 111-517 (1) und GST-Nedd4.1/2-41; AS 329-658 (2)) wurden in dem Bakterienstamm E. coli BL21DE3 exprimiert, gereinigt und an Glutathion-Agarose gebunden. Gleiche Mengen des immobilisierten Fusionsroteins wurden mit einem Synaptosomenextrakt inkubiert und anschließend gewaschen. Als Negativkontrolle diente GST ohne Fusion (4), als Positivkontrolle GST-p1294/Spa1 (AS 875-1547) (3). Überstand und Sediment der Experimente wurden durch SDS-PAGE aufgetrennt, auf Nitrozellulose transferiert und die Membran mit Antikörpern gegen Neuroligin 1 und Synaptophysin analysiert. Die Visualisation immunreaktiver Banden erfolgte durch ECL. Quelle: Diplomarbeit Antje Neeb, 1998. B: Immunpräzipitation. Der Antikörper L067 gegen Neuroligin 1,2,3 wurde an ProteinSepharose immobilisiert und mit einem Synaptosomenextrakt inkubiert und gewaschen. Die so isolierten Proteine sind einer SDS-PAGE unterzogen und auf Nitrozellulose transferiert worden. Die Membran wurde per Immunoblot mit Antikörpern gegen Nedd4.1, Neuroligin 1, $-2,-3$ und Syntaxin analysiert. Als Kontrolle diente dasselbe Experiment, durchgeführt mit dem Antikörper 4C12, der Neuroligin nicht präzipitiert. Immunreaktive Banden wurden mit ECL visualisiert. 
Der Kontrollantikörper präzipitierte weder Neuroligin noch Nedd4.1, was darauf hinweist, daß die Präzipitation von Nedd4.1 durch Bindung an Neuroligin erfolgte und nicht etwa auf unspezifische Interaktion mit dem Antikörper oder dem Trägermaterial zurückzuführen ist.

Sowohl die Sedimentation von Neuroligin durch die rekombinanten Nedd4.1-Fragmente, als auch die Bindung von nativen Nedd4.1 an Neuroligin, die durch die Immunpräzipitation nachgewiesen wurde, bestätigen die im Hefesystem gefundenen Interaktionen.

\subsubsection{Gewebeverteilung von Nedd4.1}

RNA-Blots mit Poly(A)-angereicherten RNAs aus verschiedenen Geweben der Ratte wurden mit einem radioaktiv markierten Fragment der Nedd4.1-cDNA unter stringenten Bedingungen hybridisiert. Das Autoradiogramm des hybridisierten Blots wird in Abbildung 6A gezeigt.

Nedd4.1-mRNA war in allen untersuchten Geweben nachweisbar, eine verstärkte Expression war in den Fraktionen aus Lunge, Leber, Niere und Testis zu erkennen. Das detektierte Transkript war ca. 5,6 kb groß, es ergab sich kein Hinweis auf Spleißvarianten (Abb. 6A).

Um die Ergebnisse der RNA-Expressionsanalyse mit proteinchemischen Daten zu komplementieren, wurden Homogenate unterschiedlicher Gewebe der Ratte wurden per Immunoblot mit dem Nedd4.1.6-Antiserum analysiert. Ähnlich der Nedd4.1-mRNA (Abb. 6B) war das Nedd4.1-Protein in allen untersuchten Geweben nachweisbar. Starke Proteinexpression wurde in der Lunge, der Leber und im Gehirn detektiert, während in den anderen untersuchten Geweben nur Spuren nachweisbar waren. Die Ergebnisse zeigen, daß Nedd4.1 ubiquitär exprimiert wird, und in relativ großen Mengen auch im adulten Gehirn vorkommt. 
A

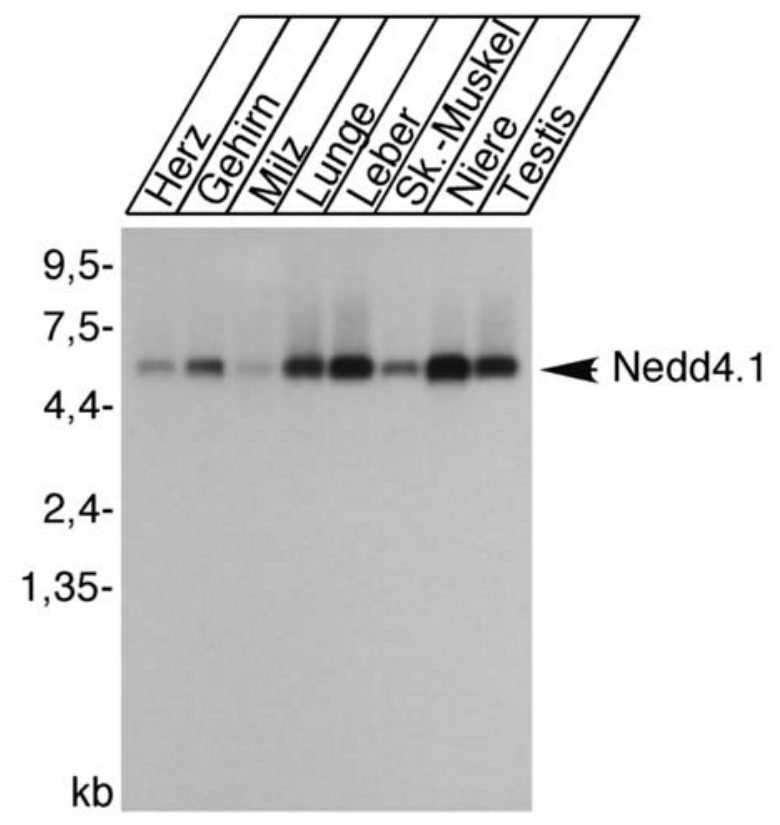

B

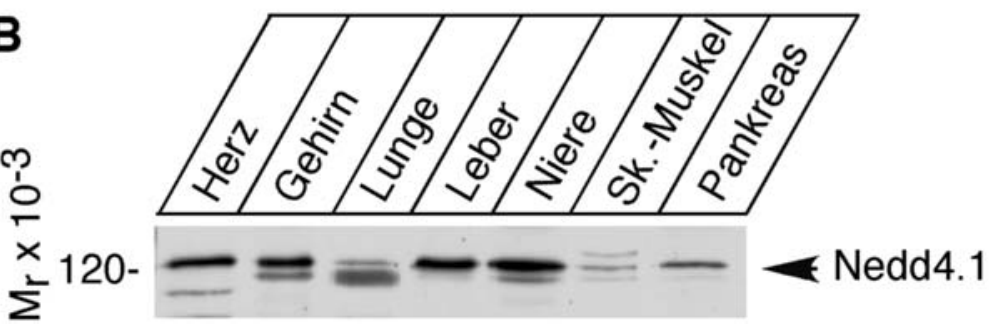

Abb. 6: Gewebeverteilung von Nedd4.1.

A: Ein kommerziell erworbener Northernblot mit mRNA der angegebenen Gewebe einer adulten Ratte (Clontech) wurde mit einem radioaktiv markierten Nedd4.1-DNA-Fragment (bp 979-1890; Genbanknummer RU50842) unter hoch stringenten Bedingungen hybridisiert. Die Auswertung der Banden erfolgte mittels eines Autoradiogrammes. Quelle: Diplomarbeit Antje Neeb, 1998. B: Gleiche Proteinmengen von Homogenaten verschiedener Gewebe der Ratte wurden per SDS-PAGE aufgetrennt, auf Nitrozellulose transferiert und mit dem Antiserum Nedd4.1.6 inkubiert. Immunreaktive Banden wurden durch ECL visualisiert.

\subsubsection{Gewebeverteilung von Nedd4.1 innerhalb des Gehirns}

Aufbauend auf den Ergebnissen der Gewebeverteilung von Nedd4.1 und Neuroligin aufbauend sollte in Folge untersucht werden, ob Nedd4.1 und Neuroligin 1 auch innerhalb des Gehirns in denselben Regionen kollokalisieren. 


\subsubsection{In-situ-Hybridisierung}

Das Expressionsmuster von Nedd4.1-mRNA im Gehirn wurde mittels in-situ-Hybridisierung und Westernblotanalyse untersucht (Abb. 7).

A

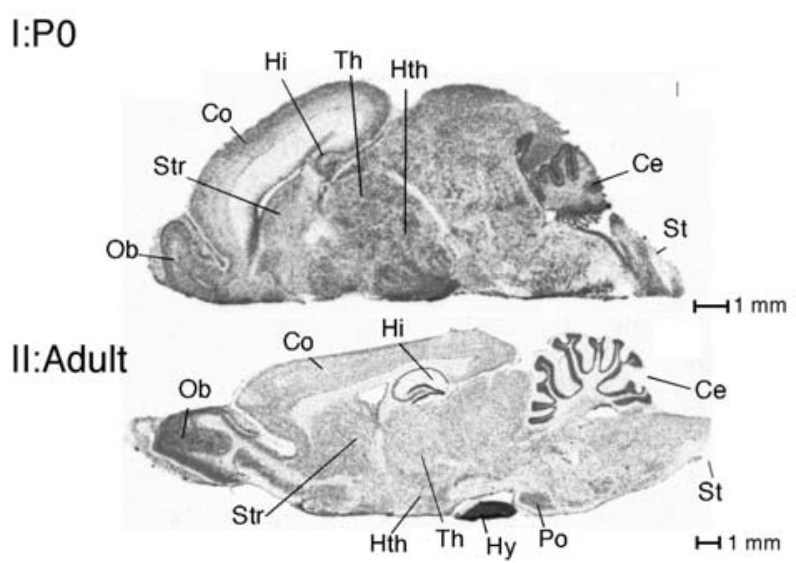

B

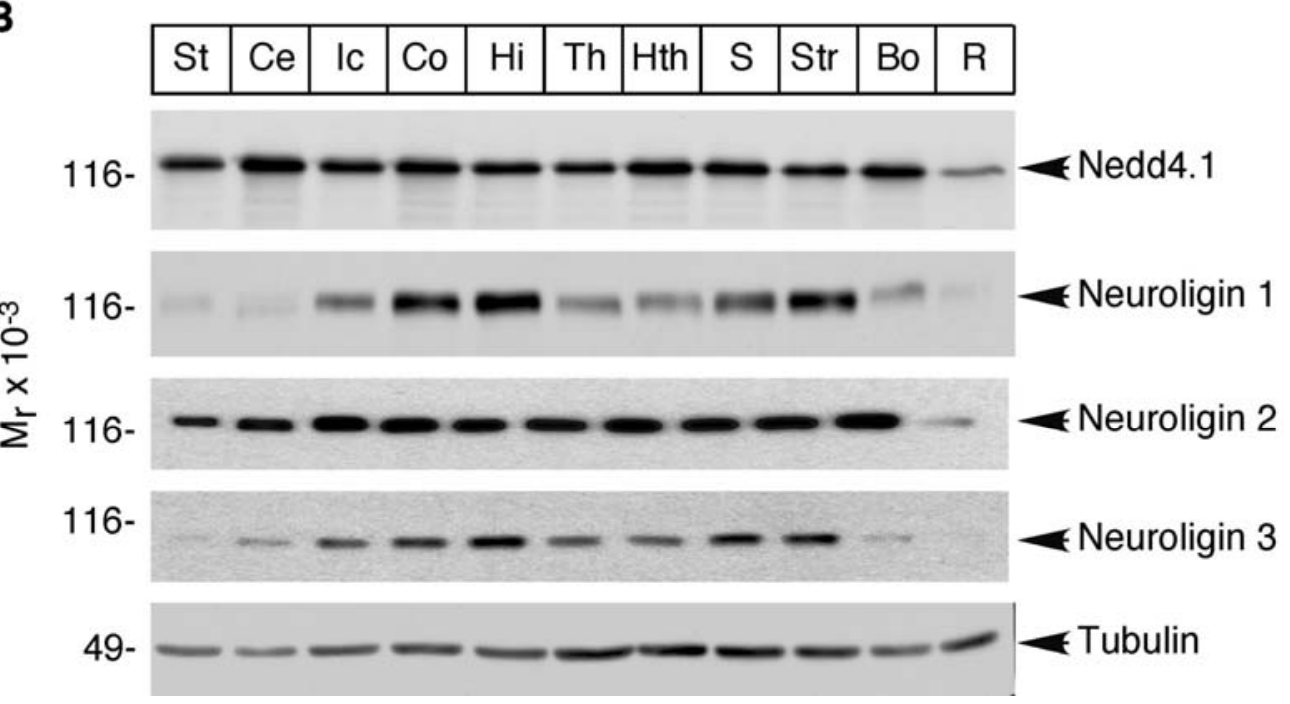

Abb. 7.: Regionale Expression von Nedd4.1 im Gehirn der Ratte.

A: Autoradiogramme der in-situ-Hybridisierung mit antisense-Oligos für Nedd4.1. Abgebildet ist je ein repräsentatives Resultat zweier unabhängiger Experimente mit unterschiedlichen Oligos. Die Negativkontrollen ergaben kein Signal (nicht gezeigt). Die Hybridisierung erfolgte auf dehydrierten, mit 4\% Paraformaldehyd fixierten Sagittalschnitten. I: Neugeborenes Gewebe (P0). II: Adultes Gehirn (3 Monate). B: Immundetektionsanalyse der Proteinexpression in den angegebenen Gehirnregionen. Homogenate aus dem Gehirn einer adulten Ratte wurden per SDS-PAGE aufgetrennt, auf Nitrozellulose transferiert und mit Antikörpern gegen Neuroligin 1, Neuroligin 2, Neuroligin 3 und Nedd4.1 analysiert. Tubulin diente als Ladekontrolle.

St, Stammhirn; Ce, Cerebellum; Ic, Inferior colliculus; Co, Cortex; Hi, Hippocampus; Th, Thalamus; Hth, Hypothalamus; Se, Septum; Str, Striatum; Bo, Bulbus olfactorius; R, Rückenmark; Po, Pons; Hy, Hypophyse. 
Für die radioaktive Markierung wurden zwei verschiedene, spezifische, zur mRNA antisense orientierte Oligonukleotide verwendet. Die Hybridisierung erfolgte sowohl auf adultem, als auch auf dem Gewebe neugeborener Tiere, um die entwicklungabhängige Dynamik der Nedd4.1-Expression zu dokumentieren (Abb. 7A). Es wurden sagittale Gehirnschnitte angefertigt. Die Ergebnisse der beiden verwendeten antisense-Oligonukleotide waren nahezu identisch, Kontrollexperimente, in denen ein Überschuss von nicht markiertem Oligo zugegeben wurde, ergaben kein Signal.

Nedd4.1 wird in nahezu allen Bereichen des Gehirns exprimiert. Regionen mit hoher Konzentration von Gliazellen (weiße Masse des cerebralen Cortex und des Cerebellums) werden (wenn auch schwächer) markiert, was auf die Expression von Nedd4.1 hauptsächlich in nicht neuronalen Zellen des Gehirns hinweist. Die Neuroligin-Expression ist weitestgehend neuronenspezifisch (Song et al., 1999). Die Nedd4.1-Expression im Neugeborenen-Gehirn ist mehr oder weniger gleichmäßig über das gesamte Gewebe verteilt, während im adulten Gehirn Zonen starker und schwächerer Expression zu sehen sind. Bereiche konzentrierter Expression finden sich im Hippocampus (Stratum pyramidale und Gyrus dentatus), im Bulbus olfactorius, in der Körnerzellschicht des Cerebellums, der Hypophyse sowie in der Pons. Die Verteilung ähnelt in weiten Bereichen der der Neuroligine (Frederique Varoqueaux und JiYing Song, pers. Mittlg.; Ichtchenko et al. 1996).

\subsubsection{Immunoblotanalyse der Gewebeverteilung von Nedd4.1 im Gehirn}

Die Gehirnregionenverteilung der Nedd4.1-mRNA wurde mit der des Nedd4.1-Proteins verglichen (Abb. 7B). Hierfür wurden Immunoblots von Homogenaten unterschiedlicher Gehirnregionen einer adulten Ratte per SDS-PAGE aufgetrennt, auf Nitrozellulose transferiert und die Membran mit Antiseren gegen Nedd4.1 und Neuroligin 1 analysiert. Sowohl Nedd4.1 als auch Neuroligin 1 waren in allen untersuchten Geweben detektierbar, was mit den Ergebnissen der in-situ-Hybridisierung übereinstimmt. Während Nedd4.1 eine sehr gleichmäßige Expression zeigt (nur im Rückenmark ist eine geringere Proteinkonzentration zu detektieren), wird Neuroligin 1 im Cortex, Hippocampus, Septum und Striatum besonders stark exprimiert. 


\subsubsection{Nedd4.1 und Neuroligin 1 kollokalisieren in Neuronen}

Immundetektion und in-situ-Hybridisierung zeigten, daß Neuroligin und Nedd4.1 in denselben Regionen des Gehirns exprimiert werden. Um direkt zu testen, ob sich die Koinzidenz der Expression auch auf dieselben Zellen erstreckt, wurden Doppelfärbungen mit Antikörpern gegen beide Proteine auf Sagittalschnitten des Gehirns einer adulten Ratte durchgeführt (2.2.4.1).

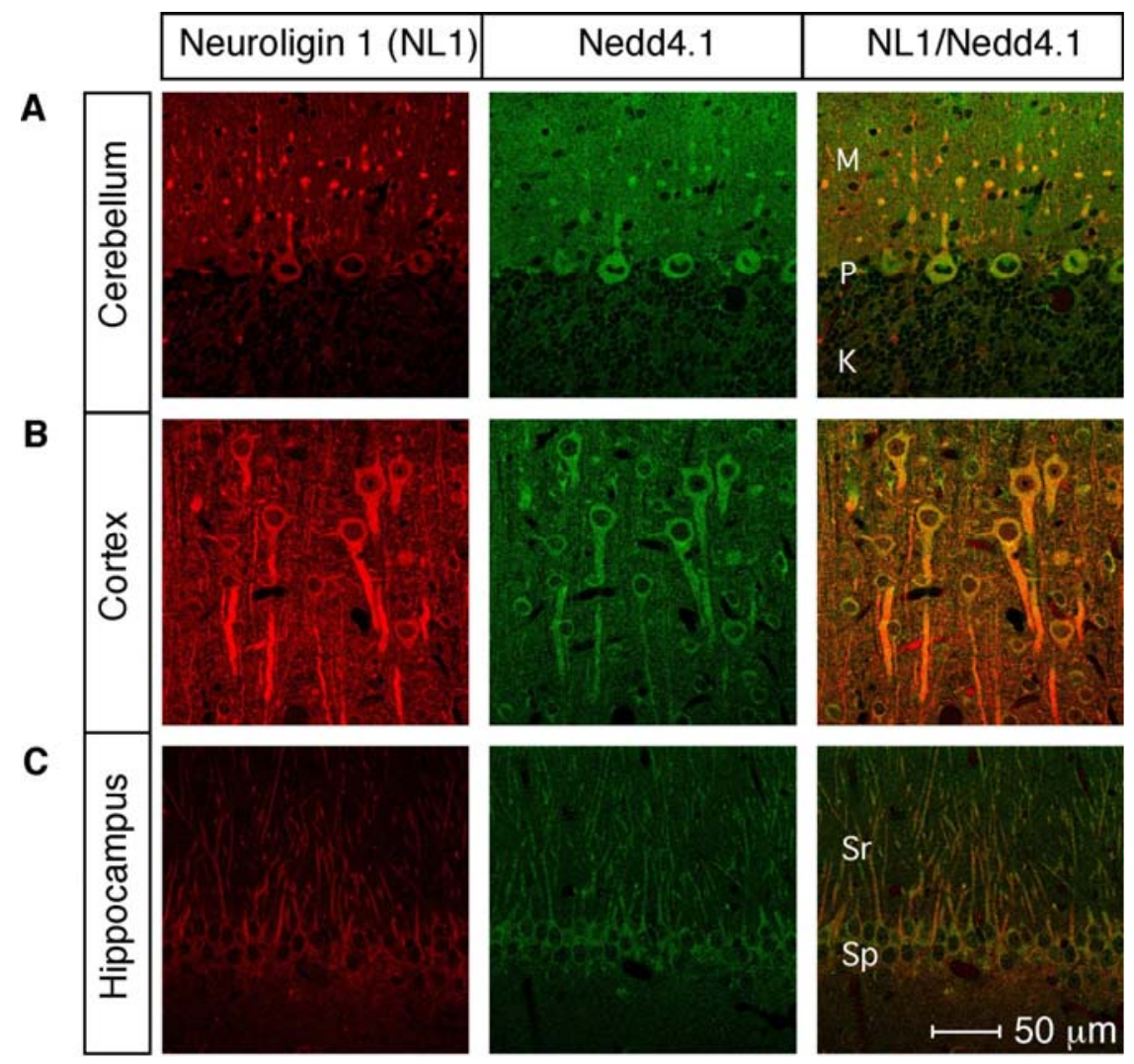

Abb.8: Immunohistochemische Analyse der Verteilung von Neuroligin 1 und Nedd4.1 in Neuronen des Rattengehirns

Sagittale Gehirnschnitte einer adulten Ratte wurden mit Antikörpern gegen Neuroligin 1 (NL1)(4C12, monoklonal, rot) und Nedd4.1 (Nedd4.1.6, grün) angefärbt (siehe Methode 2.2.4.1). Die Visualisierung erfolgte durch konfokale Lasermikroskopie (Zeiss, LSM510). In der Überlagerung erscheinen Bereiche überlappender Signale gelb. Gezeigt werden Ausschnitte aus Cerebellum (A), Cortex (B) und Hippocampus (C). K, Körnerzellschicht; P, Purkinjezellschicht; M, Molekularzellschicht; Sp, Stratum pyramidale; Sr, Stratum radiatum.

Wie Abbildung 8 zeigt, kollokalisieren Nedd4.1 und Neuroligin 1 in den meisten Neuronen des Gehirns. Beide Proteine sind beispielsweise in den Pyramidenzellen des Cortex und des Hippocampus sowie den Purkinjezellen des Cerebellums angereichert, wobei Zellkörper und 
Dendriten gefärbt werden. Die Färbung der Pyramidenzellen finden sich vor allem in den apikalen, in geringerem Ausmaß aber auch in den Basaldendriten. Axone und Zellkerne wurden nicht markiert.

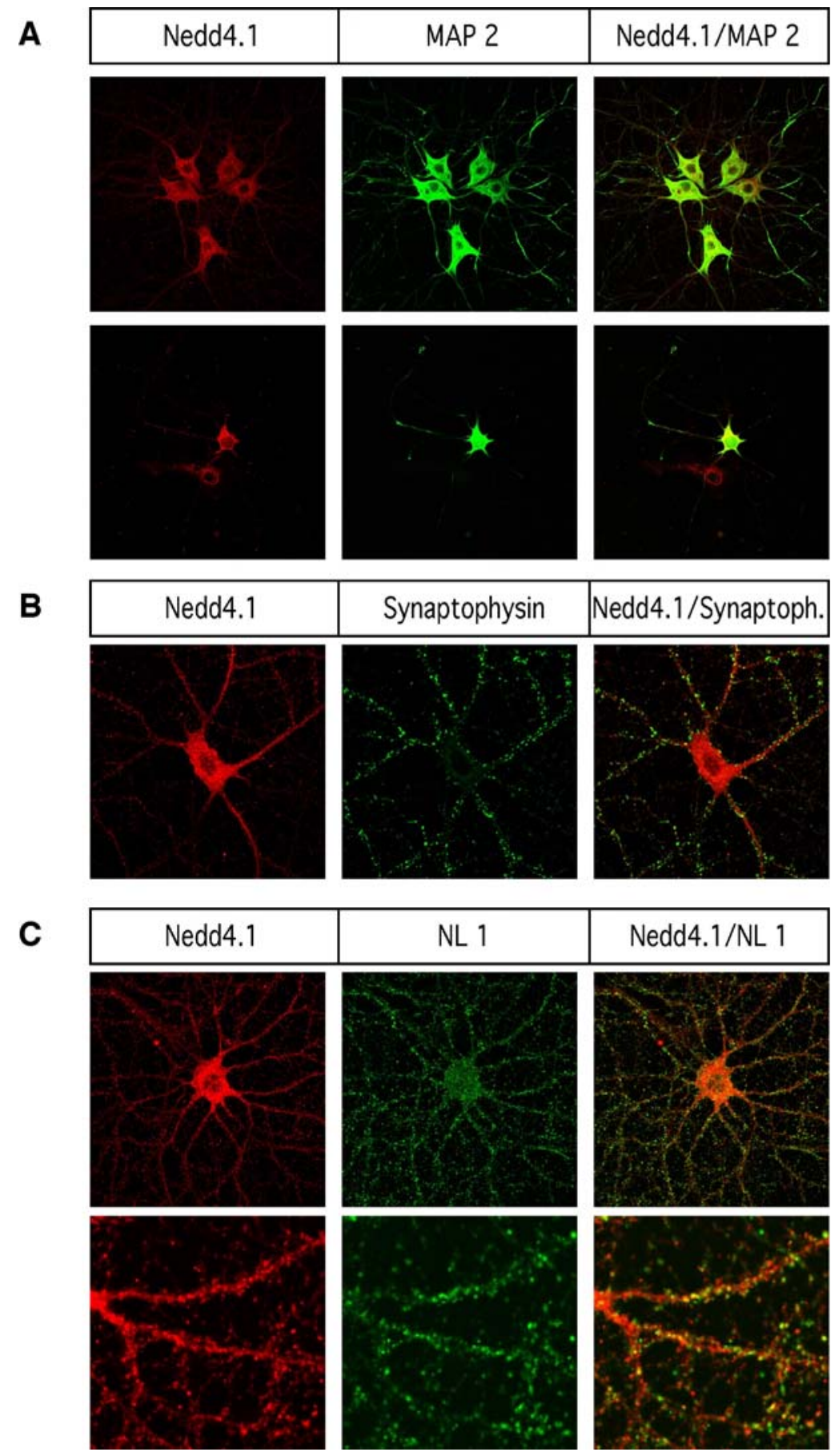

\section{Abb.9: Immunfärbung kultivierter Neuronen mit Antiseren gegen Nedd4.1 und Markerproteine.}

Primärkulturen von Neuronen des Hippocampus der Ratte (Tag 21 und älter) wurden fixiert und mit Antikörpern gegen die angegebenen Proteine gefärbt. A: Doppelfärbung mit antiMAP2 (grün) und Nedd4.1.6 (rot). B: Doppelfärbung mit 4C12 (anti-Neuroligin 1, grün) und Nedd4.1.6 (rot). Die Visualisierung erfolgte durch konfokale Lasermikroskopie (Zeiss, LSM510). In der Überlagerung erscheinen Bereiche überlappender Signale gelb. 
Abb. 9 zeigt die Verteilung von Nedd4.1 in kultivierten hippocampalen Neuronen im Vergleich mit Markerproteinen. MAP2 ist ein Markerprotein für Neuronen, es findet sich spezifisch in neuronalen Zellkörpern und Dendriten. Die Doppelfärbung mit Nedd4.1.6 und anti-MAP2-Antikörper bestätigt die bereits im Gewebe gefundene somatodendritische Verteilung von Nedd4.1. Die MAP2-negative Zelle unten ist vermutlich eine Gliazelle (Abb. 9A), die Nedd4.1 exprimiert. Der Antikörper 4C12 gegen Neuroligin 1 zeigt die typische punktierte Färbung eines synaptischen Proteins. Nedd4.1 kollokalisiert partiell mit Neuroligin 1 in synaptischen Strukturen, weist aber eine diffusere Verteilung in Dendrit und Zellkörper auf (Abb. 9B).

\subsubsection{Subzelluläre Verteilung von Nedd4.1}

Neuroligin 1 ist auf der postsynaptischen Membran glutamaterger Synapsen lokalisiert. Um herauszufinden, ob auch Nedd4.1 an der synaptischen Plasmamembran zu finden ist, wurde eine subzelluläre Fraktionierung von cerebralem Cortexhomogenat nach Huttner et al. (1983) durchgeführt.

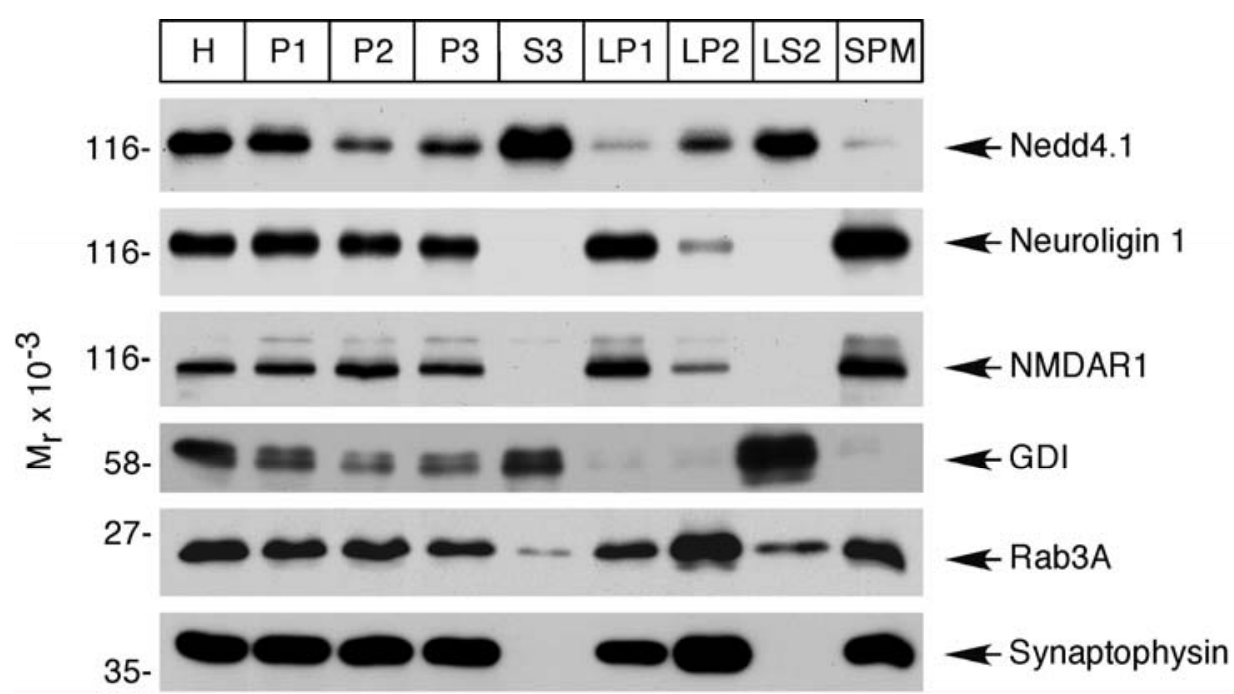

Abb. 10: Subzelluläre Lokalisation von Nedd4.1

Durch Subfraktionierung der Proteine des cerebralen Cortex der Ratte ergaben sich folgende Fraktionen: Homogenat (H), Kernpellet (P1), Synaptosomenpellet (P2), Pellet leichter Membranen (P3), Cytosol (S3), lysierte Membranen der Synaptosomen (LP1), synaptische Vesikel (LP2), synaptosomales Cytosol (LS2) und synaptische Plasmamembranen (SPM). Gleiche Proteinmengen der Fraktionen wurden durch SDS-PAGE aufgetrennt, auf Nitrozellulose transferiert und mit Antikörpern gegen die angegebenen Proteine inkubiert. Die Banden wurden durch ECL analysiert. 
Durch differentielle Zentrifugation kann auf biochemischen Wege untersucht werden, in welchen Kompartimenten Proteine angereichert sind. Das Ergebnis ist in Abbildung 10 gezeigt. Um die Qualität der Fraktionierung zu belegen, wurden Antikörper gegen Markerproteine verwendet. Als cytosolischer Marker diente GDI. GDI zeigte sich in der Fraktion des synaptischen Cytosols (LS2) stark angereichert, in den membranassoziierten Fraktionen LP1, LP2 und SPM hingegen war es fast nicht nachweisbar. Neuroligin 1 und die Glutamatrezeptoruntereinheit NMDAR1 sind postsynaptische Marker. Sie waren in den cytosolischen Fraktionen S3 und LS2 nicht zu finden, zeigten sich aber angereichert in der Fraktion synaptischer Plasmamembranen (SPM). Das Vesikelmarkerprotein Synaptophysin war fast ausschließlich in membranassoziierten Fraktionen detektierbar und akkumulierte in der LP2-Fraktion. Die Synaptophysin-Bande in der SPM-Fraktion ist durch „gedockte“ Vesikel zu erklären. Rab3A bindet reversibel an synaptische Vesikel, es war folglich sowohl in den löslichen, cytosolischen Fraktionen (LS2), als auch in der Vesikelfraktion (LP2) zu finden. Der Nachweis von Rab3A in der Fraktion der synaptischen Plasmamembranen (SPM) erklärt sich, wie bei Synaptophysin, durch gedockte Vesikel.

Das Verteilungsmuster von Nedd4.1 weist auf Anwesenheit verschiedener Untergruppen hin. Der größere Anteil des Proteins ist löslich und findet sich in den Fraktionen des zellulären beziehungsweise synaptosomalen Cytosols. Ein anderer Teil ist jedoch membrangebunden, wahrscheinlich vermittelt durch membranassoziierte Proteine. Die Anwesenheit von Nedd4.1 in der Fraktion der synaptischen Plasmamembranen korreliert gut mit dem bereits festgestellten somatodendritischen Verteilungsmuster und spricht für eine spezifische Interaktion mit Neuroligin.

\subsubsection{Elektronenmikroskopie}

Um nachzuweisen, ob sich Nedd4.1-Protein in der Synapse befindet, wurden Teile des Gehirns einer adulten Ratte mit dem Antikörper Nedd4.6 gefärbt und per Elektronenmikroskopie analysiert. Abb. 11 zeigt einen repräsentativen Ausschnitt aus dem cerebralen Cortex. Das Signal des Nedd4.1-Antikörpers konzentriert sich in der Postsynapse und ist besonders intensiv in der Region dicht unterhalb des synaptischen Spaltes. Die Daten zeigen, daß Nedd4.1-Moleküle auf der postsynaptische Seite des synaptischen Spalts lokalisiert sind. Da die Neuroligine 1, -2 und -3 ebenfalls postsynaptisch lokalisiert sind (Song et al., 1999), unterstützen diese Befunde die Hypothese einer postsynaptischen Interaktion zwischen Neuroligin und Nedd4.1. 


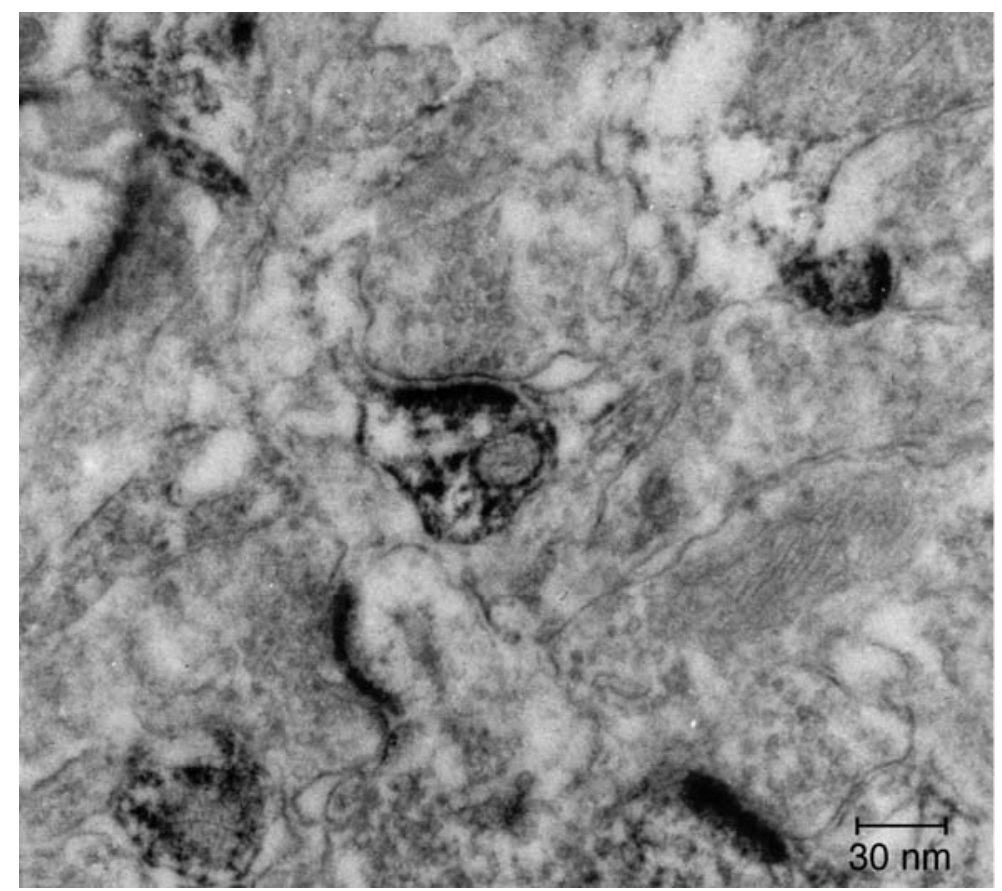

\section{Abb. 11: Elektronenmikroskopische Detektion von Nedd4.1 in der Synapse}

Die Abbildung zeigt einen repräsentativen Ausschnitt aus dem cerebralen Cortex einer adulten Ratte. In der Mitte der Abbildung ist eine Synapse zu erkennen. Das Nedd4.1-Signal ist in der Postsynapse konzentriert. Das Material wurde mit Antikörper gegen Nedd4.1 behandelt und mit Hilfe eines Rasterelektronenmikroskops (Zeiss, LEO 912AB) untersucht.

\subsubsection{Entwicklungsabhängige Expression von Nedd4.1 im Gehirn}

Die entwicklungsabhängige Expression von Proteinen kann Aufschluss über deren Rolle während der Differenzierung eines Gewebes spielen. Da Neuroligin 1 ausschließlich im Gehirn exprimiert wird und auch Nedd4.1 dort zu finden ist (vergl. 3.2.4) wurden Rattenhirnhomogenate verschiedener Altersstufen per SDS-PAGE aufgetrennt, auf Nitrozellulose transferiert und die Membran durch Immundetektion mit Antikörpern gegen verschiedene Proteine analysiert (Abb. 12). Neuroligin zeigt, ebenso wie die NMDARezeptoruntereinheit NMDARI das typische Muster eines synaptischen Proteins. Es ist während der Embryonalentwicklung nur in Spuren vorhanden. Die Expression beginnt kurz nach der Geburt und steigt dann parallel zur Synapsenzahl an, um sich dann im adulten Tier auf einem recht hohen Niveau zu stabilisieren.

Nedd4.1 wird bereits im embryonalen Gehirn stark exprimiert. Das hohe Expressionsniveau bleibt einige Tage nach der Geburt stabil, um dann kontinuierlich auf eine vergleichsweise niedrige Expressionsrate im adulten Gehirn herabreguliert zu werden. 


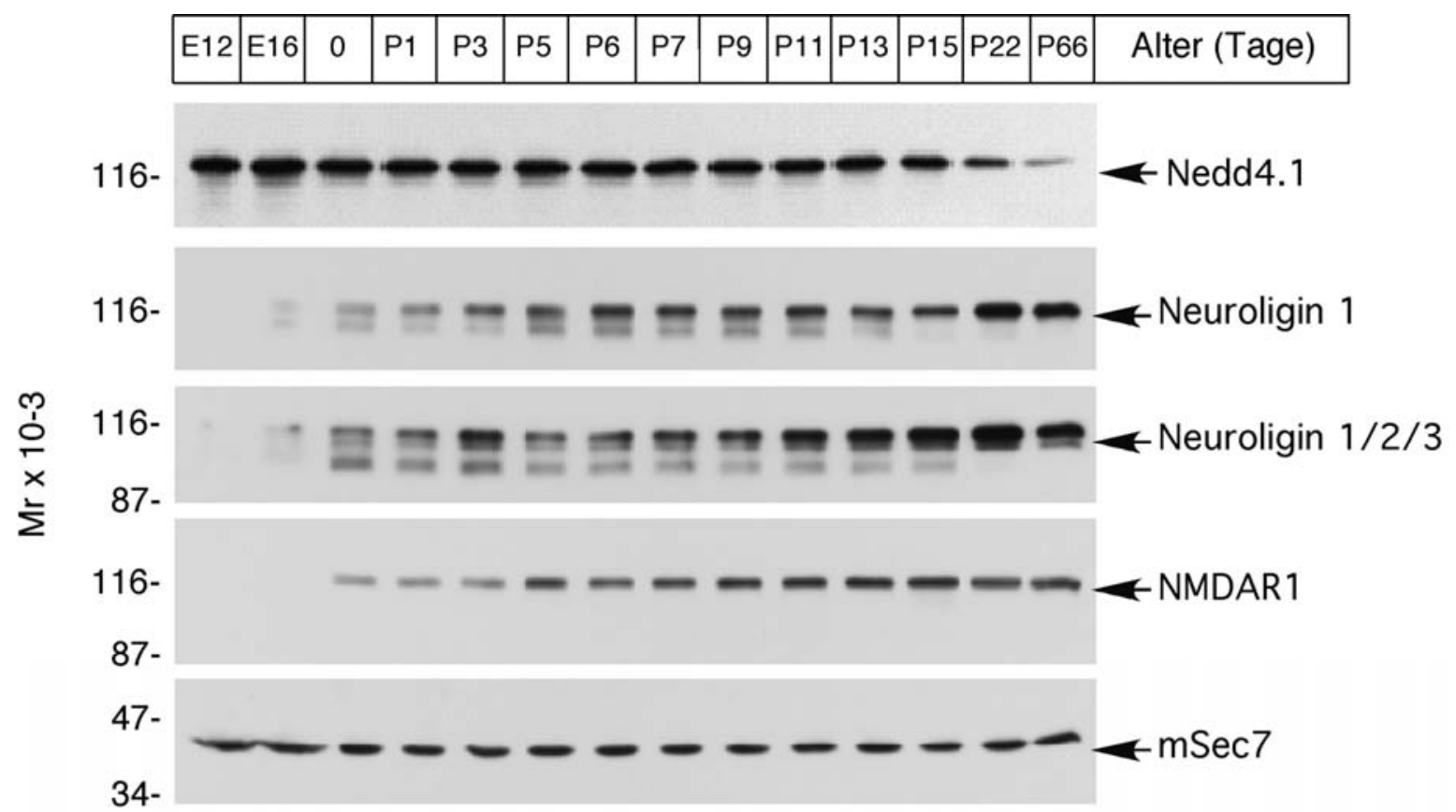

Abb. 12: Entwicklungsabhängige Expression von Neuroligin und Nedd4.1

Gehirnhomogenate von Ratten unterschiedlicher Altersstufen wurden durch SDS-PAGE aufgetrennt, auf Nitrozellulose-Membran transferiert und mit Antikörpern gegen die angegebenen Proteine analysiert. Immunreaktive Banden wurden mit ECL visualisiert. E, embryonaler Tag; P, postnataler Tag.

\subsubsection{Funktionelle Analyse der Interaktion zwischen Nedd4.1 und Neuroligin}

Nachdem eine Interaktion zwischen Neuroligin und Nedd4.1 nachgewiesen, die interagierenden Domänen kartiert und Expressionsprofile der Proteine verglichen worden waren, sollte in weiterführenden Experimenten die funktionelle Relevanz dieser Interaktion untersucht werden. Insbesondere sollte analysiert werden, ob Neuroligine Substrate von Nedd4.1 sind und ubiquitiniert werden. Außerdem sollte nachgewiesen werden, ob ihre Expression durch Nedd4.1-vermittelte Modifikation beeinflußt wird.

\subsubsection{Die Mutante Nedd4.1 ${ }^{\mathrm{C} 843 \mathrm{~S}}$}

Die kovalente Bindung zwischen dem C-Terminus von Ubiquitin und bestimmten Lysinresten der Zielproteine resultiert aus dem Zusammenspiel der substraterkennenden Ubiquitinligasen (E3) mit den ubiquitinaktierenden (E2) und den ubiquitinkonjugierenden Enzymen (E1), (Scheffner et al., 1995; Huibregtse et al., 1995). Nedd4.1 und andere Ubiquitinligasen vom 
HECT-Typ binden Ubiquitin in hochenergenen Thioesterbindungen. Diese Bindung wird von einem hochkonservierten Cysteinrest vermittelt, der für die Funktion der Ubiquitinligase essentiell ist. Als Kontrolle für die nachfolgend beschriebenen Experimente diente eine Mutante, deren katalytisch aktiver Cysteinrest (AS 843) gegen ein Serin ausgetauscht wurde (Abb. 13A). Die Strategie zur Einführung einer gezielten Nukleotidsubstitution durch PCR ist im Methodenteil (2.2.1.2) erklärt. Die Mutante erhielt die Bezeichnung Nedd4.1 ${ }^{\mathrm{C} 843 \mathrm{~S}}$.

Exprimiert man Nedd4.1 ${ }^{\text {C843S }}$ und Wildtyp-Nedd4.1, zeigt sich ein deutlicher Unterschied in der Fähigkeit dieser Proteine, Ubiquitin zu binden. HEK293-Zellen wurden mit leerem Vektor pcDNA3, Nedd4.1 oder Nedd4.1 ${ }^{\mathrm{C} 843 \mathrm{~S}}$ transformiert. Zusätzlich wurden Neuroligin 1 und ein His 6 -markierter Ubiquitin-Vorläufer (Treier et al., 1994; Abb. 13B) in die Zellen gebracht. Die Zellen wurden aufgeschlossen, die enthaltenen Proteine solubilisiert und eine

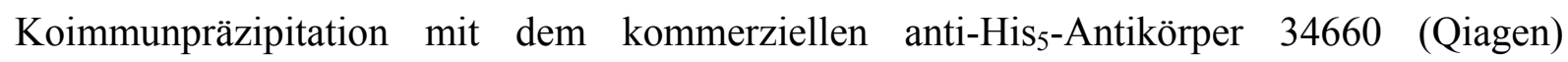
durchgeführt. Dies sollte zur Immunpräzipitation des His $_{6}$-Ubiquitins und aller kopräzipitierten Proteine führen. Die Proteine im Präzipitat wurden per SDS-PAGE aufgetrennt, auf Nitrozelluose transferiert und die Membran mit Antikörpern gegen Nedd4.1, Neuroligin 1 und $\mathrm{His}_{5}$ (Abb. 13C) mittels Immundetektion analysiert. Betrachtet man die Immundetektionsanalyse mit Nedd4.1.6, so zeigt sich, daß ausschließlich das WildtypNedd4.1 im Pellet der His 5 -Immunpräzipitation zu finden ist. Offensichtlich kann nur die Wildtypform, nicht aber die Mutante Nedd4.1 ${ }^{\mathrm{C} 843 \mathrm{~S}}$ mit His $_{6}$-Ubiquitin kopräzipitieren.

Die Immundetektionsanalyse derselben Membran mit anti-His 5 -Antikörper zeigte in den Fraktionen, in denen Nedd4.1 mit His $_{6}$-markiertem Ubiquitin koexprimiert wurde, eine zusätzliche $120 \mathrm{kDa}$ große Bande, bei der es sich wahrscheinlich um ubiquitiniertes Nedd4.1 handelt. Bei Koexpression von Nedd4.1 ${ }^{\mathrm{C} 843 \mathrm{~S}}$ anstelle der Wildtypform ist keine solche Bande detektierbar.

Das Experiment zeigt, daß rekombinantes Nedd4.1 im Gegensatz zu Nedd4.1 ${ }^{\text {C843S }}$ in vivo ubiquitiniert wird und die inaktive Mutante Nedd4.1 $1^{\mathrm{C} 843 \mathrm{~S}}$ ein vielseitig einsetzbares Kontrollprotein ist.

Die Immundetektionsanalyse desselben Experimentes mit L067 (anti-Neuroligin 1/2/3) zeigt, daß es nicht gelungen ist, auf diesem Wege ubiquitinierte Neuroligin 1-Moleküle im anti$\mathrm{His}_{5}$-Immunpräzipitat anzureichern und nachzuweisen (Abb. 13C). Mögliche Erklärungen sind, daß die Halbwertszeit von ubiquitiniertem Neuroligin $1 \mathrm{zu}$ kurz ist, um in einem Präzipitationsverfahren in nachweisbaren Mengen angereichert zu werden, bzw. daß Neuroligin nicht von Nedd4.1 ubiquitiniert wird. 
A

Lys Leu Pro Arg Ala His Thr Cys Phe Asn Arg Leu Asp Leu Pro Nedd4.1 (AS 847-861)

AAG CTG CCC AGA GCA CAT ACC TGC TTC AAC CGC CTG GAC CTG CCA Nedd4.1 (bp 2539-2583)

C AGA GCA CAT ACC TCC TTC AAC CGC CTG G Mutationsoligo 1252

Arg Ala His Thr $\underset{\star}{\star}$ Phe Asn Arg Leu

Nedd4.1 (AS 850-858)C854S

B

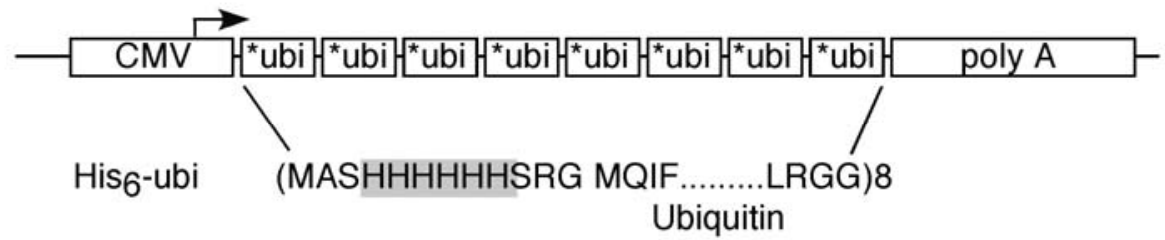

C
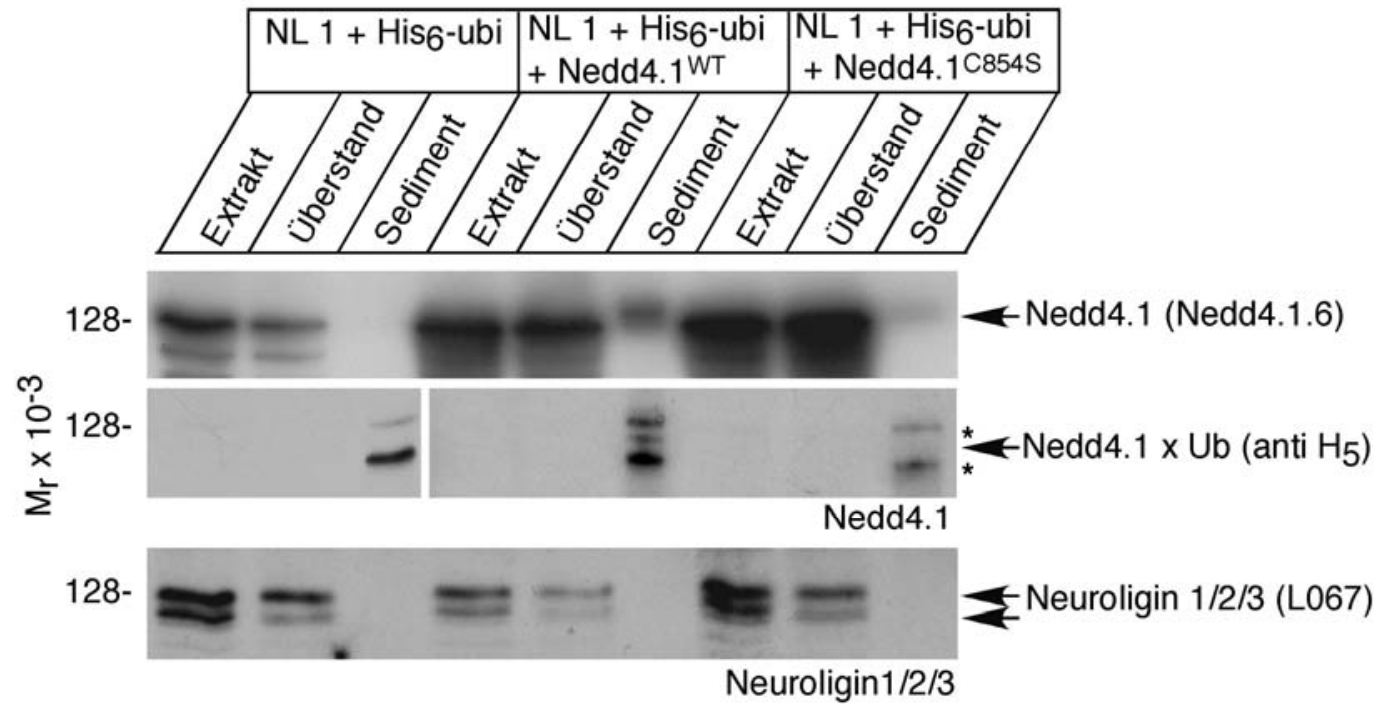

\section{Abb. 13: Die Mutante Nedd4.1 ${ }^{\mathrm{C} 843 \mathrm{~S}}$.}

A: Darstellung der Nedd4.1-Sequenz (bp 2539-2583, Genbanknummer RU50842) und des Mutationsoligonukleotids 1252, das die Substitution des Guanins 2561 durch ein Cystein bewirkt und so den Austausch des katalytisch aktiven Cystein ${ }^{854}$ in der HECT-Domäne durch Serin zur Folge hat. B: Struktur des für die Expression des His 6 -markierten Ubiquitinvorläufers verwendeten Vektorabschnitts. Der Vektor beinhaltet die CMV Promotor/Enhancer-Region (CMV), der die Expression von acht Ubiquitineinheiten mit Nterminalen Markierungen $\left({ }^{*}\right)$ steuert. Unterhalb der Vektorabbildung ist die Sequenz des $\mathrm{His}_{6}$ markierten Ubiquitins aufgeführt. C: Immunpräzipitation aus HEK293-Zelllysat mit His $5^{-}$ Antikörpers (Qiagen). Die Transformation erfolgte mit Kalziumphosphat. In den Zellen wurden Neuroligin 1 und His $_{6}$-markiertes Ubiquitin (siehe B) mit leerem pcDNA3-Vektor, Nedd4 oder Nedd4. $1^{\text {C843S }}$ koexprimiert. Die Zellen wurden nach 48 Stunden geerntet, mit 1\% Triton X-100 solubilisiert und die nicht löslichen Bestandteile durch Ultrazentrifugation abgetrennt. Aus dem Extrakt wurden His $_{6}$-gekoppelte Proteine mit einem kommerziellen His $_{5}$-Antikörper (Qiagen) durch Immunpräzipitation isoliert, per SDS-PAGE aufgetrennt und auf Nitrozellulose transferiert. Die Immundetektionsanalyse erfolgte mit den Antikörpern Nedd4.1.6, 34660 (His 5 , Qiagen) und L067 (Neuroligin 1/2/3). Die Visualisierung immunreaktiver Banden erfolgte durch ECL. 


\subsubsection{Der Einfluß von Nedd4.1 auf die Konzentration von Neuroligin in der Zelle}

Aus den Experimenten von Staub et al. (1996) ist bekannt, daß Nedd4.1 die Expression und Lokalisation des amiloridsensitiven, epithelialen Natriumkanals ENaC reguliert. ENaC wird durch Nedd4.1 ubiquitiniert und in Folge dieser Ubiquitinierung endocytiert und lysosomal abgebaut, was zu einer reduzierten Oberflächenexpression von $\mathrm{ENaC}$ führt (Staub et al. 1997). Mit dem nachfolgend beschriebenen Test sollte herausgefunden werden, ob die Neuroligine einem ähnlichen Effekt unterliegen.

In stabil Neuroligin 1-exprimierenden HEK293-Zellen der Linie B11 wurden der Vektor pcDNA3 ohne Insertion oder mit insertiertem Nedd4.1 bzw. Nedd4.1 ${ }^{\text {C843S }}$ transient überexprimiert und die Konzentration von Neuroligin 1 mittels Immundetektion gemessen (Abb. 14).

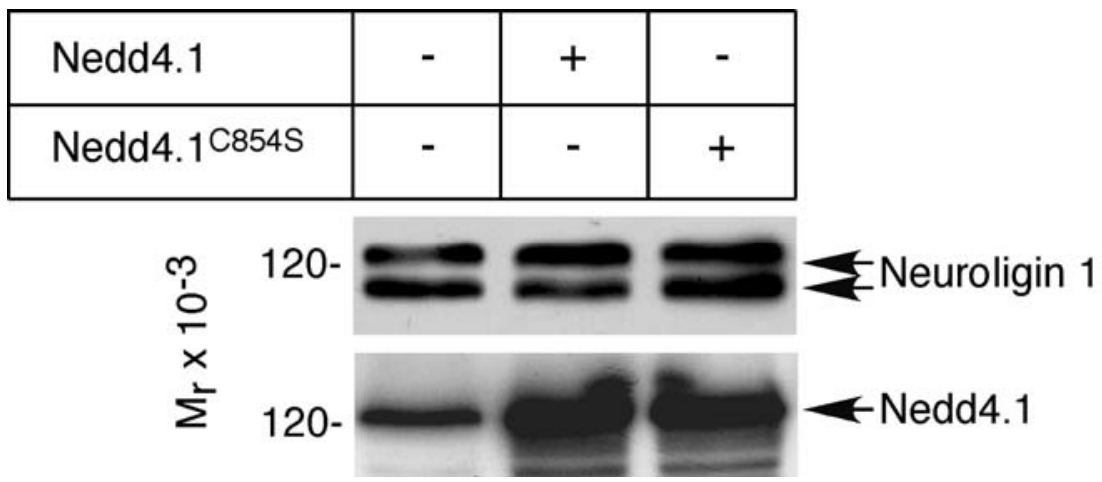

Abb. 14: Der Einfluß von Nedd4.1 auf die Neuroligin 1-Konzentration innerhalb der Zelle.

HEK293-Zellen der stabil Neuroligin exprimierenden Linie B11 wurden mittels der Kalziumphosphatmethode mit pcDNA3, Nedd4.1 oder Nedd4.1 ${ }^{\mathrm{C} 83 \mathrm{~S}}$ transformiert. Nach ca. 48 Stunden wurden die Zellen solubilisiert und in SDS-Probenpuffer aufgenommen. Gleiche Mengen Protein wurden durch SDS-PAGE aufgetrennt, auf Nitrozellulose transferiert und mit Antikörpern gegen Neuroligin und Nedd4 analysiert. Die Visualisierung der Banden erfolgte durch ECL.

Die Expression von Nedd4.1 und der Mutante ist war nachweisbar, die Bande in der Kontrolle ohne Transformation von Nedd4.1 war auf endogenes Nedd4 zurückzuführen. Wie Abbildung 14 zeigt, war die Neuroligin 1-Expression unabhängig von der Koexpression der beiden Nedd4.1-Varianten konstant. Die Daten legen den Schluß nahe, daß die Expression von Neuroligin in HEK293-Zellen keiner strengen Regulation durch Nedd4.1-abhängige Ubiquitinierung unterliegt. Es kann allerdings nicht ausgeschlossen werden, daß die Menge an endogen in HEK293 exprimiertem Nedd4 ausreichte, um einen Nedd4.1-vermittelten, ubiquitinabhängigen Regulationsmechanismus zu saturieren. 


\subsubsection{DHFR-Fusionsproteine als interne Kontrolle}

Die bisher zur Analyse der Ubiquitinierung von Neuroligin 1 durch Nedd4.1 gewählten experimentellen Ansätze sind insofern nicht zwingend schlüssig, als Unterschiede in den Expressionsraten transfizierter Proteine (3.2.10.1) oder niedrige Transfektionsraten (3.2.10.2) zu falsch negativen Ergebnissen führen können. Um diese Frage abschließend zu klären, wurde deshalb ein Ansatz gewählt, in dem das potentiell durch Ubiquitinierung regulierte Protein gleichzeitig und in exakt denselben Mengen mit einem kotransfizierten Kontrollprotein verglichen werden kann. Das verwendete Konstrukt wurde von Prof. Dr. Martin Scheffner zur Verfügung gestellt. Es kodiert für eine Mutante der Dehydrofolatreduktase (DHFR), deren Lysin an der Aminosäureposition 48 gegen Arginin ausgetauscht wurde und deren C-terminales Ende linear mit Ubiquitin fusioniert wurde. Beide Maßnahmen erschweren proteosomale Degradation und tragen zur Stabilisierung des Proteins bei. Für die Detektion des Proteins wurde ein HA-Epitop eingefügt. Neuroligin 1 wurde so hinter die Ubiquitin-cDNA-Sequenz kloniert, daß die DNA-Sequenzen von DHFR, Ubiquitin und Neuroligin als Fusionsprotein translatiert werden. Nach der Synthese eines solchen Fusionsproteins wird das Neuroligin 1 von einer Isopeptidase abgetrennt (Abb. 15A). Der Aufbau des Konstruktes ermöglicht die Herstellung gleicher Mengen stabilisierter DHFR und Neuroligin 1 in der Zelle und so die ratiometrische Bestimmung von Veränderungen der Neuroligin 1-Konzentration.

Das Fusionsprotein wurde mit dem Vektor pcDNA3 ohne insert, sowie mit insertiertem Nedd4.1 bzw. Nedd4.1 ${ }^{\text {C843S }}$ in HEK293-Zellen exprimiert. Die Mengen an DHFR und Neuroligin 1 innerhalb der Zelle wurden nach SDS-PAGE und Transfer auf Nitrozellulose mittels Immundetektion mit Hilfe von Antikörpern gegen das HA-Epitop (für den DHFRNachweis), und Neuroligin 1 miteinander verglichen. Die Nedd4.1-Expression wurde ebenfalls per Immundetektion belegt. Wie Abbildung 15B zu entnehmen ist, war bei keinem der genannten Experimente eine Veränderung der Neuroligin 1-Konzentration relativ zur DHFR-Kozentration zu erkennen. 


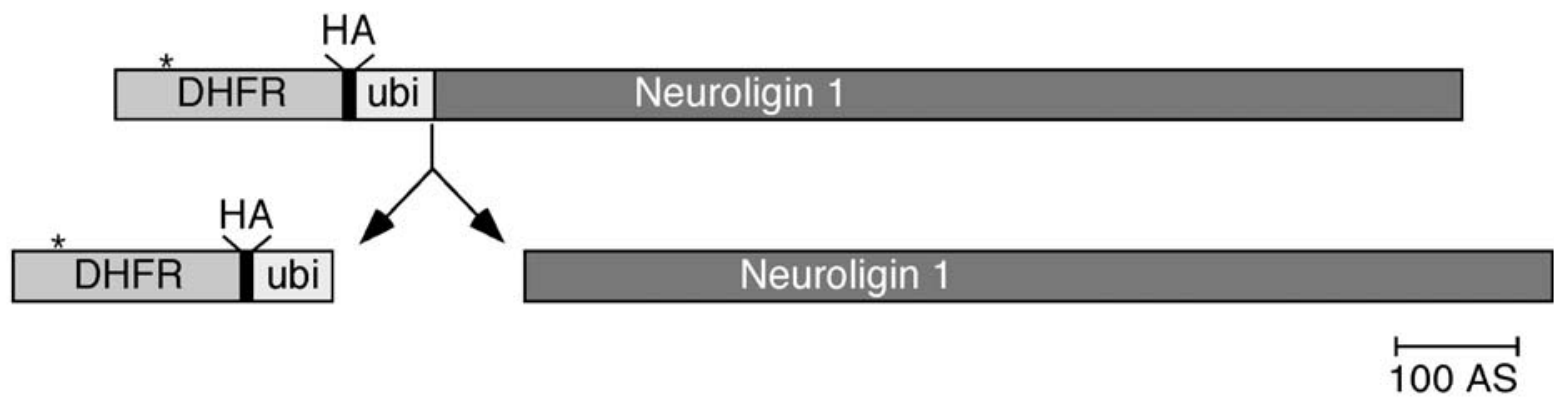

B

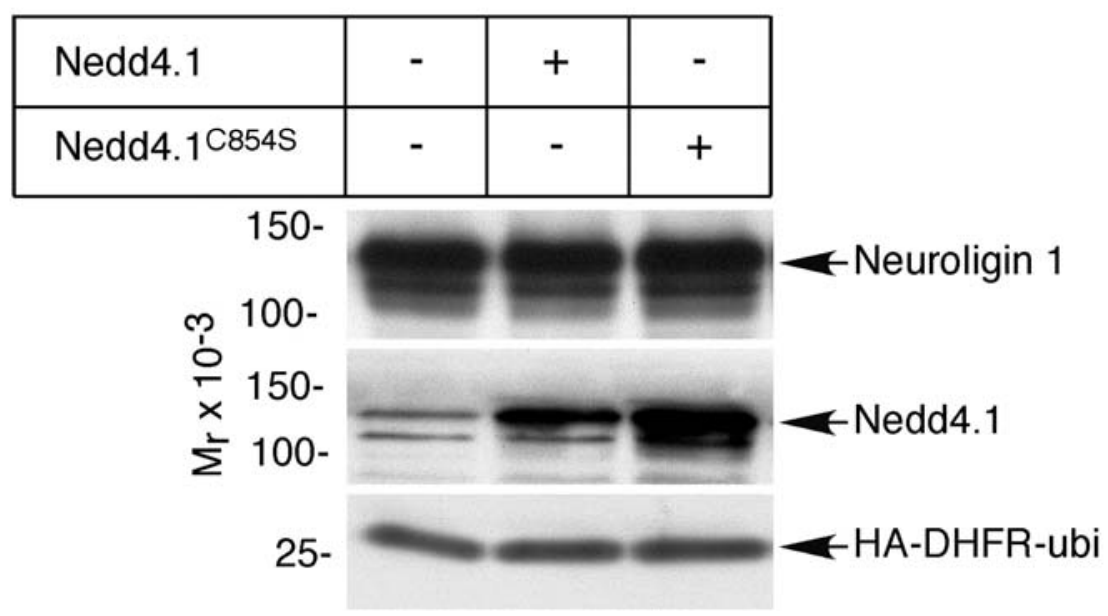

Abb. 15: Das DHFR-Fusionsprotein als interne Kontrolle.

A: Darstellung des DHFR-Fusionsproteins. DHFR: Dehydrofolatreduktase, HA: Influenza Hemaglutinin Epitop, ubi: Ubiquitin. (*) kennzeichnet die L48R-Permutation. B: HEK293Zellen unter Verwendung von Superfect (Qiagen) mit dem unter A gezeigten Konstrukt und mit pcDNA3, pcDNA3-Nedd4.1 oder pcDNA3-Nedd4.1 ${ }^{\mathrm{C} 843 \mathrm{~S}}$ transformiert. Die Zellen wurden geerntet und solubilisiert. Der Proteinextrakt wurde mittels SDS-PAGE aufgetrennt und auf Nitrozellulose transferiert. Die Analyse erfolgte durch Antikörper gegen Neuroligin 1 (4C12), Nedd4.1 (Nedd4.1.6) und das HA-Epitop (MMS-101R, Babco). Die Visualisierung der Banden erfolgte durch ECL.

Gemeinsam mit den unter 3.2.10.1 und 3.2.10.2 beschriebenen Resultaten zeigen diese Daten, daß Nedd4.1 und Neuroligin 1 zwar in vivo miteinander interagieren und im Gehirn weitestgehend kollokalisiert sind, Neuroligin 1 jedoch nicht durch Nedd4.1 überführt und in seiner Expression reguliert wird.

\subsubsection{Die Nedd4.1-Deletionslinie in Mäusen}

Um genaueren Aufschluss über die Funktion von Nedd4.1, seine Rolle während der Entwicklung und mögliche Zielproteine $\mathrm{zu}$ erlangen, wurde mit Hilfe homologer 
Rekombination in ES-Zellen eine Nedd4.1-Deletionsmutationslinie in Mäusen (,knockout“ (KO)-Linie) generiert.

\subsubsection{Strategie der Nedd4.1-Deletion und Generation des Zielvektors}

Die Deletionsmutagenese erfolgt über homologe Rekombination an einer definierten Stelle des Mausgenoms. Es ist daher notwendig, die genomische DNA-Sequenz des anvisierten Bereiches zu kennen. Genomische Nedd4.1-Sequenzen wurden aus einer genomischen Lambda FIX II-Phagen-Bibliothek der Maus isoliert. Die Hybridisierung erfolgte mit den ersten 805 Basenpaaren der cDNA-Sequenz von Nedd4.1, einem HindIII/XbaI-Fragment. Die Inserts der positiven Lamba-Klone wurden durch analytische Restriktionsverdaue miteinander verglichen, anhand von Hybridisierungen mit dem 5'-Ende der cDNA von Nedd4.1 auf Exone getestet und teilweise sequenziert. Zwei der isolierten Klone überlappten im Bereich dreier Exone, die die Basenpaare 460-672 der Nedd4.1 mRNA enthielten. Abbildung 16 zeigt die Anordnung von Restriktionsschnittstellen und Exonen in dem für die Klonierung des Zielvektors verwendeten Bereich.

Der für die Erzeugung der Deletionsmutante verwendete Nedd4.1-Zielvektor wurde in pTKNeo3a kloniert (Abb. 16). Als Selektionsmarker trägt pTKNeo3a eine Neomycinresistenz-Kassette $\left(n e o^{\mathrm{R}}\right)$, die den aufnehmenden Zellen Resistenz gegen Neomycin verleiht. Das Gen steht unter der Kontrolle des Herpes-simplex-Virus-ThymidinkinasePromotors und eines Polyoma-Virus-Enhancers. Die Kassette enthält ferner eine synthetische Translations-Initiationssequenz sowie ein Polyadenylierungssignal. Im Nedd4.1-Zielvektor wurde $n e o^{\mathrm{R}}$ von zwei Fragmenten des Nedd4.1-Gens flankiert, welche die Grundlage für die homologe Rekombination lieferten. Am 5'-Ende der Kassette wurde als so genannter langer Arm ein 5,6 kb großes BHI-Fragment aus dem genomischen Klon pNedd4.1-18-22 eingeführt, am 3'-Ende, als kurzer Arm, der via PCR amplifizierte Bereich zwischen BHI und NheI von 1,4 kb Größe. Nach dem kurzen Arm folgten zwei Thymidinkinase-Kassetten (TK). Diese dienen dem Ausschluß von Zellen, die den Zielvektor ungerichtet insertiert haben. Im Falle der gewünschten, homologen Rekombination wurden die TK-Kassetten nicht in das Genom integriert, da sie außerhalb des homologen Bereiches liegen. Bei den weit häufigeren zufälligen Insertionen führte die TK-Expression bei Zugabe eines synthetischen Guaninanalogs wie Gancyclovir zum Absterben der betroffenen Zelle (Mansour et al., 1988). Die Eliminierung des Proteins erfolgt durch Deletion eines oder mehrerer Exone im vorderen Bereich des Gens im Austausch gegen die $n e o^{\mathrm{R}}$-Kassette. Im vorliegenden Fall führte die 
Elimination zum Abbruch des abgelesenen Transkriptes nach 153 AS. Das Teilprotein ist in der Regel nicht funktionsfähig und wird von der Zelle abgebaut.

\section{Strategie der Nedd4.1 Deletion}
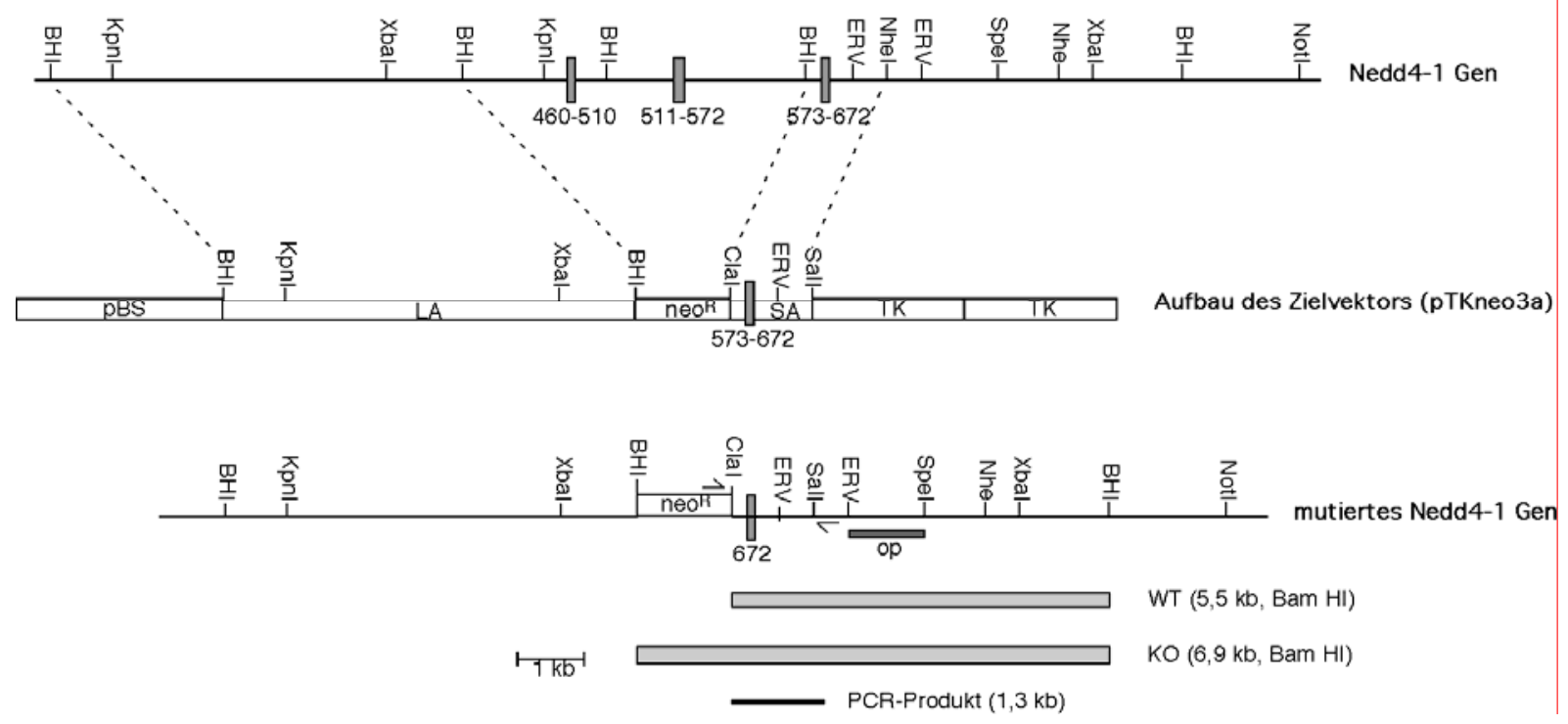

\section{Abb. 16: Strategie der Nedd4.1 Deletion.}

Die Darstellung skizziert oben den für die Herstellung des Zielvektors verwendeten Bereich des Nedd4.1-Wildtyp-Gens. Eingezeichnet sind die kartierten Restriktionsschnittstellen und die Exon/Intronstruktur (oben). In der Mitte ist die Struktur des Zielvektors gezeigt, in diesem ist die Sequenz zwischen langem und kurzen Arm durch die neo ${ }^{\mathrm{R}}$-Kassette ersetzt. Darunter wird die Struktur des aus homologer Insertion des Vektors mutierten Nedd4.1-Gens gezeigt. LA, langer Arm; SA, kurzer Arm; neo ${ }^{\mathrm{R}}$, Neomycinresistenz-Kassette; TK, ThymidinkinaseKassette; OP, Sonde für die Genotypisierung; WT, Wildtyp; KO, Deletionsmutante. Die Pfeile kennzeichnen die Lage der Primer für die Genotypisierungs-PCR, der schwarze Balken zeigt Lage und Größe des resultierenden PCR-Produktes, graue Balken die mit der Sonde hybridisierenden BHI-Fragmente.

\subsubsection{Herstellung rekombinanter ES-Zellen und Aufbau der Mauslinie}

Der Nedd4.1-Zielvektor wurde, wie im Methodenteil (2.2.4.5) beschrieben, in embryonale Mäusestammzellen (ES-Zellen) transformiert und die entstandene Zellpopulation mit Neomycin und Gancyclovir auf homologe Rekombinanten selektiert. Überlebende Klone wurden isoliert und vermehrt. 


\subsubsection{Analyse der ES-Zellen und Generation von Chimären}

Die Aufnahme des Vektors an der vorgesehenen Stelle hatte neben dem Austausch von 4,5 kb Gensequenz gegen die neo ${ }^{\mathrm{R}}$-Kassette auch die Elimination einer BHI-Restriktionsschnittstelle zur Folge. Aufgrund dieser Elimination ist im Fall eines homologen Rekombinationsereignisses an dieser Stelle ein längeres BHI-Restriktionsfragment zu erwarten (6,9 kb statt des 5 kb-Fragmentes im Wildtyp-Gen, Abb. 16). Zur Identifizierung positiver Klone wurde genomische DNA aus den isolierten ES-Zellen einem Restriktionsverdau mit BHI unterzogen und per Gelelektrophorese aufgetrennt. Die DNA wurde im Southernblot-Verfahren mit einem ERV/SpeI-Fragment hybridisiert, das am 3'Ende des kurzen Arms lokalisiert ist und mit dem 6.9 bzw. 5kb großen BHI-Fragment hybridisiert. Parallel wurde zusätzlich ein PCR-Verfahren angewendet. Durch spezifische Oligonukleotide in der neo ${ }^{\mathrm{R}}$-Kassette (Oligo 428) und hinter dem 3'-Ende des kurzen Arms (Oligo 2081) wird in den Zellen, in denen das gewünschte Rekombinationsereignis stattgefunden hat, ein 1,6 kb langes PCR-Fragment amplifiziert. Beispiele für die Analyse der ES-Klone mit beiden Methoden werden in Abbildung 17 gezeigt.

Es konnten in 182 getesteten ES-Zellklonen 18 Positive gefunden werden. Zwei Klone (die Nummern 1C1 und 2H9) wurden zur Erzeugung der Deletionslinie expandiert und für die Injektion in Blastozysten verwendet.

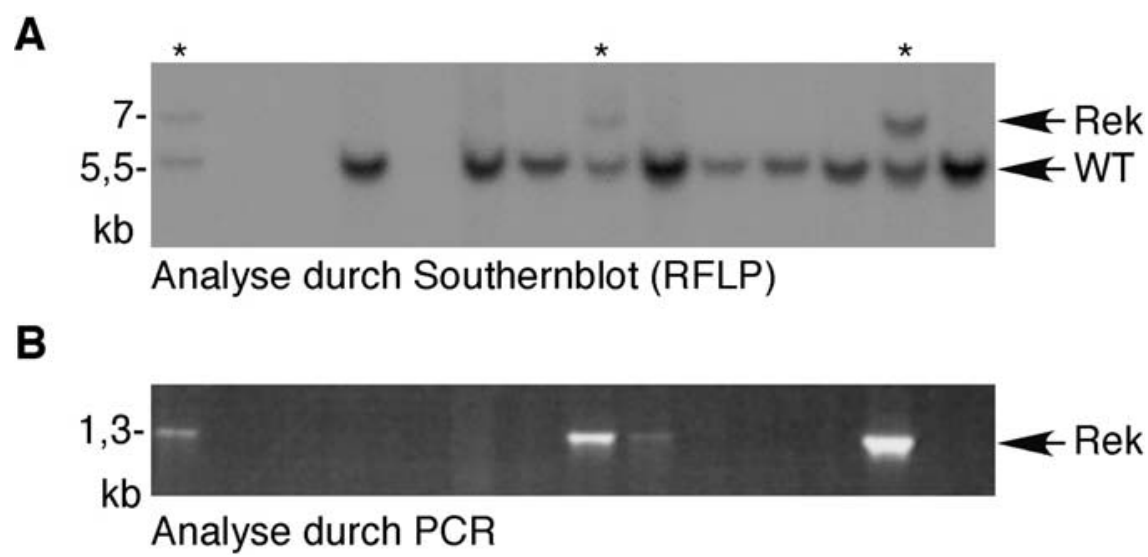

\section{Abb. 17: Genotypisierung der Stammzellen.}

A: Genomische DNA wurde aus den kultivierten Stammzellen gereinigt und einem Restriktionsverdau mit der Endonuklease BHI unterzogen. Die entstehenden Fragmente wurden durch Agarosegelelektrophorese aufgetrennt und auf Nylonmembran transferiert. Relevante Fragmente wurden durch Hybridisierung mit der in Abb. 14 skizzierten Sonde detektiert. Die Visualisierung der Banden erfolgte mittels eines Autoradiogramms. B: PCRAnalyse derselben DNA mit definierten Oligos (siehe Abb. 14). Nachgewiesene homologe Rekombinationsereignisse wurden mit einem Stern $\left(^{*}\right)$ gekennzeichnet. 
Die Blastozysteninjektion und die Verpaarung der Tiere wurde von Mitarbeitern des Tierhauses in Göttingen unter Leitung von Dr. K. Riedesel durchgeführt. Hochgradig chimäre Männchen (> $60 \%$ ) wurden weiterverpaart. In der F1-Generation wurden die ersten heterozygoten Tiere identifiziert, welche die Grundlage für die weitere Zucht darstellten.

\subsubsection{Genotypisierung der Mäuse}

Nach der Entstehung der Nedd4.1-Maus-Deletionslinie und Verifikation der homologen Rekombination per Southernblot und PCR, wurde für die Genotypisierung der Mäuse routinemäßig eine PCR-Strategie auf genomischer DNA aus Schwanzbiopsien oder der Eihülle angewandt. Für das Wildtypallel wurden das Primerpaar 2817/2816, für das mutierte knockout-Allel 428/2816 verwendet. Die Wildtyp-PCR ergibt ein Fragment von 498 bp Länge, die knockout-PCR 478 bp (Abb. 18A).

A

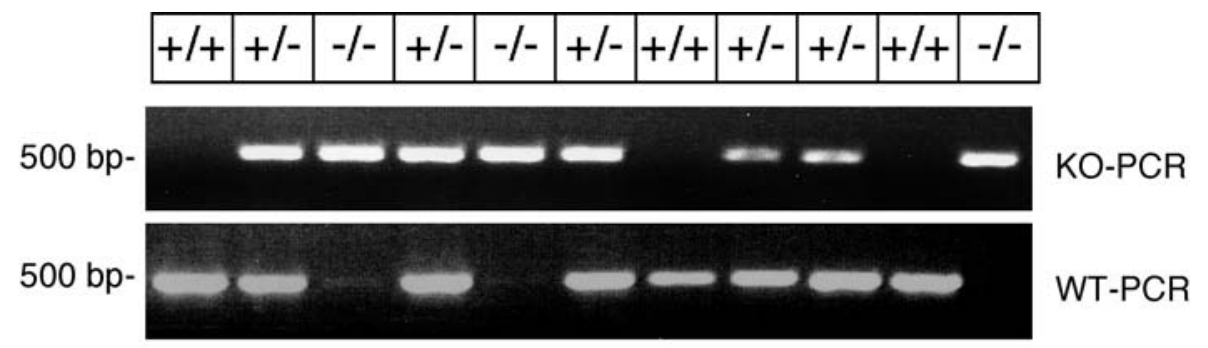

B

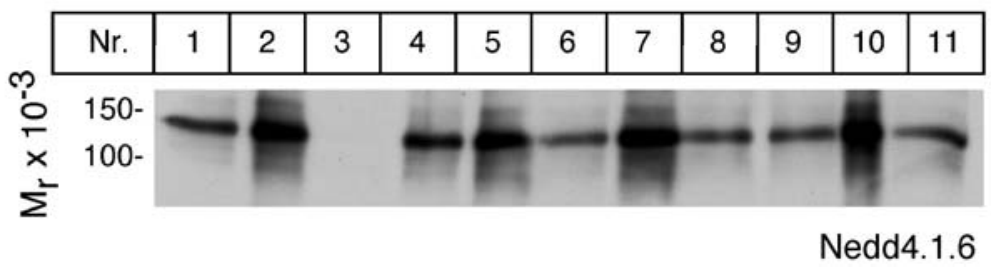

Abb. 18: Genotypisierung der Nedd4.1-Deletionslinie.

A: Genomische DNA von der Eihülle embryonaler Tiere wurde einer PCR mit spezifischen Primerpaaren für Wildtyp- oder knockout-Allel unterzogen. Das PCR-Produkt wurde mit Ethidiumbromid markiert und auf einem Agarose-Gel aufgetrennt. Die Visualisierung der Banden erfolgte mit UV-Licht. Je nach Genotyp erscheinen nur WT- $(+/+)$, nur KO- (-/-) oder beide PCR-Produkte (+/-). WT, Wildtyp; KO, Deletionsmutante. B: Nachweis der Nedd4.1Deletion im Immunoblot. Gleiche Proteinmengen aus Gesamthomogenate von Nachkommen einer Verpaarung von heterozygoten Eltern (embryonaler Tag 13.5) wurden mittels SDSPAGE aufgetrennt und auf Nitrozellulose übertragen. Die Analyse der Membran erfolgte mit dem Antikörper Nedd4.1.6 gegen Nedd4.

Abbildung 18B zeigt die Deletion von Nedd4.1 im Immunoblot. Hierfür wurden Gesamthomogenate von Nachkommen einer Verpaarung von heterozygoten Eltern (embryonaler Tag 10.5) in gleicher Gesamtproteinmenge mittels SDS-PAGE aufgetrennt und 
auf Nitrozellulose übertragen. Die Analyse erfolgte mit dem Antikörper Nedd4.1.6 gegen Nedd4.1 Die Genotypisierung der ersten acht Würfe sind in Tab. 2 aufgeführt.

Tab. 2: Statistik der ersten acht Würfe aus der F2-Generation der Nedd4.1Deletionslinie.

Während das Auftreten der Wildtyp (+/+) bzw. heterozygoten Tiere (+/-) der zu erwartenden 1:2:1-(+/+:+/-:-/-)-Verhältnis entspricht, läßt die Abwesenheit von homozygoten KO-Tieren (/-) auf einen Absterben in der embryonalen Phase oder während der Geburt vermuten. Die Genotypisierung erfolgte durch PCR mit spezifischen Primern auf Basis genomischer DNA von Schwanzbiobsien etwa drei Wochen alter Tiere.

\begin{tabular}{|c|c|c|c|c|c|c|c|}
\hline $\begin{array}{c}\text { Genotyp } \\
\text { Anzahl je Wurf }\end{array}$ & $+/+$ & $\begin{array}{c}\text { davon } \\
\text { tot }\end{array}$ & $\begin{array}{c}+/- \\
\text { davon } \\
\text { tot }\end{array}$ & $\begin{array}{c}-/- \\
\text { davon } \\
\text { tot }\end{array}$ & $\begin{array}{c}\text { nicht ermittelbar } \\
\text { (tot geboren) }\end{array}$ \\
\hline 3 & 1 & - & 2 & - & - & - & - \\
\hline 2 & 1 & - & - & - & - & - & 1 \\
\hline 2 & - & - & 2 & 2 & - & - & - \\
\hline 4 & 1 & - & 3 & - & - & - & - \\
\hline 6 & 1 & - & 5 & - & - & - & - \\
\hline 5 & 1 & 1 & 2 & 1 & - & - & 2 \\
\hline 5 & 2 & - & 4 & - & - & - & - \\
\hline 6 & 1 & - & 4 & 2 & - & - & 1 \\
\hline$\sum 34$ & $\sum 8$ & $\sum 1$ & $\sum 22$ & $\sum 5$ & $\sum 0$ & $\sum 0$ & $\sum 4$ \\
\hline $\boldsymbol{\varnothing} 4,25$ & $\mathbf{0 , 8}$ & $:$ & $\mathbf{2 , 2}$ & $\mathbf{2}$ & $\mathbf{0}$ & & $\mathbf{0 , 4}$ \\
\hline
\end{tabular}

Die durchschnittliche Wurfgröße betrug 4,25 Tiere, die geringe Anzahl von Nachkommen erhöhte sich im Verlauf der Züchtung von anfänglich zwei bis drei Jungen auf vier bis fünf. Bei jungen Mausmüttern ist eine kleinere Nachkommenzahl normal, trotzdem bleiben die beobachteten Würfe weit unter der üblichen Zahl von 10-12 Jungen zurück. Betrachtet man die Genotypverteilung der ersten acht Würfe der F2-Generation, so fällt auf, daß das Auftreten von Wildtyp- und heterozygoten Tieren im Mittel etwa der nach Mendel zu erwartenden Relation von 1:2 (+/+:+/-) entsprechen. Es konnten aber keine deletionsmutierten Nachkommen identifiziert werden (Tab. 2). Hinzu kam ein überdurchschnittlich hoher Anteil totgeborener, bzw. vorzeitig abgestorbener heterozygoter Tiere. Der Befund legte die Vermutung nahe, daß die Tiere mit homozygoter Nedd4.1-Deletion bereits in der embryonalen Phase oder während der Geburt starben.

Um diese Vermutung zu überprüfen, wurden F1-Nachkommen unterschiedlichen Alters genotypisiert (Tab. 3). Bei den Untersuchungen wurde einer hohe Anzahl absorbierter Embryonen beobachtet. 
Tabelle 3: Zusammenfassung von Genotypisierungen in verschiedenen Altersstufen. Embryonen der angegebenen Altersstufen, Neugeborene und drei Wochen alte Tiere der F2Generation wurden durch PCR mit spezifischen Primern auf Basis genomischer DNA der Eihülle oder von Schwanzbiobsien der Tiere genotypisiert. Die älteste, lebende Maus mit homozygoter Nedd4.1-Deletion wurde am embryonalen Tag 18.5 identifiziert. E, embryonaler Tag; P, postnataler Tag.

\begin{tabular}{|c|c|c|c|c|c|}
\hline Alter/Genotyp & $+/+$ & $+/-$ & $-/-$ & Absorbiert & $\begin{array}{c}\text { Anzahl der } \\
\text { Würfe }\end{array}$ \\
\hline E10.5 & 6 & 7 & 2 & 3 & 1 \\
\hline E13.5 & 6 & 12 & 1 & 3 & 1 \\
\hline E16.5 & 6 & 5 & 5 & 4 & 1 \\
\hline E18.5 & 11 & 18 & 1 & - & 2 \\
\hline P0 & 8 & 17 & 0 & - & 2 \\
\hline P21 & 25 & 65 & 0 & - & 8 \\
\hline
\end{tabular}

\subsubsection{Biochemische Analyse der heterozygoten Tiere}

Der Phänotyp der heterozygoten Nachkommen unterschied sich nicht von dem der WildtypTiere, sie waren normal groß, fertil und zeigen keine Entwicklungsstörungen. Das Verhalten der Tiere war normal, weder verstärkt aggressiv, noch sozial benachteiligt. Das Aufzuchtverhalten der heterozygoten Muttertiere zeigte keine Auffälligkeiten.

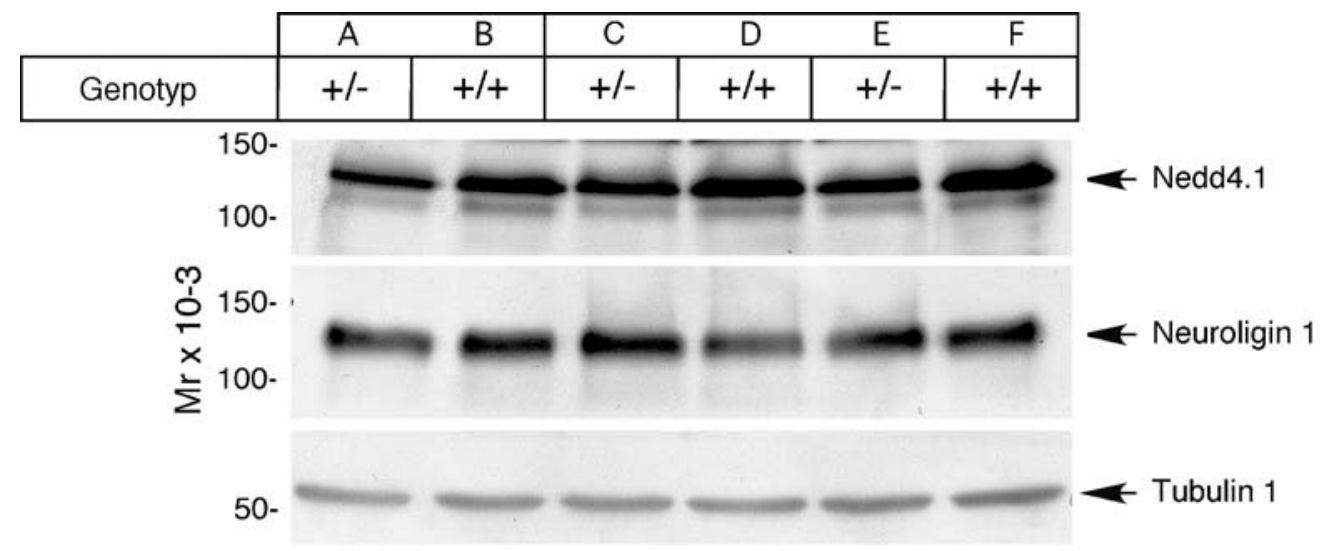

Abb. 19: Immundetektionsnachweis von Nedd4.1 im Gehirn von heterozygoten Nedd4.1Deletionsmutanten.

Gehirnhomogenate gleicher Proteinkonzentrationen von homo- und heterozygoten Tieren (P51) wurden mit SDS-PAGE aufgetrennt, auf Nitrozellulose transferiert und mit Antikörpern gegen Nedd4, Neuroligin 1 und Tubulin 1 (als Ladekontrolle) untersucht. Immunreaktive Banden wurden mit ECL visualisiert. Die Analyse der Nedd4.1-Konzentration ergab einen Gen-Dosis-Effekt mit geringeren Ned4.1-Mengen in heterozygoten Mutanten. Die Menge des enthaltenen Neuroligin 1 blieb unverändert. 
Für die Analyse der Nedd4.1-Expression wurde Gesamtgehirnhomogenat von heterozygoten Tieren zweier Würfe gleichen Alters (P51) der F2-Generation durch SDS-PAGE aufgetrennt, auf Nitrozellulose transferiert und mit Antikörpern gegen Nedd4.1 mittels Immundetektion analysiert. Der Vergleich der Nedd4.1-Expression durch Immundetektion, ergab einen GenDosis-Effekt (Abb. 19). Der Gehalt an Nedd4.1-Protein in den Gehirnen der heterozygoten Tieren war geringer als der von Tieren mit zwei Allelen des Nedd4.1-Gens.

Bei Analyse derselben Proben mit dem Antikörper 4C12 gegen Neuroligin 1,-2 und -3 konnte trotz der Verringerung der Nedd4.1-Konzentration keine Veränderung der Neuroligin-Menge im Gehirn der heterozygoten Tiere festgestellt werden.

\subsubsection{Die homozygoten Nedd4.1-knockout-Tiere}

\subsection{Phänotyp}

Da keine lebend geborenen homozygoten KO-Mäuse gefunden wurden, sind die Embryonen der Nedd4.1-Deletionsmutante analysiert worden. Die detaillierte Analyse der Linie ist noch nicht abgeschlossen, im Rahmen der vorliegenden Arbeit sollen an dieser Stelle die vorläufigen Erkenntnisse aber nicht unerwähnt bleiben. Das älteste lebende KO-Tier ist am embryonalen Tag 18,5 durch PCR auf Basis von DNA aus der Eihülle identifiziert worden. Photographien homozygoter Tiere liegen von E13,5 und E16,5 vor (Abb. 20). Augenscheinlich entwickeln sich die Tiere normal. So sind die Entwicklungen der Extremitäten und der Augen vollständig. Auffallend ist allerdings, daß die Tiere kleiner sind als ihre Geschwister (Abb. 20B). Dieser Größenunterschied ist schon am embryonalen Tag 13,5 offensichtlich und am embryonalen Tag 26,5 stark ausgeprägt. Auffällig ist außerdem, daß die Vaskularisierung der Eihülle homozygoter Tiere stark reduziert ist (Abb. 20). 


\section{$\mathrm{E} 13,5$}

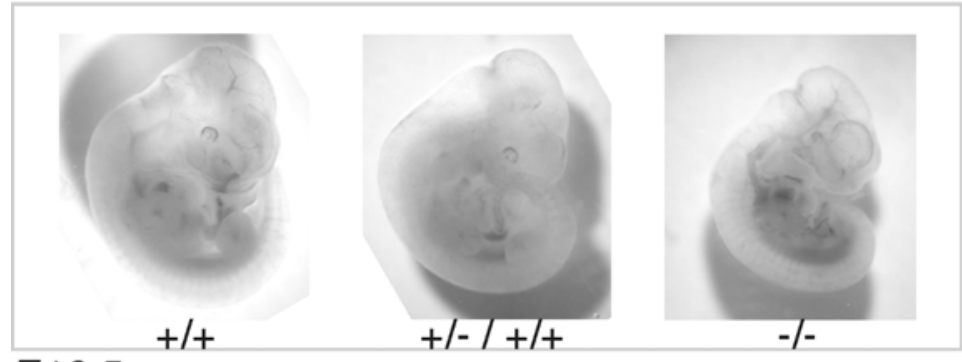

$\mathrm{E} 16,5$

$+1+\quad+/-1+/+2$

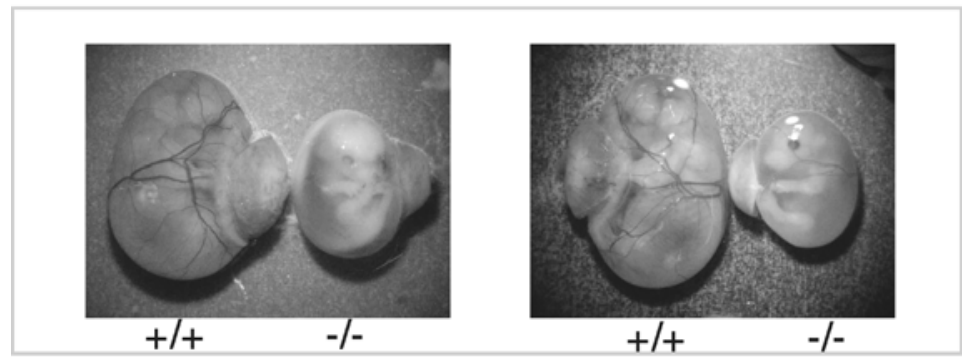

Abb. 20: Phänotyp der Nedd4.1-KO-Mäuse.

Die abgebbildeten Mäuseembryonen sind Wurfgeschwister und repräsentieren Wildtyp-, Heterozygote und KO-Tiere am embryonalen Tag 13,5 und 16,5. E, embryonaler Tag.

\subsection{Die Neuroligin -Konzentration in homozygoten Nedd4.1-Deletionsmutanten}

Die Ergebnisse der vorliegenden Arbeit zeigten die Interaktion von Neuroligin 1 und -2 mit Nedd4.1 in vitro und in vivo. Die funktionellen Analysen (3.2.10) konnten nicht belegen, daß die Interaktion zwischen Nedd4.1 und Neuroligin zur ubiquitinabhängigen Reduktion der Neuroligin 1-Moleküle führt.

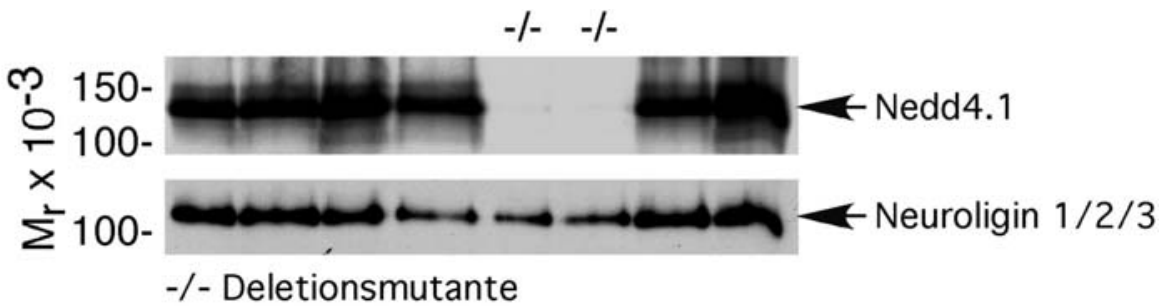

Abb. 21: Immundetektionsnachweis von Nedd4.1 und Neuroligin in Nedd4.1deletionsmutanten Embryonen.

Gesamthomogenate von Nachkommen einer Verpaarung von heterozygoten Eltern (embryonaler Tag 10.5) gleicher Proteinkonzentration wurden mittels SDS-PAGE aufgetrennt und auf Nitrozellulose übertragen. Die Analyse erfolgte mit Antikörpern gegen Nedd4.1 und Neuroligin, wie angegeben. E, embryonaler Tag. 
Um zu testen, ob sich dies auch im Mausmodell bestätigt, wurde die NeuroliginKonzentration in den homozygoten Nedd4.1-Deletionsmutanten überprüft. Hierfür wurden Gesamthomogenate von Embryonen $(E 10,5)$ eines Wurfes mittels des Immunoblotverfahren mit Antikörpern gegen Nedd4.1 und Neuroligin untersucht (Abb. 21). Es konnte kein signifikanter Unterschied bei der Neuroligin-Konzentration zwischen den Genotypen festgestellt werden.

\subsection{Protein 4.1N und Protein 4.1B}

\subsubsection{Die Interaktion von Neuroligin mit Protein 4.1N und Protein 4.1B im Hefe- Doppelhybridsystem}

In den unter 3.1 beschriebenen Hefeexperimenten sind sechs Klone gefunden worden, die homolog zu Mitgliedern der Protein 4.1-Familie sind. Sie bildeten vier unabhängige Gruppen, je zwei für Protein 4.1N und Protein 4.1B, deren Sequenzen sich alle im Bereich der hochkonservierten C-terminalen Domäne (CTD) überschneiden (Abb. 22A und B). Diese ist bereits als Bindedomäne im Zusammenhang mit anderen interagierenden Transmembranproteinen, z. B. $\beta$-Neurexin mit Protein 4.1N (Biederer und Südhof, 2001) beschrieben worden und findet sich in allen 4.1-Proteinen. Obwohl alle Klone im Neuroligin 1-Experiment gefunden worden sind, binden diese auch an den cytoplasmatischen Bereich von Neuroligin 2 (Abb. 22C).

Auf der Seite von Neuroligin ist die Beschreibung der Interaktionsbereiche komplexer. Die Elimination der letzten drei Aminosäuren, der Erkennungssequenz für die PDZ-Domänen der MAGuK-Proteine, änderte erwartungsgemäß nichts an der Interaktion mit Protein 4.1B und Protein 4.1N. Die Verkürzung um weitere drei Aminosäuren führte zur Inaktivierung des Konstruktes im Hefe-Doppelhybridsystem. Die genaue Identifizierung des Konsensus der Bindesequenz für die 4.1-Proteine war daher mit dem Hefe-Doppelhybridsystem nicht möglich, wurde aber mit einem differenzierten Ansatz (3.3.3) erreicht. 
A

Protein 4.1B (1105 AS) 4.1 HD

\begin{tabular}{l|l|l} 
SABD & CTD \\
\hline
\end{tabular}

pVP16-3-4.1B/1-147

pVP16-3-4.1B/1-113

pVP16-3-4.1B/1-131

pVP16-3-4.1B/1-135

B

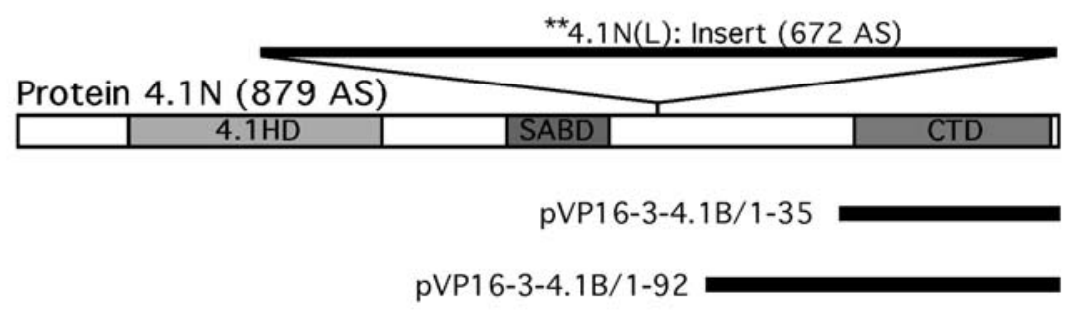

pVP16-3-4.1B/1-92

$\stackrel{\longmapsto}{100 \mathrm{AS}}$

C

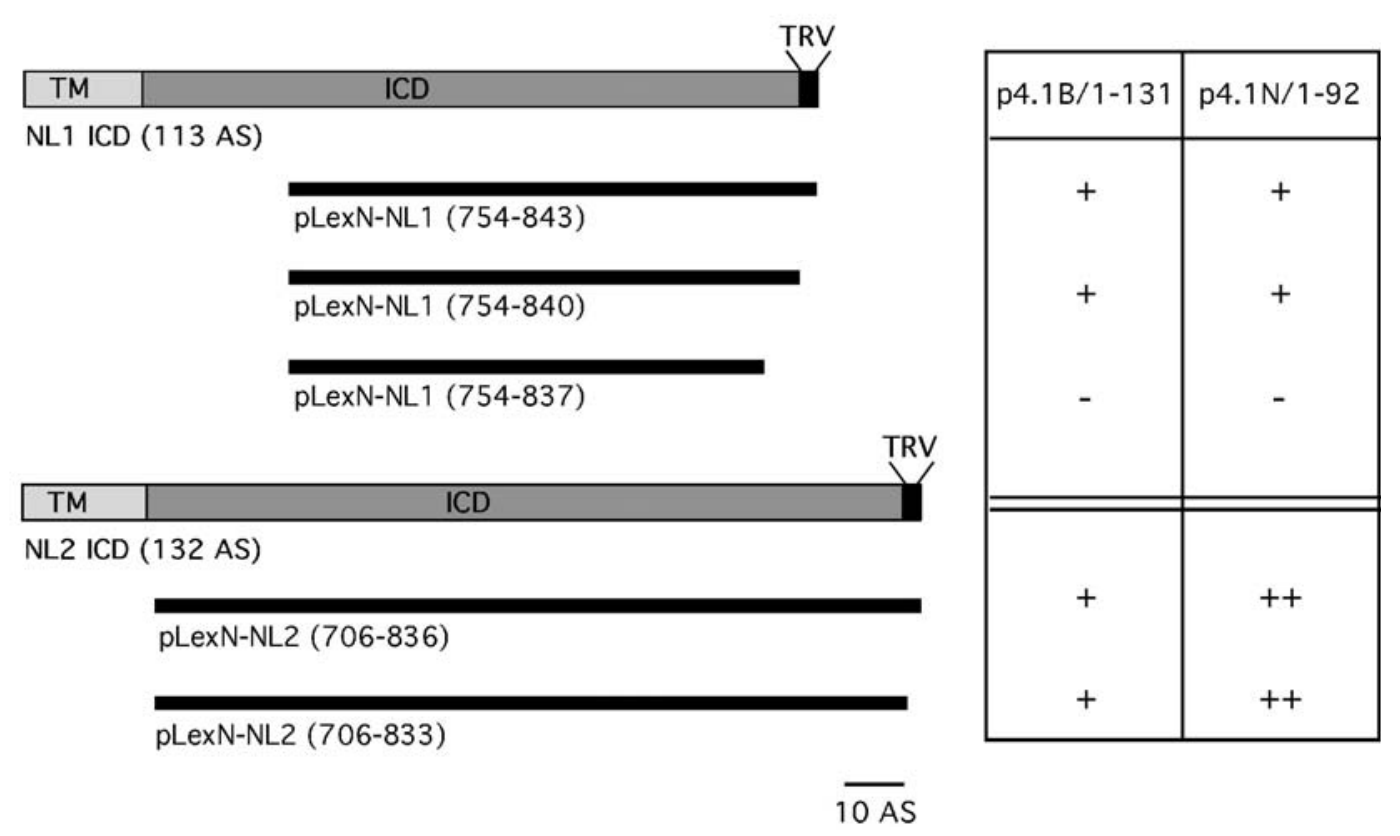

Abb. 22: Struktur der im Hefe-Doppelhybridsystem identifizierten 4.1-Klone.

Schematische Darstellung der Proteine 4.1B (A) und Protein 4.1N (B). Die Domänen sind grau unterlegt, die Lage der identifizierten pVP16-3-Klone durch Balken gekennzeichnet. 4.1HD, 4.1-Homologiedomäne oder FERM-Domäne; SABD, Spectrin/Actin Bindedomäne; CTD, C-terminale Domäne.

C: Die skizzierten Neuroligin-Konstrukte wurden mit p4.1N/1-92 und p4.1B/1-131 in Hefen kotransformiert und die rekombinanten Hefen einem $\beta$-Galaktosidase-Filtertest unterzogen. -, negativ; +, positiv; ++, stark positiv. In Klammern die im Konstrukt enthaltenen Aminosäuren von Neuroligin 1 und Neuroligin 2. 


\subsubsection{Die Protein 4.1-Antikörper}

Unter Verwendung von GST-Fusionsproteinen als Antigen (GST-4.1B/1-147, AS 806-1260 und GST-4.1N/1-92, AS 696-879) wurden je zwei Antiseren gegen Protein 4.1N und Protein 4.1B in Kaninchen erzeugt.

Die Antikörper gegen Protein 4.1B tragen die Namen 4.1B17 und 4.1B18. Sie erkennen rekombinantes 4.1B im Lysat transient transformierter HEK293-Zellen sowie eine Doppelbande von etwa 120 und $140 \mathrm{kDa}$ in einem synaptosomalen Extrakt (P2; Abb. 23). Diese stimmt mit der berechneten Größe der beiden Spleißvarianten und dem Bandenmuster der veröffentlichten Antikörper überein (Parra et al., 2000).

Die Antikörper gegen Protein 4.1N wurden 4.1N21 und 4.1N22 genannt. Im Westernblot auf Synaptosomenextrakt detektieren sie zwei Banden über und unterhalb des Markers von etwa 110 und $90 \mathrm{kDa}$, die Spleißvarianten der kleineren Isoform (97 kDa) von Protein $4.1 \mathrm{~N}$ sind (Walensky et al. 1999). Die größere Isoform von Protein 4.1N wird von den Antikörpern im Synaptosomenextrakt nicht erkannt, eventuell weil diese im verwendeten Gewebe nicht oder nur wenig exprimiert wird. Rekombinantes Protein 4.1N-L, der großen Isoform, wird jedoch von beiden Antiseren detektiert. Der Antikörper 4.1N22 ist spezifisch für 4.1N, 4.1N21 kreuzreagierte mit rekombinantem 4.1B (Abb. 23).

In den nachfolgend beschriebenen Experimenten wurden, falls nicht anders erwähnt, die Antikörper 4.1B17 und 4.1N22 verwendet. 

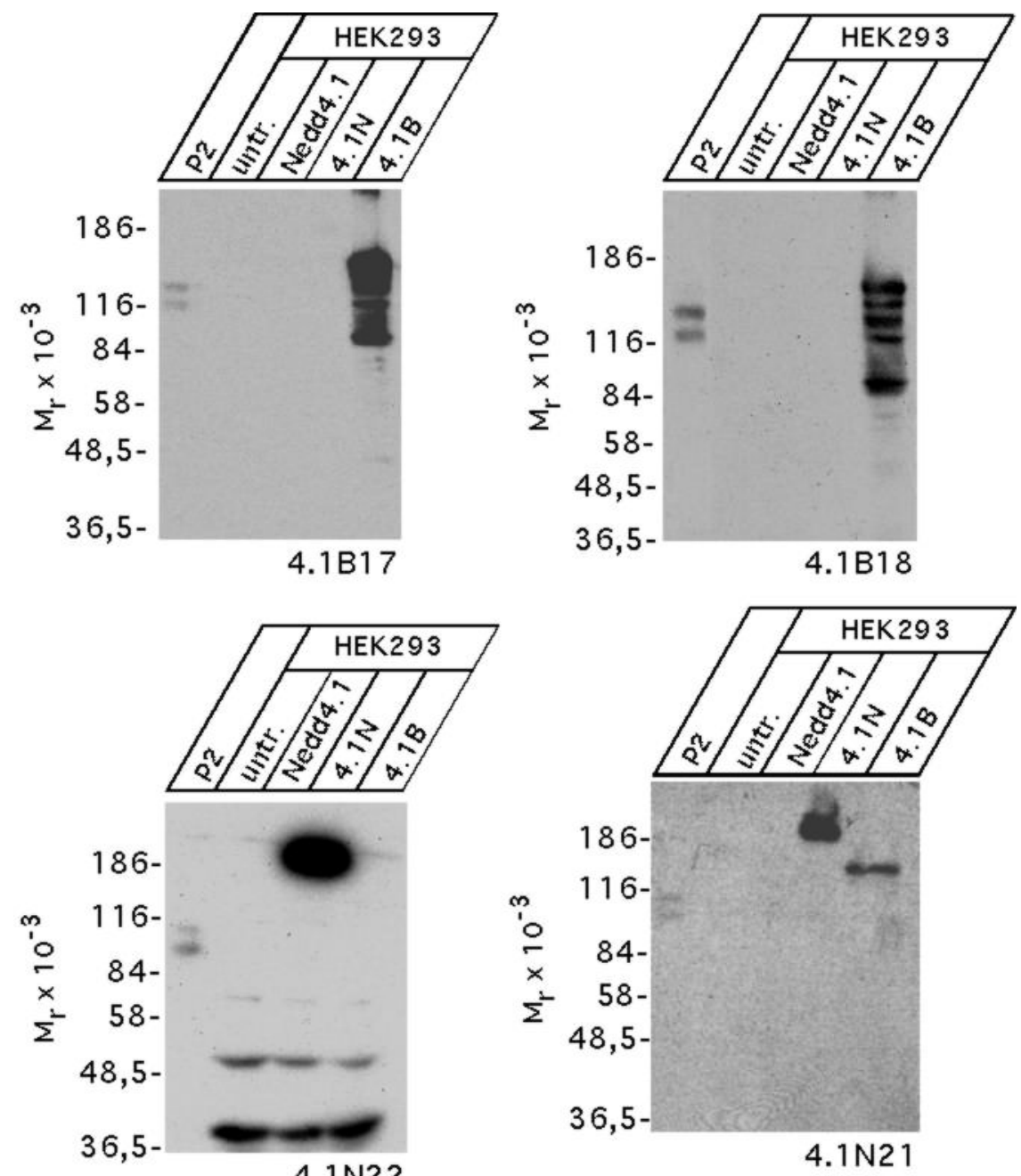

Abb. 23: Die Protein 4.1-Antikörper.

Die Antiseren 4.1B17, 4.1B18, 4.1N21 und 4.1N22 wurden auf einem Extrakt ungereinigter Synaptosomen (P2) sowie auf solubilisierten HEK293-Zellen getestet, die nicht, mit einem nicht verwandten Protein (Nedd4.1) oder mit Protein 4.1N bzw. Protein 4.1B transformiert worden waren. Immunreaktive Banden wurden mit ECL visualisiert.

\subsubsection{Lokalisation der 4.1-Bindestelle auf der intrazellularen Domäne von Neuroligin 1}

Wie unter 3.3.1 beschrieben, konnte die Kartierung der Protein 4.1-Bindestelle in der Neuroliginsequenz nicht mit Methoden des Hefe-Doppelhybridsystems erreicht werden. Um $\mathrm{zu}$ analysieren, welche Sequenzbereiche von Neuroligin 1 die Bindung an Protein 4.1 vermitteln, wurde daher eine Oligoeptid-spot-Membran verwendet. Die kommerziell erworbene Membran trug 102 überlappende Peptide, die jeweils 18 Aminosäuren der intrazellulären Domäne von Neuroligin 1 trugen. Die Peptide waren so angeordnet, daß sich die Sequenz von Punkt zu Punkt jeweils um eine Aminosäure verschob. Die so erhaltene Membran wurde mit GST-Fusionsprotein der C-terminalen Domäne von Protein 4.1B 
(p4.1B/1-147, AS 806-1260) inkubiert und gewaschen. Gebundenes Fusionsprotein wurde anschließend mit Hilfe des Antikörpers 4.1B17 nachgewiesen und mittels Immunoblot detektiert. Das Ergebnis der Immundetektion zeigt Abbildung 24A, die markierten Aminosäurebereiche sind Abbildung 24B illustriert. Mit diesem Verfahren wurden in der intrazellulären Domäne von Neuroligin 1 zwei Interaktionsbereiche detektiert. Der Erste liegt nahe bei der Transmembrandomäne zwischen den Aminosäuren 726 und 739 mit einer Minimalsequenz zwischen den Aminosäuren 729 und 735 der Proteinsequenz von Neuroligin 1. Der zweite Bereich bildet sich aus zwei überlappenden positiven Sequenzen zwischen Aminosäure 762 und 795, ihre Minimalsequenzen liegen zwischen den Aminosäure 763 und 775, sowie Aminosäure 778 und 788.

A

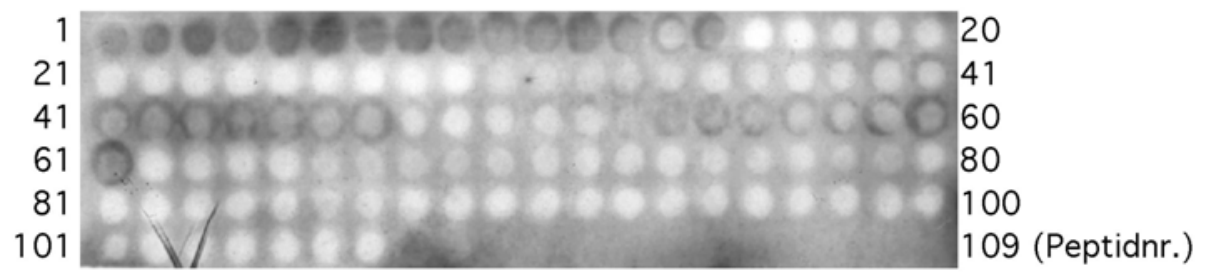

B

\title{
718 YYKKDKRRHDVHRRCSPQRTTTNDLTHAPEEEIMSLQMKHTD 759 760 LDHECESIHPHEVVLRTACPPDYTLAMRRSPDDYPLMTPNTI 808 \\ 809 TMIPNTIPGIQPLHTFNTFTGGQNNTLPHPHPHPHSHSTTRV 843
}

\begin{abstract}
Abb. 24: Detektion der Protein 4.1-Bindestelle auf der intrazellulären Domäne von Neuroligin 1.

A: Eine spot-Membran mit überlappende 18meren Polypeptiden der intrazellulären Domäne von Neuroligin 1 (Jerini, Berlin) wurde mit gereinigtem GST-Fusionprotein (p4.1B/1-147, AS 806-1260) inkubiert und anschließend gewaschen. Das auf der Membran gebundene Fusionsprotein wurde mit dem Antikörper 4.1B17 detektiert. Die Visualisierung immunreaktiver Spots erfolgte durch ECL. B: Illustration der positiven Bereiche der intrazellulären Domäne von Neuroligin 1 (AS 718-843). Die positiven Bereiche wurden hellgrau, die Minimalsequenzen, die in allen markierten Peptiden vollständig enthalten sind, wurden dunkelgrau unterlegt.
\end{abstract}

\subsubsection{Koimmunpräzipitation von Protein 4.1B mit Neuroligin-Antikörper}

Um die in den Hefe-Doppelhybridexperimenten nachgewiesene Interaktion zwischen den 4.1Proteinen und den Neuroliginen zu verifizieren, wurde eine Immunpräzipitation mit dem pan- 
Neuroligin-Antikörper L067 durchgeführt. Der Antikörper wurde, wie unter 3.2.3 beschrieben, an Protein-G-Sepharose gebunden und mit einem synaptosomalen Extrakt inkubiert. Der Proteinextrakt, der Überstand nach der Präzipitation sowie das Sediment, in dem der Antikörper, Neuroligin und die mit Neuroligin interagierenden Proteinen enthalten waren, wurden in SDS-Probenpuffer aufgenommen, durch SDS-PAGE aufgetrennt und auf Nitrozellulose transferiert. Die Membran wurde mit den Antikörpern 4.1B17 und 4F9 (antiNeuroligin 1/2/3) analysiert. Als Kontrolle diente eine Immunpräzipitation unter den gleichen Bedingungen bei Verwendung eines Antikörpers, der Neuroligin nicht präzipitiert (4C12). Protein 4.1B wurde mit Neuroligin kopräzipitiert, nicht jedoch im Kontrollexperiment. Die erfolgreiche Präzipitation von Neuroligin durch L067, nicht jedoch durch den Kontrollantikörper, wurde durch die Analyse des Blottes mit dem Neuroligin-Antikörper 4F9 nachgewiesen.

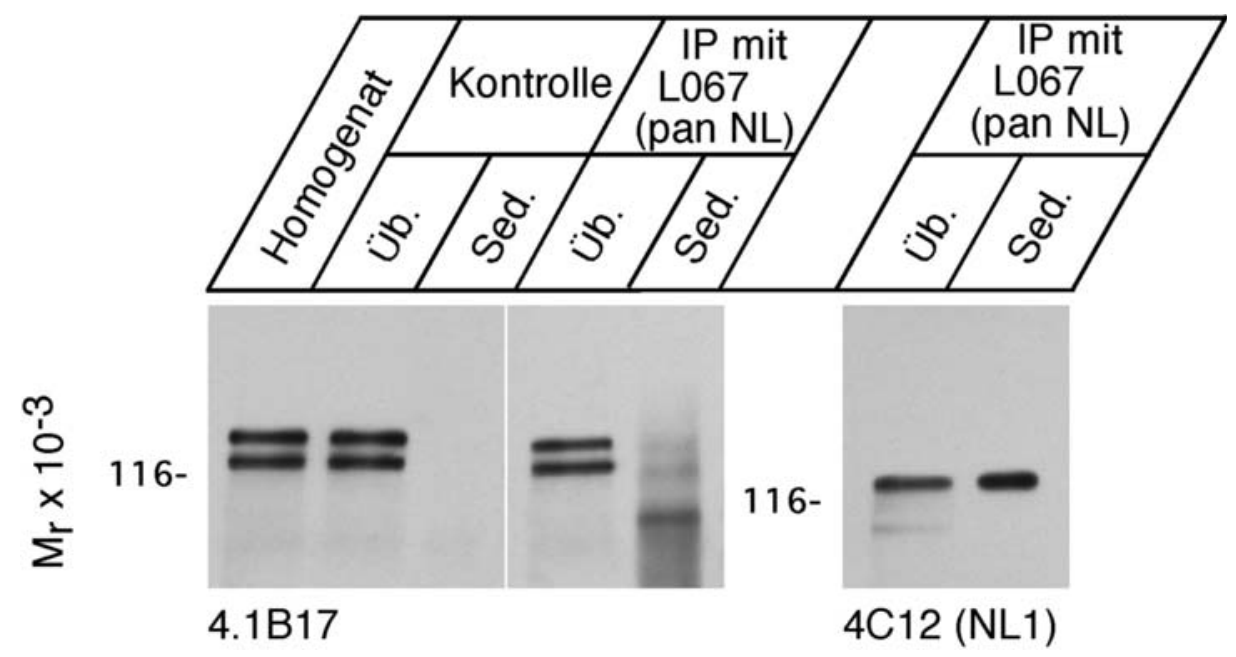

Abb. 25: Koimmunpräzipitation von Protein 4.1B mit Neuroligin-Antikörper.

Der Antikörper L067 gegen Neuroligin 1, -2, -3 wurde an Protein-Sepharose immobilisiert und mit einem Extrakt ungereinigter Synaptosomen inkubiert und gewaschen. Aufgetragen sind Extrakt, Überstand und Sediment. Analysiert wurde mit Antiseren gegen Protein 4.1B und Neuroligin 1, -2 und -3. Als Kontrolle diente eine Immunpräzipitation mit dem Antikörper 4C12, der Neuroligin nicht präzipitiert. Immunreaktive Banden wurden mit ECL visualisiert.

\subsubsection{Gewebeverteilung von Protein 4.1B und Protein 4.1N}

Um die Verteilung der Proteine 4.1N und 4.1B innerhalb der Gewebe mit der von Neuroligin zu vergleichen, wurden Expressionsmuster der 4.1-Proteine in der Ratte auf mRNA- und Proteinebene untersucht (Abb. 26A). Die mRNA-Analyse zeigte die Expression beider Proteine im Gehirn und der Niere, Protein 4.1N war außerdem im Herz, der Lunge, der Leber 
und Testis zu finden. Von beiden Proteinen existierten mehrere Transkripte sowie Spleiß- und Polyadinylierungs-Varianten, deren stärkste Expression jeweils im Gehirn zu beobachten war (Abb. 26).

\section{A Northernblot}

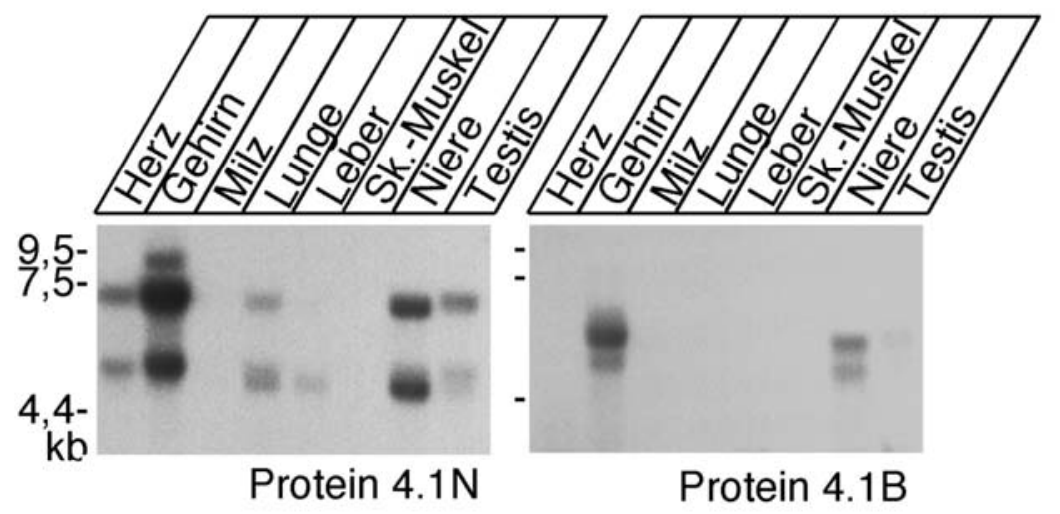

B Westernblot
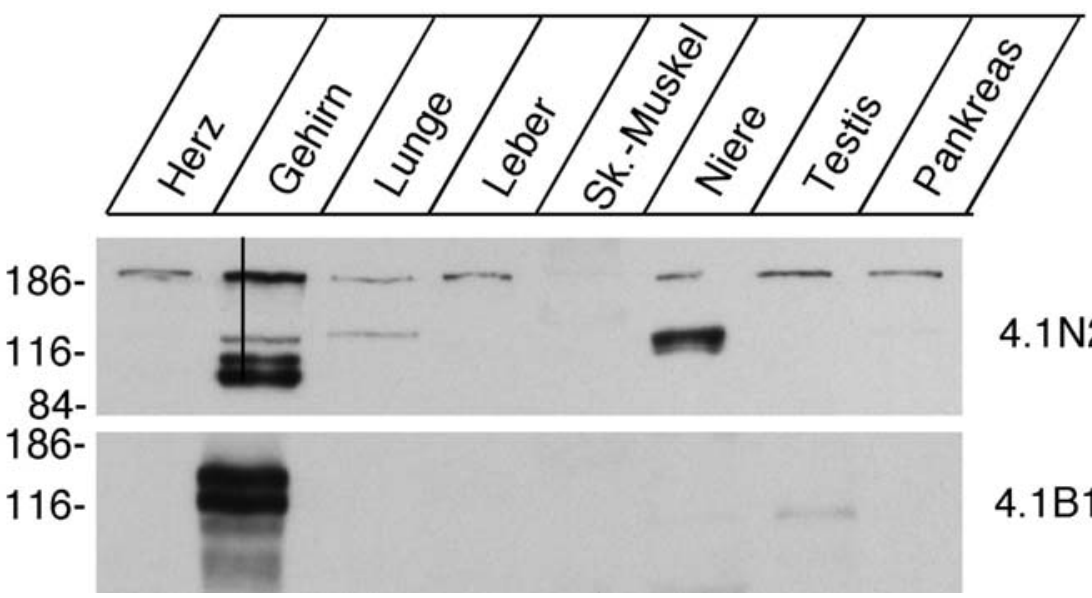

4.1N22

4.1B17

Abb. 26: Gewebeverteilung von Protein 4.1N und Protein 4.1B.

A: Kommerziell erworbene Northernblots mit mRNA der angegebenen Gewebe einer adulten Ratte (Clontech) wurden mit einem radioaktiv markierten DNA-Fragment (Protein 4.1N, bp 2230-3650, Genbanknummer AB019256; Protein 4.1B, bp 2379-3264, Genbanknummer AB023204) unter hochstringenten Bedingungen hybridisiert. Die Auswertung der Banden erfolgte mittels Autoradiogramm B: Homogenate verschiedener Gewebe der Ratte wurden in gleicher Menge durch SDS-PAGE aufgetrennt, auf Nitrozellulose transferiert und mit Protein 4.1-Antiseren inkubiert. Immunreaktive Banden wurden durch ECL visualisiert.

Von Protein 4.1N zeigten sich insgesamt drei Transkripte, zwei häufige von ca. 7,6 und 5,2 kb sowie eine seltenere, ca. $9 \mathrm{~kb}$ große Bande, die nur im Gehirn detektiert wurde. Von Protein 4.1B sind zwei Transkripte im Gehirn detektierbar, sie sind etwa 6,2 und 5,2 kb groß. In der 
Niere finden sich ebenfalls zwei, etwas kleinere Transkripte. Die Größenangaben wurden anhand der Marker extrapoliert. Von beiden Protein 4.1-Isoformen sind Spleißvarianten dokumentiert, deren Expression das komplexe Bandenmuster in den Northernblots erklärt.

In Abb. 26B ist die Immunoblotanalyse der Gewebeverteilung von Protein 4.1N und Protein 4.1B zu sehen. Homogenate von verschiedenen Geweben der Ratte wurden hergestellt, die in ihnen enthaltenen Proteine solubilisiert, per SDS-PAGE aufgetrennt und auf Nitrozellulose transferiert. Diese Membran wurde mit Antikörpern gegen die 4.1-Proteine (3.3.2) mittels der Immundetektionsmethode analysiert Der Antikörper 4.1N22 (gegen Protein 4.1N) detektierte vier unterschiedlich große Banden im Gehirn. Eine ubiquitäre ca. 200 kDa große, deren Größe der L-Form des Proteins entsprach, zwei Banden mit 90 bzw. 110 kDa, welche ausschließlich im Gehirn expremiert wurden sowie eine schmale Bande bei $130 \mathrm{kDa}$, die auch in der Niere erkennbar war, wurden detektiert.

Protein 4.1B war vorwiegend im Gehirn nachweisbar. Das Antiserum 4.1B17 erkannte im Gehirnhomogenat zwei 120 und 140 kDa große Banden. Eine dünne, kleinere Bande im Testis findet keine Entsprechung im Northernblot und war wahrscheinlich auf Kreuzreaktionen mit verwandten Proteinen zurückzuführen. Der Bande in der Nierenfraktion des Northernblot stand kein korrelierendes Signal im Immunoblot gegenüber.

\subsubsection{Regionale Verteilung von Protein 4.1N und Protein 4.1B im Gehirn}

Wie in den Experimenten mit Nedd4.1 (siehe 3.2.5) wurde nun für die Protein 4.1-Isoformen die mRNA-Verteilung und die Lokalisation des Proteins innerhalb des Gehirns mit den entsprechenden Daten für Neuroligin verglichen.

\subsubsection{In-situ-Hybridisierung}

Wie unter 3.2.5.1 beschrieben, wurden mit je zwei unabhängigen antisense-Oligonukleotiden Hybridisierungen auf adultem und neugeborenem Gewebe durchgeführt. Die beiden für die Protein-4.1-Varianten spezifischen Oligonukleotide ergaben jeweils identische Resultate, Kontrollexperimente, in denen ein Überschuss von nicht markiertem Oligonukleotid zugegeben wurde, ergaben kein Signal. 
Beide Protein 4.1-Isoformen wurden in nahezu allen Bereichen des Gehirns exprimiert. Regionen mit hoher Konzentration von Gliazellen, wie die weiße Masse des cerebralen Cortex und des Cerebellums, waren unmarkiert, was auf neuronenspezifische Expression hindeutet.
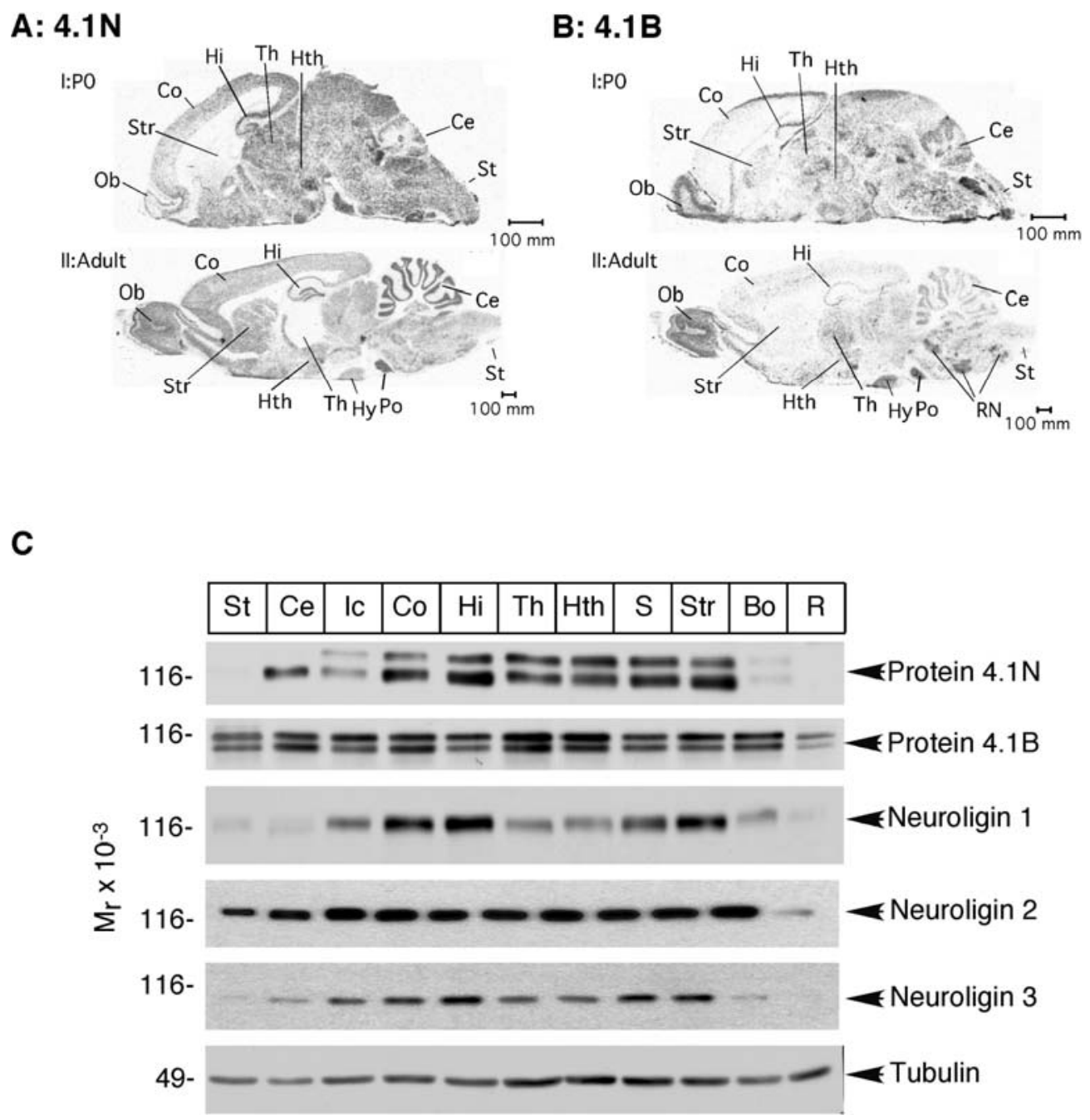

Abb. 27.: Regionale Expression von Protein 4.1N und Protein 4.1B im Gehirn der Ratte. Autoradiogramme der in-situ-Hybridisierung von antisense-Oligos auf 4.1-mRNA. Abgebildet wird je ein exemplarisches Resultat zweier unabhängiger Oligonukleotide von Protein 4.1N (L und S-Variante) (A) und Protein 4.1B (B). Die Negativkontrollen ergaben kein Signal (nicht gezeigt). Die Hybridisierung erfolgte auf dehydrierten, mit 4\% Paraformaldehyd fixierten Sagittalschnitten. Hybridisierung auf neugeborenem (P0) und adultem Gewebe (3 Monate). C: Immundetektionsanalyse der Proteinexpression in den angegebenen Gehirnregionen. Homogenate aus dem Gehirn einer adulten Ratte wurden per SDS-PAGE aufgetrennt, auf Nitrozellulose transferiert und mit Antikörpern gegen Neuroligin $1,-2,-3$ und Protein 4.1 analysiert. Tubulin diente als Ladekontrolle.

St, Stammhirn; Ce, Cerebellum; Ic; Inferior colliculus; Co, Cortex; Hi, Hippocampus; Th, Thalamus; Thr, Nucleus thalamicus reticulare; Hth, Hypothalamus; Se, Septum; Str, Striatum; Bo, Bulbus olfactorius; R, Rückenmark; Po, Pons; Hy, Hypophyse, RN, RaphéNuklei. 
Die Expression von Protein 4.1N ist innerhalb der Neuronenpopulation sowohl im Neugeborenen-Gehirn, wie auch im adulten ubiquitär, das Gehirn ist gleichmäßig gefärbt. Alle Schichten des celebralen Cortex sind positiv, ebenso Stammhirn, Hypothalamus und Striatum (hier deutlich erkennbar ohne Signal die Streifen weißer Masse). Bereiche stärkerer Expression finden sich im Bulbus olfactorius, der Pons, der Körnerzellschicht des Cerebellums und im Hippocampus (CA1-3 und Gyrus dentatus). Auffallend ist die absolute Abwesenheit von 4.1N-mRNA im Thalamus, mit Ausnahme des Nucleus thalamicus reticulare im adulten, nicht aber im Neugeborenen-Gehirn.

Die mRNA von Protein 4.1B weist bei beiden untersuchten Altersstufen ein weniger homogenes Verteilungsmuster auf. Die Expression ist insgesamt schwächer als die von Protein 4.1N, aber ebenfalls neuronal. Hohe Konzentrationen von 4.1B-mRNA finden sich im Bulbus olfactorius, der Hypophyse, der Pons und in den Raphé-Nuklei des Stammhirns. Der Thalamus ist positiv. Die 4.1B-mRNA-Expression im Striatum, Cortex und im Gyrus dentatus hingegen ist sehr schwach ausgeprägt.

Die hier gefundenen mRNA-Expressionmuster der Proteine 4.1N und 4.1B entsprechen weitgehend der pan-neuronalen Expression der drei bekannten Neuroligin-mRNAs (Frederique Varoqueaux und Ji-Ying Song, pers. Mittlg.; Ichtchenko et al., 1996). Offensichtlich werden Protein 4.1N und Protein 4.1B mit diesen Neuroliginen in den meisten Neuronen koexprimiert, was die Hypothese einer funktionellen Interaktion dieser Proteine unterstützt.

\subsubsection{Immundetektion von Protein 4.1N und Protein 4.1B in den Gehirnregionen}

Vergleicht man die Proteinkonzentrationen innerhalb der verschiedenen Regionen in der Immundetektionsanalyse (Abb. 27B) mit den Ergebnissen der in-situ-Hybridisierung, so fällt auf, daß die Verteilungsmuster von mRNA und Protein weitestgehend übereinstimmen. Hinsichtlich der Verteilung von Protein 4.1 mRNA- bzw. Protein-Expression sind Diskrepanzen im Striatum und im Bulbus olfactorius zu vermerken. Abschließend kann zusammengefasst werden, daß sowohl Neuroligin, als auch die 4.1-Proteine in allen Bereichen des Gehirnsgemeinsam exprimiert werden. Regionen größter Übereinstimmung finden sich im Cortex, Hippocampus und Striatum. 


\subsubsection{Neuroligin 1 und Protein 4.1B kollokalisieren in Neuronen}

Immundetektion und in-situ-Hybridisierung zeigten, daß die Neuroligine und die beiden untersuchten 4.1-Proteine weitestgehend in denselben Regionen des Gehirns exprimiert werden. Um zu analysieren, ob in diesen Bereichen beide Proteine in denselben Zellen zu finden sind, wurden Immunofluoreszenz-Doppelfärbungen mit Antikörpern gegen Neuroligin 1 und Protein 4.1B auf Sagittalschnitten des Gehirns einer adulten Ratte durchgeführt. Die Koexpression von Protein 4.1N mit Neuroligin 1 konnte nicht untersucht werden, da die Antikörper gegen Protein 4.1N für die Immunhistochemie nicht geeignet sind. Abbildung 28 zeigt einen entsprechend gefärbten Ausschnitt aus dem Cerebellum. Neuroligin 1 und Protein 4.1B zeigen zwar teilweise differente Verteilungsmuster, sind aber deutlich im Somata und in den Dendriten von Purkinjezellen kollokalisiert.

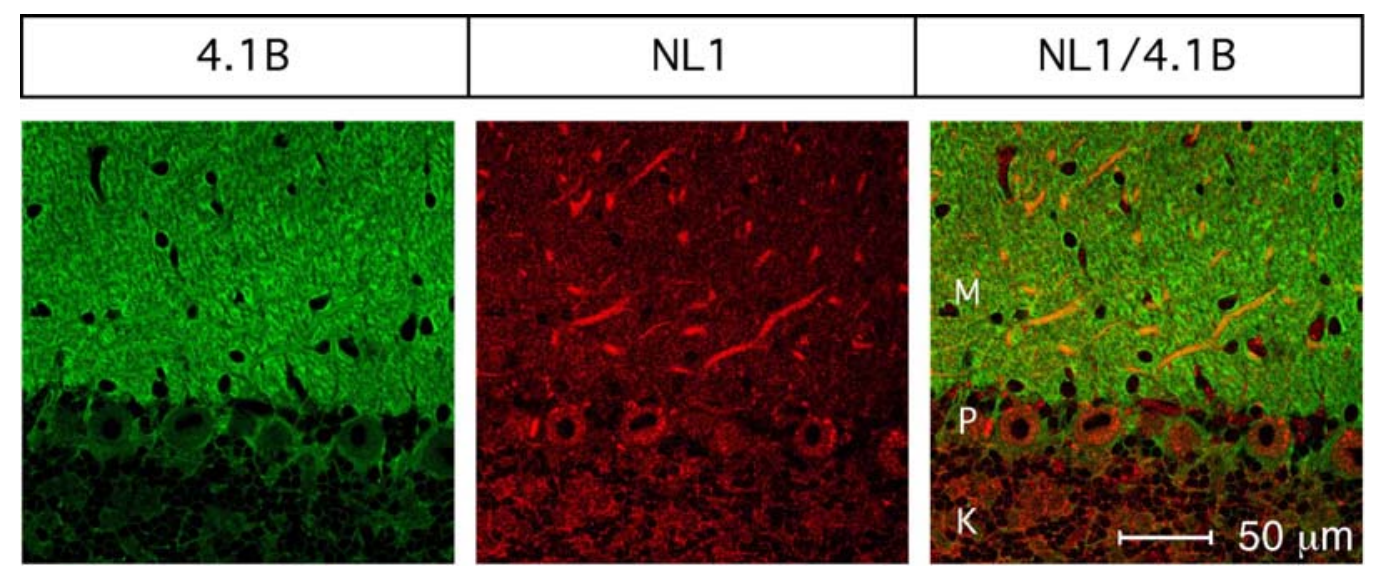

Abb.28: Immunohistochemische Analyse der Verteilung von Neuroligin 1 und Protein 4.1B in Neuronen des Rattengehirns.

Sagittale Gehirnschnitte einer adulten Ratte wurden parallel mit Antikörpern gegen Neuroligin 1 (4C12, monoklonal, rot) und Protein 4.1B (4.1B17, grün) und entsprechenden fluoreszenzmarkierten Antikörpern angefärbt. Die Visualisierung erfolgte durch konfokale Lasermikroskopie (Zeiss, LSM510). In der Überlagerung erscheinen Bereiche überlappender Signale gelb. Gezeigt ist ein Ausschnitt aus dem Cerebellum. K, Körnerzellschicht; P, Purkinjezellschicht; M, Molekularzellschicht.

\subsubsection{Subzelluläre Lokalisation der Proteine 4.1N und 4.1B}

Die subzelluläre Lokalisierung von Protein 4.1N und Protein 4.1B wurde unter Zuhilfenahme der unter 3.2.7 beschriebenen subzellulären Fraktionierung bei Verwendung der gleichen Kontrollen analysiert. Das Ergebnis zeigt Abbildung 29. Beide Protein 4.1-Isoformen waren sowohl in cytosolischen, wie auch in Membranfraktionen zu finden. Dieser Befund impliziert, 
daß die Proteine löslich sind, aber konstitutiv Transmembranproteine wie Neuroligin binden können. Wie die Markerproteine zeigten, war die auf alle Fraktionen ausgedehnte Verteilung nicht auf eine unsaubere Trennung der Fraktionen zurückzuführen. Es ist daher anzunehmen, daß beide Isoformen in den unterschiedlichsten Bereichen der Zelle unterschiediche Zielproteine binden. Dennoch waren beide Proteine partiell in den Fraktionen des synaptischen Cytosols (LS2), wie auch auf synaptischen Plasmamembranen (SPM) angereichert. Beide Proteine sind zumindest teilweise synaptisch lokalisierbar.

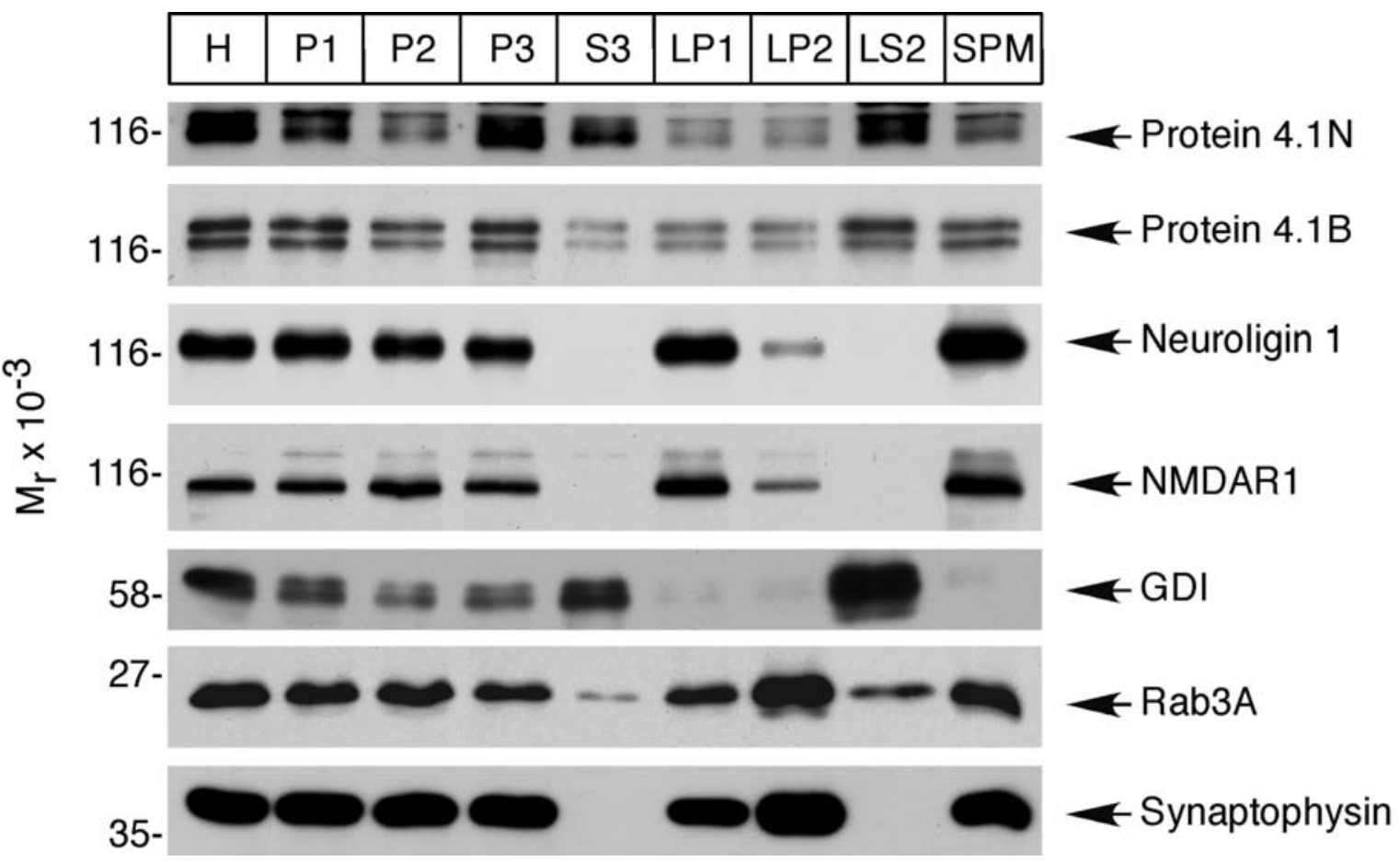

Abb.29: Subzelluläre Lokalisierung der Proteine 4.1N und 4.1B

Die subzelluläre Fraktionierung des cerebralen Cortex der Ratte durch differentielle Zentrifugation ergab folgende Fraktionen: H, Homogenat; P1, Nuklei; P2, Synaptosomen; P3, Leichte Membranen; S3, Cytosol; LP1, lysierte Synaptosomenmembranen, LP2, synaptische Vesikel; LS2, Cytosol der Synaptosomen; SPM, synaptische Plasmamembranen. Die Proteine in den Fraktionen wurden einer SDS-PAGE unterzogen, auf Nitrozellulose transferiert und die Membran mittels Immundetektionsanalyse mit Antikörpern gegen folgende Markerproteine analysiert: NMDAR1 (postsynaptische Glutamatrezeptoruntereinheit), GDI (Cytosol), Rab3a und Synaptophysin (synaptische Vesikelproteine). Die Visualisierung der Banden erfolgte mit ECL. Neuroligin zeigt, wie NMDAR1, das typische Verteilungsmuster eines Bestandteils der postsynaptischen Verdichtung. Beide Protein 4.1-Isoformen sind sowohl in der cytosolischen, wie in den Membranfraktionen zu finden und in den synaptische Fraktionen LS2 und SPM gemeinsam mit Neuroligin angereichert. 


\subsubsection{Entwicklungsabhängige Expression der Proteine 4.1N und 4.1B}

Die entwicklungsabhängige Expression von Protein 4.1B und Protein 4.1N wurde, wie auch für Nedd4.1 (3.2.7), per Immundetektion in Gehirnhomogenaten von Ratten unterschiedlicher Altersstufen analysiert, um so zu testen, ob sich Hinweise auf eine Rolle der Proteine bei Entwicklungsvorgängen im Gehirn finden. Es wurden die bereits beschriebenen Proben verwendet. Wie Abbildung 30 zeigt, ist das Expressionmuster beider Isoformen dem von Neuroligin und anderen synaptischen Proteinen sehr ähnlich. Sowohl Protein 4.1B, als auch Protein 4.1N werden im Embryo in geringen Mengen exprimiert, während der posnatalen Phase steigt die Expression kontinuierlich und parallel zur Synapsenzahl an, bis sie im erwachsenen Gehirn ein Plateau auf hohem Niveau erreicht.

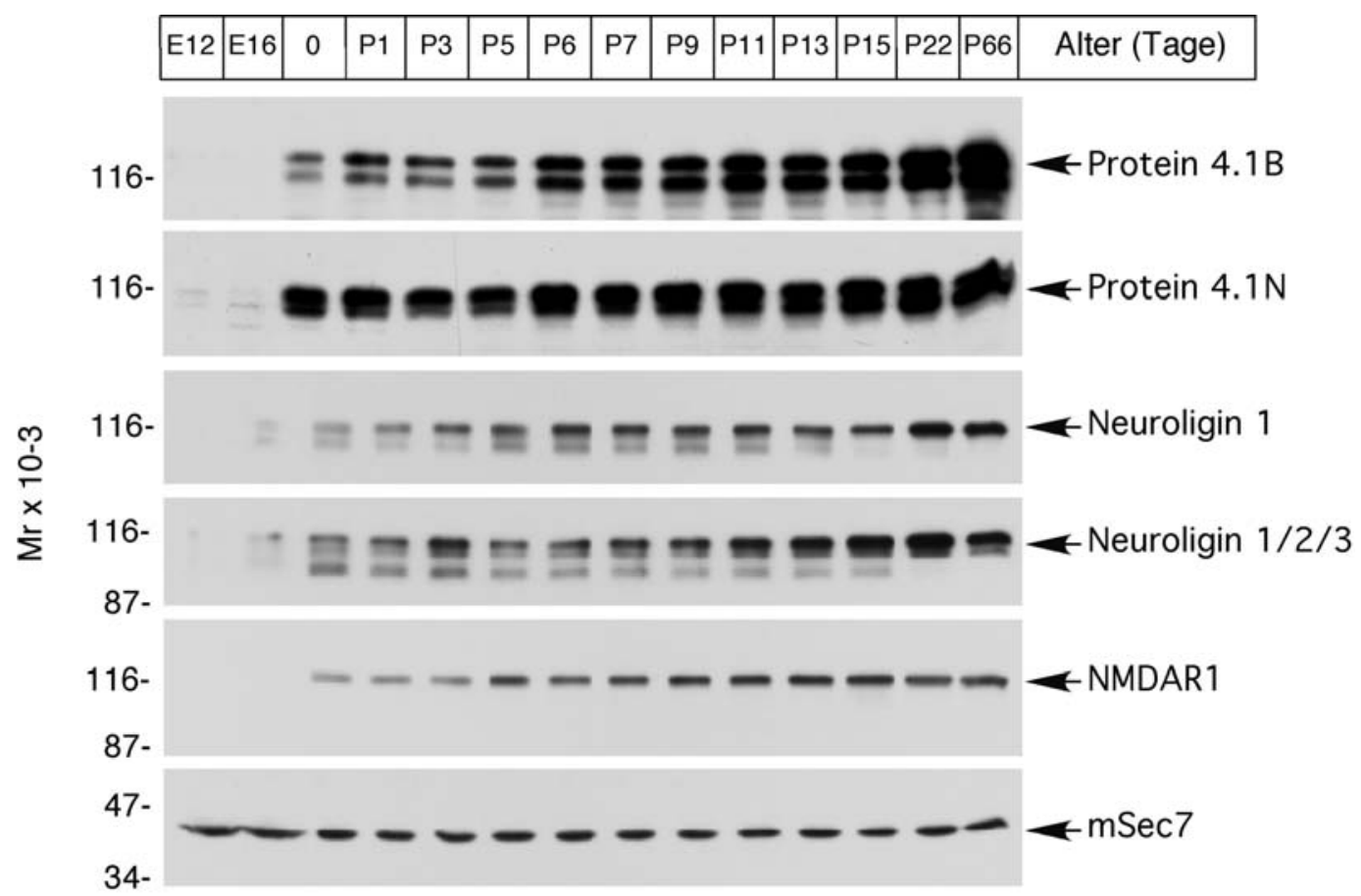

\footnotetext{
Abb. 30: Expression von Protein 4.1N und Protein 4.1B während der Entwicklung Gesamtgehirnhomogenate von Ratten verschiedener Altersstufen wurden durch SDS-PAGE aufgetrennt, auf Nitrozellulosemembran transferiert und mittels Immundetektion mit spezifischen Antikörpern gegen die aufgeführten Proteine analysiert. E, embryonaler Tag; P, postnataler Tag. Das entwicklungsbedingte Expressionsmuster von Protein 4.1B und Protein $4.1 \mathrm{~N}$ ähnelt stark dem des Neuroligin und anderer synaptischer Proteine und entspricht der Synapsendichte. Als Ladekontrolle wurde ein Antikörper gegen $\mathrm{mSec} 7$ verwendet, da dieses Protein in allen Entwicklungsstufen gleichbleibend exprimiert wird. Immunreaktive Banden wurden durch ECL visualisiert.
} 


\subsubsection{Interaktion von Protein 4.1N und Protein 4.1B mit MAGuK-Proteinen}

Die 4.1-Proteine bilden Komplexe mit PDZ-Domänenproteinen und TransmembrandomänenProteinen des Typs 1. Am besten untersucht ist der Komplex zwischen Protein 4.1R, p55 und Glycophorin C (Marfatia et al., 1995 und 1997; Hemming et al., 1994 und 1995). Die Bildung des Komplexes benötigt zwei Bindestellen am 4.1-Protein: Die CTD für die Bindung an das Transmembrandomänenprotein (vergl. 3.3.1) und die 4.1-Homologiedomäne (4.1HD), die an die HOOK-Region des PDZ-Domänenproteins bindet. HOOK-Regionen sind in p55 (Marfatia et al., 1995), in hDlg (humanes Dlg/SAP97; Lue et al., 1994) und CASK (Cohen et al., 1998) identifiziert worden.

Mit Hilfe von Kosedimentationsexperimenten mit GST-Fusionsproteinen der 4.1Homologiedomäne von Protein 4.1B und Protein 4.1N sollte getestet werden, welche der mit Neuroligin interagierenden MAGuK-Proteine als Protein 4.1-Bindepartner in Frage kommen. Das Ergebnis zeigt Abbildung 31. GST-Fusionsproteine der 4.1-Homologiedomäne von Protein 4.1N (AS 90-305) und Protein 4.1B (AS 142-324) wurden in dem Bakterienstamm E. coli BL21-DE3 exprimiert, gereinigt und an Glutathion-Agarose immobilisiert. Die Proteine wurden mit einem Extrakt ungereinigter Synaptosomen inkubiert und anschließend gewaschen. Als Negativkontrolle diente GST ohne Fusion. Die Analyse von Homogenat, Überstand nach der Sedimentation und Sediment erfolgte durch Immunoblot nach SDSPAGE, unter Verwendung von Antikörpern gegen SAP97, PSD93, PSD95 und SAP102. Die Antikörper gegen SAP97 und PSD93 reagierten mit dem GST-Protein und wurden daher vor der Immundetektionsanalyse mit immobilisiertem GST-Protein von kreuzreaktiven Bestandteilen gereinigt.

PSD95 und SAP97 waren in den Sedimenten beider Protein 4.1-Isoformen zu finden, wobei PSD95 stärker mit Protein 4.1B und SAP97 eher mit Protein 4.1N interagierte. PSD93 ist nur im Pellet von Protein 4.1N detektierbar. Der Antikörper zeigte trotz Präinkubation mit GST immer noch eine starke Hintergrundaktivität, die die Interpretation des Ergebnisses erschwerte. SAP102 interagierte mit keiner der beiden Isoformen. Die Kontrollexperimente mit reinem GST blieben erwartungsgemäß ohne Signal im Sediment, das Ergebnis ist folglich nicht auf unspezifisch gebundenes Protein zurückzuführen. 


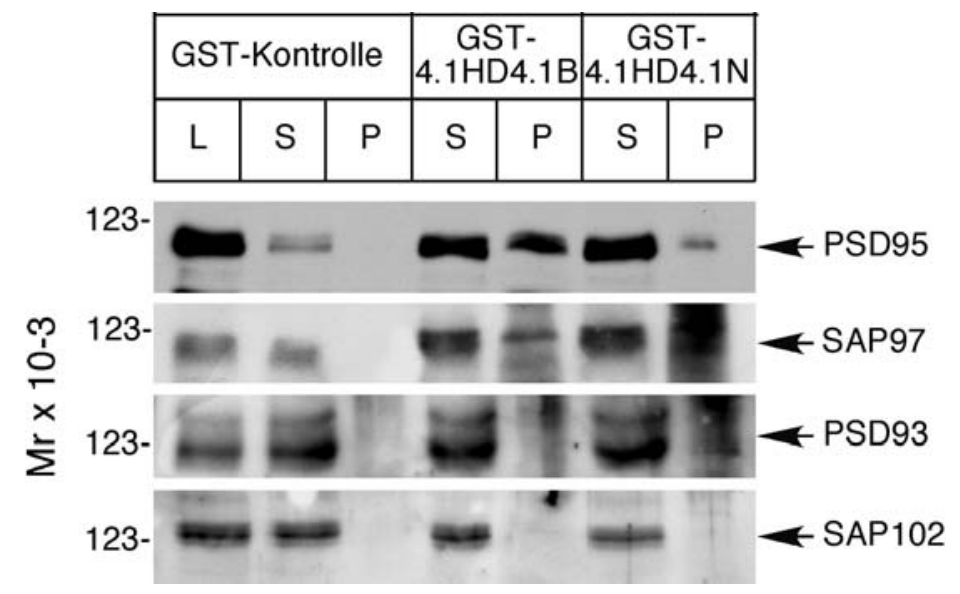

Abb. 31: Kosedimentationsexperiment mit den 4.1-Homologiedomäne von Protein 4.1N und Protein 4.1B

GST-Fusionsproteine mit den 4.1-Homologiedomänen von Protein 4.1N (AS 90-305) und Protein 4.1B (AS 142-324) wurden in dem Bakterienstamm E. coli BL21-DE3 exprimiert, gereinigt und an Glutathion-Agarose gebunden. Gleiche Mengen des immobilisierten Fusionsroteins wurden mit einem Synaptosomenextrakt inkubiert und anschließend gereinigt. Als Negativkontrolle diente GST allein. Überstand und Sediment der Experimente wurden durch SDS-PAGE aufgetrennt, auf Nitrozellulose transferiert und mit Antikörpern gegen PSD95 (918), SAP97 (ABR2108339A), PSD93 (919) und SAP102 (921) inkubiert. Die Visualisierung immunreaktiver Banden erfolgte durch ECL.

\subsubsection{Integration des cytoplasmatischen Teils von Neuroligin 1 in Aktin- Mikrofilamenten}

Im Anschluss sollte getestet werden, ob Neuroligin in das Cytoskelett integriert wird und ob, wie bei Neurexin (Biederer und Südhof, 2001), die Bindung an ein MAGuK-Protein für die Integration relevant ist. Zu diesem Zweck wurden GST-Fusionproteine der cytoplasmatischen Domäne von Neuroligin 1 mit und ohne der PDZ-Erkennungssequenz bakteriell exprimiert und aufgereinigt. Das gereinigte Protein wurde zu einem hoch konzentrierten Extrakt von solubilisiertem Rattenhirn-Protein gegeben, aus dem sich unter den hier gewählten Bedingungen schnell Aktin-Mikrofilamente bilden (Stokes et al., 1991). Der Extrakt wurde über Nacht bei $4^{\circ} \mathrm{C}$ inkubiert und dann einer differentiellen Zentrifugation unterzogen, um Aktin-assoziierte Proteine in der Cytoskelett-Fraktion anzureichern. Abbildung 32 zeigt die Immundetektionsanalyse des Experimentes. Ein Teil der GST-NL1-ICD-Fraktion wurde gemeinsam mit den Cytosklett-Proteinen Aktin und Protein 4.1B im Sediment P1 pelletiert, ein anderer Teil bleibt in der löslichen Phase. GDI, als Negativkontrolle, war in der P1Fraktion nicht nachweisbar. Nach Resuspension und erneuter Zentrifugation von P1 wurde wiederum ein Teil des GST-NL1-ICD in das zweite Sediment P2 überführt und 
kosedimentierte dort mit Aktin und Protein 4.1B. Ein anderer Teil befand sich in der löslichen Fraktion S2. Möglicherweise handelt es sich hierbei um inaktive Degradationsprodukte, die durch die lange Inkubationszeit entstanden sind. Die Entfernung der PDZ-Erkennungssequenz am äußersten C-Terminus hatte keinen Einfluss auf die Aktin-Bindung des Proteins.

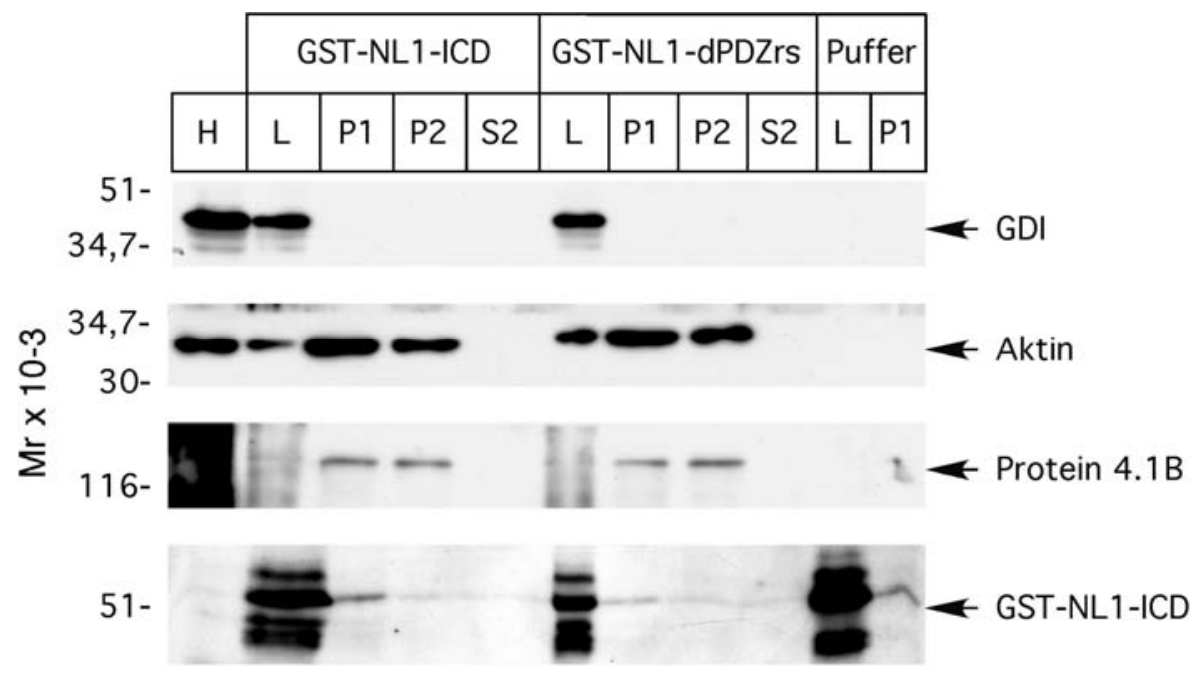

Abb. 32: Integration der cytoplasmatische Domäne von Neuroligin 1 in AktinMikrofilamente.

GST-Fusionproteine der cytoplasmatischen Domäne von Neuroligin 1 mit (GST-NLI-ICD, AS 718-843) und ohne die PDZ-Erkennungssequenz (GST-NL1-dPDZrs, AS 718-840) wurden in dem Bakterienstamm E. coli BL21-DE3 exprimiert, extrahiert und gereinigt. Sie wurden über Nacht bei $4^{\circ} \mathrm{C}$ mit solubilisiertem Rattenhirn-Proteinen $(\mathrm{H})$ inkubiert, um die Neubildung von Aktin-Mikrofilamenten zu induzieren. Das P1-Sediment wurde durch Zentrifugation hergestellt, resuspendiert und erneut zentrifugiert, um das zweite Sediment P2 und den Überstand S2 zu erhalten. In den gereinigten Sedimenten kam es zu einer Anreicherung von Bestandteilen des Cytoskeletts. Äquivalente Mengen des Proteins aus den einzelnen Fraktionen wurden per SDS-PAGE aufgetrennt, auf Nitrozellulose geblottet und mit Antikörpern gegen die angegebenen Proteine analysiert. Der Nachweis der Fusionsproteine erfolgt durch den Antikörper L066, der mit dem cytoplasmatischen Teil von Neuroligin 1 reagiert. Die Visualisierung immunreaktiver Banden erfolgte durch ECL.

\subsubsection{Zielsteuerung von Neuroligin 1-EGFP-Konstrukten in HEK293-Zellen}

Bei Experimenten mit verschiedenen Neuroligin 1-GFP-Fusionsproteinen zeigte sich, daß diese unterschiedliche Verteilungsmuster innerhalb der Zelle aufwiesen. Für die Untersuchungen wurden zunächst zwei Expressionsvektoren verwendet: pNL1fl-EGFP und pNL1/dICD-EFGP. Die Konstrukte sind in Abbildung 33A skizziert.

pNL1fl-EGFP beinhaltet die vollständige cDNA-Sequenz von Neuroligin 1, an deren 3'-Ende im Leserahmen die Sequenz für EGFP fusioniert ist. Die Fusion führt zur Inaktivierung der 
PDZ-Erkennungssequenz am äußersten C-terminalen Ende von Neuroligin 1, erhält aber den Zugang für alle anderen Bindungspartner. Im Konstrukt pNL1/dICD-EFGP hingegen war die gesamte cytoplasmatische Domäne durch die EGFP-Fusion ersetzt worden. Das Produkt dieses Vektors ist nicht mehr in der Lage, intrazelluläre Interaktionspartner von Neuroligin 1 zu binden.

A

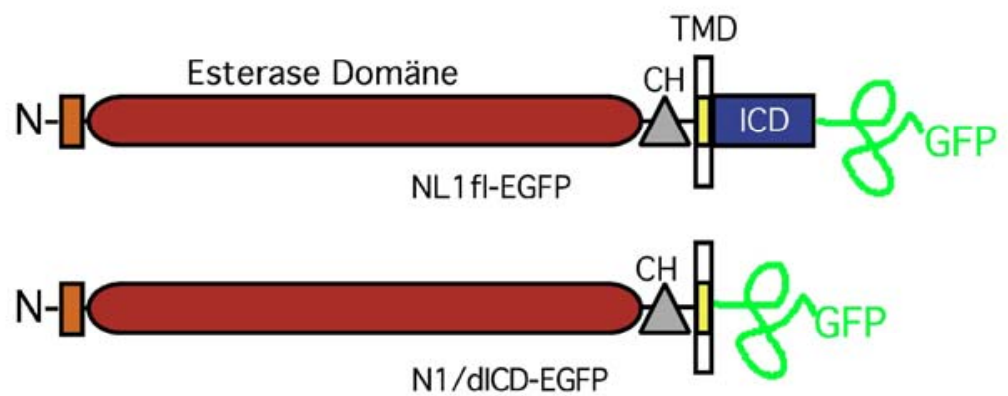

B

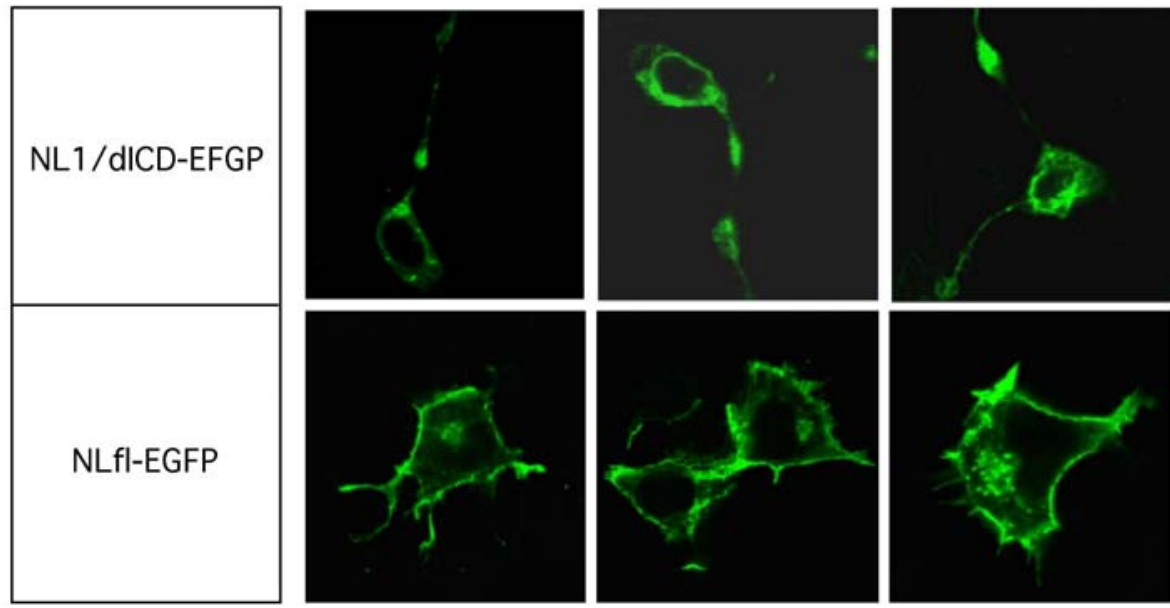

Abb. 33: Die Neuroligin 1-EGFP-Fusionsproteine und ihre Lokalisation in HEK293Zellen

A: Schematische Darstellung der Neuroligin 1-EGFP-Fusionsproteine. Bei NLfl-EGFP ist das EGFP direkt mit dem C-terminalen Ende von Neuroligin 1 fusioniert und blockiert auf diese Weise die Interaktion zu den PDZ-Domänen der MAGuKs. In NL1/dICD-EFGP fehlt die ICD von Neuroligin 1 und ist komplett gegen das EGFP-Fusionat ausgetauscht. B: HEK293Zellen wurden mit den unter A skizzierten Konstrukten mittels der Kalziumphosphat-DNAKopräzipitatmethode transfiziert. Die Visualisierung des EGFP-Signals erfolgte mittels konfokaler Lasermikroskopie (Zeiss LSM510). Im Gegensatz zu NLfl-EGFP wird NL1/dICD-EFGP nicht zur Plasmamembran transportiert.

Abbildung 33B zeigt die Lokalisation der Konstrukte in HEK293-Zellen nach transienter Transfektion mittels Kalziumphosphat-DNA-Kopräzipitat. NL1fl-EGFP weist die typische Verteilung eines Plasmamembran-Proteins auf. Es ist vor allem an der Plasmamembran und 
im perinuklearen Bereich transfizierter Zellen detektierbar. NL1/dICD-EFGP wird im Gegensatz dazu nicht zur Zellmembran transportiert. Es zeigt ein granuläres, intrazelluläres Verteilungsmuster. Offensichtlich benötigt Neuroligin 1 für den Transport aus dem Golgiapparat zur Plasmamembran die Interaktion mit einem cytoplasmatischen Protein, nicht jedoch mit den PDZ-Domänen der MAGuK-Proteine. Gute Kandidaten für die Zielsteuerung von Neuroligin und anderen Transmembrandomänen-Proteinen an die Plasmamembran sind die 4.1-Proteine.

\subsubsection{Zielsteuerung der Neuroligin 1-EGFP-Fusionsproteine in Neuronen}

Um zu untersuchen, ob das Lokalisationsdefizit von NL1/dICD-EFGP auch in Nervenzellen besteht, wurden die unter 3.3.13 beschriebenen NL1-EGFP-Konstrukte in hippocampalen Neuronen (Tag 6 in Kultur) transfiziert. Für die Identifizierung von spines wurden rekombinante FLAG-markierte Aktin-Proteine koexprimiert, die Gegenfärbung mit Antikörpern gegen die präsynaptischen Marker Synaptobrevin oder Synaptophysin diente dem Nachweis der synaptischen Lokalisation der Konstrukte. Die Transfektion erfolgte am Tag 6 in Kultur.

Abbildung 34A zeigt ein Neuron am Tag 8 in Kultur, zum diesem Zeitpunkt finden sich noch keine maturen Synapsen in der Kultur. Das Neuron wurde mit dem rot fluoreszierenden Protein dsRed und pNL1fl-EGFP kotransformiert. Die Abbildung zeigt die Plasmamembranlokalisierung des Konstruktes, welches den von dsRed markierten cytoplasmatischen Bereich der Zelle umrahmte. Wie schon in den HEK293-Zellexperimenten beschrieben, behindert die Blockierung der PDZrs im Konstrukt NL1fl-EGFP nicht die Zielsteuerung des Konstruktes zur Plasmamembran.

Die synaptische Lokalisation von NL1fl-EGFP ist in der Abbildung 34B belegt. Sie zeigt den Ausschnitt eines Neurons am Tag 21, welches mit NL1fl-EGFP transfiziert und nach der Fixierung mit einem anti-Synaptobrevin-Antikörper als präsynaptischer Marker gefärbt worden war. In der Vergrößerung zeigten sich deutlich die gegenüberliegenden Signale von Synaptobrevin und EGFP, die auf postsynaptische Lokalisation des Neuroligin 1Fusionsproteines hindeuteten (34B, rechts).

Die Lokalisation von NL1fl-EGFP in spines, aktinreichen Ausformungen des Dendriten, die der Synapsenbildung vorausgehen, wurde durch Koexpression mit Flag-fusioniertem Aktin erreicht. Das Flag-Epitop wurde mit spezifischen Antikörpern in der Zelle detektiert und 
einem rot-fluoreszierenden sekundären Antikörpern angefärbt. Abbildung 34C zeigt die Kollokalisation von NL1fl-EGFP und Aktin in den spines.

Die Transfektion mit pNL1/dICD-EFGP resultierte, wie schon im Fall der HEK293Zelltranfektion, auch in Neuronen eine intrazelluläre Färbung. Abbildung 34D zeigt die Gegenfärbung eines Neurons, welches mit NL1/dICD-EFGP trandfiziert worden war mit einem Synaptobrevin-Antikörper. Das Signal konzentriert sich im Kern und im Soma und zeigt keine Anreicherung an der Membran oder der Synapse (Abb. 34D). Auch konnten bei Kotransfektion mit Flag-markiertem Aktin und anschließender Immunfärbung mit FlagAntikörper keine NL1/dICD-EFGP-Moleküle in spines detektiert werden (Abb. 34E).

Um genauer zu lokalisieren, welcher Bereich von Neuroligin 1 für die Zielsteuerung verantwortlich ist, wurde eine Reihe von Neuroligin 1-GFP-Konstrukten hergestellt. Die Konstrukte sind ähnlich aufgebaut wie pNL1fl-EFGP, enthalten aber nur Teilbereiche der intrazellulären Domäne. Es wurden insgesamt fünf Konstrukte zwischen pNL1/dICD-EFGP (A) und pNL1fl-EFGP (G) hergestellt, deren Sequenzlänge im intrazellulären Bereich vom kürzeren zum längeren etwa 25 Aminosäuren betrug. Diese wurden wie oben beschrieben, in Neuronen transfiziert. Die synaptische Lokalisation wurde durch Gegenfärbung mit Synaptophysin-Antikörper und die Lokalisation in spines, wie oben beschrieben durch Kotransfektion mit Flag-fusioniertem Aktin und anschließender Gegenfärbung mit anti-FlagAntikörpern nachgewiesen. Bereits das erste, um 25 Aminosäuren verlängerte Konstrukt NL1-EGFP-F (AS 1-750) erfuhr die korrekte Lokalisation in die spines (Abb. 34F), wie auch alle längeren. Interessanterweise korrespondierte der entsprechende Abschnitt mit dem ersten Teil der mutmaßlichen Protein 4.1-Bindestelle (3.3.2). 


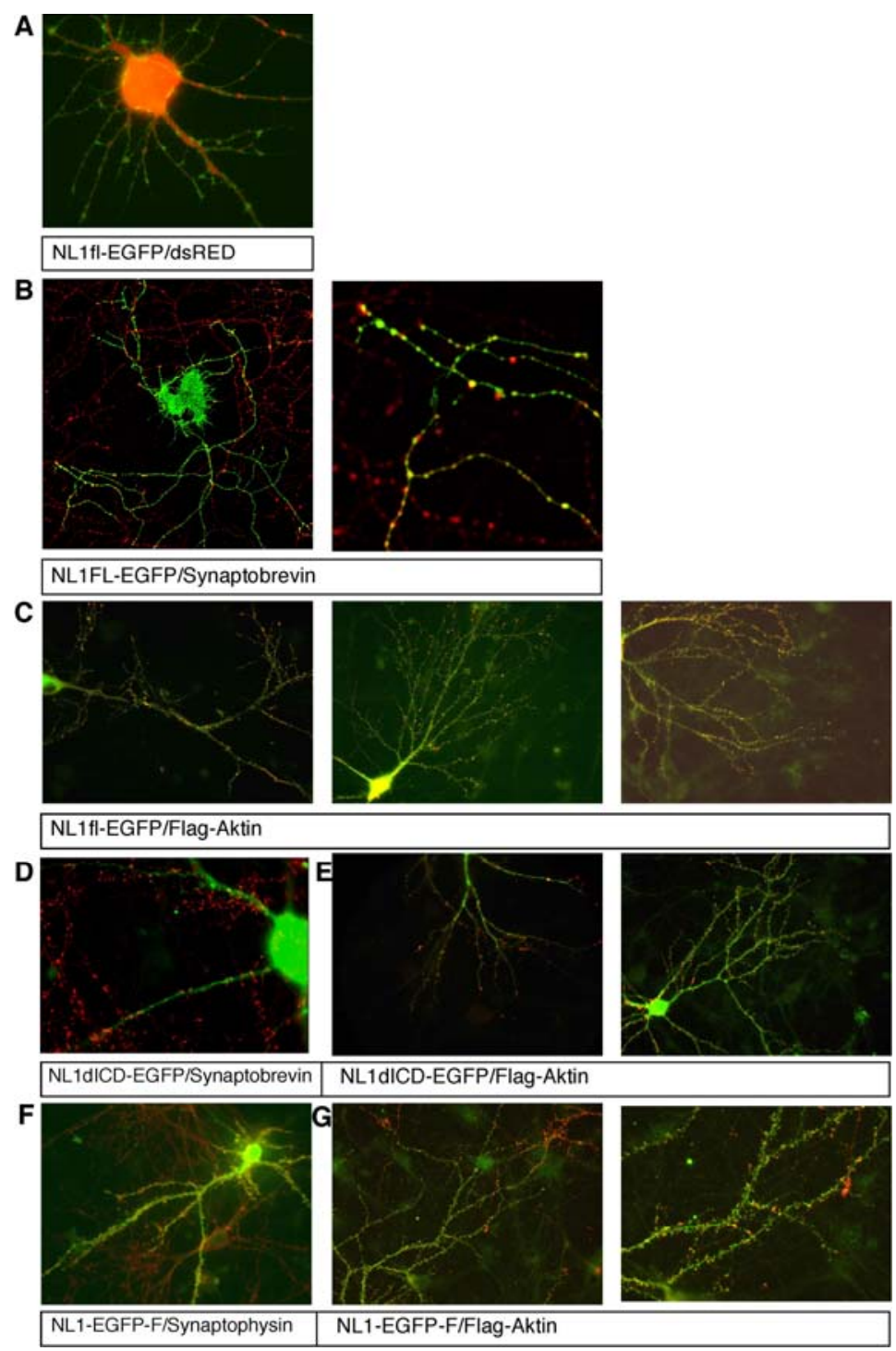

Abb. 34: Lokalisation überexprimierter Neuroligin 1-EGFP-Konstrukte in kultivierten Neuronen.

Primärkulturen von Neuronen des Hippocampus der Ratte wurden am 6. Tag in Kultur transfiziert und mit Antikörpern gegen die angegebenen Proteine gefärbt. A: Hippocampales Neuron mit NL1fl-EGFP und dsRed als cytosolischem Marker kotransfiziert (Tag 8 in Kultur). Das EGFP-Signal befindet sich an der Plasmembran. B: Hippocampales Neuron mit NL1fl-EGFP transfiziert und mit Antikörper gegen Synaptobrevin als synaptischer Marker gegengefärbt. (Tag 21 in Kultur) C: Hippocampales Neuron mit NL1fl-EGFP und Flag-Aktin für die Detektion von spines kotransfiziert. Gegenfärbung mit Flag-Antikörper (in rot; Tag 21 in Kultur). D: Hippocampales Neuron mit NL1dICD-EGFP transfiziert und analog zu B mit Antikörper gegen Synaptobrevin als synaptischer Marker gegengefärbt. (Tag 21 in Kultur) E: Transfektion mit NL1dICD-EGFP und Flag-Aktin, Gegenfärbung mit Flag-Antikörper analog zu C. F: Transfektion mit NL1-EGFP-F, Gegenfärbung mit Synaptophysin-Antikörper als synaptischer Marker analog zu B und D. G: Transfektion mit NL1-EGFP-F und Flag-Aktin, Gegenfärbung mit Flag-Antikörper analog zu C und E. Die Visualisierung erfolgte durch konfokale Lasermikroskopie (Zeiss, LSM510). In der Überlagerung erscheinen Bereiche überlappender Signale gelb. 


\subsection{Analyse der Proteinexpression von Neuroligin 1/2/3-Deletionsmutanten Mäusen}

Abschließend sollte in Neuroligin 1, -2, -3-deletionsmutanten Mäusen untersucht werden, ob die Expression der in der vorliegenden Arbeit charakterisierten Interaktionspartner Nedd4.1, Protein 4.1N und Protein 4.1B durch die Deletion von Neuroligin beeinflusst wird. Die Mauslinie ist von Prof. Dr. Nils Brose generiert und zur Verfügung gestellt worden.

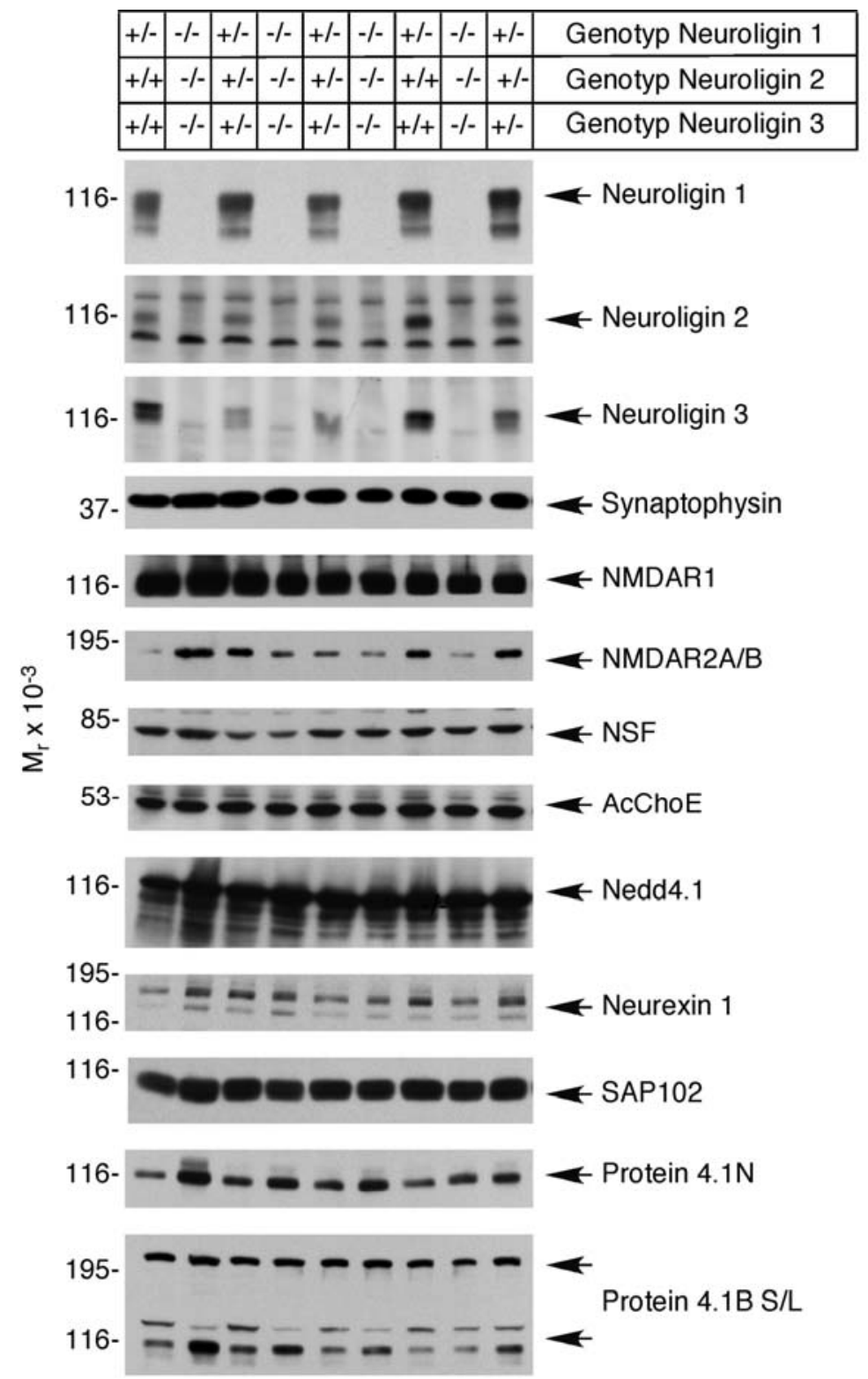

Abb. 35: Immundetektionsanalyse der Expression von verschiedenen Markerproteinen im Gehirn von Neuroligin 1, -2, -3-deletionsmutanten Mäusen.

Gehirnhomogenate gleicher Proteinkonzentrationen von Tieren der angegebenen Genotypen (P0) wurden mit SDS-PAGE aufgetrennt, auf Nitrozellulose transferiert und mit Antikörpern gegen die angegebenen Proteine untersucht. Immunreaktive Banden wurden mit ECL visualisiert. 
Für die Analyse wurden die Proteine aus Gesamtgehirnhomogenaten von neugeborenen Tieren einer Immunoblotanalyse unterzogen. Es wurden Geschwistertiere von zwei Würfen untersucht. Als Kontrolle dienten Tiere mit mindestens einem Wildtypallel je Neuroligin-Gen. Das Ergebnis zeigt Abbildung 35. Die Konzentration von Nedd4.1, wie auch von SAP102, NMDAR1, NSF und der Acetylcholinesterase waren auch in Abwesenheit von Neuroligin 1-3 unverändert. Leichte, genotypabhängige Schwankungen zeigten einige Spleißvarianten der 4.1-Proteine, die NMDA-Rezeptoruntereinheit NMDAR2a/b, Neurexin und Synaptophysin. 


\section{DISKUSSION}

Synapsen sind die Schaltstellen der Informationsweiterleitung im Nervensystem. Die meisten dieser asymmetrischen Verbindungspunkte zwischen der präsynaptischen aktiven Zone und der postsynaptischen Verdichtung werden im Säugergehirn nach der Geburt gebildet. Im Verlauf der postnatalen Entwicklung wird ein Großteil der Verbindungen wieder eliminiert, andere stabilisiert. Man geht heute davon aus, daß sowohl bei der Synthese als auch bei der Modulation der Synapsenstabilität Zelladhäsionsproteine beteiligt sind (Hagler et al., 1998). Vor allem die Familie der Cadherine (Fannon und Colman 1996, Ushida et al., 1997) und ihre Verwandten, die Cadherin-ähnlichen-Rezeptoren (CNR; Kohmura et al., 1998), aber auch das synaptische Zelladhäsionsprotein SynCAM (Biederer et al., 2002) werden in diesem Zusammenhang als für die Synaptogenese bedeutsame Proteine diskutiert. Diese Proteine bilden homotypische Verbindungen mit Molekülen desselben Subtyps.

Der asymmetrische Charakter der Synapse mit definierter prä- und postsynaptischer Seite legt jedoch die Beteiligung eines asymmetrischen Zell-Adhäsionssystems nahe. Die Verbindung zwischen Neuroligin und $\beta$-Neurexin stellt möglicherweise ein solches System dar. Beide Proteine sind Mitglieder komplexer Familien von Zelloberflächenproteinen, die in der Lage sind, heterotypische Zelladhäsion zu vermitteln (Nguyen und Südhof, 1997). In eukaryotischen Zellen rekombinant exprimiertes Neuroligin induziert die Bildung von Semisynapsen in kokultivierten Neuronen (Scheiffele et al., 2000). Diese Eigenschaften deuten darauf hin, daß das Neuroligin/ $\beta$-Neurexin-System direkt an der Steuerung der späten Schritte der Synaptogenese beteiligt ist. Während die extrazelluläre Interaktion zwischen Neuroligin und $\beta$-Neurexin recht gut untersucht wurde, ist darüber, wie Neuroligin das von $\beta$ Neurexin erhaltene Signal intrazellulär weiterverarbeitet, wenig bekannt.

Durch die Ergebnisse meiner vorangehenden Diplomarbeit konnte ich drei Proteine als potentielle Interaktionspartner von Neuroligin identifizieren: die Ubiquitinligase Nedd4.1 und die Strukturproteine 4.1N und 4.1B. In der vorliegenden Arbeit wurden diese Proteine hinsichtlich ihrer Lokalisation, Funktion und Interaktion mit Neuroligin detailiert charakterisiert. 


\subsection{Nedd4.1}

\subsubsection{Ubiquitinierung reguliert die Stabilität und Zusammensetzung von Synapsen}

Die kovalente Bindung von Ubiquitin an Proteine beeinflußt deren Aktivität, Lokalisation und Lebensdauer (Hochstrasser et al., 1996). Hierbei entscheidet die Anzahl der addierten Ubiquitinreste über die Metabolisierung des Proteins. Multiubiquitinierte Proteine werden von einem cytosolischen Komplex aus Threoninproteasen, dem 26S-Proteasom abgebaut (Ciechanover, 1994; Jentsch und Schlenker, 1995). Für die ligandenvermittelte Endozytose von Membranrezeptoren ist ein Ubiquitinrest ausreichend (Hicke und Riezman, 1996; Hochstrasser, 1996). Nedd4 und andere HECT-Domänenproteine sind vorwiegend an letzterem Metabolisierungsweg beteiligt.

Ubiquitinierung steuert eine Reihe von wichtigen Prozessen wie die Zell-Zyklusregulierung, Apostose oder die Transkription (Wilkinson et al., 1997). Die Modulation von Synapsen ist ein ähnlich dynamischer Prozess und von grundlegender Bedeutung für die Verarbeitung und Speicherung von Information im Gehirn (Luscher et al., 2000; Yuste et al., 2001). Einmal gebildet, ändern Synapsen aktivitätsbedingt ihre Größe (Murthy et al., 2001), Form (Geinisman et al., 1991; Toni et al., 1999) und Proteinzusammenstellung (Okabe et al., 1999). Der überwiegende Teil dieser Modulationsprozesse findet in der postsynaptischen Verdichtung statt (Husi et al., 2000; Sheng et al., 2002).

Es gibt mehrere Hinweise darauf, daß Ubiquitin und ubiquitinkonjugierende Enzyme maßgeblich an der Regulation der synaptischen Modulation beteiligt sind. Die Beteiligung von ubiquitinprozessierenden Proteinen an der Regulierung von Wachstum und Differenzierung, synaptischer Transmission und Plastizität ist in jüngster Zeit in mammalen und invertebraten Synapsen beschrieben worden (Hicke, 2001; Hegde et al., 1997; Jiang et al., 1998; DiAntonio et al., 2001; Wilson et al., 2002; Murphey et al., 2002). Deletionsmutanten von highwire, einer Ubiquitinligase in Drosophila, zeigen einem dramatischen Anstieg der Synapsenzahl und -größe bei gleichzeitiger Verminderung der synaptischen Aktivität (DiAntonio et al., 2000). Ein identischer Phänotyp entsteht bei Überexpression der deubiquitinierenden Proteasen fat-facets aus Drosophila und UBP2 aus der Hefe in den Larven von Drosophila (DiAntonio et al., 2000), ein Hinweis auf ein enges 
Zusammenspiel von ubiquitinierenden und deubiquitinierenden Enzymen bei der Kontrolle von Synaptogenese.

Ubiquitinierte Proteine sind in mammalen Synapsen abundant (Chapman et al., 1994). Die Verteilung von Ubiquitin im Gehirn impliziert eine Beteiligung bei der Steuerung des Auswachsens von Dendriten und dem Prozess der Synaptogenese (Flann et al., 1997). In der Tat gelang Ehlers (2003) der Nachweis aktivitätsbedingter, bidirektionaler und reversibler Veränderungen in der Proteinzusammensetzung der postsynaptischen Verdichtung. Die Veränderungen involvierten Glutamatrezeptoren, Adaptorproteine und Signalenzyme, die koregulierte Gruppen bildeten. Die beobachteten aktivitätsbedingten Veränderungen in der Proteinzusammensetzung der Synapse waren direkt mit deren Ubiquitinierung verknüpft.

\subsubsection{Ubiquitinligasen katalysieren die Bindung von Ubiquitin an ihre Zielproteine}

Die kovalente Bindung zwischen dem C-Terminus von Ubiquitin und bestimmten Lysinresten der Zielproteine resultiert aus dem Zusammenspiel der substraterkennenden Ubiquitinligasen (E3) mit den ubiquitinaktierenden (E2) und den ubiquitinkonjugierenden Enzymen (E1), (Scheffner et al., 1995; Huibregtse et al., 1995).

E3-Proteine werden in zwei Kategorien eingeteilt. Einige E3-Proteine fungieren als Brückenproteine, die E2-Enzyme und Substratproteine miteinander verbinden und deren Ubiquitinierung durch E2-Enzyme zu ermöglichen (Skowyra et al., 1997; Feldman et al., 1997). Andere katalysieren direkt die Übertragung von Ubiquitin nachdem sie von ihrem E2Interaktionspartner mit Ubiquitin in Form einer hochenergenen Thioesterverbindung beladen wurden. E3-Proteine, die Thioesterbindungen formen können, faßt man in der Familie der HECT-Domänenproteine (homolog zum E6AP-ㄷ-erminus) zusammen (Scheffner et al., 1995; Huibregtse et al., 1995). Zu ihr gehören unter anderem Nedd4 und E6AP. Das humane E6AP bindet an das E6-Protein des humanen Papilomavirus und leitet in Folge dieser Interaktion die Degradierung des onkogenen Proteins p53 ein, die zur Entwicklung von Cervixkarzinomen führen kann (Huibregtse et al., 1991 und 1993). Die Rolle von E6AP in Abwesenheit von Viruspartikeln ist nicht bekannt. Eine Reihe von Mutationen in E6AP-Gen führen jedoch zur Ausbildung des Angelman-Syndroms, eine Erbkrankheit, die von motorischen Dysfunktionen und mentaler Retardierung begleitet ist (Kishino et al., 1997; Matsuura et al., 1997). 


\subsubsection{Nedd4.1 ist eine Ubiquitinligase}

Die Ubiquitinligase Nedd4 wurde ursprünglich aus einer Maus-cDNA-Bibliothek neuronaler Vorläuferzellen gemeinsam mit anderen Gene isoliert, deren Expression im Verlauf der weiteren Entwicklung herabreguliert wird (Kumar et al., 1992). Es existieren zwei Isoformen in Säugern, Nedd4.1 und Nedd4.2 (Kumar et al., 1992; Kamynina et al., 2001). Die Sequenz von Nedd4.1 in der Ratte, Maus und Mensch gliedert sich in drei, beziehungsweise vier, beim Menschen) WW-Domänen, eine C2-Domäne und eine Ubiquitinligasedomäne vom HECTTyp. Darüber hinaus finden sich zwei konservierte Phosphorylierungsstellen (Abb. 2). In Nedd4.2 fehlt die C2-Domäne.

C2-Domänen binden kalziumabhängig Phospholipide (Ponting und Parker, 1996). Sie finden sich in einer Reihe von Proteinen. Zu den bekanntesten zählen die Phospholipase C (Stahl et al., 1988; Suh et al., 1988), Synaptotagmin (Perin et al., 1990) und Munc13 (Brose et al., 1995). Die C2-Domäne von Nedd4.1 ist homolog zu der in Synaptotagmin und der Proteinkinase C (Plant et al., 1997), allerdings ist eins der fünf konservierten kalziumbindenden Aspartate durch ein Asparagin substituiert. Dennoch bindet Kalzium an die C2-Domäne von Nedd4.1 und induziert die Translokalisation des Proteins an die Plasmamembran (Plant et al., 1997).

Für Nedd4.1 sind verschiedene Interaktionspartner beschrieben worden. Der am besten charakterisierte ist der epitheliale Natrium-Kanal ENaC (Staub et al., 1996), dessen Oberflächenexpression durch Nedd4.1 reguliert wird. Nedd4-Proteine binden außerdem an die L-Domäne der Matrixproteine von Retroviren (Harty et al., 1999, 2000, 2001; Kikonyogo et al., 2001; Yasuda et al., 2002), die nachfolgende Addition von Multiubiquitinketten fördert die Aufnahme und Freisetzung der Viruspartikel in die befallene Zelle durch Endocytose. Weitere Interaktionen mit so unterschiedlichen Proteinen, wie die mit dem Guanin-NukleotidAustauschfaktor CNrasGFP (Pham und Rotin, 2001), dem Golgi-lokalisierten Transmembrandomänenprotein N4WBP5A (Konstas et al., 2002) und dem Adaptorprotein Grb10 (Morrione et al., 1999) weisen ebenfalls darauf hin, daß Nedd4.1 ein Regulatorprotein für mehrere Zielproteine ist und in eine Reihe verschiedener zellulärer Prozesse eingreifen kann. 


\subsubsection{Nedd4.1 und Neuroligin interagieren über WW-Domänen}

Die Interaktion von Nedd4.1 und Neuroligin wurde im Hefe-Doppelhybridsystem identifiziert und mit Hilfe von Kosedimentationsexperimenten und Koimmunpräzipitation verifiziert. Die im Hefesystem gefundenen Nedd4.1-Klone binden mit der zweiten und dritten WW-Domäne an Neuroligin, derselbe Bereich vermittelt auch die Interaktion mit ENaC (Staub et al., 1996). WW-Domänen sind 38 Aminosäuren lange Protein-Protein-Interaktionsmodule (André und Springael, 1994; Bork und Sudol, 1994). Sie binden an eine als PY-Motiv bezeichnete prolinreiche Sequenz mit dem Konsensus XPPXY, wobei X eine nicht konservierte Aminosäure bezeichnet (Staub et al.,1996). Die Mutation im PY-Motiv von ENaC führt zu Liddle's Syndrom, einer autosomalen dominanten Form der Hypertonie (Schild, 1996). In allen Neuroliginisoformen befindet sich eine solche Konsensussequenz (Abb. 3 und 36). Mutationsstudien auf Grundlage der Sequenz von Neuroligin 1 bestätigten die prognostizierte Konsensussequenz als interaktionsvermittelnde Domäne (Abb. 3). Aufgrund der Sequenzhomologie der Neuroligine im Bereich des PY-Motivs ist davon auszugehen, daß diese Region auch in den anderen Isoformen die Interaktion vermittelt.

\subsubsection{Nedd4.1 und Neuroligin kollokalisieren auf der postsynaptischen Seite exzitatorischer Synapsen}

Expressionsanalysen in verschiedenen Geweben zeigten, daß Nedd4.1 in allen untersuchten Geweben expremiert wird (Neeb, 1998, Staub et al., 1996). Eine leicht verstärkte Expressionsrate war in Lunge, Leber und der Niere zu finden (Abb. 8). Alle drei NeuroliginIsoformen sind gehirnspezifisch und auf der postsynaptischen Seite des synaptischen Spalts lokalisiert (Song et al., 1998). Da Nedd4.1 zunächst in Verbindung mit dem epithelialen Natriumkanal $\mathrm{ENaC}$, der präferentiell in der Niere und der Lunge zu finden ist, analysiert wurde, ist seine Lokalisation im Gehirn bislang nicht untersucht worden.

Immundetektionsstudien und in-situ-Hybridisierung in der vorliegenden Arbeit zeigten, daß Nedd4.1 wie die Neuroligine in nahezu allen Regionen des Gehirns expremiert werden (Abb. 7). Doppelfärbungen mit Antikörpern gegen beide Proteine auf kultivierten hippocampalen Neuronen und Sagittalschnitten des Gehirns einer adulten Ratte zeigten, daß Nedd4.1 und NL1 in den meisten Neuronen des Gehirns kollokalisierten (Abb. 8 und 9) und in exzitatorischen Zellen konzentriert sind. Gefärbt wurden Zellkörper und Dendriten, während 
Axone und Zellkerne nicht markiert wurden. Die Analyse einer subzellulären Fraktionierung mit einem Antikörper gegen Nedd4.1 zeigte eine Anreicherung in zwei unterschiedlichen Fraktionen. Ein Teil des Nedd4.1-Proteins fand sich in den Fraktionen des zellulären beziehungsweise synaptosomalen Cytosols. Ein anderer Teil war membrangebunden, wahrscheinlich vermittelt durch membranassoziierte Proteine und kollokalisierte mit den Neuroliginen in der Fraktion der synaptischen Plasmamembranen (Abb. 10). Diese Ergebnisse korrelierten mit dem bereits festgestellten somatodendritischen Verteilungsmuster. Elektronenmikroskopische Analysen bestätigen die synaptische Lokalisation von Nedd4.1. Immunfärbungen ergaben, daß das Nedd4.1-Protein auf der postsynaptischen Seite und dort besonders im Bereich dicht unterhalb des synaptischen Spaltes anreichert ist (Abb. 11).

\subsubsection{Die Expression von Nedd4.1 beginnt bereits während der Embryonalentwicklung}

Mit Hilfe von Immundetektionsanalysen wurde die entwicklungsabhängige Expression von Nedd4.1 im Gehirn der Ratte im Vergleich mit Neuroligin und anderen Markerproteinen untersucht. Nedd4.1 wurde, anders als die typischen synaptischen Proteine wie die Neuroligine oder der NMDA-Rezeptor (Abb. 12), bereits im frühesten untersuchten Stadium (embryonaler Tag 12) stark expremiert. Die Expression des Proteins ist über einen langen Entwicklungszeitraum auf einem recht hohen Niveau, um dann kontinuierlich auf eine relativ niedrige Expressionsrate im adulten Tier herabreguliert zu werden (Abb. 12).

Die Entwicklung des zentralen Nervensystems in der Ratte beginnt etwa um den embryonalen Tag 8 mit der Ausbildung der Neuralplatte aus dem Ektoderm. Am Tag 10 beginnt die Formation des Neuralrohrs und damit die Generation der ersten Nervenzellen aus den neuronalen Vorläuferzellen. Ab dem Tag 12 beginnt die Formation der ersten Synapsen. Die eigentliche Synaptogenese beginnt allerdings erst in den ersten Tagen nach der Geburt. Dann wird ein Übermaß Synapsen gebildet, die dann in einem Prozess der Feinregulierung je nach Intensität der Benutzung verfestigt oder destabilisiert werden. Nedd4.1 wurde, wie bereits erwähnt, ursprünglich aus einer Mäusegehirn-cDNA-Bibliothek gemeinsam mit einer Gruppe anderer Gene neuronaler Vorläuferzellen isoliert, deren Expression im Verlauf der Entwicklung des Nervensystems herabreguliert wird (Kumar et al., 1992). Sein Expressionsmuster während der Entwicklung des Gehirns legt eine Rolle bei der Regulierung der Differenzierung von Nervenzellen nahe. 


\subsubsection{Die Bindung von Nedd4.1 an Neuroligin resultiert nicht in dessen Ubiquitinierung}

Die Bindung von Nedd4.1 und Nedd4.2 an ENaC führt zur Ubiquitinierung eines spezifischen Lysinrestes am C-Terminus des Proteins (Staub et al., 1996; Harvey et al., 1999 und 2001; Kamynina et al., 2001a, b). Als Konsequenz der Ubiquitinierung wird die Anzahl der an der Oberfläche befindlichen Rezeptormoleküle stark reduziert (Staub et al., 1997). Ein ähnlicher Mechanismus wurde auch für die Interaktion von Neuroligin mit Nedd4.1 postuliert, konnte aber durch die Ergebnisse der vorliegenden Arbeit nicht bestätigt werden. Es ist in drei verschiedenen Ansätzen nicht gelungen, die kovalente Bindung von Ubiquitin an Neuroligin oder eine Reduktion von rekombinantem Neuroligin in vivo als Konsequenz der Interaktion mit koexpremiertem Nedd4.1 nachzuweisen (3.3.10; Abb. 13 bis 15). Die mögliche Erklärung, daß das für die Experimente verwendete Nedd4.1-Konstrukt bei rekombinanter Expression möglicherweise nicht aktiv sein könnte, wurde nicht bestätigt. So konnte die Bindung von Ubiquitin an rekombinantes Nedd4.1 nachgewiesen und eine nicht mit Ubiquitin reagierende Mutante generiert werden (Abb. 13). Sie diente in den funktionellen Exprimenten als Negativkontrolle. Auch die Annahme, daß überproportionale Neusynthese des rekombinanten Neuroligins 1 den Effekt des durch Ubiquitin bedingten Abbaus überlagern könnte, konnte durch die Verwendung von stabilisierter DHFR als Expressionkontrolle ausgeschlossen werden (Abb.15). Es ist also davon auszugehen, daß die Bindung von Nedd4.1 an Neuroligin nicht zur Ubiquitinierung des Proteins führt. Auch die Bindung des Adaptermoleküls Grb10 an die C2-Domäne von Nedd4.1 resultiert nicht in dessen Ubiquitinierung (Morrione et al., 1999). Möglicherweise dienen einige Proteine der Zielsteuerung von Nedd4.1. Es wäre vorstellbar, daß Neuroligin Nedd4.1 in der Postsynapse fixiert, um die Ubiquitinierung und damit die Lebensdauer anderer Proteine der postsynaptischen Verdichtung im Verlauf der Synaptogenese oder Synapsenmodulation zu regulieren.

\subsubsection{Die Nedd4.1-Deletionsmutante in der Maus}

Um weiteren Aufschluß über die Funktion und Zielproteine von Nedd4.1 zu erhalten, wurde eine Nedd4.1-Deletionsmutante (knockout-Maus) generiert. In diesem genetischen Ansatz führte die Substitution dreier Exone im vorderen Bereich des Nedd4.1-Gens durch ein Reportergen für Neomycinresistenz zum Abbruch des Proteins nach 153 Aminosäuren. In 
homozygoten Mutanten war weder das möglicherweise C-terminal transkribierte Teilprotein noch Nedd4.1 in ganzer Länge detektierbar (Abb.18).

Der Phänotyp der heterozygoten Nachkommen unterschied sich nicht von dem der WildtypTiere, sie waren normal groß, fertil und zeigten keine Entwicklungsstörungen. Das Verhalten der Tiere erwies sich als normal, sie zeigten sich weder verstärkt aggressiv noch sozial benachteiligt. Beim Aufzuchtverhalten der Muttertiere waren ebenfalls keine Auffälligkeiten $\mathrm{zu}$ beobachten. Trotzdem ergab der Vergleich der Nedd4.1-Expression mittels Immundetektion einen klassischen Gen-Dosis-Effekt (Abb. 19). Der Gehalt an Nedd4.1Protein in den Gehirnen der heterozygoten Tiere war um etwa 50 Prozent geringer als der von Tieren mit zwei Allelen des Nedd4.1-Gens.

\subsubsection{Nedd4.1 ist für die Embryonalentwicklung essentiell}

Die homozygoten Nedd4.1-knockout-Mäuse starben bereits im Embryonalstadium. Das älteste lebende Tier wurde am embryonalen Tag 18,5 identifiziert. Der Phänotyp der Nedd4.1-deletierten Embryos erschien oberflächlich normal. Die Extremitäten und Augen waren vollständig entwickelt, der Aufbau des Gehirns erschien normal. Auffallend war allerdings, daß die Tiere wesentlich kleiner als ihre Geschwister sind und die Vaskualisierung der Eihäute eingeschränkt war (Abb. 20), was Hinweise auf Defizite bei der Angiogenese hinweist. Um den Grund des embryonal letalen Phänotyp der Nedd4.1-deletierten Tiere zu ergründen, sind weitere Untersuchungen nötig, die über den zeitlichen Rahmen der vorliegenden Arbeit hinausgehen. Die Arbeiten werden fortgeführt.

HECT-Domänenproteine sind an der Differenzierung des Zentralnervensystems maßgeblich beteiligt. Angelman-Syndrom-Patienten mit Mutationen im E6AP-Gen beispielsweise leiden unter massiven Beeinträchtigungen im kognitiven Bereich, unter Tremor, Lähmungen, Bewegungsstörungen, Schlaflosigkeit, sind stumm und neigen zu unkontrolliertem Gelächter (Angelman, 1965; Zori et al., 1992). Mäuse, die die Mutationen des Angelman-Syndroms tragen, zeigen ebenfalls motorische Beeinträchtigungen bis hin zu Lähmungen und Defizite in der langfristigen Verstärkung synaptischer Kontakte (long-term potentiation, LTP), in Folge eines Anstiegs von Substratproteinen durch ausbleibende Ubiquitinierung (Jiang et al., 1998). LTP bildet die molekularen Grundlage für Lernen und Gedächtnis. Diese Befunde lassen 
vermuten, daß auch andere HECT-Domänenproteine wie zum Beispiel Nedd4 neuronale Differenzierung regulieren.

Die in den Nedd4.1-Deletionsmutanten beobachteten dramatischen phänotypischen Veränderungen sicher nicht ausschließlich auf neuronale Dysfunktionen zurückzuführen. Vielmehr läßt die ubiquitäre Verteilung des Nedd4.1-Proteins eine Rolle als Effektor in verschiedenen Metabolisierungswegen vermuten. Vermutlich führt die Eliminierung von Nedd4.1 zur Dysfunktion verschiedener Signaltransduktionskaskaden in unterschiedlichen Geweben, in deren Folge es zur Akkumulation von Substratproteinen kommt, die zur Fehlentwicklungen und embryonalen Absterben des Organismus führt. Die eingehende Analyse der Maus-Deletionslinie wird bei diesen Fragen Aufschluß liefern.

\subsubsection{Die Expression von Neuroligin in Nedd4.1-knockout-Mäusen ist unverändert}

Weder der Gen-Dosis-Effekt in den heterozygoten Tieren, noch die vollständige Deletion des Nedd4.1-Proteins in den homozygoten knockout-Mäusen beeinflußt die Anzahl der Neuroligin-Moleküle im Gehirn (Abb. 19 und 21). Da die Interaktion von Nedd4.1 und Neuroligin nicht zu Ubiquitinierung und Reduktion der Neuroliginmoleküle führte, überrascht dieses Ergebnis nicht (siehe 4.5). Genausowenig wirkt sich die Deletion von Neuroligin 1, -2 und -3 aus dem Mäusegehirn auf die Konzentration von Nedd4.1 im Gehirn aus (Abb. 35).

Die ursprüngliche Arbeitshypothese, daß die Bindung und die daraus resultierende Ubiquitinierung des transsynaptischen Zelladhäsionsmolekül Neuroligin direkt als Erklärung für die aktivitätsabhängige Eliminierung von Synapsen im Verlauf der frühen postnatalen Phase der Gehirnentwicklung herangezogen werden kann, konnte durch die Ergebnisse der vorliegenden Arbeit nicht bestätigt werden.

\subsubsection{Fazit}

Nedd4.1 ist als erste Ubiquitinligase in der Postsynapse lokalisiert worden. Seine Interaktion mit dem synaptischen Zelladhäsionsprotein Neuroligin, die hohe Konservierung der Interaktionsdomäne, sein Expressionsmuster im Verlauf der frühen Entwicklung des Gehirns und nicht zuletzt der frühe Tod der Deletionsmutanten im Verlauf der Embryonalentwicklung machen dieses Protein $\mathrm{zu}$ einem höchst interessanten Kandidaten für ein zentrales 
Regulatorprotein der Synapsenmodulation. Möglicherweise dirigiert die Interaktion mit Neuroligin Nedd4.1 zu postsynaptischen Kompartimenten, wo es andere Proteine des postsynaptischen Signaltransduktionapparates ubiquitiert und so auf die Proteinzusammensetzung der Postsynapse Einfluß nimmt.

\subsection{Protein 4.1N und Protein 4.1B}

\subsubsection{Die Proteine 4.1N und 4.1B sind Bestandteile des Cytoskeletts}

Die anderen beiden Proteine, die aufgrund ihrer Interaktion mit Neuroligin in der vorliegenden Arbeit genauer untersucht wurden, sind Protein 4.1N und Protein 4.1B. Sie sind Mitglieder der 4.1-Proteinfamilie, einer wachsenden Familie von Cytoskelettproteinen. Den Prototyp dieser Familie repräsentiert das Protein 4.1R. Es ist in den Erythrocyten im submembranen Cytoskelett lokalisiert, wo es für dessen strukturelle Stabilität wichtig ist. Weitere Mitglieder der Protein-4.1-Familie im mammalen Gehirn sind neben Protein 4.1R (erythrocyte; Holzwarth et al., 1976; Conboy et al., 1986)) das Protein 4.1G (general; Parra et al., 1998), Protein 4.1N (neuronal; Walensky et al., 1999; Yamakawa et al., 1999) und Protein 4.1B (brain; Parra et al., 2000; Yamakawa et al., 2000). Jedes der Proteine west ein typisches Expressionsprofil auf, besitzt mehrere Spleißvarianten und wird von seperaten Genen kodiert (Peters et al., 1998; Parra et al., 2000).

Die 4.1-Proteine regulieren die Dynamik und Beweglichkeit des Cytoskeletts, einem Netz aus Fasern, das die gesamte Zelle ausfüllt und ihre Form bestimmt. Die Hauptkomponente dieser Fasern ist das ATP-bindende Protein Aktin,. Aktin polymerisiert zu Filamenten, welche im Gleichgewicht zum monomeren Aktin stehen. Bündel von Filamenten dienen vorwiegend der Unterstützung von Fortsätzen, während Netzwerke häufig zur Versteifung der Plasmamembran dienen. Aktin-Netzwerke werden über Transmembranproteine mit der Plasmamembran verbunden. Die Quervernetzung von Aktinfilamenten zu Bündeln und Netzwerken wird von Proteinen wie Spektrin vermittelt. Spektrin bildet Tetramere, welche von 4.1-Proteinen zusammengehalten werden. Erst die Tetramerisierung ermöglicht Spektrin, die für die Aktin-Quervernetzung benötigten zwei Aktinbindestellen zur Verfügung zu stellen. Das Zusammenspiel dieser drei Proteine, gemeinsam mit einigen anderen, bestimmt die Beweglichkeit des Cytoskeletts und damit die Fähigkeit der Zelle, ihre Form zu verändern. 


\subsubsection{Cytoskelettproteine modulieren und stabilisieren Synapsen}

Neben der Gestaltung von Form und Fortbewegungsfähigkeit einer Zelle besitzt das Cytoskelett eine weitere essentielle Funktion. Im Verlauf der Evolution wurde es notwendig, der Tendenz der Membranproteine, frei auf der Ebene der Zellmembran zu diffundieren entgegenzuwirken. Für die Kommunikation von Zellen müssen Zelladhäsionsproteine und die Proteine des funktionellen Signalapparates an der Kommunikationsstelle konzentriert sein, um miteinander $\mathrm{zu}$ interagieren und auf diese Weise die gerichtete Signalübertragung zu gewährleisten. Das Cytoskelett ist in der Lage, die Akkumulation und Fixierung der notwendigen Komponenten an den Orten der Kommunikation zu regulieren.

Die Synapsen im Nervensystem sind hoch spezialisierte Zell-Zell-Kontakte, deren Proteinzusammensetzung und Funktionalität äußerst dynamisch ist. Sowohl in der präsynaptischen aktiven Zone (Bradke et al., 1999), als auch in der postsynaptischen Verdichtung (Fischer et al., 1998) besteht eine dichte Ansammlung von Proteinen, deren Zusammenstellung und Ausformung von Cytoskelettproteinen reguliert wird. Die Ausbildung und das Lösen von Proteinverbindungen in diesen Regionen werden unter anderem von Strukturproteinen wie den 4.1- und MAGuK-Proteinen vermittelt. Diese stehen, wie nachfolgend genauer erläutert wird, in enger Verbindung zueinander.

\subsubsection{Die 4.1-Proteine sind Ankerproteine für eine Reihe unterschiedlicher Proteine}

Neben der Quervernetzung von Spektrintetrameren vermitteln die 4.1-Proteine über ihre konservierten Domänen die Integration von funktionellen Komponenten in das Cytoskelett. Alle Mitglieder der Protein-4.1-Familie besitzen dieselbe charakteristische Anordnung dreier Domänen, der N-terminalen 4.1-Homologiedomäne (FERM-Domäne oder 4.1HD), gefolgt von der zentralen Spektrin/Aktin Bindedomäne (SABD) und der C-terminalen Domäne (CTD) (Abb 22). Die 4.1-Proteine benutzen diese spezifischen Domänen um eine Reihe sehr unterschiedlicher Interaktionspartner $\mathrm{zu}$ binden. So sind für die 4.1-Homologiedomäne Transmembranproteine wie Glycophorin C und D (Hemming et al., 1994; Marfatia et al., 1995), MAGuK-Proteine wie p55 oder hDLG (Marfatia et al., 1995; Pasternack et al., 1985),

Signaltransduktionsproteine wie $\mathrm{Ca}^{2+}$-Calmodulin (Tanaka et al., 1991) oder der Zellzyklusregulator CD44 (Nunomura et al., 1997) als Bindeproteine beschrieben worden. Die 4.1-Homologiedomäne kann inter- und intramolekular mit dem C-Terminus und anderen 
4.1-Homologiedomänen interagieren. Ihre Bindungseigenschaften werden von Phosphoinositiden und durch Phosphorylierung unterschiedlicher Proteinkinasen reguliert (Hamada et al., 2000; Pearson et al., 2000). Die Spektrin/Aktin Bindedomäne stellt über Spektrin den Kontakt zum Aktincytoskelett her (Ohanian et al., 1984). Die C-terminale Domäne interagiert mit der AMPA-Rezeptoruntereinheit GluRI (Shen et al., 2000), dem Chaperon FKBP13 (Walensky et al., 1998) und NuMA (Ye et al., 1999), einem Bestandteil des nuklearen Mitoseapparats.

\subsubsection{Die 4.1-Poteine und Synaptogenese}

Da 4.1-Proteine als Interaktionspartner des potentiellen Synaptogeneseregulators Neuroligin fungieren, ist es natürlich von Interesse, ob 4.1-Proteine auch mit Entwicklungsprozessen im Allgemeinen und in der Synapse im Besonderen in Verbindung stehen könnten. In diesem Zusammenhang ist die Interaktion des MAGuKs CASK mit Protein 4.1 (Cohen et al., 1998) bedeutsam. CASK bindet den C-Terminus von Syndecan-2, einem Zelladhäsionsprotein aus der Familie der Zelloberflächen-Heperansulfatproteoglycane (HSPGs). Das Protein ist spezifisch synaptisch lokalisiert und akkumuliert relativ spät in der Synapse (Ethel et al., 1999, Hsueh et al., 1999). Syndecan-2 fördert die Reifung von dendritischen spines, jenen Ausformungen synaptischer Dendriten, welche die Grundlage für die postsynaptische Verdichtung liefern (Ethel et al., 1999, 2001). Spines entstehen induziert durch präsynaptische Aktivität durch lokale Umformungen des Cytoskeletts an den Kontaktstellen zwischen sich entwickelnder Präsynapse und Dendrit. Überexpression von Syndecan-2 führt zur verfrühten Ausbildung von spines. Der frühe Reifungsprozess ist jedoch nicht zu beobachten, wenn der C-Terminus von Syndecan-2 fehlt (Hsueh et al., 1998). Die Interaktion mit dem MAGuK CASK und damit der Kontakt zum Cytoskelett über Protein 4.1 scheint daher für die Funktion von Syndecan-2 essentiell zu sein.

Die Interaktion zwischen CASK und Protein 4.1 ist in Erythrocyten gefunden worden. In Neuronen interagiert CASK mit $\beta$-Neurexin (Hata et al., 1996). CASK ist über Mint1 und Veli mit dem Regulator der Neurotransmittersekretion Munc18 (Butz et al., 1998) und so direkt mit dem Signaltransduktionsapparat der Präsynapse verbunden. Die Bindung CASK an Protein 4.1N (Biederer und Südhof, 2000) verbindet das Neuroligin/ $\beta$-NeurexinAdhäsionssystem mit dem Cytoskelett. Wie die Ergebnisse der vorliegenden Arbeit zeigen, ist 
auch das postsynaptische Neuroligin ebenfalls über 4.1-Proteine mit dem Cytoskelett verbunden.

\subsubsection{Neuroligin bindet an die C-terminale Domäne von Protein 4.1B und Protein 4.1N}

Die Interaktion von Neuroligin mit den Proteinen 4.1N und 4.1B wurde im HefeDoppelhybridsystem entdeckt und in Koimmunpräzipitations-Experimenten verifiziert (Abb.1, 22, und 25). Der cytoplasmatische C-Terminus von Neuroligin interagierte mit der Cterminale Domäne von Protein 4.1N und Protein 4.1B (Abb. 25). Auf der Seite von Neuroligin schien eine Ansammlung positiv geladener Reste nahe der Transmembrandomäne gemeinsam mit einer weiteren weiter C-terminalen Region für die Bindung von 4.1-Proteinen verantwortlich zu sein (Abb 26 und 36). Ähnliche, membranständige, positiv geladene Regionen vermitteln auch in Glycophorin C (Marfatia et al., 1994), GluRI (Shen et al., 2000), Paranodin (Menegoz et al., 1997), Neurexin I (Biederer und Südhof, 2001) und der Drosophila-Isoform von Neurexin IV (Ward et al., 1998) die Bindung an 4.1-Proteine. Die Tatsache, daß diese Region in dem Neuroligin 1-Konstrukt, das für den yeast-two-hybridscreen verwendet wurde, fehlte, führt zu dem Schluß, daß beide Bereiche in der Lage sind, die Bindung an Protein 4.1 zu vermitteln. Tatsächlich kommen Coleman et al. (2003) in ihren Studien über die Interaktion zwischen Protein 4.1 und AMPA-Rezeptoruntereinheiten zu einem ähnlichen Ergebnis. Sie postulieren, daß die distal gelegene Region die Bindung unterstützt und für die Untereinheitenspezifität der Interaktion sorgt. Interessanterweise ist der positiv geladenen Bereich in GluRI, welcher die Bindung an Protein 4.1 vermittelt, auch für die Zielsteuerung des Proteins essentiell (Coleman et al., 2003). Der Zusammenhang zwischen der Zielsteuerung eines Proteins und der Interaktion mit 4.1-Proteinen wird im Abschnitt 4.2.10 eingehender erläutert.

\subsubsection{Neuroligin kollokalisiert mit Protein 4.1B und Protein 4.1N in Teilen des Gehirns}

Um die in in vitro-Experimenten gefundenen Interaktionen zu stützen, ist es sinnvoll, die Expressionsprofile interagierender Proteine miteinander zu vergleichen. Auf diese Weise läßt sich ersehen, ob die Interaktionpartner sowohl räumlich, als auch zeitlich koexprimiert werden. Die Neuroligine 1, -2 und -3 sind gehirnspezifische Proteine, die spezifisch auf der postsynaptischen Seite von exzitatorischen Synapsen lokalisiert sind (Song et al., 1998). Wie 
die vorliegende Studie zeigte, werden die Proteine $4.1 \mathrm{~N}$ und $4.1 \mathrm{~B}$ abhängig von ihren Spleißvarianten sowohl auf mRNA- als auch auf Proteinebene in unterschiedlichen Geweben exprimiert (Abb. 26). Varianten beider Protein 4.1-Isoformen waren im Gehirn angereichert. Innerhalb des Gehirns waren die Proteine 4.1N und 4.1B, wie Neuroligin, in allen Regionen nachweisbar (Abb. 27B). In-situ-Hybridisierungen ergaben, daß ihre mRNA vorwiegend in Neuronen exprimiert werden (Abb 27A). Das Verteilungsmuster der Proteine deutete auf eine somatodendritische Lokalisationion hin. Die Ergebnisse deckten sich in weiten Teilen mit den publizierten (Parra et al., 2000; Walensky et al., 1999) und der Kollokalisation von Protein 4.1N mit den postsynaptischen Markerproteinen PSD95 und GluRI (Walensky et al., 1999). Die Analyse der subzellulären Fraktionierung mit Antikörpern gegen beide Proteine wies, sowohl Protein 4.1N als auch Protein 4.1B in allen Kompartimenten der Zelle nach (Abb. 29). Neben den 4.1-Proteinen in der cytosolischen Fraktion akkumulierten Teile des zellulären 4.1-Proteins, vermutlich gebunden an Membranproteine, in den Fraktionen der synaptischen Plasmamembranen. Die Befunde stehen in guter Übereinstimmung mit Veröffentlichungen, nach denen alle vier neuronalen 4.1-Proteine in Präparationen der postsynaptischen Verdichtung nachweisbar sind (Scott et al., 2001). Zusätzliche Immunfärbungen (Abb. 28) wiesen die Kollokalisation von Neuroligin 1 und Protein 4.1B in den Somata und Dendriten von Purkinjezellen nach.

\subsubsection{Die Expression von Neuroligin, Protein 4.1B und Protein 4.1N verläuft parallel zur Synaptogenese}

In Studien zur entwicklungsabhängigen Expression zeigten die Proteine 4.1N und 4.1B das typische Expressionsprofil synaptischer Proteine, ebenso wie die Neuroligine und die NMDA-Rezeptoruntereinheit NMDARI (Song et al., 1998). Beide 4.1-Proteine waren bereits im Embryonalgewebe nachweisbar (Abb. 30) . Deutliche Expression war kurz nach der Geburt zu beobachten und in der Folge stieg die Expressionsrate parallel zur Synapsenzahl. Das entwicklungsabhängige Expressionsprofil und die gemeinsame Lokalisation von Neuroliginen und 4.1-Proteinen auf der postsynaptischen Seite von exzitatorischen Synapsen unterstützen die im Doppelhybridsystem und in den Koimmunpräzipitations-Experimenten gefundene Interaktion. Nachfolgend soll nun erörtert werden, welche Funktion diese Interaktion in vivo hat. 


\subsubsection{Neuroligin und 4.1-Proteine bilden Komplexe mit MAGuK-Proteinen}

Die 4.1-Proteine sind Ankerproteine, welche die Proteine des funktionellen Apparats mit dem Cytoskelett verbinden. Ein in diesem Zusammenhang immer wiederkehrendes Prinzip ist ein ternärer Komplex zwischen einem 4.1-Protein, einem MAGuK und einem Transmembranprotein des Typs I.

Der Komplex zwischen Protein 4.1R, p55 und Glycophorin C in der Erythrocytenmembran ist bereits detailiert charakterisiert worden (Marfatia et al., 1995 und 1997; Hemming et al., 1994 und 1995). In die Formation des Komplexes sind zwei Bindestellen am 4.1-Protein involviert, die C-terminale Domäne bei der Bindung an das cytoplasmatische Ende des Transmembrandomänenprotein und die 4.1-Homologiedomäne bei der Interaktion mit einer als HOOK-Region bezeichneten Sequenz im PDZ-Domänenprotein. Andere Beispiele sind die Komplexe zwischen Neurexin, Protein 4.1N und dem MAGuK CASK (Biederer und Südhof, 2001) sowie zwischen AMPA-Rezeptoruntereinheiten, Protein 4.1N und einer bestimmten Spleißvariante des MAGuKs SAP97 (Rumbaugh et al., 2003; Shen et al., 2000).

Es lag die Vermutung nahe, daß auch Neuroligin Bestandteil eines solchen Komplexes ist. In der vorliegenden Studie wurde die Bindung von Neuroligin 1 und -2 an Protein 4.1N und Protein 4.1B in vitro nachgewiesen und in vivo verifiziert und damit ein klarer Hinweis auf die Existenz eines solchen ternären Komplexes gefunden. Neuroligine binden eine Reihe von Proteinen der MAGuK-Familie wie zum Beispiel PSD95, PSD93, SAP97 und SAP102 (Irie et al., 1997). In Kosedimentationsexperimenten wurde die Fähigkeit dieser MAGuKs, an die 4.1-Homologiedomäne von Protein 4.1N und Protein 4.1B zu binden, überprüft (Abb. 31). Die MAGuKs PSD95 und SAP97 interagierten mit beiden Protein 4.1-Isoformen, wobei PSD95 stärker zur Bindung an Protein 4.1B tendierte und SAP97 eine höhere Affinität zu Protein 4.1N zeigte. Die Interaktion mit PSD93 konnte nur für Protein 4.1N gezeigt werden, SAP102 band keines der beiden 4.1-Proteine.

\subsubsection{Die Verankerung von Neuroligin im Cytoskelett ist nicht abhängig von seiner Interaktion mit MAGuK-Proteinen}

Für Neurexin wurde gezeigt, daß die Integration seines cytoplasmatischen C-Terminus in das Cytoskelett über Protein 4.1N von der Anwesenheit der PDZ-Erkennungssequenz für CASK 
abhängig ist (Biederer und Südhof, 2001). In der vorliegenden Arbeit konnte dies für Neuroligin nicht bestätigt werden (Abb. 32). Die Experimente zeigten, daß die cytoplasmatische Domäne in Aktin-Mikrofilamente integriert wird und daß dieser Prozeß unabhängig von der Bindung des Proteins an PDZ-Domänen ist. Die Integration von Neuroligin in das Aktincytoskelett verläuft also entweder direkt oder wahrscheinlicher durch Interaktion mit 4.1-Proteinen.

\subsubsection{Der cytoplasmatische C-Terminus, nicht aber die PDZ-Interaktion ist essentiell für die Zielsteuerung und Neuroligin}

Es gibt einige Hinweise darauf, daß 4.1-Proteine über ihre Funktion als universelle Ankerproteine hinaus an der Zielsteuerung von Proteinen beteiligt sind. In Erythrocyten, die kein Protein 4.1R bilden, erscheinen weder Glycophorin C noch p55 an der Plasmamembran (Shi et al., 1999). In Deletionsmutanten des Drosophila-Homologs von Protein 4.1, Coracle, kommt es nicht mehr zur Akkumulation seines Interaktionspartners Neurexin IV an der Plasmamembran (Lamb et al., 1998). Die Lokalisierung der AMPA-Rezeptoruntereinheiten GluR-A und GluR-D in HEK293-Zellen und in kultivierten Neuronen ist ebenfalls abhängig von der Fähigkeit der Rezeptoren, 4.1-Proteine zu binden (Coleman et al., 2003; Shen et al., 2000), Ein ähnliches Phänomen ist auch für den Inositol-1,4,5-Triphosphat-Rezeptor des Typs I beschrieben worden (Zhang et al., 2002). Lokalisationsstudien in humanen Leberzellinien und kultivierten hippocampalen Neuronen der vorliegenden Arbeit sollten analysieren, ob ein ähnliches Prinzip auch für Neuroligin zu beobachten ist. Tatsächlich war die Translokalisation von rekombinanten Neuroligin 1-GFP-Fusionsproteinen an die Plasmamembran von der Anwesenheit des cytoplasmatischen C-Terminus abhängig. Eine Minimalsequenz in Form der ersten 25 Aminosäuren des cytoplasmatischen Teils von Neuroligin 1 ermöglichte bereits die korrekte Lokalisation zur Plasmamembran. Interesseanterweise wurde in dieser Region eine der beiden Interaktionsdomänen für Protein 4.1 kartiert (Abb. 26). Die Entfernung der Erkennungsequenz für die PDZ-Domänen der MAGuKs hatte keine Auswirkung auf die Lokalisation des Konstrukts (Abb. 33 und 34). Diese Ergebnisse legen die Schlußfolgerung nahe, daß 4.1-Proteine aber nicht PDZ-Domänenproteine wie die MAGuKs für die Zielsteuerung von Neuroliginen zur Plasmamembran verantwortlich sein könnten. 


\subsubsection{Fazit}

Neuroligin bindet neben den bereits beschriebenen intrazellulären Interaktionspartnern, den MAGuK-Proteinen PSD95, PSD93, SAP97, SAP102 und der Ubiquitinligase Nedd4.1, zwei neuronale Cytoskelettproteine, Protein 4.1N und Protein 4.1B. Diese verankern Proteine mit dem Cytoskelett und ermöglichen auf diese Weise die Akkumulation von funktionellen Komponenten an den Orten der Zell-Zell-Kommunikation, wie zum Beispiel den Synapsen. Die Ergebnisse der vorliegen Arbeit deuten darauf hin, daß die Bindung von Neuroligin an 4.1-Proteine Einfluß auf die Zielsteuerung und Verankerung von Neuroliginen in das Aktincytoskelett der postsynaptischen Verdichtung nimmt. Neuroligin verfügt über die Interaktion mit den Proteinen 4.1N und Protein 4.1B und die MAGuK-Proteine über ein dynamisches Netz an Verbindungen zu einer Reihe von unterschiedlichen postsynaptischen Proteinen. Wie im Fall der Interaktion von Neurexin, CASK und Protein 4.1N auf der präsynaptischen Seite verknüpfen so die Neuroligine auf der postsynaptischen Seite funktionell relevante Proteine mit den Strukturproteinen des Cytoskeletts. Auf diese Weise ist das von Neuroligin und $\beta$-Neurexin gebildete Zelladhäsionsystem Ausgangs- und Steuerungspunkt für die Akkumulation, den Erhalt und die Dynamik von synaptischen Proteinkomponenten an den Kontaktstellen zwischen Axon und Dendrit. 


\section{ZUSAMMENFASSUNG}

Die Neuroligine sind postsynaptisch lokalisierte Transmembranproteine. Sie bilden mit $\beta$ Neurexin ein transsynaptisches Zelladhäsionssystem, dessen Lokalisation und Eigenschaften auf eine Beteiligung an der Steuerung von Synaptogeneseprozessen hinweisen. Während die Interaktion mit $\beta$-Neurexin recht gut charakterisiert ist, war über die intrazellulären Bindungspartner der Neuroligine zu Beginn der hier beschriebenen Studien wenig bekannt. In der vorliegenden Arbeit wurden drei Proteine untersucht, die an den cytoplasmatischen Teil von Neuroligin binden, die Ubiquitinligase Nedd4.1 und die Strukturproteine Protein 4.1N und Protein 4.1B. Diese wurden hinsichtlich ihrer Lokalisation, Funktion und Interaktion mit Neuroligin charakterisiert. Alle drei Interaktionen wurden im Hefe-Dopppelhybridsystem gefunden und konnten durch Kosedimentationsexperimente sowie Koimmunpräzipitationen verifiziert werden.

Ubiquitinligasen wie Nedd4.1 regulieren durch Ubiquitinierung verschiedener Zelloberflächenproteine deren ligandenvermittelte Endozytose und anschließende Degradation im Lysosom (Hicke und Riezman, 1996; Hochstrasser, 1996). Auf diese Weise wird eine Reihe wichtiger zellulärer Prozesse, unter anderem die Modulation von Synapsen, reguliert. Die Ergebnisse der vorliegenden Arbeit lokalisieren Nedd4.1 als erste Ubiquitinligase in der Postsynapse, in der ein Großteil der ubiquitinregulierten Modulationen in der Synapse stattfinden. Sie zeigen die Interaktion zwischen den WW-Domänen von Nedd4.1 und einer als PY-Motiv bezeichneten Region am C-Terminus von Neuroligin. Nedd4.1 wird ubiquitär in allen untersuchten Geweben und Gehirnregionen exprimiert, Neuroligin und Nedd4.1 kollokalisierten im Somata und Dendriten von Nervenzellen. Ein Teil des zellulären Nedd4.1 akkumuliert, gebunden an Transmembrandomänenproteine wie Neuroligin, an der postsynaptischen Plasmamembran. Die Interaktion zwischen Nedd4.1 und Neuroligin resultiert nicht in dessen Ubiquitinierung. Offensichtlich bindet Neuroligin Nedd4.1 in der submembranen Matrix der Postsynapse, um so andere postsynaptische Zielproteine zu beeinflussen. Um Aufschluß über die Funktion und Zielproteine von Nedd4.1 zu erhalten, wurde eine Nedd4.1-Deletionsmutante in der Maus generiert. Diese Mutanten sterben bereits im Embryonalstadium, Nedd4.1 ist also für die Embryonalentwicklung essentiell. Die Konzentration von Neuroligin wird von der Nedd4.1-Deletion in den 
Embryonen nicht beeinflußt. Die weiterführende Analyse dieser Deletionsmutante wird Aufschluß über die Funktion von Nedd4.1 in der Embryonalentwicklung liefern.

Die Proteine 4.1N und 4.1B koordinieren die Integration von funktionellen Proteinkomponenten in das Cytoskelett und tragen über die Vernetzung von Spektrintetrameren zu dessen Stabilisierung bei. Wie die vorliegende Studie zeigt, werden beide hier analysierten 4.1-Proteine präferentiell im Gehirn exprimiert, finden sich aber auch in der Lunge, der Niere und im Skelettmuskel. Protein 4.1B kollokalisiert mit Neuroligin im Somata und den Dendriten von Nervenzellen. Die entwicklungsabhängige Expression der Proteine $4.1 \mathrm{~N}$ und 4.1B verläuft parallel $\mathrm{zu}$ der von Neuroligin und dem Anstieg der Synapsenzahl. Die Ergebnisse der vorliegenden Arbeit zeigen die Existenz von ternären Komplexen zwischen Neuroligin, 4.1-Proteinen und den MAGuKs PSD95, PSD93 und SAP97 in der submembranen Matrix der Postsynapse. Ein ähnlicher ternärer Komplex ist auch für den extrazellulären Bindungspartner von Neuroligin $\beta$-Neurexin mit CASK und Protein 4.1 auf der präsynaptischen Seite beschrieben worden ist (Biederer und Südhof, 2000). Die vorliegenden Daten zeigen außerdem, daß die Protein-4.1-Binderegion der Neuroligine, nicht aber die Erkennungssequenz für die MAGuK-Proteine für die Zielsteuerung und Verankerung von Neuroligin in das Aktincytoskelett beziehungsweise zur Plasmamembran essentiell ist. 


\section{LITERATURVERZEICHNIS}

Anderson, J. M. (1996) Cell signaling: MAGUK magic. Curr. Biol. 6, 382-384.

André, B., Springael, J. Y. (1994) WWP, a new amino acid motif present in single or multiple copies in various proteins including dystrophin and the SH3-binding Yes-associated protein YAP65. Biochem. Biophys. Res. Commun. 205(2), 1201-1205.

Angelman, H. (1965) 'Puppet' children. A report on three cases. Dev. Med. Child. Neur. 7, 681-688.

Auld, V. J., Fetter, R. D., Broadie, K., Goodman, C. S. (1995) Gliotactin, a novel transmembrane protein on peripheral glia, is required to form the blood-nerve barrier in Drosophila. Cell 81, 757-767.

Barnstable, C. J., Hofstein, R., Akagawa, K. (1985) A marker of early amacrine cell development in rat retina. Brain Res. 352(2):286-90.

Benson, D. L., Tanaka, H, (1998) N-cadherin redistribution during synaptogenesis in hippocampal neurons. J. Neurosci. 18(17), 6892-6904.

Biederer T., Yildrim S.., Mozhayeva, M., Atasoy D., Liu X., Kavalali, E. T., Südhof T. C. (2002) SynCAM, a synaptic adhesion molecule that drives synapse assembly. Science 297, 1525-1531.

Bollinger, M. F., Frei, K., Einterhalter, K. H., Gloor, S. M. (2001) Identification of a novel neuroligin in humans which binds to PSD-95 and has a widespread expression. Biochem J. $356,581-588$.

Bork, P., Sudol, M. (1994) The WW domain: a signalling site in dystrophin? Trends Biochem. Sci. 19(12), 531-533. 
Bozdagi, O., Shan, W., Tanaka, H., Benson, D. L., Huntley, G. W. (2000) Increasing numbers of synaptic puncta during late-phase LTP: N-cadherin is synthesized, recruited to synaptic sites, and required for potentiation. Neuron 28, 245-259.

Bradke F, Dotti CG.(1999) The role of local actin instability in axon formation. Science 283(5409), 1931-1934.

Brandstatter, J. H., Lohrke, S., Morgans, C. W., Wassle, H. (1996) Distributions of two homologous synaptic vesicle proteins, synaptoporin and synaptophysin, in the mammalian retina. J Comp Neurol 370, 1-10.

Brenman, J. E., Chao, D. S., Gee, S. H., McGee, A. W., Craven, S. E., Santillano, D. R., Wu, Z., Huang, F., Xia, H., Peters, M. F., Froehner, S. C., Bredt, D. S. (1996) Interaction of nitric oxide synthase with the postsynaptic density protein PSD-95 and alpha1-syntrophin mediated by PDZ domains. Cell 84, 757-767.

Brose, N., Huntley, G. W., Stern-Bach, Y., Sharma, G., Morrison, J.H., Heinemann, S. F. (1994) Differential assembly of coexpressed glutamate receptor subunits in neurons of rat cerebral cortex. J. Biol. Chem. 269, 16780-16784.

Brose N., Hofmann K., Hata Y., Südhof T. C. (1997) Mammalian homologues of Caenorhabditis elegans unc-13 gene define novel family of $\mathrm{C} 2$-domain proteins. J. Biol. Chem. 270(42), 25273-25280.

Brose, N. (1999) Synaptic cell adhesion proteins and synaptogenesis in the mammalian central nervous system. Naturwiss. 86, 516-524.

Bruses, J. L. (2000) Cadherin-mediated adhesion at the interneuronal synapse. Curr. Opin. Cell Biol. 12, 593-597.

Butz, S., Okamoto, M., Südhof, T. C. (1998) A tripartite protein complex withthe potential to couple synaptic vesicle exocytosis to cell adhesion in brain. Cell 94, 773-782. 
Cantallops, I., Cline, H. T. (2000) Synapse formation: if it looks like a duck and quacks like a duck .... Curr Biol. R620-623.

Caruthers, M. H., Beaton, G., Wu, J. V., Wiesler, W. (1992) Chemical synthesis of deoxyoligonucleotides and deoxyoligonucleotide analogs. Proc. Nat. Sc. 91, 5022-5026.

Chapman, A. P., Smith, S. J., Rider, C. C., Beesley, P. W. (1994) Multiple ubiquitin conjugates are present in the rat brain synaptic membranes and postsynaptic densities. Neurosci. Lett. 168, 238-242.

Chiba, A., Keshishian, H. (1996) Neuronal pathfinding and recognition: roles of cell adhesion molecules. Dev. Biol. 18, 424-432.

Ciechanover, A. (1994) The ubiquitin-proteasome protealytic pathway. Cell 79 (1), 13-21.

Cohen, A. R., Woods, D. F., Marfatia, S. M., Walther, Z., Chishti, A. H., Anderson, J. M. (1998) Human CASK/LIN-2 binds syndecan and protein 4.1 and localizes to the basolateral membrane of epithelial cells. J. Cell Biol. 142, 129-138.

Coleman, S. K., Cai, C., Mottershead, D. G., Haapalahti, J. P., Keinanen, K. (2003) Surface expression of GluR-D AMPA receptor is dependent on an interaction between its C-terminal domain and a 4.1 protein. J. Neurosci. 23(3), 798-806.

Conboy, J., Mohandas, N., Tchernia, G., Kan, Y. W. (1986) Molecular basis of hereditary elliptocytosis due to protein 4.1 deficiency. N. Engl. J. Med. 315, 680-685.

Craven, S. E., Bredt, D. S. (1998) PDZ proteins organize synaptic signaling pathways. Cell 93, 495-498.

Deguchi M., Hata, Y., Takeuchi, M., Ide, N., Hirao, K., Yao, I., Irie, M., Toyoda, A., Takai, Y. (1998) BEGAIN (brain-enriched guanylate kinase-associated protein), a novel neuronal PSD-95/SAP90-binding protein. J. Bio.l Chem. 273, 26269-26272. 
DiAntonio A., Haghighi A. P., Portman S. L., Lee J. D., Amaranto A. M., Goodman C. S. (2001) Ubiquitination-dependent mechanisms regulate synaptic growth and function. Nature 412(6845), 449-452.

Ehlers, M. D. (2003) Activity level controls postsynaptic composition and signaling via the ubiquitin-proteasome system. Nat. Neurosci. 6 (3), 231-242.

Ethell, I. M. und Yamaguchi, Y. (1999) Cell surface heparan sulfate proteoglycan syndecan-2 induces the maturation of dendritic spines in rat hippocampal neurons. J. Cell Biol. 144(3), $575-586$.

Ethell, I. M., Irie, F., Kalo, M. S., Couchman, J. R., Pasquale, E. B., Yamaguchi, Y. (2001) EphB/syndecan-2 signaling in dendritic spine morphogenesis.

Neuron 31(6), 1001-1013.

Fannon, A. M., Colman, D. R. (1996) A model for central synaptic junctional complex formation based on the differential adhesive specificities of cadherins. Neuron 17, 423-434.

Feldman R. M., Correll C. C., Kaplan K. B., Deshaies R. J. (1997) A complex of Cdc4p, Skp1p, and Cdc53p/cullin catalyzes ubiquitination of the phosphorylated CDK inhibitor Sic1p. Cell 91(2), 221-230.

Fields, S., Song, O. (1989) A novel system to detect protein-protein interactions. Nature 340, 245-246.

Fischer M., Kaech S., Knutti D., Matus A.(1998) Rapid actin-based plasticity in dendritic spines. Neuron 20(5), 847-54.

Flann S., Hawkes R. B., Riederer B. M., Rider C. C., Beesley P. W. (1997) Changes in ubiquitin immunoreactivity in developing rat brain: a putative role for ubiquitin and ubiquitin conjugates in dendrite outgrowth and differentiation. Neuroscience 81(1), 173-187. 
Geinisman, Y., deToledo-Morrell, L., Morrell, F. (1991) Induction of long-term potentiation is associated with an increase in the number of axospinous synapses with segmented postsynaptic densities. Brain Res. 566 (1-2), 77-88.

Goodman, C. S. (1996) Mechanisms and molecules that control growth cone guidance. Annu. Rev. Neurosc. 19, 341-377.

Grand, S. G., O’Dell, T. J., Karl, K. A., Stein, P. L., Soriano, P., Kandel, E. R. (1992) Impaired long term potentiation, spatial learning, and hippocampal development in fyn mutant mice. Science 258, 1903-1910.

Guan, K. L., Dixon, J. E. (1991) Eucaryotic proteins expressed in Escheria coli: an improved trombin cleavage and purification procedure of fusion proteins with Glutathione-Stransferase. Anal. Biochem. 192, 262-267.

Hagler, D. J., Goda, Y. (1998) Synaptic adhesion: The building blocks of memory? Neuron 20, 1059-1062.

Hamada, K., Shimizu, T., Marsui, T., Tsukita, S., Hakoshima, T. (2000) Structural basis of the membrane-targeting and unmasking mechanisms of the radaxin FERM domain. EMBO J. $19,4449-4462$.

Harty R. N., Paragas J., Sudol M., Palese P. (1999) A proline-rich motif within the matrix protein of vesicular stomatitis virus and rabies virus interacts with WW domains of cellular proteins: implications for viral budding. J. Virol. 73(4), 2921-2929.

Harty R. N., Brown M. E., Wang G., Huibregtse J., Hayes F. P. (2000) A PPxY motif within the VP40 protein of Ebola virus interacts physically and functionally with a ubiquitin ligase: implications for filovirus budding. Proc. Natl. Acad. Sci. U S A 97(25), 13871-13876.

Harty R. N., Brown M. E., McGettigan J. P., Wang G., Jayakar H. R., Huibregtse J. M., Whitt M. A., Schnell M. J. (2001) Rhabdoviruses and the cellular ubiquitin-proteasome system: a budding interaction. J. Virol. 75(22), 10623-10629. 
Harvey; K. F., und Kumar, S. (1999) Nedd4-like proteins: an emerging family of ubiquitinprotein ligases implicated in diverse cellular functions. Trends Cell Biol. 9, 166-169.

Harvey K. F., Dinudom A., Cook D. I., Kumar S.(2001) The Nedd4-like protein KIAA0439 is a potential regulator of the epithelial sodium channel. J. Biol. Chem. 276(11), 8597-8601.

Hata, Y., Butz, S., Südhof, T. C. (1996) CASK: a novel dlg/PSD95 homolog with an Nterminal calmodulin-dependent protein kinase domain identified by interaction with neurexins. J. Neurosci. 16, 2488-2494.

Hegde A. N., Inokuchi K., Pei W., Casadio A., Ghirardi M., Chain D. G., Martin K. C., Kandel E. R., Schwartz J. H. (1997) Ubiquitin C-terminal hydrolase is an immediate-early gene essential for long-term facilitation in Aplysia. Cell 89(1), 115-126.

Hemming, N. J., Anstee, D. J., Mawby, W. J., Reid, M. E., Tanner, M. J. (1994) Localization of the 4.1-binding site on human erythrocyte glycophorins C and D. Biochem. J. 299, 191196.

Hicke, L. und Riezman, H. (1996) Ubiquitination of a yeast plasma membrane receptor signals ist ligand-stimulated endocytosis. Cell. 84. 277-287.

Hicke, L. (1997) Ubiquitin-dependent internalisation and down-regulation of plasma membrane proteins. FASEB J. 11 (14), 1215-1226.

Hicke, L. (2001) Protein regulation by monoubquitin. Nat. Rev. Mol. Cell. Biol. 2, 195-201.

Higuchi, R. (1990). In PCR Protocols: A Guide to Methods and Applications, M. A. Innis, D. H. Gelfand, J. J. Sninsky und T. J. White, eds. (New York: Academic Press), 177-183.

Hirayama, T., Sugino, H., Yagi, T. (2001) Somatic mutations of synaptic cadherin (CNR family) transcripts in the nervous system. Genes Cells. 6, 151-64.

Hochstrasser, M. (1996) Protein degradation or Regulation: Ub the judge. Cell 84, 813-815. 
Holzwarth, G., Yu, J., Steck, T. L. (1976) Heterogenetiy in the conformation of different protein fractions from the human erythrocyte membrane. J. Supramol. Struct. 4, 161-168.

Hoover, K. B. und Bryant, P. J. (2000) The genetics of the 4.1 family: organizers of the membrane and cytoskeleton. Curr. Opin. Cell Biol. 12, 229-234.

Hortsch, M., Patel, N. H., Bieber, A. J., Traquina, Z. R., Goodman, C. S. (1990) Drosophila Neurotactin, a surface glycoprotein with homology to serine esterases, is dynamically expressed durin embryogenesis. Development 110, 1327-1340.

Hsueh, Y. P., Yang, F. C., Kharazia, V., Naisbitt, S., Cohen, A. R., Weinberg, R. J., Sheng, M. (1998) Direct interaction of CASK/LIN-2 and syndecan heparan sulfate proteoglycan and their overlapping distribution in neuronal synapses. J. Cell Biol. 142(1), 139-151.

Hsueh, Y. P. und Sheng, M. (1999) Regulated expression and subcellular localization of syndecan heparan sulfate proteoglycans and the syndecan-binding protein CASK/LIN-2 during rat brain development. J. Neurosci. 19(17), 7415-7425.

Huibregtse J. M., Scheffner M., Howley P. M. (1991) A cellular protein mediates association of p53 with the E6 oncoprotein of human papillomavirus types 16 or 18. EMBO J. 10, 41294135.

Huibregtse J. M., Scheffner M., Howley P. M. (1993) Cloning and expression of the cDNA for E6-AP, a protein that mediates the interaction of the human papillomavirus E6oncoprotein with p53. Mol. Cell. Biol. 13, 775-784.

Huibregtse J. M., Scheffner M., Beaudenon S., Howley P. M. (1995) A family of proteins structurally and functionally related to the E6-AP ubiquitin-protein ligase. Proc Natl Acad Sci U S A 92(7), 2563-2567. Erratum in: Proc Natl Acad Sci U S A 1995, 92(11), 5249.

Huntley, G. W. und Benson, D. L. (1999) Neuronal (N)-cadherin at developing thalamocortical synapses provides an adhesion mechanism for the formation of somatopically organized connections. J. Comp.Neurol. 407, 453-471. 
Husi, H., Ward, M. A., Choudhary, J. S. Blackstock, W. P., Grand, S. G. (2000) Proteomic analysis of NMDA receptor-adhesion protein signaling complexes. Nat. Neurosci. 3, 661-669.

Huttner, W. B., Schiebler, W., Greengard, P. und De, C. P. (1983) Synapsin I (protein I), a nerve terminal-specific phosphoprotein. III. It's association with synaptic vesicles studied in a highly purified synaptic vesicle preperation. J. Cell. Biol. 96, 1374-1388.

Ichtchenko, K., Hata, Y., Nguyen, T., Ullrich, B., Missler, M., Moomaw, C., Südhof, T. C. (1995) Neuroligin 1: a splice site specific ligand for $\beta$-Neurexins. Cell 81, 435-443.

Ichtchenko, K., Nguyen, T., Südhof, T. C. (1996) Structures, alternative splicing, and neurexin binding of multiple neuroligins. J. Biol. Chem. 271, 2676-2682.

Inoue, A., Sanes, J. R. (1997) Lamina-specific connectivity in the brain: regulation by Ncadherin, neurotrophins, and glycoconjugates. Science 276, 1428-1431.

Irie, M., Hata, Y., Takeuchi, M., Ichtchenko, K., Toyoda, A., Hirao, K., Takai, Y., Rosahl, T W., Südhof, T. C. (1997) Binding of Neuroligins to PSD 95. Science 277, 1511-1515.

Jahn, R., Schiebler, W., Ouimet, C., Greengard, P. (1985) A 38,000-dalton membrane protein (p38) present in synaptic vesicles. Proc Natl Acad Sci U S A 82(12), 4137-4141.

Jentsch, S., Schlenker, S. (1995) Selektive protein degradation: a journey's end within the proteasome. Cell 82 881-884.

Jiang Y. H., Armstrong D., Albrecht U., Atkins C. M., Noebels J. L., Eichele G., Sweatt J. D., Beaudet A. L. (1998) Mutation of the Angelman ubiquitin ligase in mice causes increased cytoplasmic p53 and deficits of contextual learning and long-term potentiation. Neuron 21(4), 799-811.

Kamynina, E., Debonneville, C., Bens, M., Vandewalle, A., Staub, O. (2001) A novel mouse Nedd4 protein suppresses the activity of the epithelial Na+ channel. FASEB J. 15, 204-214. 
Kamynina, E., Tauxe, C., Staub, O. (2001) Distinct characteristics of two human Nedd4 proteins with respect to epithelial $\mathrm{Na}(+)$ channel regulation. Am. J. Physiol. Renal. Physiol. 281(3), F469-77.

Kikonyogo A., Bouamr F., Vana M. L., Xiang Y., Aiyar A., Carter C., Leis J. (2001) Proteins related to the Nedd4 family of ubiquitin protein ligases interact with the L domain of Rous sarcoma virus and are required for gag budding from cells. Proc Natl Acad Sci U S A 98(20), 11199-11204.

Kim, E., Naisbitt, S., Hsueh, Y. P., Rao, A., Rothschild, A., Craig, A. M., Sheng, M. (1997) GKAP, a novel synaptic protein that interacts with the guanylate kinase-like domain of the PSD-95/SAP90 family of channel clustering molecules. J. Cell. Biol. 136, 669-78.

Kim, J. H., Liao, D., Lau, L.-F., Huganir, R. L. (1998) SynGAP: a synaptic RasGAP that associates with the PSD95/SAP90 protein family. Neuron 20, 683-691.

Kishino, T., Lalande, M., Wagstaff, J. (1997) UBE3A/E6-AP mutation causes Angelman syndrome. Nat. Genet. 15, 70-73.

Kohmura, N., Senzaki, K., Hamada, S., Kai, N., Yasuda, R., Watanabe, M., Ishii, H., Yasuda, M., Mishina, M., Yagi, T. (1998) Diversity revealed by a novel family of cadherins expressed in neurons at a synaptic complex. Neuron 20,1137-1151.

Konstas A. A., Shearwin-Whyatt L. M., Fotia A. B., Degger B., Riccardi D., Cook D. I., Korbmacher C., Kumar S. (2002) Regulation of the epithelial sodium channel by N4WBP5A, a novel Nedd4/Nedd4-2-interacting protein. J Biol Chem. 277(33), 29406-29416.

Kornau, H., Seeburg, P., Kennedy, M. (1997) Interactions of ion channels and receptors with PDZ domain proteins. Curr. Opin. Neurobiol. 7, 386-373.

Kumar, S., Tomooka, Y., Noda, M. (1992) Identification of a set of genes with developmentally down-regulated expression in the mouse brain. Biochem Biophys Res Commun. 185(3), 1155-1161. 
Lämmli, U. K. (1970) Cleavage of structural proteins during the assembly of the head of bacteriophage T4. Nature 227, 680-685.

Lamb, R. S., Ward, R. E., Schweizer, L., Fehon, R. G. (1998) Drosophila coracle, a member of the protein 4.1 superfamily, has essential structural functions in the septate junctions and developmental functions in embryonic and adult epithelial cells. Mol. Biol. Cell 9(12), 35053519.

Li, C., Takei, K., Geppert, M., Daniell, L., Stenius, K., Chapman, E. R., Jahn, R., De Camilli, P., und Südhof, T. C. (1994). Synaptic targeting of rabphilin-3A, a synaptic vesicle Ca2+/phospholipid-binding protein, depends on rab3A/3C. Neuron 13, 885-98.

Lue, R. A., Marfatia, S. M., Branton, D., Chishti, A. H. (1994) Cloning and characterization of hdlg: the human homologue of the Drosophila discs large tumor suppressor binds to protein 4.1. Proc. Natl. Acad. Sci. U S A. 91(21), 9818-9822.

Luscher C., Nicoll, R. A., Malenka, R. C., Muller, D. (2000) Synaptic plasticity and dynamic modulation of the postsynaptic membrane. Nat Neurosci. 545-50.

Mansour, S. L., Thomas, K. R., Capecchi, M.R. (1988) Disruption of the proto-oncogene int-2 in mouse embryo-derived stem cells: a general strategy for targeting mutations to nonselectable genes. Nature 336(6197), 348-352.

Marfatia, S. M., Lue, R. A., Branton, D., Chishti, A. H. (1995) Identification of the 4.1 binding interface on glycophorin C and p55, a homologue of the Drosophila disc-large tumor suppressor protein. J. Biol. Chem. 270, 715-719.

Matsuura, T., Sutcliffe, J. S., Fang, P., Galjaard, R.-J., Jiang, Y.-H., Benton, C. S., Rommens, J. M., Beaudet, A. L. (1997) De novo truncating mutations in E6-AP ubiquitin ligase gene (UBE3A) in Angelman syndrome. Nat. Genet. 15, 74-77.

Menegoz, M., Gaspar, P., Le Bert, M., Galvez, T., Burgaya, F., Palfrey, C., Ezan, P., Arnos, F., Girault, J. A. (1997) Paranodin, a glycoprotein of neuronal paranodal membranes. Neuron 19(2), 319-331. 
Missler M., Fernandez-Chacon, R., Südhof, T. C (1998) The making of neurexins. J. Neurochem. 71, 1339-1347.

Missler, M. und Südhof, T. C. (1998) Neurexins: three genes and 1001 products. Trends Genet. 14(1): 20-26.

Morrione A., Plant P., Valentinis B., Staub O., Kumar S., Rotin D., Baserga R. (1999) mGrb10 interacts with Nedd4. J Biol Chem 274(34), 24094-24099.

Murphey, R. K. und Godenschwege, T. A. (2002 New roles for ubiquitin in the assembly and function of neuronal circuits. Neuron 36(1), 5-8.

Murthy, V. N., Schikorski, T., Stevens, C. F., Zhu, Y. (2001) Inactivity produces increases in neurotransmitter release and synapse size. Neuron 32(4), 673-682.

Neeb, A (1998) Untersuchung der Interaktion von Neuroliginen mit Proteinen des Säugergehirns. Diplomarbeit Biologie; Georg-August Universität Göttingen.

Niethammer, M., Valtschanoff, J. G., Kapoor, T. M., Allison, D. W., Weinberg, R. J., Craig, A. M., Sheng, M. (1998) CRIPT, a novel postsynaptic protein that binds to the third PDZ domain of PSD-95/SAP90. Neuron 20, 693-707.

Nunomura, W., Takakuwa, Y., Tokimitsu, R., Krauss, S. W., Kawashima, M., Mohandas, N. (1997) Regulation of CD44-protein 4.1 interaction by Ca2+ and calmodulin. Implications for modulation of CD44-ankyrin interaction. j. Biol. Chem. 272, 30322-30328.

Nygen, T. und Südhof, T. C. (1997) Binding properties of neuroligin 1 and neurexin $1 \beta$ reveal function as heterophilic cell adhesion molecules. J. Biol. Chem. 272, 26032-26039.

Obata, S., Sago, H., Mori, N., Davidson, M., St John, T., Suzuki. S. T. (1998) A common protocadherin tail: multiple protocadherins share the same sequence in their cytoplasmic domains and are expressed in different regions of brain. Cell. Adhes. Commun. 6, 323-333. 
Ohanian, V., Wolfe, L. C., John, K. M., Pinder, J. C., Lux, S. E., Gratzer, W. B., (1984) Analysis of the ternary interaction of the red cell membrane skeletal proteins spectrin, actin, and 4.1. Biochemistry 23, 4416-4420.

Okabe, S., Kim, H. D., Miwa, A., Kuriu, T., Okado, H. (1999) Continual remodeling of postsynaptic density and its regulation by sinaptic activity. Nat. Neurosci. 4, 1006-1013.

Pak, D. T., Yang, S., Rudolph-Correia, S., Kim, E., Sheng, M. (2001) Regulation of dendritic spine morphology by SPAR, a PSD-95-associated RapGAP. Neuron. 31, 289-303.

Parra, M., Gascard, P., Walensky, L. D., Snyder, S. H., Mohandas, N., Conboy, J. G. (1998) Cloning and characterisation of 4.1G (EPB41L2), a new member of the skeletal protein 4.1 (EPB41) gene family. Genomics 49, 298-306.

Parra, M., Gascard, P., Walensky, L. D., Gimm, J. A., Blackshaw, S., Chan, N., Takakuwa, Y., Berger, T., Lee, G., Chasis, J. A., et al. (2000) Molecular and functional characterisation of protein 4.1B, a novel member of the protein 4.1 family with high level, focal expression in brain. J. Biol. Chem. 275, 3247-3255.

Pasternack, G. R., Anderson, R. A., Leto, T. L., Marchesi, V. T. (1985) Interactions between protein 4.1 and band 3. An alternative binding site for an element of the membrane skeleton. J. Biol. Chem. 260, 3676-3683.

Pearson, M. A., Reczek, D., Bretscher, A., Karplus, P. A. (2000) Structure of the ERM protein moesin reveals the FERM domain fold masked by an extended actin binding tail domain. Cell 101, 259-270.

Perin, M. S., Fried, V. A., Mignery, G. A., Jahn, R., Südhof, T. C. (1990) Phospholipid binding by a synaptic vesicle protein homologues to the regulatory region of protein kinase $\mathrm{C}$. Nature 345 (6272), 260-263.

Peters, L. L., Weier, H. U., Walensky, L. D., Snyder, S. H., Parra, M., Mohandas, N., Conboy, J. G. (1998) Four paralogues protein 4.1 genes map to distinct chromosomes in mouse and human. Genomics 54, 348-350. 
Petrenko, A. G., Lazaryeva, V. D., Geppert, M., Tarasyuk, T. A., Moomaw, C., Khokhlatchev A. V., Ushkaryov, Y. A., Slaughter, C., Nasimov, I. V., Südhof T. C. (1993) Polypeptide composition of the alpha-latrotoxin receptor. High affinity binding protein consists of a family of related high molecular weight polypeptides complexed to a low molecular weight protein. J. Biol. Chem. 268, 1860-1867.

Pham N. und Rotin D. (2001) Nedd4 regulates ubiquitination and stability of the guaninenucleotide exchange factor CNrasGEF. J Biol Chem. 276(50), 46995-47003.

Plant, P., Yeger, H., Staub, O., Horward, P., Rotin, D. (1997 The C2 domain of the ubiquitin ligase Nedd4 mediates Ca2+-dependent plasma membrane localisation. J. Biol. Chem. 272 (51), 32329-32336.

Ponting C. P., Parker P. J. (1996) Extending the C2 domain family: C2s in PKCs delta, epsilon, eta, theta, phospholipases, GAPs, and perforin. Protein Sci. 5(1), 162-166.

Ranscht, B. (2000) Cadherins: molecular codes for axon guidance and synapse formation. Int. J. Dev. Neurosc. 18, 643-651.

Rao, A., Harms, K. J., Craig, A. M. (2000) Neuroligation: building synapses around the neurexin-neuroligin link. Nat Neurosci. 3, 747-749.

Rosahl, T. W., Geppert, M, Spillane, D., Herz, J., Hammer, R. E., Malenka, R. C., Südhof T. C. (1993) Short-term synaptic plasticity is altered in mice lacking synapsin I. Cell. 75(4):661670.

Rumbaugh, G., Sia, G. M., Garner, C. C., Huganir, R. L. (2003) Synapse-associated protein97 isoform-specific regulation of surface AMPA receptors and synaptic function in cultured neurons. J Neurosci. 23(11), 4567-4576.

Saiki, R. K., Gelfand, D. H., Stoffel, S., Scharf, S. J., Higuchi, R., Horn, G. T., Mullis, K. B., Erlich, H. A. (1988) Primer-directed enzymatic amplification of DNA with a thermostable DNA polymerase. Science 239, 487-491. 
Sambrook, J., Fritsch, E. F., Maniatis, T. E. (1989) Molecular cloning: a laboratory manual. Cold Spring Harbor, NY.

Sanger, F., Nicklen, S., Coulson, A. R. (1977) DNA-sequencing with chain terminating inhibitors. Proc. Nat. Acad. Sci. 74, 5463-5467.

Scheffner M., Nuber U., Huibregtse J. M. (1995) Protein ubiquitination involving an E1-E2E3 enzyme ubiquitin thioester cascade. Nature 373(6509), 81-83.

Scheiffele, P., Fan, J., Choih, J., Fetter, R., Serafini, T. (2000) Neuroligin expressed in nonneuronal cells triggers presynaptic development in contacting axons. Cell 101, 657-69.

Schild L., Lu Y., Gautschi I., Schneeberger E., Lifton R. P., Rossier B. C. (1996) Identification of a PY motif in the epithelial $\mathrm{Na}$ channel subunits as a target sequence for mutations causing channel activation found in Liddle syndrome. EMBO J. 15(10), 2381-2387.

Scott C, Keating L, Bellamy M, Baines AJ. (2001) Protein 4.1 in forebrain postsynaptic density preparations: enrichment of 4.1 gene products and detection of $4.1 \mathrm{R}$ binding proteins. Eur. J. Biochem. 268(4), 1084-1094.

Shen, L., Liang, F., Walensky, L. D., Huganir, R. L. (2000) Regulation of AMPA receptor GluRI subunit surface expression by a $4.1 \mathrm{~N}$-linked actin cytoskeletal association. J. Neurosci. 20, 7932-7940.

Sheng M. und Kim., E. (1996) Ion channel associated proteins. Curr. Opin. Neurobiol. 6, 602-608.

Sheng M. und Kim., E. (2002) Postsynaptic signaling and plasticity mechanisms. Science 298, 776-780.

Shi, Z. T., Afzal, V., Coller, B., Patel, D., Chasis, J. A., Parra, M., Lee, G., Paszty, C., Stevens, M., Walensky, L., Peters, L. L., Mohandas, N., Rubin, E., Conboy, J. G. (1999) 
Protein 4.1R-deficient mice are viable but have erythroid membrane skeleton abnormalities. $J$ Clin Invest. 103(3), 331-40.

Shisheva, A., Südhof, T. C., Czech, M. P. (1994) Cloning, characterization, and expression of a novel GDP dissociation inhibitor isoform from skeletal muscle. Mol. Cell. Biol. 14(5), 34593468 .

Skowyra D., Craig K. L., Tyers M., Elledge S. J., Harper J. W. (1997) F-box proteins are receptors that recruit phosphorylated substrates to the SCF ubiquitin-ligase complex. Cell 91(2), 209-219.

Song, J.-Y., Ichtchenko, K., Südhof, T. C., Brose, N. (1998) Neuroligin 1 is a postsynaptic cell adhesion molecule of excitory synapses. Proc. Natl. Acad. Sci. USA 96, 1100-1105.

Sonyang, Z., Fanning, A. S., Fu, C., Xu, J., Marfatia, S. M., Chishti, A. H., Crompton, A., Chan, A. C., Andersonk, J. M., Cantley, L. C. (1997) Recognition of unique carboxylterminal motifs by distinct PDZ domains. Science 275, 73-77.

Southern, E. M. (1975) Detection of specific sequences among DNA fragments separated by gel electrophoresis. J. Mol. Biol. 98, 503-517.

Stahl M. L., Ferenz C. R., Kelleher K. L., Kriz R. W., Knopf J. L.(1988) Sequence similarity of phospholipase C with the non-catalytic region of src. Nature 332(6161), 269-272.

Staub, O., Dho, S., Henry, P. C., Correa, J., Ishikawa, T., McGlade, J., Rotin, D. (1996) WW domains of Nedd4 bind to the proline-rich PY motifs in the epithelial Na+-channel deleted in Liddle's syndrome. EMBO J. 15(10), 2371-2380.

Staub, O., Gautschi, I., Ishikawa, T., Breitschopf, K., Ciechanover, A., Schild, L., Rotin, D. (1997) Regulation of stability and function of the epithelial $\mathrm{Na}+$ channel $(\mathrm{ENaC})$ by ubiquitination. EMBO J. 16 (21), 6325-6336.

Stokes, D. L., DeRosier, D. J. (1991) Growth conditions control the size and order of actin bundles in vitro. Biophys. J. 59(2), 456-465. 
Sugino, H., Hamada, S., Yasuda, R., Tuji, A., Matsuda, Y., Fujita, M., Yagi, T. (2000) Genomic organization of the family of CNR cadherin genes in mice and humans. Genomics. $63,75-87$.

Suh P. G., Ryu S. H., Moon K. H., Suh H. W., Rhee S. G. (1988) Cloning and sequence of multiple forms of phospholipase C. Cell 54(2), 161-169.

Takeichi M. (1988) The cadherins: cell-cell adhesion molecules controlling animal morphogenesis. Development 102, 639-655.

Takeichi M. (1994) The cadherin cell adhesion receptor family: roles in multicellular organization and neurogenesis. Prog. Clin. Biol. Res. 390, 145-153.

Tanaka, T., Kadowaki, K., Lazarides, E., Sobue, K. (1991) Ca2(+)-dependent regulation of the spectrin/actin interaction by calmodulin and protein 4.1. J. Biol. Chem. 266, 1134-1140.

Tezuka, T., Umemori, H., Akiyama, T., Nakanishi, S., Yamamoto, T. (1999) PSD-95 promotes Fyn-mediated tyrosine phosphorylation of the N-methyl-D-aspartate receptor subunit NR2A. Proc. Natl. Acad. Sci. U S A. 96, 435-40.

Toni, N., Buchs, P. A., Nikonenko, I., Bron, C. R., Muller, D. (1999) LTP promotes formation of multiple spine synapses between a single axon terminal and a dendrite. Nature 402 (6760), 421-425.

Towbin, H., Staehli, T., Gordon, J. (1979) Electrophoretic transfer of proteins from polyacrylamide gels to nitrocellulose sheets: procedure and some application. Proc. Nat. Acad. Sci. 76 (9), 4350-4354.

Treier, M., Staszewski, L. M., Bohmann, D. (1994) Ubiquitin-dependent c-Jun degradation in vivo is mediated by the delta domain.Cell 78(5), 787-798.

Uchida, N., Honjo, Y., Jhnson, K. R., Wheelock, M. J., Takeichi, M. (1997) The catenin/cadherin adhesion system is localized in the synaptic junctions bordering transmitter release zones. J. Cell. Biol. 135, 767-779. 
Ullrich, B., Ushkaryov, Y. A., Südhof, T. C. (1995) Cartography of the neurexins: More than 1000 isoforms generated by alternativ splicing and expressed in distinct subsets of neurons. Neuron 14, 497-507.

Ushkaryov, Y. A., Petrenko, A. G., Geppert, M., Südhof, T. C. (1992) Neurexins: Synaptic cell surface proteins related to $\alpha$-latrotoxin receptor and laminin. Science 257, 50-56.

Ushkaryov, Y. A, Hata, Y., Ichtchenko, K., Moomaw, C., Alfendis, Slaughter, C., Südhof T. C. (1994) Conserved domain structure of beta neurexins. Unusual cleaved signal sequences in receptor-like neuronal cell-surface proteins. J. Biol. Chem. 269, 11987-11992.

Uchida, N., Honjo, Y., Johnson, K. R., Wheelock, M. J., Takeichi, M. (1997) The catenin/cadherin adhesion system is localized in the synaptic junctions bordering transmitter release zones. J. Cell. Biol. 135, 767-779.

Vojtek, A. B., Hollenberg, S. M., Cooper, J. A. (1993) Mammalian Ras interacts directly with the serine/threonine kinase Raf. Cell 74, 205-214.

Walensky, L. D., Gascard P., Fields, M. E., Blackshaw, S., Conboy, J. G., Mohandas, N., Snyder, S. H. (1998) The 13-kD FK506 binding protein FKBP13 interacts with a novel homologue of the erythrocyte membrane cytoskeletal protein 4.1. J. Cell Biol. 6, 141-153.

Walensky, L. D., Blackshaw, S., Liao, D., Watkins, C. C., Weier, H. U., Parra, M., Huganir, R. L., Conboy, J. G., Mohandas, N., Snyder, S. H. (1999) A novel neuron-enriched homolog of the erythrocyte membrane cytoskeletal protein 4.1. J. Neurosci. 19, 6457-6467.

Ward, R. E. 4th, Lamb, R. S., Fehon, R. G. (1998) A conserved functional domain of Drosophila coracle is required for localization at the septate junction and has membraneorganizing activity. J. Cell Biol. 140(6), 1463-73.

Wilimzig, M. (1985) LiCl-boiling method for plasmid mini-preps. TIG June 1985. 
Wilkinson K. D. (1997) Regulation of ubiquitin-dependent processes by deubiquitinating enzymes. FASEB J. 11(14), 1245-56.

Willnow, T. E., Herz, J. (1994) Homologous recombination for gene replacement in mouse cell lines. Methods Cell Biol 43, 305-334

Wilson S. M., Bhattacharyya B., Rachel R. A., Coppola V., Tessarollo L., Householder D. B., Fletcher C. F., Miller R. J., Copeland N. G., Jenkins N. A. (2002) Synaptic defects in ataxia mice result from a mutation in Usp14, encoding a ubiquitin-specific protease. Nat Genet. $32(3), 420-5$.

$\mathrm{Wu}$, Q. and Maniatis, T. (1999) A striking organization of a large family of human neural cadherin-like cell adhesion genes. Cell 97, 779-790

Wu, Q., Zhang, T., Cheng, J. F., Kim, Y., Grimwood, J., Schmutz, J., Dickson, M., Noonan, J. P., Zhang, M. Q., Myers, R. M., Maniatis, T. (2001) Comparative DNA sequence analysis of mouse and human protocadherin gene clusters. Genome Res. 11(3),389-404.

$\mathrm{Wu}$, Q., Maniatis, T. (2000) Large exons encoding multiple ectodomains are a characteristic feature of protocadherin genes. Proc. Natl. Acad. Sci. U S A. 97(7), 3124-3129.

Yagi, T. and Takeichi, M. (2000) Cadherin superfamily genes: functions, genomic organization, and neurologic diversity. Genes Dev. 14, 1169-1180

Yamakawa, H., Ohara, R., Nakajima, D., Nakayama, M., Ohara, O. (1999) Molecular characterisation of a new member of the protein 4.1 family (brain 4.1) in rat brain. Mol. Brain Res. 70, 197-209.

Yamakawa, H. und Ohara, O. (2000) Comparison of mRNA and protein levels of four members of the protein 4.1 family: the type II brain $4.1 / 4.1 \mathrm{~B} / \mathrm{KIAA} 0987$ is the most predominant member of the protein 4.1 family in rat brain. Gene 248(1-2), 137-45.

Yasuda J., Nakao M., Kawaoka Y., Shida H. (2003) Nedd4 regulates egress of Ebola viruslike particles from host cells. J. Virol. 77(18), 9987-9992. 
Ye, K., Compton, D. A., Lai, M. M., Walensky, L. D., Snyder, S. H. (1999) Protein 4.1N binding to nuclear mitotic apparatus protein in PC12 cells mediates the antiproliferative actions of nerve growth factor. J. Neurosci. 19, 10747-10756.

Yuste, R., Bonhoeffer, T. (2001) Morphological changes in dendritic spines associated with long-term synaptic plasticity. Annu Rev Neurosci. 24, 1071-1089

Zhang W. and Benson, D. L. (2001) Stages of synapse development defined by dependence on F-actin. J. Neurosci. 21 5169-5181

Ziff, E. B. (1997) Enlightening the postsynaptic density. Neuron 19, 1163-1174.

Zori, R. T., Hendrickson, P., Woolven, S., Whidden, E. M., Gray, B., Williams, C. A. (1992) Angelman syndrome: clinical profile. J. Child. Neurol. 7, 270-280. 


\section{PUBLIKATIONEN}

Direct interaction between the ARF-specific guanine nucleotide exchange factor msec7-1 and presynaptic Munc13-1.

Neeb A., Koch H., Schurmann A., Brose N. (1999)

Eur J Cell Biol. 78(8): 533-8.

Interaction of Neuroligin 1 with a neuronal member of the band 4.1 protein family Neeb A., Dresbach T., Varoqueaux F., Ohara O., Gundelfinger E. D., Brose N. (2000) Göttinger Neurobiologentagung, Göttingen (Posterpräsentation)

Neuroligin 1 interacts with a neuronal member of the band 4.1 protein family

Neeb A., Dresbach T., Varoqueaux F., Ohara O., Gundelfinger E. D., Brose N. (2001)

Metting of the Society for Neuroscience, San Diego, USA (Posterpräsentation) 


\section{DANKSAGUNGEN}

Mein besonderer Dank gilt Herrn Prof. Dr. Nils Brose für die Anregung des Themas, seine exzellente Betreuung und ständige Diskussionsbereitschaft während der Anfertigung meiner Arbeit.

Herrn Prof. Dr. R. Hardeland danke ich herzlich für die Vertretung meiner Dissertation an der Universität, seine Hilfsbereitschaft und ständige Bereitschaft, den Prozess der Arbeit mitzuverfolgen.

Herrn Prof. Dr. D. Doenecke danke ich für die Übernahme des Korreferats.

Torsten Hartmann, Aleksandra Ivonovic, Sönke Tobaben und Frederique Varoqueaux danke ich für das Korrekturlesen und die moralische Unterstützung beim Ausfertigen der Arbeit.

Ich danke meinen Laborkollegen Yaisa Andrews, Iris Augustin, Andrea Betz, Dr. Aleksandra Ivanovic, Harald Junge, Stefan Kalla, Hiroshi Kawabe, Henriette Koch, Guido Meyer, Kerstin Reim, Oliver Schlüter, Dina Speidel, Sönke Tobaben, Frederique Varoqueaux und Sonja Wojcik für die sehr gute Zusammenarbeit..

Fritz Benseler und Ivonne Thanhäuser danke ich für gute Sequenzen und exzellente Oligos.

Der Computerabteilung und besonders Beate Beschke und Hajo Horn danke ich von Herzen für die Hilfe bei den vielen großen und kleinen Tücken der Technik.

Allen guten Geistern der Abteilung, Irma Büchler, Gabriele Endo, Birgit Gläser, Ingrid Hille, Klaus und Thea Hellmann, Martin Theuerkorn, Sally Wenger und Astrid Zeuch sowie den Mitarbeitern des Tierhauses, danke ich für die hervorragenden Arbeitsbedingungen.

Und nicht zuletzt danke ich Torsten, Jonas und Noam für die Zeit, ihre Geduld und Verständnis. 


\section{LEBENSLAUF}

Persönliche Daten: Antje Neeb

Geboren am 04.05.1973 in Bad Arolsen

Familie, zwei Kinder

\section{Schulausbildung}

1979-1983 Grundschule Bad Arolsen

1983-1992 Christian-Rauch-Gymnasium Bad Arolsen

\section{Studium und wissenschaftliche Arbeiten}

09/1992-08/1998 Studium der Biologie an der Georg-August-Universität in Göttingen

04/1995 Vordiplom

10/1997

Diplomprüfung in den Fächern Genetik und Biochemie und physikalischer Chemie

10/1998 Hochschulabschluß zur Diplom-Biologin, Universität Göttingen Thema der Diplomarbeit: "Interaktionen von Neuroliginen mit Komponenten des Säugergehirns"

11/98- 10/02 Experimentelle Arbeiten zur vorliegenden Dissertation in der Abteilung für Molekulare Neurobiologie am Max-Planck-Institut für experimentelle Medizin in Göttingen bei Prof. Dr. N. Brose 